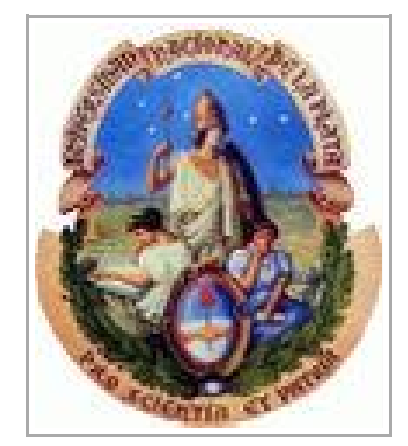

\author{
UNIVERSIDAD NACIONAL DE LA PLATA \\ FACULTAD DE CIENCIAS NATURALES Y MUSEO \\ DOCTORADO EN CIENCIAS NATURALES
}

\title{
"ESTUDIO DE LA ESTRUCTURA DE LAS COMUNIDADES DE AVES ASOCIADAS A ÑIRANTALES (Nothofagus antarctica) DEL CENTRO-OESTE DE LA PROVINCIA DEL CHUBUT, PATAGONIA ARGENTINA, SOMETIDOS A DIFERENTES TIPOS DE IMPACTO AMBIENTAL"
}

DOCTORANTE: Lic. Daniel E. Szulkin Dolhatz DIRECTOR: Dr. Ricardo Jorge Casaux

CO-DIRECTOR: Dr. Carlos Aquiles Darrieu

TESIS PARA OPTAR AL GRADO DE DOCTOR EN CIENCIAS NATURALES 
A mi amada familia: Silvana, Rocío y Francisco, por ser los principales generadores de amor en mi vida. A mis queridos padres Simón y Beatríz por enseñarme el valor del conocimiento.

En junio de 1810, un siempre comprometido Manuel Belgrano escribía: "perecieron los bosques como el inmenso mar respecto de la corta población que teníamos... hemos visto a los montañeses dar por el pie a un árbol frondoso, en lo más florido de la primavera, solo por probar el filo del hacha... causa el mayor sentimiento ver tantos árboles muertos... Se presiente ya lo detestables que seremos a la generación venidera, si... no nos ponemos activos..." ManuelBelgrano

"Todas las cosas, todo cuanto entiendo, lo entiendo solo porque lo amo"

León Tolstoi

"Somos los humanos, el único componente de la naturaleza que posee conciencia de sí mismo".

Elisee Reclús

"Si no hacemos lo imposible, tendremos que enfrentarnos con lo impensable"

Murray Bookschin 


\section{AGRADECIMIENTOS}

En primer lugar a mi compañera de ruta en la vida Silvana y, que junto a mis dos soles Rocío y Francisco debieron soportar mis largas ausencias e incertidumbres. A pesar de ello, fueron siempre el permanente sostén de mi trabajo y de mi vida por su ayuda moral y amor. A mi madre por brindarme siempre su alegría y aliento en el estudio. A mi hermana Lidia por su asistencia a mi familia durante mis viajes y ayuda incondicional. A mis suegros Adelina y Albino quiénes desde su afecto y predisposición me ayudaron a tener momentos de tranquilidad. Por último, a mis abuelos Alter y Chana Szulkin porque pusieron en mí, la semilla de tomar conciencia que el conocimiento es el camino hacia la libertad!

A los propietarios de los establecimientos Alejandro Garzonio, Rony Jones, Pérez, Héctor Jones, Julio (Turco) Rodríguez, a los responsables de la EEAF INTA Aldea Escolar - Trevelin Martín Honoratto y Carlos Buduva, por haberme facilitado el permiso de ingreso a sus predios para realizar los relevamiento de datos que permitieron hacer este estudio.

A Nidia Hansen por facilitarme con gran generosidad bibliografía referida al tema y su apoyo incondicional para los diseño de muestreo, a Axel von Muller por ayudarme a orientarme en los cálculos estadísticos y a conocer en mayor profundidad la dinámica de los ñirantales y el bosque en general. A Pedro Blendingher por guiarme en el armado de las primeras matrices de cálculo.

A Liliana Contardi por su aporte en el diseño de muestreo de vegetación. A Horacio Claverie de la Dirección General de Bosques y Parques de la Provincia del Chubut por su aporte en lo referido a datos de base del bosque andino patagónico y en especial los datos referidos a los ñirantales de Chubut.

A Victoria Lantscheiner de la EEA INTA San Carlos de Bariloche - Río Negro, por haberme aportado bibliografía relacionada con la propia temática, donde ella misma intervino en su elaboración, transmitiendome su experiencia.

A Héctor Gonda por entregarme generosamente todas las imágenes de aves del presente trabajo que en la mayoría de los casos eran además verdaderas obras de arte. A Noelia Locícero por su aporte en la elaboración del abstract. A María Vanesa Lencinas por su aporte bibliográfico actualizado para el análisis final.

A mis grandes amigos Roberto Hlousek y Víctor Mondino por su ayuda incondicional en distintas etapas del trabajo de tesis.

A Alejandra Tártara quién me ayudó en algunos muestreos y especialmente a Romina Gonc con quién hicimos parte del trabajo conjuntamente.

A mis compañeros del CIEMEP (Centro de Investigaciones de Estepa y Montañas Patagónicas): Miguel Archangelsky por su ayuda en el armado del diseño de muestreo de artrópodos y muy especialmente a Laura Miserendino con quién realice los últimos y esenciales cálculos estadísticos a la par que me daba el fundamental apoyo anímico para culminar la Tesis.

A mi Director y Codirector de tesis, respectivamente Pipo Casaux por su inmensa paciencia y brindar sus grandes conocimientos generosamente y a, Carlos Darrieu por aceptar ser su doctorante, hacerme sentir siempre muy cómodo y casi en familia en su laboratorio de Ornitología del Museo de la UNLP y por su predisposición a transmitirme toda su experiencia.

Nuevamente, les agradezco a todos!, ya que hicieron posible este aporte para la preservación del maravilloso bosque andino patagónico!. 


\section{INDICE}

$\begin{array}{ll}\text { Agradecimientos } & 03\end{array}$

$\begin{array}{ll}\text { Índice } & 04\end{array}$

$\begin{array}{ll}\text { Resumen } & 07\end{array}$

$\begin{array}{ll}\text { Abstract } & 10\end{array}$

Capítulo 1: INTRODUCCIÓN 13

1.1 Introducción General 13

1.2 Objetivos e Hipótesis $\quad 22$

1.2.1 Objetivo principal $\quad 22$

1.2.2 Objetivos específicos 22

1.2.3 Hipótesis 23

Capítulo 2: CARACTERIZACIÓN DE LOS ÑIRANTALES 24

2.1.1 Generalidades $\quad 24$

2.1.2 Características de los ñirantales $\quad 30$

2.1.3 Impactos antrópicos sobre los ñirantales $\quad 37$

2.1.3.1 Ñirantales transformados en pasturas $\quad 38$

2.1.3.2 Ñirantales con extracción de leña por manchones $\quad 41$

2.1.3.3 Nirantales quemados hace 15 y 25 años 43

2.1.3.4 Ñirantales con extracción de leña por parquizado 44

2.1.3.5 Nirantales primarios $\quad 47$

2.2 Caracterización de la fauna $\quad 49$

2.2.1 Fauna en gral. $\quad 49$

2.2.2 Artrópodos $\quad 49$

2.2.3 Avifauna $\quad 52$

Capítulo 3: MATERIALES Y MÉTODOS 58

$\begin{array}{ll}3.1 \text { Ubicación } & 58\end{array}$

3.2 Caracterización y síntesis evolutiva del área $\quad 59$

3.3 Climatología 62

3.4 Biogeografía $\quad 64$

3.5 Consideraciones generales $\quad 65$

3.6 Datos de variables climáticas 69 
3.7 Muestreo de vegetación

3.8 Muestreo de avifauna

4.1 Resultados de las unidades de vegetación según usos o perturbaciones

4.1.1 Ñirantales convertidos en pasturas 91

4.1.2 Ñirantales con extracción de leña por manchones 94

4.1.3 Ñirantales quemados hace 15 años 98

4.1.4 Ñirantales quemados hace 25 años 102

4.1.5 Ñirantales con extracción de leña por parquizado 106 4.1.6 Ñirantales primarios 110

4.2 Comparación entre sitios con diferentes usos 114

4.3 Resultados de las comunidades de artrópodos de los ñirantales sometidos a diferentes usos

4.3.1 Ñirantales convertidos en pasturas

4.3.2 Ñirantales con extracción de leña por manchones

4.3.3 Ñirantales quemados hace 15 años

4.3.4 Ñirantales quemados hace 25 años

4-3.5 Ñirantales con extracción de leña por parquizado

4.3.6 Ñrantales primarios

4.3.7 Comparación entre sitios asociados a diferentes usos

161

4.3.8 Eficiencia de las técnicas de muestreo

162

4.4 Resultados de las comunidades de aves asociadas a

bosques de Ñire

166

4.4.1 Composición específica de la comunidad 166

4.4.2. Riqueza específica

4.4.3. Abundancia absoluta

4.4.4 Abundancia relativa

4.4.5 Nivel de conservación

4.4.6 Índice SUMIN (Suma de Índices)

4.4.7 SUMIN vs. Usos de los ñirantales 
4.4.10 Índice de Diversidad de Margaleff 179

4.4.11 Índice de Equitatividad 180

$\begin{array}{ll}\text { 4.4.12 Trofismo } & 181\end{array}$

4.4.13 Índices Biológicos vs. Estacionalidad 185

$\begin{array}{ll}\text { 4.4.14 Análisis de los Agrupamientos } & 185\end{array}$

4.4.15 Análisis de Correspondencia Canónica (CCA) 191

Capítulo 5: DISCUSIÓN 199

5.1 Dinámica general de la avifauna 199

$\begin{array}{ll}\text { 5.1.1 Abundancia y riqueza específica } & 199\end{array}$

5.1.2 Estado de conservación 201

5.1.3 Gremios tróficos $\quad 206$

5.1.4 Variación de los índices biológicos según la estacionalidad climática $\quad 210$

5.1.5 Migración de las aves 212

5.1.6 Variación de los índices biológicos en relación a los usos de los ñirantales 213

5.2 Dinámica de los ñirantales sometidos a diferentes usos 215

$\begin{array}{ll}\text { 5.2.1 Nirantales primarios } & 216\end{array}$

5.2.2 Ñirantales con extracción de leña por parquizado 221

5.2.3 Ñirantales sometidos a la acción del fuego 224

5.2.4 Nirantales con extracción de leña por manchones 230

5.2.5 Ñrantales convertidos en pasturas 233

5.3 Comparación de técnicas de muestreo 238

5.3.1 Muestreo de artrópodos $\quad 238$

$\begin{array}{ll}\text { 5.3.1 Muestreo de aves } & 238\end{array}$

$\begin{array}{lr}\text { Capítulo 6: CONCLUSIONES } & \mathbf{2 4 0}\end{array}$

$\begin{array}{lr}\text { Capítulo 7: BIBLIOGRAFÍA } & \mathbf{2 4 5}\end{array}$

$\begin{array}{lr}\text { ANEXO } & 294\end{array}$ 


\section{RESUMEN}

El objetivo general del estudio es conocer la dinámica de las comunidades de aves asociadas a bosques de Nire (Nothofagus antartica) del Noroeste de Chubut, sometidos a diferentes tipos de impacto.

El estudio se desarrolló entre julio de 2008 y junio de 2010, realizándose muestreos de campo trimestrales. Se estudiaron ñirantales sometidos a los siguientes usos: extracción de leña por parquizado y por manchones, bosques incendiados hace 15 y 25 años, bosque convertido a pasturas y como testigos se consideraron ñirantales primarios. El área de muestreo se encuentra dentro de la cuenca del río Futaleufú, entre los meridianos $71^{\circ} 23^{\prime}$ y $71^{\circ} 36^{\prime} \mathrm{O}$ y los paralelos $43^{\circ} 05^{\prime}$ y $43^{\circ} 14^{\prime}$ ' $\mathrm{S}$ y la altura de los sitios de muestreo fluctuó entre 525 y 855 m.s.n.m.

Los objetivos específicos del trabajo fueron: 1) realizar el inventario de la avifauna representada en los ñirantales del centro-oeste de Chubut, 2) determinar la abundancia, riqueza específica, diversidad $y$, caracterizar la estructura de las comunidades de aves asociadas a ñirantales sometidos a diferentes impactos, 3) determinar la magnitud de los cambios intra e interanuales en la estructura de la comunidades de aves, 4) caracterizar los gremios tróficos asociados a la estructura de la vegetación y a la comunidad de artrópodos y, 5) analizar la estructura de la comunidad de aves según sus niveles de conservación.

Por cada tipo de impacto se consideraron 2 réplicas (en total 12 sitios de muestreo) para el muestreo de la vegetación y, en cada sitio de muestreo se seleccionaron al azar tres parcelas de $100 \mathrm{~m}^{2}$ cada una. Los muestreos de frutos fueron realizados durante el verano en las cinco especies que más frutos ofertaban en cada réplica. Para las capturas de artrópodos se utilizaron trampas fluid interception, sticky traps y se obtuvieron muestras del dosel de la vegetación y del suelo mediante el uso de sacabocados. A partir del material recolectado se calcularon los principales índices biológicos. Los muestreos de aves fueron realizados trimestralmente mediante dos técnicas: puntos de conteo (PC) y línea transecta (LT). En cada uno de los sitios de muestreo se ubicaron tres LT de 350 metros cada una y seis PC. En base a los datos registrados se calcularon los principales índices biológicos, el Índice SUMIN, el Índice SUMIN máximo, la categorización de conservación y se describió la estructura trófica. Para todos los casos en donde se realizaron comparaciones, se utilizó el número de especies (S) y el número de individuos $(\mathrm{N})$.

Los ñirantales primarios presentaron un estado de conservación adecuado, lo cual permite la preservación de su variabilidad espacial y estacional. En el estrato arbustivo de los sitios perturbados por incendios se observó una clara disminución de especies de origen nativo y un mayor porcentaje de especies de origen exótico. En dichos sitios el estado sanitario de los ñires fue bueno, siendo bajo su diámetro, lo que se corresponde con el estado de regeneración de los individuos. En el estrato arbóreo de los sitios con extracción de leña por manchones y por parquizado predominaron especies pertenecientes al estrato arbóreo de origen nativo tales como Ñire y Maitén. Estos Ñires presentaron un estado sanitario fluctuante entre deficiente y muy bueno y, un tamaño relativamente grande, aunque no se registraron renovales debido a la actividad ganadera que no favorecen el renuevo del bosque. Los sitios convertidos a pasturas presentaron la mayor cobertura de especies pertenecientes al estrato herbáceo de origen nativo. 
Allí no se registraron especies pertenecientes al estrato arbóreo, encuentrándose seriamente comprometida la regeneración y rehabilitación del bosque de Ñire.

Los artrópodos asociados a los diferentes usos de los ñirantales se mantuvieron activos durante todo el año, tolerando condiciones extremas durante los meses fríos y presentando picos de actividad durante los meses más cálidos. No se observaron diferencias en cuanto a la abundancia de los órdenes representados en los sitios sometidos a diferentes tipos de impacto, e incluso la riqueza e índices de diversidad, dominancia y equitatividad fueron similares entre los sitios. La variación estacional de la abundancia de los órdenes de artrópodos, los índices de diversidad y de dominancia estuvo relacionada con las condiciones climáticas, principalmente la temperatura y la fenología de la vegetación independientemente del tipo de impacto. La abundancia de individuos de los artrópodos representados en las capturas aumentó con el incremento de la cobertura del estrato arbóreo. Sin embargo, en los sitios convertidos a pasturas se observó una relación inversa entre el número de individuos, la cobertura del estrato herbáceo y la temperatura. Este patrón se explicaría por las mayores temperaturas relativas, las que en pasturas afectan negativamente a los artrópodos $\mathrm{y}$, por la menor heterogeneidad de estos ambientes, lo que está asociado a una menor disponibilidad de micro-hábitats. Las técnicas de muestreo, mediante muestras provenientes de las trampas "Sticky traps", "Fluid interception", y del dosel de la vegetación capturaron una mayor cantidad de individuos del orden Díptera, debido a que son más eficientes en la captura de individuos voladores. Las muestras provenientes de las trampas "Fluid interception", del suelo y del dosel de la vegetación fueron más abundantes y diversas que las provenientes de las trampas "Sticky traps". La diversidad de los órdenes artrópodos asociados a bosques de Ñire fue similar entre los sitios de muestreo, no siendo afectados drásticamente por las perturbaciones derivadas de la extracción de leña por parquizado y por manchones y de los incendios dado que en éstos sitios se mantuvo la cobertura vegetal con hábitats y condiciones microclimáticas favorables. Sin embargo, en los bosques convertidos a pasturas las condiciones microclimáticas y los hábitats se encuentran drásticamente modificados, lo que afecta la dinámica comunitaria de los artrópodos.

Con respecto a la avifauna, se registraron un total de 49 especies mediante el método PC y 44 especies mediante LT, este bajo número de especies es propio de los bosques andino-patagónicos debido a: a) la insularidad de los bosques andino-patagónicos, b) movimientos orogénicos, c) glaciación relativamente reciente y, d) fríos extremos en el semestre otoño-invierno. La riqueza específica (13 - 29), la abundancia de individuos (1,73 - 10,44 indv./ha/estación), la diversidad específica $(0,55-2,05)$, y el índice de conservación $(9,5$ - 12,5) variaron según el tipo de ñirantal considerado.

Se observó mayor abundancia, riqueza específica y diversidad de aves en los ñirantales sometidos a disturbios intermedios, principalmente ñirantales con extracción de leña mediante parquizado, seguidos por ñirantales incendiados hace 15 años y 25 años, luego ñirantales con extracción de leña por manchones, observándose los menores valores en los ñirantales transformados en pasturas y en los primarios.

Los ñirantales primarios poseen una comunidad de aves con especies de mayor nivel del índice de conservación, emblemáticas o vulnerables debido a que en este sitio: 1) es el único donde se encuentra el Carpintero Gigante Patagónico considerado especie clave para la conservación de los bosques templados, 2) cuenta con la totalidad de los Rhinocríptidos, grupo altamente sensibles a los cambios del 
hábitat, 3) habitan la totalidad de los carpinteros propios de los bosques maduros, 4) se observó una alta relación aves residentes/aves migradoras, por lo que poseen una comunidad de aves de alta estabilidad ecológica. Lo mencionado está generado por la existencia de árboles de gran porte y de alta heterogeneidad en cuanto a su estado sanitario, y por la presencia de vegetales con gran oferta de frutos (Maytenus, Rosa Mosqueta y Laura). En todos los ambientes predominó el gremio de las aves insectívoras, seguido por el de las aves granívoras. Este patrón es común en el bosque andino-patagónico debido principalmente a que los artrópodos son generalistas y se encuentran presentes durante todo el año. La única excepción se observó en los ñirantales convertidos en pasturas donde el gremio carnívoro secundó a los insectívoros. La relativa baja abundancia de aves granívoras se debería a que el ganado y los roedores eliminan los granos. En la totalidad de los sitios, con respecto a la abundancia y riqueza específica de las aves se observó una relación positiva con la temperatura del aire y negativa en relación al viento. Las variables que mejor explican la dinámica de la avifauna se encuentran la equitatividad, diversidad y abundancia de artrópodos, abundancia de dípteros, transitabilidad, la temperatura del aire, velocidad del viento, y abundancia de frutos de Maytenus, Rosa Mosqueta y Laura. La metodología mediante PC resultó ser más eficiente que la LT.

Las diferentes acciones antrópicas afectaron en distintos niveles la comunidad de aves siendo los ñirantales primarios el último relicto para la conservación de las especies emblemáticas, vulnerables o de importancia para su conservación, y por ello se debe evitar continuar con la fragmentación del paisaje y propender a ambientes en mosaicos continuos de tal modo que esos corredores permitan mantener el hábitat lo mas adecuado posible para el natural desarrollo de la biodiversidad de los ñirantales del bosque andino-patagónico.

Palabras claves: Biodiversidad, ñirantales, avifauna, Patagonia, manejo forestal, trofismo. 


\section{ABSTRACT}

The general objective of this work is to explore the dynamics of bird communities associated with forests of Nire in the Northwest of Chubut, affected by different types of impact.

The study was conducted between July 2008 and June 2010, making quarterly field samplings. It focused on Nire forest sectors affected by selected types of impact: firewood collection in forest areas converted to grassland, firewood collection in patches, conversion of forest areas to pastures, and fires occurred 15 and 25 years ago. Unmanaged parcels of virgin forest were considered as test plots. The

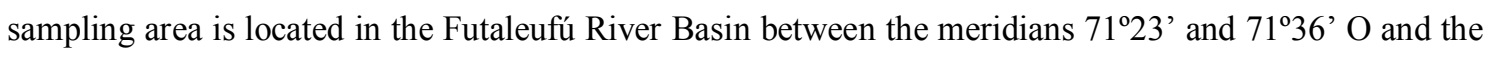
parallels $43^{\circ} 05^{\prime}$ y $43^{\circ} 14^{\prime} \mathrm{S}$, and the altitude of the sites varied between 525 y 855 metres above sea level.

The specific objectives of the work were to make an inventory of the birds living in the Nire stands (Spanish ñirantales) in the West-Central area of Chubut; to determine their abundance, specific richness and diversity, characterizing the structure of bird communities associated with ñirantales affected by different environmental impacts; to determine the extent of the intra and inter annual changes in the bird community structure; to assess the trophic sectors associated to vegetation structure, and to analyze the community structure and each species according to their conservation levels.

Two replica stands were considered for each type of impact (12 sampling sites in all) for the vegetation sampling, set on three $100 \mathrm{~m} 2$ plots, placed randomly within each replica stand. Fruit sampling was made for those five species supplying more fruit to the environment within each plot, collecting the data during the summer season. Interception traps and sticky traps were used for arthropod sampling points, and samples were collected from canopy and soil using an Auger. The main biological parameters were estimated on the basis of the material collected. Bird samplings were made quarterly through two different procedures: counting points and line transect. Three $350 \mathrm{~m}$-line transects and six counting points were set in each replica plot. On the basis of this data, the main biological parameters were assessed: the SUMIN index and maximum SUMIN index, Conservation Category and Trophic Structure. The number of species $(\mathrm{S})$ and the number of individuals $(\mathrm{N})$ were used in all cases in which comparisons were made.

Unmanaged virgin Nire stands presented an appropriate conservation status, which allows the preservation of its spatial and seasonal variability. In the sites disturbed by fires the arboreal layer showed a clear decline of native species and a higher percentage of species of exotic origin. These sites showed a good sanitary status of the trees (Ñires), although the diameter of the trees was low, which corresponds with the state of regeneration of individuals. In the arboreal layer of those sites affected by firewood collection in patches and by forest conversion to grassland, native species such as Nire and Maitén predominated. These Nires showed a very good sanitary status and a relatively great size, although cattle activity does not favour the renewal of the forest. Those sites converted to pastures showed a higher presence of native herbaceous species. No trees were registered in those areas, which imply that regeneration and rehabilitation of the Nire forest are seriously threatened there.

The arthropods associated to the Nirantales kept fully active along the whole year, tolerating extreme conditions during the cold months and displaying activity peaks during the warmest months. No differences were observed in terms of abundance of orders in the sites affected by different types of 
impact, and even wealth and diversity, dominance and evenness indexes were similar between the sites. The seasonal variation observed in the abundance of the orders of arthropods collected and in the indexes of diversity and dominance appeared closely related to the environmental climatic conditions, especially temperature, and the fenology of the vegetation regardless of the type of impact. The abundance of individuals belonging to the orders represented in the captures increased in parallel with the increase of the cover of the arboreal layer. This pattern could be explained not only by the influence of higher relative temperatures, which affect arthropods negatively in pastures, but also by the lower heterogeneity of these environments, due to a smaller availability of microhabitats. In relation to the sampling techniques, the samples collected with "Sticky traps", "Fluid interception" traps and those set onto the vegetation canopy enabled the collection of a greater amount of individuals belonging to the Díptera order, which might be due to the fact that these traps are more efficient in catching flying individuals. Samples from "Fluid interception" traps both at the ground level and onto the canopy were more abundant and diverse than the ones collected with "Sticky traps". The diversity of arthropod orders associated to forests of Nire was similar between the different sampling sites, and it was not drastically affected by disturbances derived from firewood collection from patches, forest convertion to grassland or fires, given that these areas still have their vegetal cover along with its habitats and favourable microclimatic conditions. Nevertheless, in those forests converted to pastures the microclimatic conditions and the habitats were drastically modified, which affects the community dynamics of arthropods.

As regards birdlife, a total 49 species were recorded with the counting points method and other 44 species with the line transects method. This small number of species is characteristic of the Andean Patagonian forest due to: the insular location of the forests, orogenic movements, relatively recent glaciation and extreme low temperatures in the autumn-winter semester. Specific richness (13 - 29), individual abundance $(1,73-10,44 \mathrm{indv}$./ha/season), specific diversity $(0,55-2,05)$ and conservation index varied according to the kind of Nirantal studied.

Greater abundance, specific wealth and diversity were observed within the Nire stands subjet to intermediate disturbances, mainly stands affected by firewood collection caused by forest conversion into grasslands, Ñire stands impacted by fire between 15 and 25 years ago, firewood collection from patches. The least abundance was recorded in those Nirantales converted into pastures and in virgin ones.

Unmanaged virgin Nire stands hold a bird community whose species emblematic or endangered, experience the highest conservation index given that: it is the only place where the large Patagonian Woodpecker can be found - considered a keystone specie for the preservation of temperate forest, it has the entire Rhinocryptides specie - highly sensitive to changes in the habitat, it is home to the all the woodpecker species living in mature forests, and it is a place of highly ecologically stable bird community given by the detected high resident/migrating bird relationship. This is due to the existence of large trees and their highly heterogeneous sanity conditions, and the presence of plants with a wide range of fruits (Maytenus, Rose Hip and Laura). In all the sites there is a predominance of insectivorous birds, followed by granivorous birds. This pattern is common to the Andean Patagonian forest mainly for the fact that arthropods are generalist and are found during the whole year. The exception is observed in the Nire stands converted into pasture areas, where carnivorous birds appear after insectivorous ones. The relatively low abundance of granivorous birds may be due to the fact that cattle and rodents eliminate the 
grains. Regarding bird abundance and specific wealth, all sites showed a positive relation with air temperature and a negative incidence of wind. Among the variables to better explain birdlife dynamics are arthropod evenness, diversity and abundance, diptera abundance, transitability, air temperature, wind speed and abundance of fruits Maytenus, Rose Hip and Laura provide the site with. The counting point methodology was more efficient than the line transect methodology.

Different anthropic activities affect birdlife at different levels, remaining thus Nire stands as an ultimate shelter for emblematic, endangered or keystone species to conservation. Therefore, it is imperative to stop landscape fragmentation and, at the same time, to promote a habitat restoration through continuous mosaics, forming corridors of proper environmental conditions for the natural development of the Nire stands biodiversity in the Andean Patagonian forest.

Key words: Biodiversity, Ñire stands, birdlife, Patagonia, forest management, trophism. 


\section{INTRODUCCIÓN}

\section{1 - Introducción General}

El bosque andino-patagónico, posee una alta singularidad biogeográfica, representando aproximadamente el $50 \%$ de la superficie total de las formaciones boscosas templadas del mundo. La notable integridad ecológica y el elevado valor de conservación de estos ambientes es altamente reconocida dentro de los ecosistemas del planeta por el World Resources Institute (W.W.F. et al. 2001) por lo que fue categorizada como uno de los "Global 200 sites" del planeta (Olson y Dinerstein 1997, DGByP 2010).

Dentro de los cambios ambientales, la deforestación y la transformación de ambientes han sido uno de los mayores factores que han impactado sobre los recursos naturales forestales (Albarracín Franco et al. 2014). Los severos procesos de degradación a los que fueron sometidos los bosques resultaron en la pérdida de biomasa, dando como resultado un bosque empobrecido con escasa capacidad de proporcionar bienes y servicios.

Estos bosques empobrecidos requieren ser manejados adecuadamente para su recuperación con el fin de presentarse como una alternativa productiva y económica viable (Montenegro et al. 2004).

Argentina se encuentra en una situación crítica en cuanto a la existencia de bosques, a la biodiversidad existente en los mismos y a su capacidad para conservarlos (Morello y Mateucci 1999). En 1875 Argentina contaba con 160 millones de hectáreas de bosques, montes y selvas, pero a partir de ese año la superficie forestal disminuyó a 106 millones de hectáreas en 1914, a 60 millones de hectáreas en 1956 (Morello y Mateucci 1999), 30 millones en 2002, 29,5 millones 
en 2004 y 29 millones de hectáreas para el año 2006 (Lavalle et al. 2010). Los datos más optimistas indican que en 2008 quedaban 33 millones de hectáreas forestales nativas (Zarrilli 2008). Por lo tanto, en menos de dos siglos el país perdió aproximadamente el $80 \%$ de la masa boscosa nativa (SAyDS 2008).

Si bien, es difícil dimensionar con exactitud la magnitud del proceso y su localización en distintos momentos, los datos demuestran una constante pérdida de superficie de Bosques Nativos (Montenegro et al. 2003 y 2004, SAyDS 2008) proceso que en la actualidad Argentina no está revirtiendo (Montenegro et al. 2004).

Al observar estos valores, no debemos olvidar que como se dijo anteriormente el fenómeno de deforestación se refiere exclusivamente a la pérdida de superficie forestal, es decir que no mide el grave proceso de "degradación" de las masas forestales restantes.

Las transformaciones mas importantes en el paisaje han ocurrido como consecuencia de la utilización de los hábitats naturales para actividades tales como uso agrícola-ganadero, urbanización y deforestación (Foley et al. 2005). Entre dichos impactos, el cambio en el uso del suelo constituye una amenaza importante a corto $y$ mediano plazo para la persistencia de las especies y se prevé que en el futuro tenga un gran impacto sobre la biodiversidad (Sala 2000, Thuiller 2007).

Una de las principales causas de extinción de especies silvestres es el empobrecimiento, degradación y fragmentación de los hábitats que éstas utilizan. Frecuentemente, la modificación de los ambientes naturales termina transformándolos en islas, conformando hábitats que se asocian generalmente con la pérdida o disminución por debajo de niveles críticos de los recursos básicos, lo que puede influir negativamente en la persistencia de las especies (Santos et al. 2002).

Conjuntamente con todo lo anterior, los ñirantales no han estado a salvo del proceso de degradación sufrido por la masa 
boscosa en Argentina. De un poco más de 500.000 hectáreas de bosques de Nire estimadas en la década del 80, a fines del siglo XX se contaba con solamente 385.000 hectáreas, lo que representa una pérdida de alrededor del $25 \%$ del total del área (Bran et al. 1998).

A su vez, del total de los ñirantales existentes, alrededor de 260.000 hectáreas están distribuidas en la provincia de Chubut representando el 40\% del bosque nativo provincial (Bran 1991, Bran et al. 1998).

Por otro lado, entre las especies arbóreas andino-patagónicas, luego del Ciprés de la Cordillera (Austrocedrus chilensis), el Ñire (Nothofagus antarctica) es la que mayor impacto ha sufrido (Bertonatti y Corcuera 2000, Hansen et al. 2002) (Tabla 1.1).

Tabla 1.1: Clasificación de especies arbóreas del bosque andino Patagónico según el nivel de incidencia de los impactos antrópicos (Hansen et al. 2002).

\begin{tabular}{|c|l|}
\hline Impacto & \multicolumn{1}{|c|}{ Especie } \\
\hline $1^{\circ}$ & Ciprés de la Cordillera \\
\hline $2^{\circ}$ & $\tilde{N}$ ire \\
\hline $3^{\circ}$ & Coinue \\
\hline $4^{\circ}$ & Araucaria \\
\hline $5^{\circ}$ & Raulí \\
\hline $6^{\circ}$ & Lenga \\
\hline
\end{tabular}

Entre los impactos sufridos por los ñirantales en Chubut podemos mencionar: incendios forestales de orígenes antrópico (intencionales o accidentales), tala del bosque para extracción de leña, reemplazo por especies forestales exóticas, urbanización o sembradíos, degradación por sobre-pastoreo, entre otros (Bertonatti y Corcuera 2000, Hansen et al. 2002). 
La intensidad de dichos impactos sobre los ñirantales es importante (Tabla 1.2), por lo que es probable que también hayan afectado a las comunidades asociadas (Bran 1991, Bran et al. 1998).

Tabla 1.2: Niveles de impactos cualitativos al que fueron sometidos los ñirantales dentro del bosque andino patagónico (Hansen et al. 2002).

\begin{tabular}{|c|c|}
\hline Tipos de Impacto & Nivel Cualitativo \\
\hline Incendios antrópicos & Muy fuerte \\
\hline Impacto por Turismo & Muy fuerte \\
\hline Extracción de leña & Fuerte \\
\hline Introducción de especies & Fuerte \\
\hline Degradación por pastoreo & Fuerte \\
\hline Plantaciones forestales & Moderado \\
\hline Urbanización & Moderado \\
\hline $\begin{array}{l}\text { Habilitación de tierras } \\
\text { agroganaderas }\end{array}$ & Leve \\
\hline Obras de infraestructura & Muy leve \\
\hline Aprovechamiento maderero & Muy leve \\
\hline Contaminación Industrial & Nulo \\
\hline $\begin{array}{l}\text { Cosecha de productos no } \\
\text { maderables }\end{array}$ & Nulo \\
\hline Producción de astillas (chips) & Nulo \\
\hline Cortas por explotación minera & Nulo \\
\hline
\end{tabular}


Entre los principales beneficios y argumentos que expresan la importancia ecológica de los ñirantales podemos mencionar su gran plasticidad, esta les permite ocupar ambientes extremos (desde mallines y turberas hasta el ecotono bosque-estepa) donde otras especies arbóreas del bosque andino-patagónico (por ejemplo, Lenga, Coihue, etc.) no podrían progresar (Hansen et al. 2002).

Los ñirantales presentan una estructura marcadamente heterogénea, lo que les permite albergar una alta biodiversidad no observable en otros tipos de estructuras del bosque andinopatagónico (Fertig 2003), y debido a su distribución, protegen las cabeceras de cuenca, contribuyendo a regular la cantidad y calidad del agua de los sectores más bajos de las cuencas, preservando de este modo la biodiversidad y estructura trófica de las mismas (Quinn et al. 1997, Collier et al. 2001).

La estructura del bosque andino-patagónico primario determina condiciones ecológicas que inciden sobre gran parte de los requerimientos de las especies de aves que lo habitan. Por lo tanto, se espera que los cambios estructurales producidos en el bosque afecten las poblaciones y comunidades de aves. A modo de ejemplo, los rodales de Lenga (Nothofagus pumilio), especie que también pertenece a la familia de los Nothofagus y es un componente de relevancia de la estructura del bosque andino-patagónico, presentan un dosel cerrado que determina la presencia de un sotobosque ralo (Martínez Pastur et al. 2001), resultando en un ambiente poco adecuado para las aves herbívoras pero, debido a la abundancia y diversidad de insectos presentes (Spagarino et al. 2001), favorecería a las especies insectívoras y omnívoras.

Se observó que en rodales de Lenga intervenidos el desarrollo del sotobosque es mayor, lo que resulta en el incremento de la oferta de semillas, flores y frutos, lo que beneficiaría a especies herbívoras y omnívoras, y la disminución de la abundancia de insectos, lo cual 
afectaría negativamente a las especies insectívoras (Deferrari et al. 2001, Spagarino et al. 2001).

Numerosos autores han documentado la incidencia sobre la densidad de las poblaciones de aves con respecto a: la disponibilidad de recursos (Raitt y Pimm 1976, Loiselle y Blake 1991, Marone 1992), las grandes variaciones en la disponibilidad de alimento que determinan cambios estacionales en la estructura de los ensambles o gremios de aves (Brooks 1997, Cueto y López de Casenave 2001), la fuerte correlación entre la variedad y tipos de sustratos presentes en el bosque con respecto al grado de segregación entre las aves de los ensambles (Carrascal y Tellería 1985) y, finalmente, su patrón alimentario (Cueto y López de Casenave 2001). Sin embargo, el bosque no solo representa para las aves una fuente de alimentos, es también un ambiente en el que se refugian y nidifican por lo que estos aspectos de la biología de las aves también pueden resultar afectados por cambios estructurales ocasionados en el bosque (Baldi y Kisbenedek 1999).

El conocimiento de la abundancia y biodiversidad de las comunidades de aves y de sus patrones espacio-temporales de uso del hábitat, entre otros aspectos, es fundamental no solo para conocer la estructura de dichas comunidades y comprender el funcionamiento del ecosistema, sino también para formular pautas de manejo y conservación (Jaksic y Feinsinger 1991). A pesar de todo lo mencionado, los estudios sobre las comunidades de aves en ñirantales son escasos y fragmentarios (Vuilleumier 1985, Iglesias 1988 y 1989, Pavic 2000, Rusch et al. 2004).

Las regiones del mundo mayormente alteradas por actividades humanas se ubican en las zonas templadas, donde muchos de los ecosistemas boscosos templados han desaparecido y los que aún persisten están fragmentados y altamente modificados (Franklin y Armesto et al. 1996). 
Para preservar la biodiversidad en las áreas boscosas se requiere el mantenimiento de todos los estadíos sucesionales del bosque. Debido a que los estadíos tempranos están generalmente bien representados, el mayor esfuerzo de conservación debe estar dirigido a preservar el bosque maduro. Por lo tanto, si en zonas sujetas a explotación forestal se asegura un manejo que mantenga la complejidad estructural del ecosistema a largo plazo con un rendimiento sostenido de los productos del bosque, el sistema podría volver a su estado original en el caso de cesar el manejo forestal (Lantschner 2005).

Como consecuencia de lo anterior, a principios de los años ' 80 en el Informe Burtland (WCED 1987) se definió el concepto de manejo sustentable como "el desarrollo que satisface las necesidades del presente sin comprometer la capacidad de las generaciones futuras de satisfacer sus propias necesidades" criterio que tuvo una gran aceptación y consenso a partir de la Conferencia de Río de Janeiro de 1992.

Uno de los principios propuestos para el manejo forestal sustentable postula que la "integridad de los ecosistemas y sus funciones ecológicas deben ser mantenidas" (Kay 1997). En este sentido, un ecosistema posee integridad si puede absorber cambios sin alterar su estado de manera permanente. En base a ello, la resiliencia sería una medida adecuada de la integridad de un ecosistema (Schlichter y Laclau 1998), de tal modo que, la capacidad de un sistema de volver a una situación similar a la original luego de un disturbio depende, entre otros factores, del estado de los ecosistemas adyacentes.

Por ello es importante analizar la situación de los ecosistemas incorporando una perspectiva ecológica a nivel de paisaje puesto que el tamaño, la forma y las relaciones espaciales de los parches del paisaje influyen sobre la estructura y función de los ecosistemas (Turner 2005). Así, un mayor conocimiento de las relaciones espacio 
temporales entre los cambios en los usos del bosque y la distribución de las especies de aves será esencial para establecer adecuadas políticas de conservación de la biodiversidad a escala regional (Turner 2005, Fischer y Lindenmayer 2006).

A pesar de todo lo mencionado, la magnitud del proceso de degradación de los ñirantales y de las implicancias a nivel ecológico que el mismo ocasiona o puede ocasionar en el corto plazo, aún no hay estudios integrativos tendientes a profundizar el conocimiento de esta problemática en el bosque andino-patagónico (Montenegro et al. 2004, Lantschner 2005).

Por tal motivo, con el fin de revertir esta situación, la Argentina junto a otros países que poseen bosques templados, realizan relevamietos acerca de la evolución de sus bosques en sus aspectos productivos, económicos y sociales, sobre las respuestas de estos a los impactos de manejo, y en relación a los aspectos que pueden modificar o adaptar para mejorarlo (Mc Ginley y Finegan 2002).

Otro mecanismo de control de los ecosistemas forestales aplicado es mediante la "Evaluación de Criterios e Indicadores Forestales" elaborado por el Center Organism for Forest Research (Carabelli et al. 2003), que permite la investigación y evaluación del bosque con el objetivo de un manejo forestal sustentable (Carabelli y Peri 2005, Lantschner 2005).

Actualmente, una de las acciones tendientes a recuperar o preservar el bosque es mediante la ejecución de la Ley N²6331 denominada de Presupuestos Minimos de Proteccion Ambiental de los Bosques Nativos sancionada en diciembre de 2007 por la Cámara de Senadores de la Nación Argentina, la propia Ley contempla Disposiciones Generales a contemplar en los manejos de bosque (CSyDNA 2007), por ejemplo, los Artículos $1^{\circ}$ y $2^{\circ}$ que establece pautas para la protección del bosque nativo (CSyDNA 2007):

ARTICULO 10.- La presente ley establece los presupuestos mínimos de protección ambiental para el enriquecimiento, la 
restauración, conservación, aprovechamiento y manejo sostenible de los bosques nativos, y de los servicios ambientales que los bosques nativos brindan a la sociedad. Asimismo, establece un régimen de fomento y criterios para la distribución de fondos por los servicios ambientales que brindan los bosques nativos.

ARTICULO 20.- A los fines de la presente ley, considéranse bosques nativos a los ecosistemas forestales naturales compuestos predominantemente por especies arbóreas nativas maduras, con diversas especies de flora y fauna asociadas, en conjunto con el medio que las rodea (suelo, subsuelo, atmósfera, clima, recursos hídricos), conformando una trama interdependiente con características propias y múltiples funciones, que en su estado natural le otorgan al sistema una condición de equilibrio dinámico y que brinda diversos servicios ambientales a la sociedad, además de los diversos recursos naturales con posibilidad de utilización económica.

Finalmente, otra actividad encaminada hacia la protección del bosque nativo, aunque a Nivel Internacional, es el "Proceso de Montreal" del cual la Argentina es signataria, pues como se indica en el $2^{\circ}$ Reporte Nacional del Proceso de Montreal (2015) la elaboración y aplicación de C\&I (criterios e indicadores) contribuiría a unificar el concepto de ordenación forestal sostenible y ayudaría a concretarlo mediante un instrumento operacional que se pueda aplicar en la práctica a través de un manejo forestal conservacionista.

En base a todo lo comentado, el objetivo del trabajo es profundizar el conocimiento de la dinámica de las comunidades de aves asociadas a los ñirantales de la provincia del Chubut sometidos a diferentes tipos de impacto ambiental. Es de esperar que los resultados permitan entender el modo en que tales comunidades de aves se interrelacionan con la vegetación y los artrópodos y a su vez, conocer el modo en que responden a la alteración del ambiente, con el fin de formularse pautas de manejo de los ñirantales para que su explotación sea ecológicamente sustentable. 


\section{2 - Objetivo e Hipótesis}

\subsubsection{Objetivo Principal}

El objetivo del presente estudio es caracterizar la estructura de las comunidades de aves y su interrelación con la vegetación e invertebrados asociados a bosques de Ñire (Nothofagus antarctica) del centro-oeste de la provincia de Chubut que fueron sometidos a diferentes impactos ambientales.

\subsubsection{Objetivos Específicos}

I. Realizar el inventario de avifauna, de sus presas potenciales y de la flora presente en los ñirantales sometidos a diferentes impactos ambientales, determinando la riqueza específica de cada grupo.

II. Determinar la estructura de las comunidades de aves y la organización de los gremios (guilds) asociados a ñirantales sometidos a diferentes impactos ambientales.

III. Determinar la cantidad y tipo de alimento disponible para las comunidades de aves asociadas a ñirantales sometidos a diferentes impactos ambientales.

IV. Evaluar la interrelación de las aves entre sí, artrópodos y con la vegetación, en función de la biodiversidad tridimensional o vertical del ambiente.

V. Realizar un análisis comparativo de los resultados obtenidos a través de las diferentes metodologías de censado de aves 
(puntos de conteo y transectas) para determinar cual es la más efectiva para estudiar los diferentes tipos de ñirantales.

VI. En base a la información obtenida, analizar la posibilidad de generar pautas de manejo tendientes al uso sustentable del bosque prestando particular atención a la conservación de la biodiversidad.

\subsubsection{Hipótesis}

Las modificaciones en las tipologías de los ñirantales, según los usos a los que fueron sometidos, generan cambios en las poblaciones de aves asociadas.

> La estructura y composición de las comunidades de aves asociadas a ñirantales están determinadas principalmente por las características estructurales del bosque $y$ por las características florísticas. 


\section{1 - CARACTERIZACIÓN DE LOS ÑIRANTALES}

\subsubsection{Generalidades}

Los ñirantales estudiados se encuentran inmersos en la conformación vegetal denominada bosque andino-patagónico. Éste bosque ocupa una delgada franja de vegetación boscosa que acompañando a la cordillera de Los Andes se extiende desde el norte de la provincia de Neuquén hasta Tierra del Fuego (Cabrera y Willinik 1973).

El sector del bosque andino patagónico estudiado se ubica en el área fitogeográfica argentina denominada Provincia Subantártica Distrito del Bosque Caducifolio (Cabrera y Willinik 1973), aunque según otros autores el área bajo estudio pertenece a la provincia fitogeográfica del Bosque Valdiviano, subregión Subantártica de la región Andina (Morrone 2006) o Bosque Andino Patagónico (SAyDS 2015) (ver Fig. 2.1).

La estructura botánica de la Provincia Subantártica está conformada por pocas especies vegetales nativas, cuya composición florística varía a lo largo de su extensión. A modo de ejemplo, la Araucaria (Araucaria araucana) domina en el sector norte, en tanto que en los sectores marginales o más secos predomina el Ñire (Donoso 1987, Bran 1991, Bran et al. 1998). 


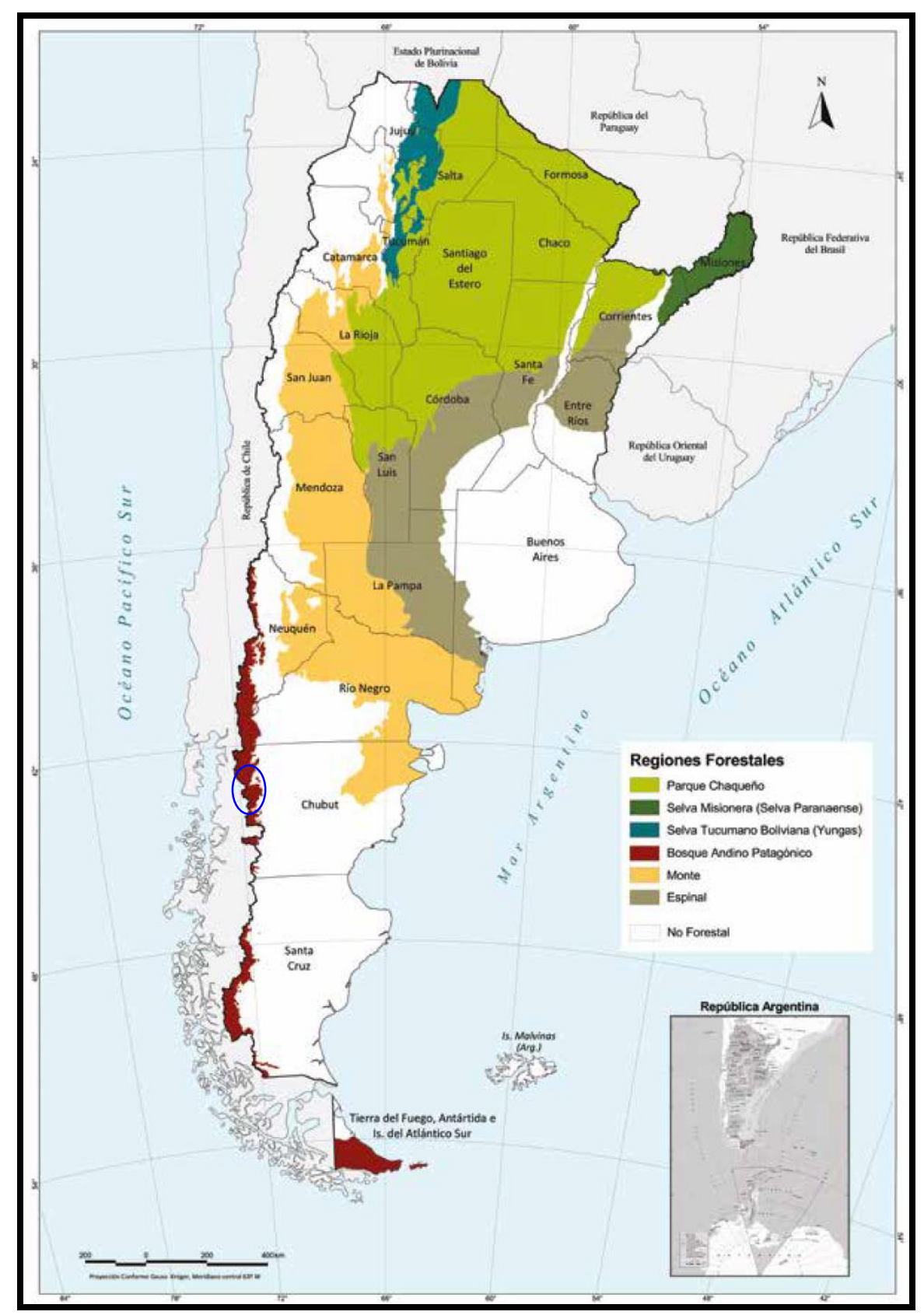

Fig. 2.1: Zonas fitogeográficas de la Argentina (SAyDS 2015) donde se representa el área estudiada. Fuente: Secretaría de Ambiente y Desarrollo Sustentable de la Nación. 2015. SIG 250: Instituto Geográfico Nacional de la República Argentina. Unidad de Manejo del Sistema de Evaluación Forestal (UMSEF) - Dirección de Bosques de la Nación.

Los bosques de Ñire en la provincia de Chubut ocupan entre 280000 (DGByP 2004) y 350000 hectáreas (Informe PIARFON 2005, Bava et al. 2008) y tienen una fuerte presencia en la estructura del bosque andino-patagónico (tabla 2.1): 
Tabla 2.1: La superficie total (ha.) y porcentual ocupada por las principales especies arbóreas del bosque andino-patagónico, y porcentaje de la superficie ocupada por losñirantales en cada provincia (Informe PIARFON 2005)

\begin{tabular}{|l|c|c|c|c|c|c|c|}
\hline \multicolumn{1}{|c|}{ Especie } & Sup. & $\begin{array}{c}\text { Sup. } \\
\mathbf{\%}\end{array}$ & Neuquén & $\begin{array}{c}\text { Río } \\
\text { Negro }\end{array}$ & Chubut & $\begin{array}{c}\text { Santa } \\
\text { Cruz }\end{array}$ & $\begin{array}{c}\text { Tierra } \\
\text { del Fuego }\end{array}$ \\
\hline Araucaria & 114000 & 4,6 & 114000 & - & - & - & - \\
\hline Nire & $\mathbf{7 2 5 5 5 3}$ & $\mathbf{2 9 , 2}$ & $\begin{array}{c}\mathbf{5 8 0 0 0} \\
\mathbf{( 1 8 \% )}\end{array}$ & $\begin{array}{c}\mathbf{3 5 1 0 0} \\
\mathbf{( 1 3 \% )}\end{array}$ & $\begin{array}{c}\mathbf{3 4 5 7 5 0} \\
\mathbf{( 3 2 \% )}\end{array}$ & $\begin{array}{c}\mathbf{9 8 9 2 0} \\
\mathbf{( 1 0 \% )}\end{array}$ & $\begin{array}{c}\mathbf{1 8 7 7 8 3} \\
\mathbf{( 2 7 \% )}\end{array}$ \\
\hline Lenga & 1355839 & 54,5 & 120000 & 202770 & 389000 & 153030 & 491039 \\
\hline Ciprés & 83615 & 3,4 & 42500 & 17240 & 23875 & - & - \\
\hline Total & 2484292 & 100 & 454500 & 308770 & 790250 & 251950 & 678822 \\
\hline
\end{tabular}

Sup. \%: Distribución porcentual de las principales especies arbóreas en el bosque andinopatagónico y distribución porcentual del total de bosque de Ñire en cada una de las provincias patagónicas.

Se desprende del cuadro, que la superficie de los bosques de Ñire se encuentra en segundo lugar en importancia tanto en el bosque andino-patagónico como en la provincia de Chubut, precedidos solamente por la especie Lenga (Nothofagus pumilio).

A su vez, el área estudiada se encuentra incluida en el ñirantal de mayor importancia a nivel provincial y del bosque andinopatagónico (DGByP 2004), encontrándose ubicada dentro del área denominada Cuenca Forestal Corcovado-Trevelin cuya superficie total es de aproximadamente 43050 hectáreas (Rusch et al. 2005).

Con el fin de propender a un uso sustentable del bosque andino-patagónico se fijaron principios y lineamientos a nivel nacional para el Manejo de Bosque General e Integral (MBGI) donde se establecieron orientaciones generales para recuperar el potencial forestal, sin perder la capacidad productiva de los sistemas ni sus funciones ecosistémicas, y donde se involucran conceptos asociados a la estructura del bosque, la conectividad y biodiversidad de los sistemas, la capacidad forrajera y la eficiencia productiva (MdIPCh 2016). Una gran superficie del bosque andino-patagónico se encuentra comprendida en categorías de conservación, lo cual genera 
un marco adecuado para las diferentes intervenciones que sean proyectadas (Tabla 2.2; SAyDS 2015).

Tabla 2.2: Distribución de las áreas forestales del bosque andino-patagónico según su categorización de conservación. Fuente: Secretaría de Ambiente y Desarrollo Sustentable. 2015. Subsecretaría de Planificación y Políticas Ambientales. Dirección Forestal - Unidad de Manejo de Sistemas Forestales, basado en información del Sistema de Áreas Forestales Protegidas, en: MPC II ${ }^{\circ}$. 2015. Second Argentine Report for the Montreal Process. National Report Based and Criteria and Indicators of the Montreal Process (en línea). Consultado ago. 2016. Disponible en http://www.montrealprocess.org/documents/publica-tions/general/2015/SecondArgentineReportfortheMontrealProcess.pdf.

\begin{tabular}{lccc} 
Cat. de conservación & \multicolumn{3}{c}{ Áreas Forestales } \\
\cline { 2 - 4 } & APN (ha) & Total (ha) & Área (\%) \\
\hline Áreas Protegidas Nacional & 820831 & & 29,27 \\
Áreas Protegidas Provincial & 227831 & 2803918 & 8,13 \\
Reserva de Biósfera & 1007612 & & 35,94 \\
Sitios Ramsar & 2957 & & 0,11
\end{tabular}

Varias provincias elaboraron su propia planificación para el enriquecimiento y conservación de bosques nativos.

En relación a lo anterior, en junio de 2010 en Chubut se aprobó la Ley NoXVII-92, la cual estuvo precedida por la Ley $N^{\circ} 26.331$ de Presupuestos Mínimos de Protección Ambiental de los Bosques Nativos, sancionada en 2007 donde se establecieron los Presupuestos Mínimos de Protección Ambiental para el enriquecimiento, la restauración, conservación, aprovechamiento y manejo sostenible de los bosques nativos y de los servicios ambientales que éstos brindan a la sociedad (SAyDS 2015).

Para ello se estableció como política de planificación el Ordenamiento Territorial de los Bosques Nativos (OTBN) para lo cual toda intervención en el bosque nativo debe encontrarse sujeta a un Plan de Conservación o de Manejo Sostenible.

En el OTBN se definieron tres categorías de conservación (Fig.2.2):

- ROJA: Sectores de muy alto valor de conservación que no deben transformarse ni ser sujetos a aprovechamiento forestal. Pueden realizarse actividades que no alteren sus atributos de conservación.

- AMARILla: Sectores de mediano valor de conservación, que no deben desmontarse. Podrán ser sometidos a aprovechamiento 
sostenible, turismo, recolección e investigación científica. A esta categoría correspondió el área bajo estudio (ver Tabla 1.4 y Fig. 2.1)

- VERDE: Sectores de bajo valor de conservación que pueden transformarse parcialmente o en su totalidad.

El desarrollo de la planificación del OTBN arrojó como resultado según Sitios de Interés Especial para la Conservación, que la provincia del Chubut posee una superficie forestal total de 1052171 ha., correspondiendo: 419351 ha. (40\%) a sectores de muy alto valor de conservación, 613324 ha. (58\%) con un nivel intermedio de conservación (dentro de la cual está comprendida el área estudiada) y finalmente, 19496 ha. (2\%) a áreas de bajo nivel de conservación (SAyDS 2015).

A pesar de lo indicado previamente, tanto en el área de estudio, como en el bosque andino patagónico en general, se efectúa principalmente un uso no sustentable del bosque (Bertonatti y Corcuera 2000). Específicamente, en los sitios analizados actuaron preponderantemente los siguientes procesos modeladores: fuego de origen intencional, tala de árboles, introducción de ganado, forestaciones con especies exóticas y todas las situaciones mencionadas tuvieron distinta intensidad, frecuencia y escala geográfica y en cierto modo generaron variación de la estructura vegetal (Veblen 1982, Veblen et al. 1996).

En la Fig. 2.2 se observa la distribución geográfica de las superficies correspondientes a los niveles de conservación según el Ordenamiento Territorial del Bosque Nativo en la provincia del Chubut: 


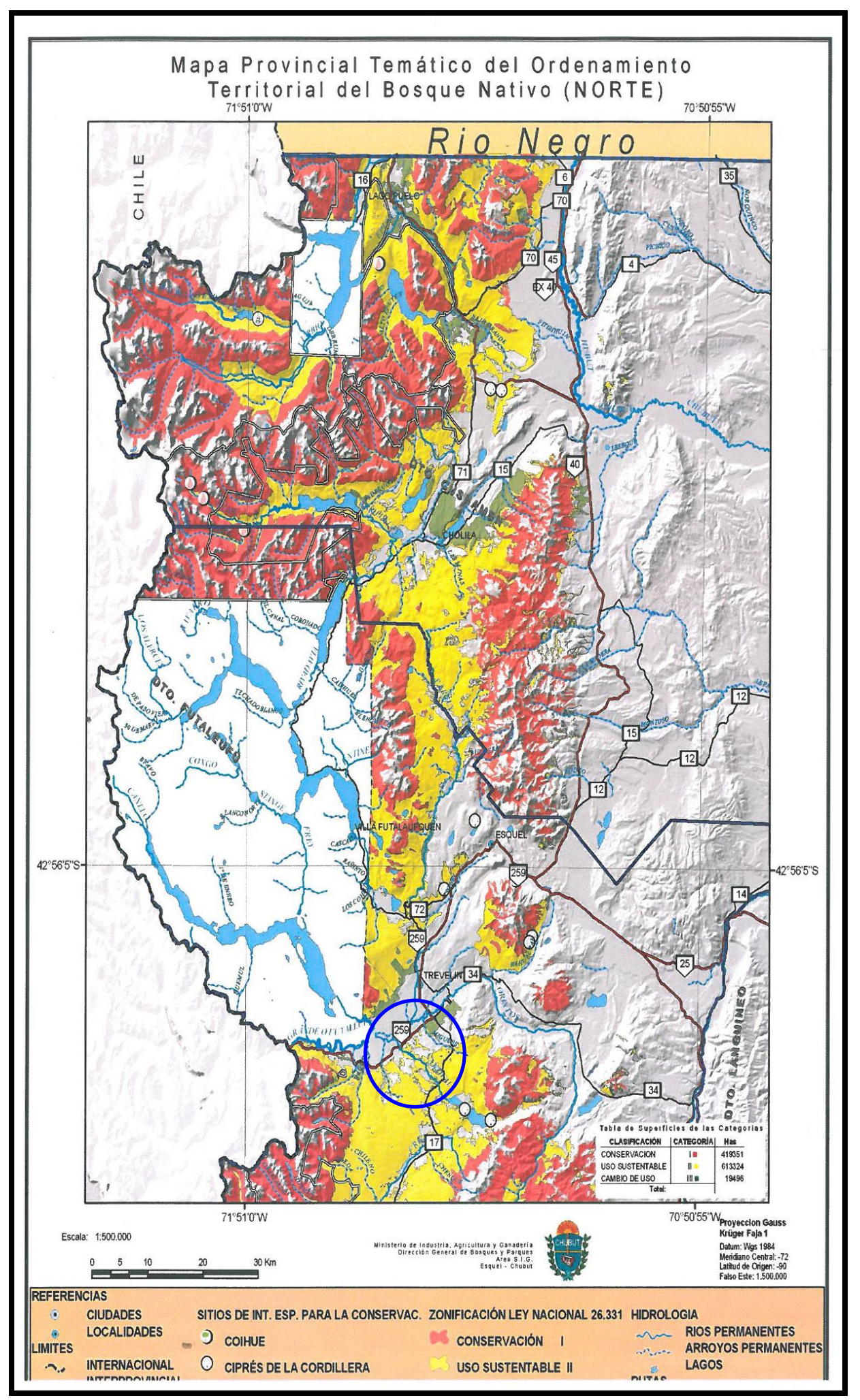

Fig. 2.2: Mapa temático del Ordenamiento Territorial del Bosque Nativo (Zona Noroeste) según niveles de Interes Especial para la Conservación. Fuente: Dirección General de Bosques y Parques (DGByP). 2010. Plan de Ordenamiento Territorial de Bosques Nativos de la Provincia del Chubut - Ley XVII. Honorable Legislatura del Chubut. Rawson - Chubut. 


\subsubsection{Características de los ñirantales}

El Ñire pertenece a la Familia Nothofagaceae, es una especie de crecimiento lento (Weinberger 1973, Premoli 1991, Quinteros 2007) y raramente alcanza edades superiores a los 200 años.

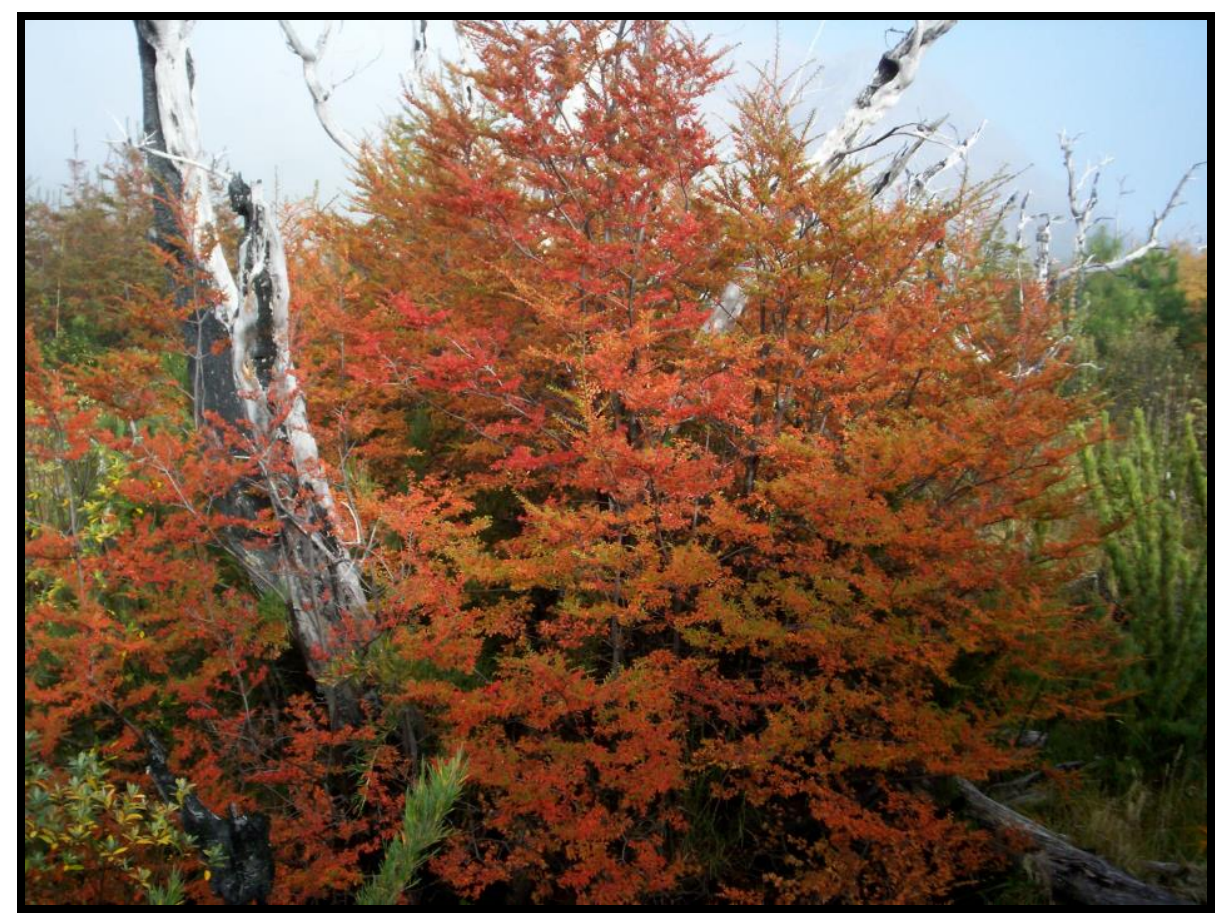

Foto 2.1: Los ñires viran su color hacia tonos rojizos en la época otoñal e invernal

Esta especie se encuentra distribuida en:

1) Sectores húmedos o en áreas de drenaje impedido situados tanto en zonas bajas como en sectores de altas elevaciones (Fig. $\mathrm{N}^{\circ} 2$ ) (Hoffmann 1991).

2) Puntos de alta pendiente y de muy baja temperatura, permitiendo desarrollarse de éste modo en los lugares límites conocidos con el nombre de "zona límite de la vegetación" o timber line (Hoffmann 1991).

3) Sectores de muy bajas temperaturas, próximas al punto de congelamiento, alrededor de los $22^{\circ}$ Centígrados bajo cero (Sakai et al. 1981, Alberdi 1987).

4) Sitios de grandes variaciones térmicas diarias con déficits de saturación atmosférica (Weinberger 1973). 
5) Áreas que sufren vientos fuertes.

6) Suelos de bajo drenaje, rocosos y parcialmente cubiertos de vegetación (Mc Quenn 1976, Veblen et al. 1977).

7) Ambientes altamente variados (Donoso 1987), que se distribuyen desde 2000 m.s.n.m. hasta casi el nivel del mar (Pisano 1977, Lugano et al. 2001).

Debido a las características mencionadas al Ñire se los encuentra en un amplio espectro de ambientes, por ejemplo es la única especie arbórea que se desarrollan en los ambientes más húmedos del bosque andino-patagónico (Veblen et al. 1996, Rusch et al. 2005).

Los suelos donde los ñirantales se desarrollan poseen una sustancial variablidad en la fertilidad y en la profundidad (Frederiksen 1988, Godagnone e Irisarri 1990) y ostentan en general una biomasa de sotobosque de gran relevancia en lo que respecta a cobertura y biomasa (San Martín et al. 1987, Collantes et al. 1989 y Martínez Pastur 2002).

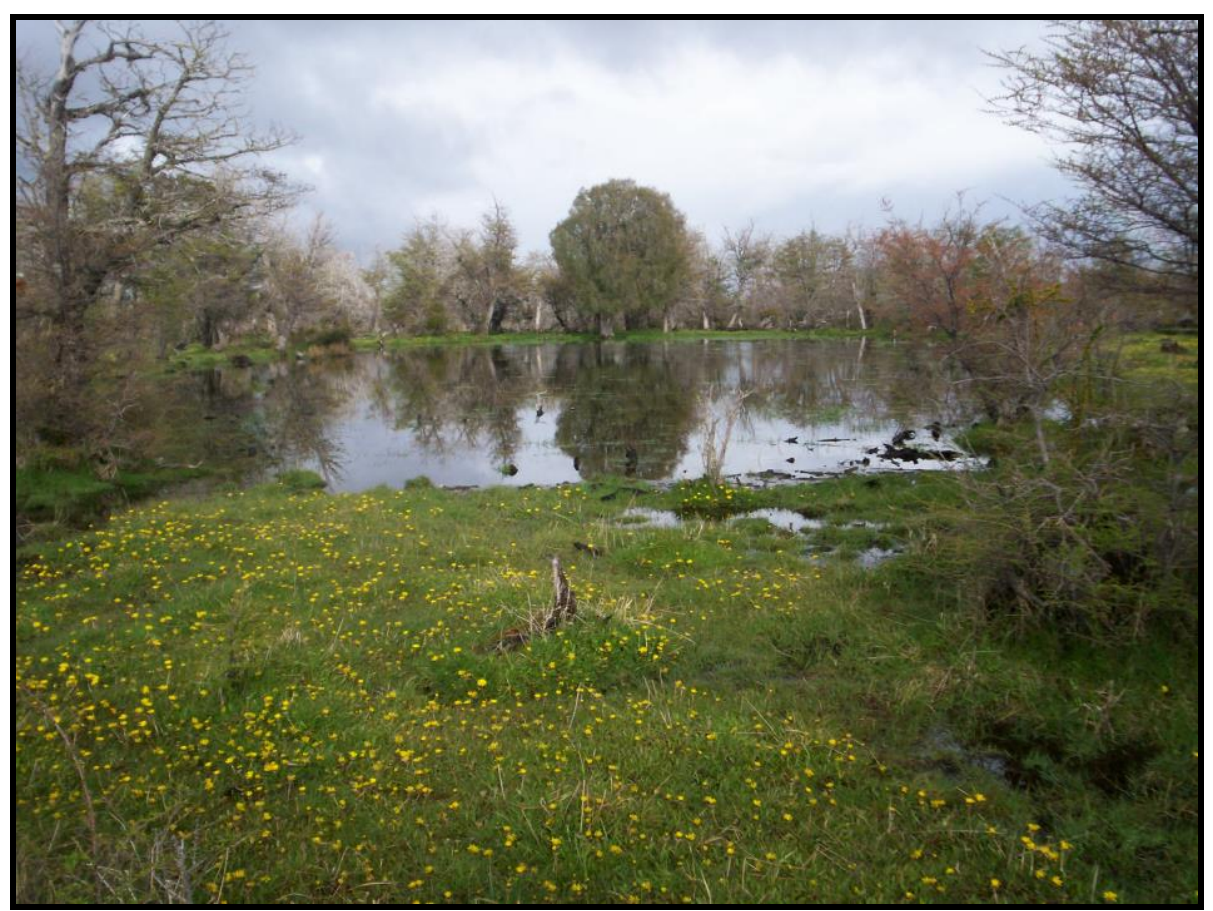

Foto 2.2: Se observa una zona donde el nivel freático se encuentra por encima del nivel del suelo, no obstante, el área anegada no es impedimento para el desarrollo del ñirantal. 
A nivel reproductivo, la abundancia de Ñire también está favorecida por su capacidad de reproducirse de modo sexual o asexual, pudiendo este último ser interpretado como una adaptación a condiciones rigurosas de hábitat (Cooke 1979).

Todo lo mencionado determina una amplia distribución del Ñire $y$, junto con la variada gama de biotopos diferentes en los que se encuentran (Mc Quenn 1976) explican la gran diferenciación intraespecífica observada en ésta especie. De este modo se pueden reconocer tres grupos poblacionales que expresan adaptaciones a diferentes condiciones ambientales: a) morfotipo arbóreo óptimo, b) morfotipo arbustivo achaparrado y, c) camefítico de turbera (Ramírez et al. 1985). Cabe indicar, que en Argentina se presentan principalmente los morfotipos arborescente y achaparrado (Donoso y Lara et al. 1996), los que a continuación son detallados:

a) Morfotipo arborescente: se presenta en condiciones óptimas de hábitat, dentro de la rigurosidad ambiental en que se desarrolla la especie. Este morfotipo es común en los sectores de bolsones de frío en la Cordillera de los Andes y en los sectores planos y es, el único que produce semillas viables (Ramírez et al. 1985). Las áreas estudiadas se correspondieron con esta estructura arbórea.

b) Morfotipo achaparrado: presenta troncos retorcidos, 0 tendidos y ramificados desde el suelo. Se presentan en condiciones muy rigurosas pero variables. Ésta estructura se halla principalmente en los sectores ubicados a elevadas altitudes o en los lugares límites conocidos con el nombre de "zona límite de la vegetación" o timber line (Hoffmann 1991). 
Si bien los ñirantales son una estructura vegetal dominada por ñires, también existen otras especies de flora que componen esta estructura (Hansen 2003).

En el ñirantal no hay un estrato dominante u homogéneo, se observan los distintos tipos de ñires (altos, bajos, achaparrados) entremezclado con claros en el bosque (Hansen 2003), a su vez como en casi todo sistema natural, el hombre no es ajeno al mismo, éste no sólo habita los ñirantales sino que desarrolla allí una actividad extractiva que modifica la presencia de los demás integrantes. Es así que según Hansen (2003), un ñirantal es un sistema conformado por los siguientes componentes:

a) Estrato Arbóreo: Este estrato se encuentra dominado por el Ñire aunque también pueden encontrarse otras especies con porte arbóreo como Maitén (Maytenus boaria), Radal (Lomatia hirsuta) y Retamo (Spartium junceum), el Ciprés de la Cordillera (Austrocedrus chilensis), el Chacay (Discaria serratifolia) y la, Lenga (Nothofagus pumilio) generalmente se hallan en un piso inferior.

Finalmente, el Coihue (Nothofagus dombeyi) se encuentra con una asociación vegetal de carácter mixto con Caña Colihue (Chusquea culeou) y Laura (Schinus patagonicus).

b) Estrato Arbustivo: En éste estrato existen especies que son ramoneadas por el ganado como por ejemplo arbustos como Berberis sp., Caña Colihue, Discaria chacaye, Maitén y, Ñire (Manacorda et al. 1995). 


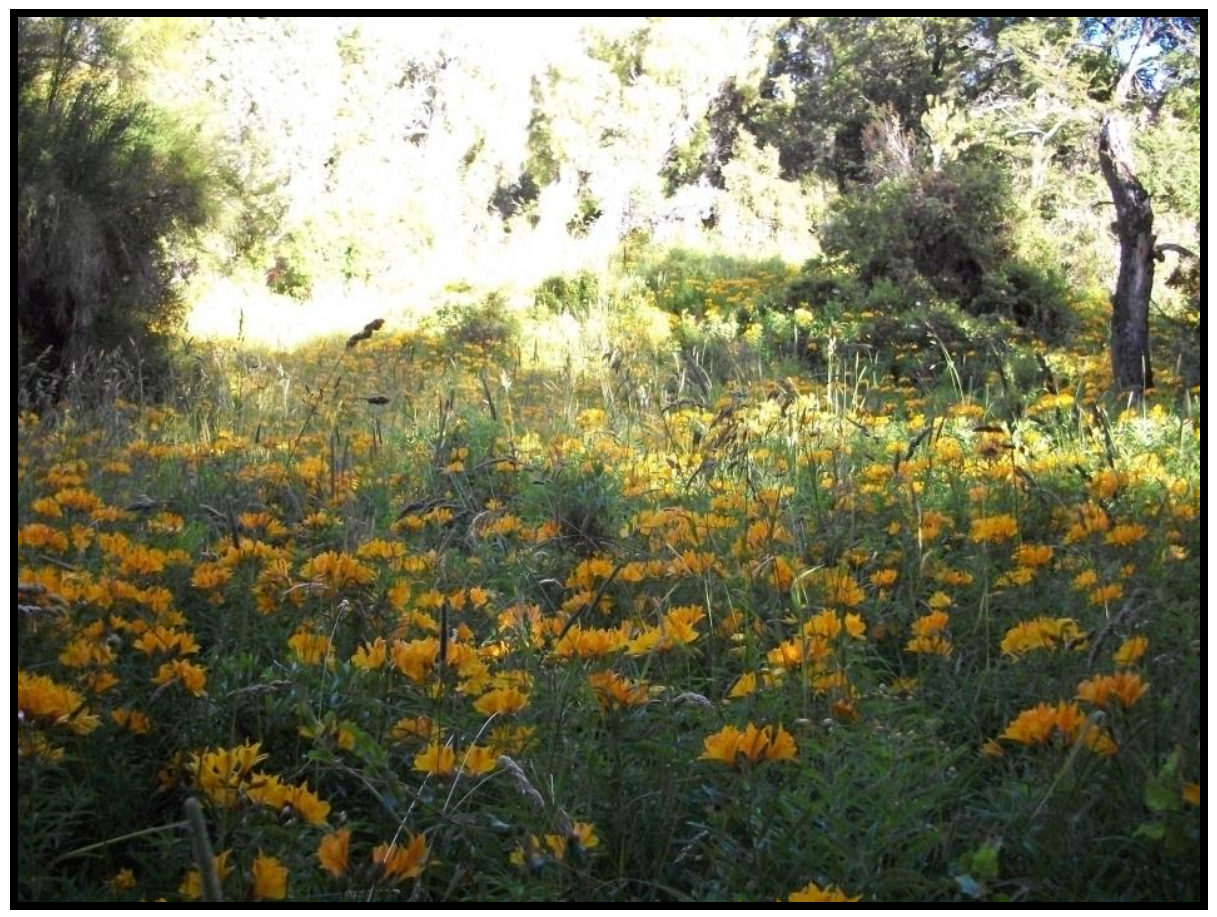

Foto 2.3: Se observa el desarrollo de una de las tipologías del estrato herbáceo.

c) Estrato Herbáceo: En este estrato se pueden encontrar especies como Holcus lanatus, Maytenus chubutensis, Poa pratensis, Elymus sp., Carex sp. y Trifolium repens, las que conforman una parte importante de la dieta de los herbívoros. Este uso forrajero es un parámetro de importancia en cuanto a la capacidad de uso de los ñirantales (Hansen 2003).

d) Fauna: Conformada principalmente por invertebrados, aves y mamíferos. Las bacterias y otros seres microscópicos realizan la descomposición de los residuos animales y vegetales. Por otro lado, los ñirantales poseen una amplia comunidad de invertebrados (arácnidos, insectos, nematodos entre otros) que permiten sostener niveles tróficos superiores conformados por macrofauna (especialmente aves insectívoras).

Es de destacar, que con frecuencia, los árboles presentan invertebrados barrenadores que producen galerías en la madera. 
e) Humanos: Elemento relevante de este sistema, ya que la actividad que allí desarrolla modifica a los otros componentes. De acuerdo a Hansen (2003) en esta región el hombre tradicionalmente ha utilizado los ñirantales para:

- Extracción de leña con la finalidad de calefaccionar viviendas

- Cría de ganado, la que convive con la actividad forestal, situación que contribuye a aumentar la complejidad del manejo de estos sistemas.

- Obtención de madera, actividad que actualmente ocurre raramente, fundamentalmente por la deficiente arquitectura de los ñires y su deficiente estado sanitario que hoy en día presentan los árboles pues suelen poseer pudriciones o galerías producidas por invertebrados barrenadores.

- Remoción de árboles para la elaboración de postes y varillas.

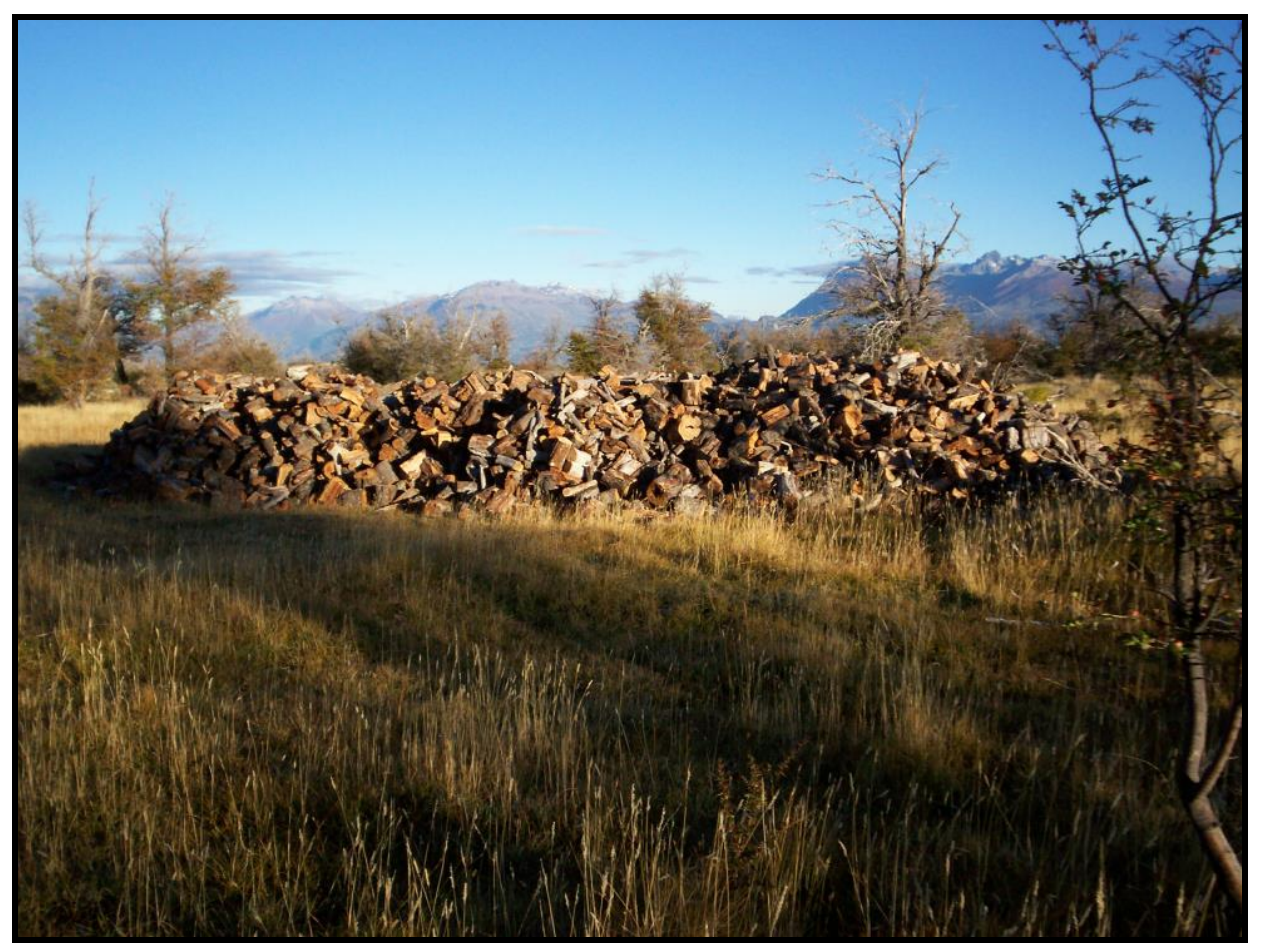

Foto 2.4: En la imagen se observa acopio de leña de Ñire para ser comercializado.

En base a lo dicho previemante, los ñirantales son la comunidad forestal del bosque andino patagónico con mayor intensidad de 
explotación (Montaña 1982, DGByP 2010) y según el Ordenamiento Territorial del Bosque Nativo de la zona Noroeste de la Provincia de Chubut (DGByP 2010) la superficie bajo estudio se encuentra en el Área de Transición (explotación intermedia a elevada) (Fig. 2.3).

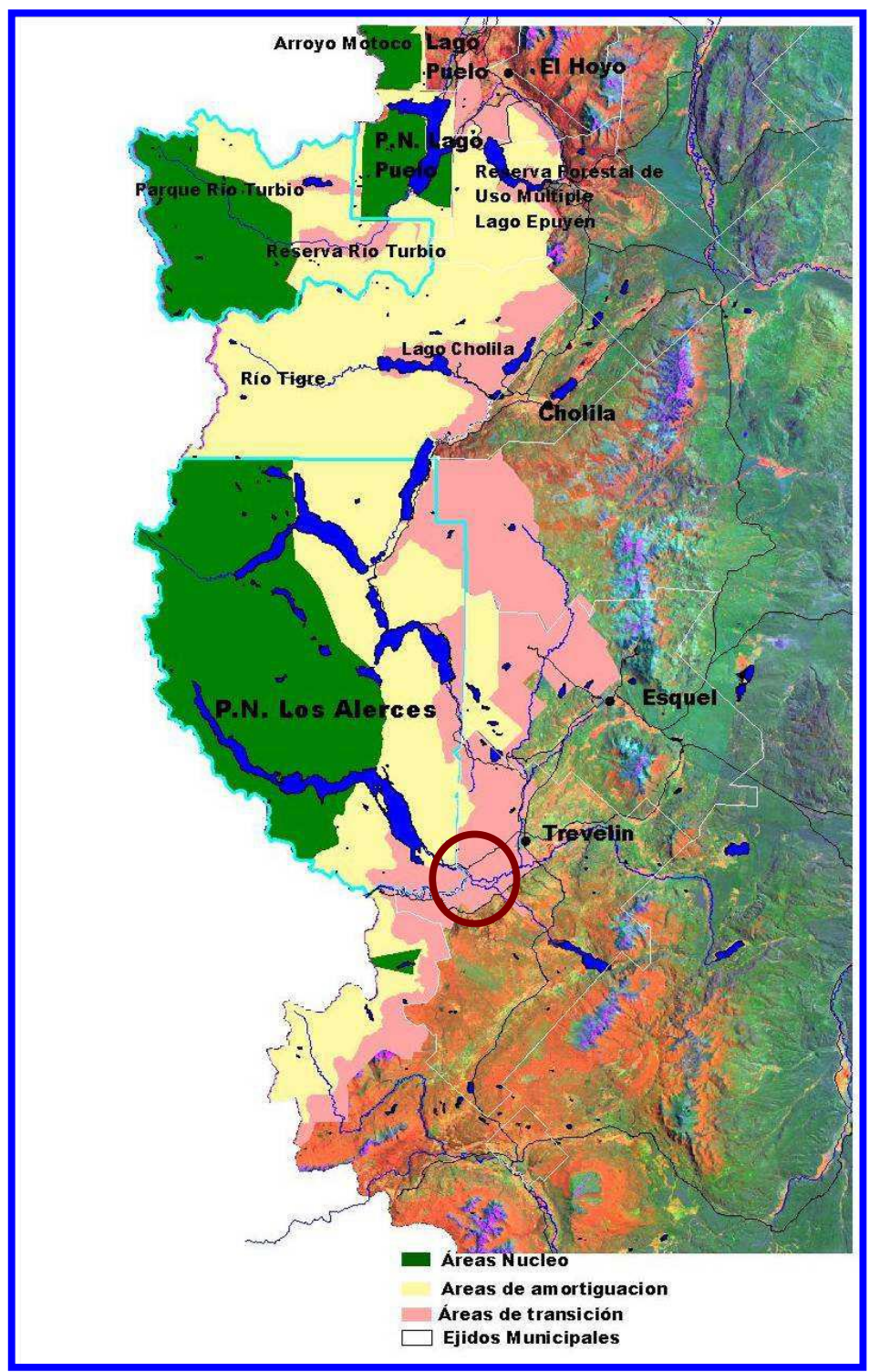

Fig. 2.3: Mapa del Ordenamiento Territorial del Bosque Nativo (Zona Noroeste) según Áreas de Uso. Fuente: Dirección General de Bosques y Parques (DGByP). 2010. Plan de Ordenamiento Territorial de Bosques Nativos de la Provincia del Chubut - Ley XVII. Honorable Legislatura del Chubut. Rawson - Chubut.

Dentro de las áreas de transición (DGByP 2010), los ñires cumplen distintas funciones ecosistémicas, siendo las más relevantes según Hansen et al. 2005: 
a) Proteger las cabeceras de las cuencas: Los ñirantales ubicados en las partes altas del relieve cumplen la doble función de protección del suelo y por lo tanto contribuyen a regular la cantidad y calidad hídrica en los sectores más bajos de la cuenca (Hansen et al. 2005), en especial cuando se desarrollan con un porte achaparrado, siempre dependiendo de factores del sitio tales como la pendiente, exposición a los vientos, entre otros (Donoso y Lara 1993). Es así que la función de protección de cuencas, cobra mayor relevancia si se piensa en regar cultivos o en la provisión de agua potable (Hansen et al. 2005).

b) Fijar carbono y generar oxígeno: son funciones de estos bosques fijar el carbono de la atmósfera (amortiguando el llamado "efecto invernadero") y generar oxígeno a través del proceso de fotosíntesis que realizan (Hansen et al. 2005).

c) Favorecer la diversidad biológica: es considerada una de las principales funciones pues esta estructura mantiene la diversidad de especies vegetales como así también de mamíferos, aves, invertebrados y biota en general, ya que los Ñirantalesactúan como hábitat de numerosas especies, manteniendo de este modo el equilibrio de todo el sistema boscoso (Hansen et al. 2005).

Es por ello que cualquier intervención debe realizarse con cuidado debido a la complejidad estructural y en función de que todo el sistema resulte sustentable a lo largo del tiempo (Hansen 2003).

\subsubsection{Impactos Antrópicos sobre los ñirantales}

Los bosques andinos patagónicos $y$, por ende los ñirantales, han estado sometidos desde comienzos del siglo XX a diferentes impactos ambientales tales como incendios, pastoreo, extracción de leña y 
madera, plantación de especies exóticas, entre otros (Donoso 1995, Lantschner 2005).

Es importante indicar que las actividades humanas son actualmente la principal fuente de impactos sobre la vegetación y la fauna de los bosques templados de la región andino-patagónica (FVSA 1994, Simonetti et al. 1995).

Los efectos ambientales derivados de las actividades humanas pueden tener consecuencias locales o regionales, dependiendo del tipo y la intensidad del impacto sobre los ecosistemas, de tal modo que la ganadería extensiva, la extracción de leña, la reforestación con especies forestales de crecimiento rápido, el desarrollo urbano, industrial y carretero, el turismo, y los emprendimientos hidroeléctricos, son algunas de las actividades actuales más relevantes en el bosque andino-patagónico y que por ende generan los impactos mas significativos (FVSA 1994, Laclau 1997, Informe PIARFON 2005).

Estas actividades producen en mayor o menor medida una serie de cambios físicos en los ecosistemas que interrumpen el estado de sucesión, produciendo a su vez cambios en la estructura, composición y dinámica de los mismos, con consecuencias socio-económicas (negativas o positivas) adicionales a los proyectos que generaron tales cambios (Carpenter 1983, Informe PIARFON 2005).

A continuación se presenta una reseña de los principales usos y sus consecuentes impactos al que fueron sometidos los ñirantales:

\subsubsection{Nirantales Transformados en Pasturas}

Los sistemas de producción de cría bovina y ovina en ñirantales son de base extensiva, siendo el pastizal natural el componente mayoritario de la dieta (Fertig 2003).

Durante los últimos cien años, los bosques andino-patagónicos han sido intensamente utilizados como áreas de pastoreo, 
particularmente en las áreas de mejor acceso (Veblen et al. 2003), lo que resulta en la alteración de la composición florística y de la estructura de los rodales de los bosques (Veblen et al. 1992, Relva y Veblen y Lorenz 1988).

En varios sitios el ganado ha impedido la recuperación postfuego y, quizás, ha producido un impacto significativo sobre la calidad y la cantidad de los combustibles (Veblen et al. 2003).

Así, el manejo ganadero con cargas bajas o moderadas permite que el ganado bovino y ovino tenga mayor oferta de forraje por animal, y por lo tanto, selecciona libremente su alimento, eligiendo principalmente al componente graminoso (von Müller 2011).

Por el contrario, al aumentar la carga o disminuir la cantidad de forraje disponible por animal y por ser los vacunos herbívoros de hábito pastoreador, es posible observar un incremento en el daño de ramas laterales de los ñires generados por ramoneo (Hansen et al. 2008).

La dependencia casi exclusiva del pastizal natural como fuente de alimentación convierte al sistema en sumamente vulnerable a las variaciones climáticas y de manejo (Hansen et al. 2004). A esto se suman los problemas asociados con la degradación de los pastizales naturales, producto del mal manejo y además del mencionado ramoneo sobre los renovales de Nire (Premoli 1991, Hansen et al. 2004).

Por ello, la mejora en la producción bovina y ovina, tiene como base indispensable el mejoramiento forrajero, solo alcanzable mediante (Fertig 2003):

- Aumento de la superficie implantada con pasturas

- Aumento de las producciones ya instaladas

- Mejora en la productividad del pastizal natural

- Incorporación de normas de manejo del ñirantal 
Estos usos de la tierra determinaron rápidos cambios en el paisaje de la región (Informe PIARFON 2005, Miserendino et al. 2010).

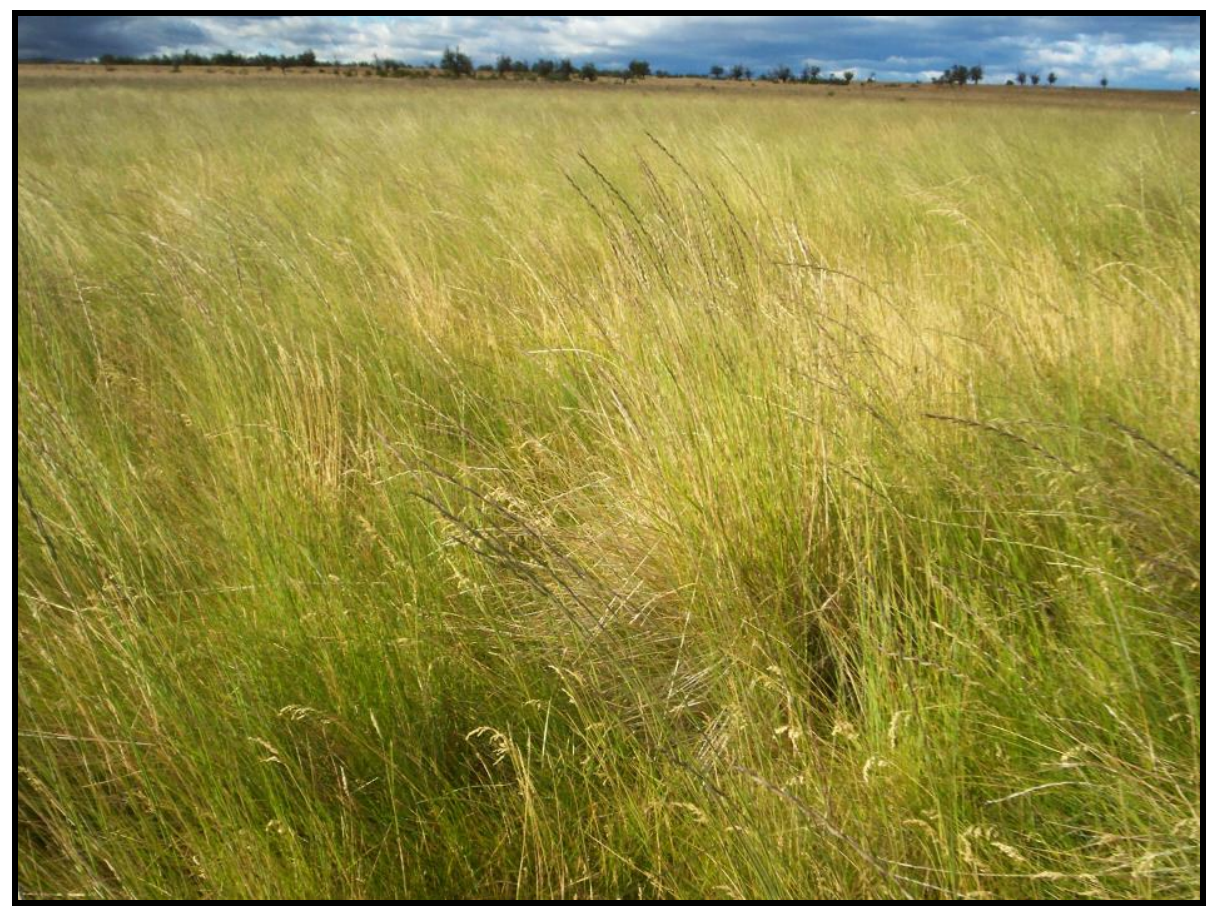

Foto 2.5: Vista de un área de pastizal rodeado de ñires.

El uso excesivo de los pastizales ha conducido a un proceso de deterioro de los ambientes con cambios en la abundancia de especies vegetales, modificación de la relación pastos/arbustos con pérdida de cobertura vegetal, todo lo cual acarrea disminución de la productividad de los pastizales (López et al. 2009).

Estos cambios en las prácticas agrícolas también tienen un amplio rango de efectos sobre la riqueza de las especies endémicas de aves terrestres y acuáticas (Duncan et al. 1999, Henderson et al. 2000, Christie et al. 2004). Por otro lado, pastizales altos o arbustales densos pueden interferir para que las aves encuentren alimentos entre las plantas bajas o entre las hojas, como así también determina que las mismas demoren en detectar o escapar de los predadores (Devereux et al. 2004 y 2005).

En torno al manejo adecuado del ganado (Hansen et al. 2008, von Müller 2011) ha generado una gran controversia acerca de si la ganadería debe ser excluida totalmente de los pastizales, ya que 
estas fueron habitadas por grandes herbívoros nativos, e.g. Ñandú (Pterocnemia pennata) y Guanaco (Lama guanicoe), los que actuaron en la modelación de la dinámica del ambiente, pero que actualmente están presentes en algunas áreas.

En los pastizales, la introducción de ganadería podría actuar como un reemplazante de los grandes herbívoros nativos (López de Casenave 2001) pues, se observó en esos sitios una comunidad de especies de aves propias de los pastizales nativos a diferencia de la comunidad de aves de los pastizales donde la ganadería había sido excluida (López de Casenave 2001).

A pesar de todo lo mencionado, se conoce poca información formal acerca de la oferta forrajera de los ñirantales y de su respuesta al manejo del ganado (Fertig 2003), lo cual hace necesario desarrollar investigaciones para recuperar la información no formal y a partir de ello elaborar estrategias de manejo silvopastoril que incrementen la productividad de los ñirantales (Fertig 2003).

\subsubsection{2 Ñirantales con Extracción de Leña por Manchones}

Los bosques de Ñire frecuentemente son excluidos de los planes de manejo forestal dado que esta especie es considerada "no maderable". Sin embargo debido a su importancia las prácticas de uso deben ser planificadas adecuadamente para favorecer las interacciones ecológicas beneficiosas de los ñires en el ecosistema y, de ese modo, que ello resulte en un incremento de la producción forrajera, en una mayor eficiencia en el uso de los recursos $y$, finalmente, en la sustentabilidad ambiental (Lencinas et al. 2008, Simanonok et al. 2011).

En el caso de los bosques de Nire, el aprovechamiento se ha concentrado en la corta selectiva de los individuos de mayor porte, individuos muertos y en ciertos casos mediante talas rasas (Reque et al. 2007). Según las estadísticas oficiales, las extracciones de Ñire 
han variado entre 15.000 y $50.000 \mathrm{~m}^{3}$ /año entre 1990 y 2015 (MdIPCh 2016).

La preponderancia de tortuosidades en los fustes y el mal estado sanitario de los individuos restringen el uso silvícola a la extracción de leña (Manacorda et al. 1995). Las cortas de intensidad elevada son cada vez menos comunes debido a la mayor producción forrajera y su consecuente uso para explotación ganadera (Peri et al. 2005) y a la vigencia de normas que prohíben el talado (DGByP 2004).

A modo de ejemplo, durante el año 2005 la extracción de leña de Ñire fue de $35.962 \mathrm{~m}^{3}$ (DGByP 2004), lo que representa una

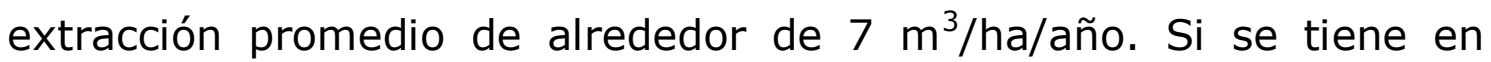
cuenta que en vivero se reportaron crecimientos equivalentes a 7,7 $\mathrm{m}^{3} / \mathrm{ha} /$ año y que en viveros la producción de Ñire es mucho mayor que en los ambientes naturales, se arriba a la conclusión de que es imposible mantener en forma sustentable los valores de explotación forestal actuales (Rusch et al. 2004).

Otro factor de relevancia de los ñirantales por su contribución al ecosistema es la vegetación de los estratos inferiores del bosque denominado sotobosque, el cual constituye (Ellum 2009):

- La base de las redes alimentarias

- El refugio de gran parte de la micro y mesofauna

- La protección del suelo contra la erosión 


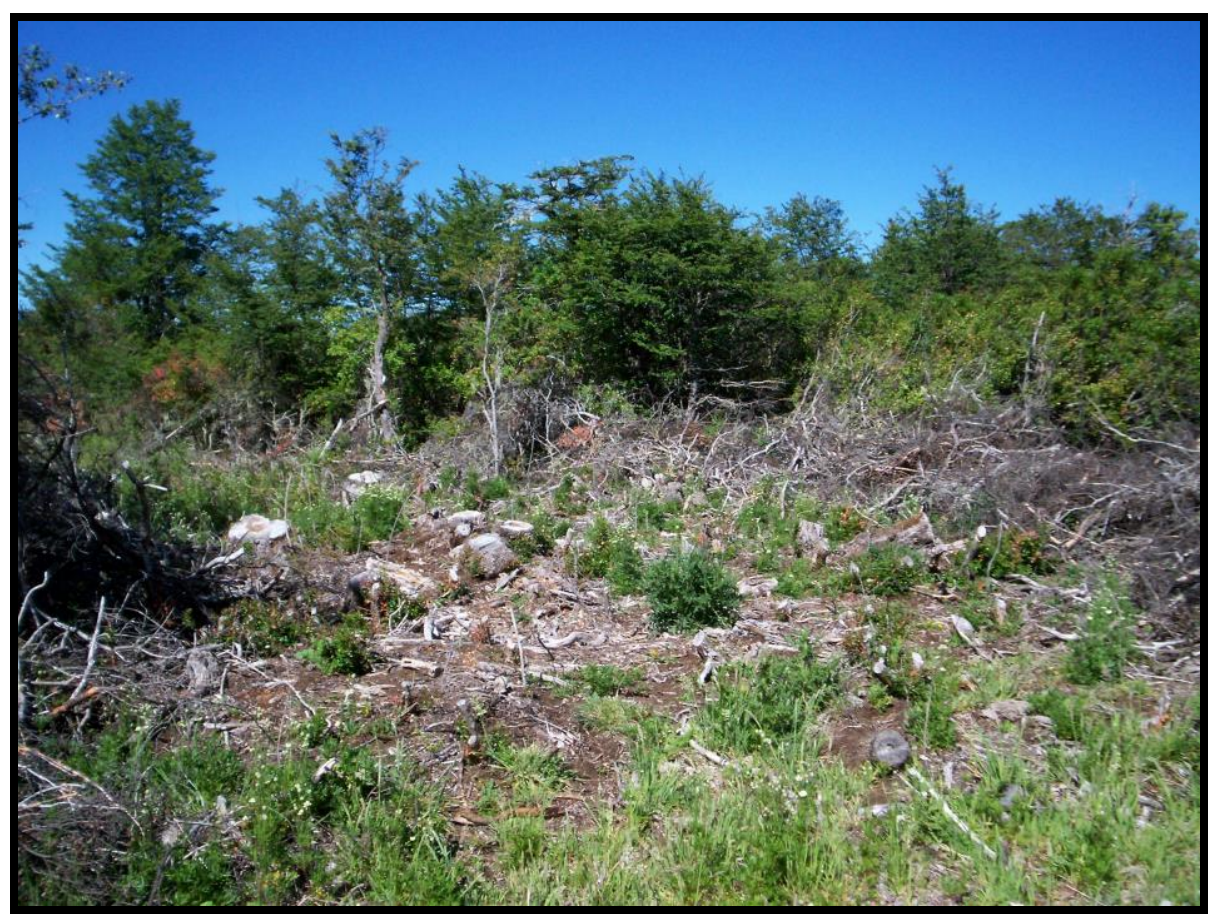

Foto 2.6: Sector del bosque de Ñire donde se visualiza la tala de individuos por manchones.

Las prácticas silviculturales que generan apertura del dosel modifican estos procesos, influyendo sobre la cobertura y la estructura del sotobosque (Klinka et al. 1996, Thomas et al. 1999).

\subsubsection{Nirantales Quemados hace 15 y 25 años}

Los incendios de bosques nativos en Patagonia, era una práctica habitual de los pueblos originarios, continuada a partir la década de 1850, por los inmigrantes europeos que ocuparon el territorio. Entre 1890 y 1930, los colonos europeos quemaron extensas áreas de los bosques andino-patagónicos para ganar campos de pasturas (MdIPCH 2016).

Se estima que en el último decenio los incendios forestales afectaron una superficie de 65.000 hectáreas. El área boscosa representa un $9,6 \%$ de los bosques de la Provincia de Chubut (MdIPCH 2016). 
La superficie media anual afectada entre los años 2002 y 2014 era de aproximadamente 3915 ha, con unos 167 focos promedio por temporada (MdIPCH 2016).

En cuanto al origen de los incendios, en el período 1993-2014 documentan el $40 \%$ de los focos se originó por negligencia como concecuencia de la quema de residuos, el $33 \%$ fueron intencionales, en tanto que solo el $1 \%$ de la superficie afectada se originaron por causas naturales, resultando ser prácticamente insignificantes (MdIPCH 2016).

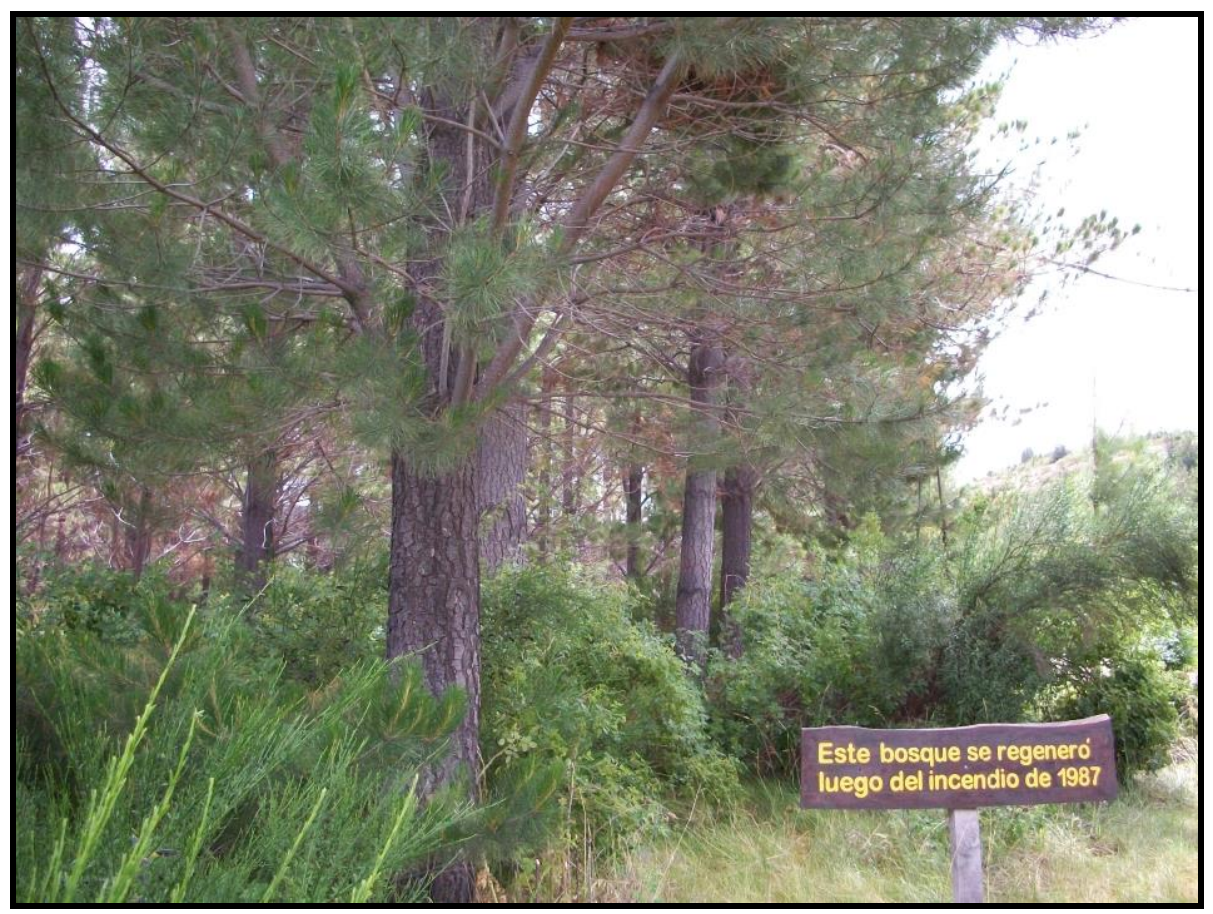

Foto 2.7: Sector que pertenecía a un Ñirantal pero que luego de un gran incendio acaecido en el año 1987 fue reemplazado por especímenes de coníferas de crecimiento rápido.

\subsubsection{4 $\underline{\text { Nirantales con Extracción de Leña por Parquizado }}$}

La actividad ganadera es la de mayor relevancia y dependencia de los recursos naturales de la zona cordillerana, siendo fundamental en la economía regional ya que está profundamente arraigada en la cultura productiva de la región (Fertig 2003, Hansen et al. 2008, MdIPCH 2016). 
El bosque cordillerano del noroeste de la Provincia de Chubut es la región desde mediados del siglo pasado, con mayor presencia de ganado bovino de la Patagonia (Guitart 2004a). Así por ejemplo, en la provincia de Chubut, el $72 \%$ de las existencias bovinas se concentran en el NO provincial donde el ñirantal constituye el área de cría (Guitart 2004b).

A su vez, de acuerdo al último Censo Nacional Agropecuario realizado en el año 2008, la región cordillerana del noroeste de la provincia de Chubut cuenta con 920 establecimientos ganaderos bovinos, de las cuales aproximadamente 100.000 cabezas de ganado se encuentran en 310.000 ha bosque nativo (MdlPCh 2016), lo que representa una densidad de ganado de 0,3 cab./ha.

Si bien esta zona es de relevancia económica pues, abastece de carne a gran parte de los mercados locales y regionales (Guitart 2004b), la herbivoría y el ramoneo del ganado pueden impedir la regeneración natural del bosque, comprometiendo el futuro del componente forestal del sistema (MdIPCh 2016).

Por ello, ningún modelo de gestión forestal sostenible es compatible con la presencia de ganadería extensiva si no se considera en alguna de sus etapas la implementación de eficaces medidas de control de las cargas animales tendientes a garantizar la regeneración natural (Guitart 2004b, Reque et al. 2007) puesto que las interacciones ecológicas en los sistemas silvopastoriles son numerosas, tanto positivas como negativas y el balance tendiente a la sustentabilidad depende especialmente de la intensidad del uso ganadero (MdIPCh 2016).

A través de la acción del ramoneo del ganado se afecta los rebrotes de Ñire y la regeneración por semillas dificultando o imposibilitando la renovación del bosque y alterando su dinámica natural (Berrios 2002, Martinez Pastur et al. 2002, Lencinas et al. 2008). Por lo tanto, las prácticas de manejo carentes de criterios de sustentabilidad y conservación han impactado desfavorablemente 
sobre estos ecosistemas donde se observan procesos avanzados de deterioro ambiental (Lencinas et al. 2008, Navarro Cerrillo et al. 2008), por ejemplo, debido a lo anterior, en el sotobosque de los ñirantales (Nothofagus antarctica) con dosel moderadamente abierto sometidos al impacto del ganado bovino y/o ovino además de la fauna silvestre se registraron elevadas coberturas de especies herbáceas nativas y exóticas, muchas de las cuales poseen alto valor forrajero (Manacorda et al. 1995, Hansen et al. 2004), contribuyendo al incremento de la riqueza específica del mencionado estrato (Bran et al. 1998, Gallo et al. 2004, Sarasola et al. 2008).

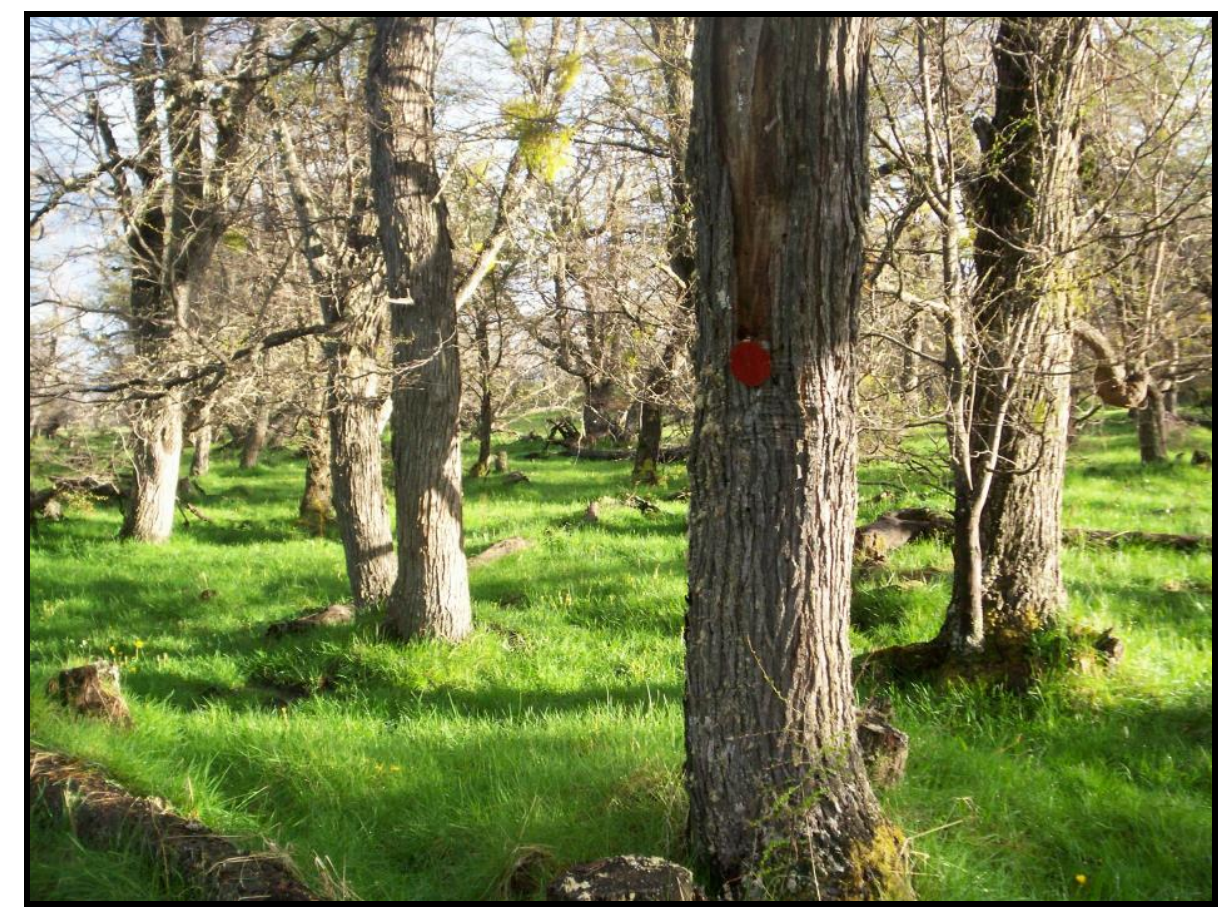

Foto 2.8: Vista de un ñirantal en parque. Obsérvese el desarrollo del estrato herbáceo.

Es importante aclarar que en los casos de estudios acerca del impacto que genera la exclusión del ganado los resultados arrojados son contrastantes entre diferentes continentes (Fuller y Gough 1999, Laiolo et al. 2004, Loe et al. 2007). 


\subsubsection{5 $\underline{\text { Nirantales Primarios }}$}

Los bosques primarios son aquellos que se han establecido sin la intervención del hombre $y$, al igual que el suelo y el agua, son sistemas vitales, con capacidad de autoconservación y autorregulación (Montenegro et al. 2003).

Estos bosques presentan una gran complejidad, involucrando beneficios tangibles e intangibles indispensables para la continuidad de la vida sobre el planeta tales como, microclimas, refugio de fauna y flora, protección de los suministros de agua y suelos, fuente de energía, oferta de vivienda y de otras necesidades que vienen con el hombre (Montenegro et al. 2003).

En este trabajo se analizaron esencialmente sitios de bosques de Ñire relativamente puros, aunque los rodales puros son la excepción en la naturaleza (Donoso 1995).

La estructura del Ñire del bosque primario en relación a la composición del sotobosque, es la resultante de procesos de facilitación y competencia. Bajo el canopeo, los árboles podrían influir en forma positiva sobre el desarrollo de la vegetación del sotobosque debido a interacciones de facilitación (Hansen 1999). Por ejemplo, en el sotobosque podría ocurrir una disminución del estrés hídrico por:

- Menores demandas por transpiración.

- Incremento del agua en el suelo (por disminución de la evaporación o por mayor capacidad de retención).

- Mayor estructura y estabilidad en el suelo.

- Incremento en la calidad del suelo por la hojarasca y/o mantillo especialmente en este caso tratándose de un bosque deciduo.

Los procesos de competencia se dan principalmente por la luz, el agua y los nutrientes y en relación a ello, los bosques primarios 
maduros se mantienen bajo una relación de equilibrio entre estos procesos (Donoso 1995).

La falta general de información limita la posibilidad de proponer pautas generales para el manejo de los bosques nativos en Patagonia y que podrían maximizar la producción del sistema y propender a su conservación (Peri et al. 2005). Debido a ello, en las últimas décadas se propusieron numerosos modelos para tratar de explicar la dinámica sucesional, uno de ellos el modelo de sucesión lineal ha sufrido numerosas críticas y, por ello, la visión de este tipo de procesos ha sido modificada.

Las diversas explicaciones de la dinámica ecosistémica han sido superados por enfoques mas integradores como lo és el Modelo de Estados y Transiciones (ME\&T) (Rusch et al. 2015).

Este modelo identifica diversos estados, los cuales se definen en base a caracteristicas de la vegetación y el suelo que se mantienen estables en el tiempo. Las primordiales premisas de este enfoque son las siguientes (López et al. 2009):

- Los cambios observables sobre la vegetación no siempre son lineales.

- El pasaje de un estado a otro no siempre es reversible.

- Puede haber más de un estado estable.

- Las transiciones negativas son más factibles que las positivas.

- El pastoreo o la carga animal no son los únicos factores que afectan la dinámica de la vegetación, sino que deben tenerse en cuenta otros factores tales como eventos climáticos inusuales (lluvias abundantes, sequías, etc.) u otros disturbios como el fuego, entre otros.

Debido a lo cual, se debería conocer en mayor profundidad la dinámica de éstos bosques para que sustentasen las propuestas de manejo (Hansen 1999, Fertig 2004, Gallo et al. 2004, Rusch et al. 2004). 
Por todo lo antedicho, el presente trabajo propone el estudio de los bosques de Ñire de la principal cuenca forestal de la provincia del Chubut con la finalidad de elaborar pautas básicas para el manejo forestal con el objetivo de analizar esencialmente los sitios de bosques de ñires puros.

\section{2 - Caracterización de la Fauna}

\subsubsection{Fauna en general}

La región del Bosque andino-patagónico se destaca por la gran variedad y riqueza de su fauna autóctona (FVSA 1994, Di Giacomo et al. 2007). Entre los mamíferos terrestres autóctonos se encuentran el Coipo (Myocastor coipus), Chinchillón Común (Lagidium viscacia), Gato Montés (Felis geoffroyi), Huemul (Hippocamelus bisulcus), Murciélago Cola de Ratón (Taradira brasiliensis), Pudú (Pudu pudu), Puma (Felis concolor), Zorro Colorado (Pseudalopex culpaeus), Zorrino (Conepatus humboldtii), Mara (Dolichotis patagonum), Guanaco (Lama guanicoe) y una amplia variedad de roedores tales como Tuco-Tuco (Ctenomys sp.), Colilargo Fueguino (Oligorizomys magellanicus), Ratón Topo Pardo (Geaxus valdivanus), entre otros y entre los anfibios y reptiles se encuentran Sapo del Bosque (Bufo spinolosus), Ranas de Cuatro Ojos (Pleuroderma bufonina $y$ Pleuroderma bibroni), Rana Marsupial (Rhinoderma darwinii), lagartijas del género Liolaemus sp. y la culebra (Tachymenis peruviana).

\subsubsection{Artrópodos}

Las prácticas de manejo del bosque, tales como poda, raleo, cosecha, extracción de leña, etc., modifican la composición y dinámica natural del bosque (Michaels y Maquillan 1995, Wigley y Roberts 1997) y pueden afectar su biodiversidad (Elliot y Swank 1994, Donoso 1995). 
Los artrópodos son el grupo más abundante de herbívoros y detritívoros en la mayoría de los ecosistemas terrestres (Seastedt y Crossley 1983), constituyendo el $85 \%$ del total de la fauna global (Kim 1993). Estos organismos intervienen en numerosos procesos biológicos (reciclado de nutrientes, dispersión de semillas, polinización, entre otros), los cuales contribuyen en gran medida al mantenimiento de la diversidad y funcionamiento de la mayoría de los ecosistemas terrestres (Didham et al. 1996, Allison et al. 1997, Schowalter y Zhang 2005, Lavelle et al. 2006). Los artrópodos ocupan nichos diversos, se distribuyen en la mayoría de los ambientes conocidos, y desarrollan roles importantes para el mantenimiento de las dinámicas de los procesos ecológicos (Hawkins y MacMahon 1989, Walker 1992).

Numerosos estudios evidencian la fuerte influencia de los artrópodos en la productividad primaria de bosques y praderas, en el mantenimiento de la estructura del suelo y en el proceso de reciclado de nutrientes, lo que involucra la interacción de una vasta diversidad de bacterias, hongos, protozoos e invertebrados (Moldenke et al. 2000, Warren y Zou 2002). Los artrópodos son los encargados de la transformación inicial del mantillo o broza que llega al suelo desde las plantas, exponiendo los nutrientes para la degradación microbiana (Berg y Laskowski 2006). La descomposición activa de la materia orgánica proveniente de plantas y animales realizada por larvas de moscas pertenecientes a las familias Calliphoridae (califóridos) y Muscidae (moscas), y de escarabajos de las familias Scarabaeidae (escarabeidos), Dermestidae (derméstidos) y Silphidae (silfidos), es esencial para el reciclado del material en el ecosistema (Kim 1993). Además de intervenir en el reciclado de nutrientes, los artrópodos presentes en el canopeo de las plantas ejercen un efecto directo e indirecto en el crecimiento de las mismas (Morrow y La Marche 1978, Nilsson 1978, Seastedt y Crossley 1983). 
Teniendo en cuenta el rol fundamental de los artrópodos en los procesos ecosistémicos, cualquier cambio en la estructura de sus comunidades puede afectar el funcionamiento del ecosistema en su conjunto (Didham et al. 1996, Ewers y Didham 2008, Vazquez et al. 2008).

Por ello, en los últimos años, los artrópodos han ganado mayor atención en prácticas y políticas de conservación (Kim 1993). Asimismo, dado que la abundancia, riqueza específica, ubicuidad y ocurrencia reflejan cambios en el paisaje, los insectos y arácnidos proveen medios factibles, sensibles y de bajo costo para medir los efectos del estrés antropogénico sobre la biodiversidad (Kim 1993, Lewis y Whitfield 1999, Danks 2001, Niemela et al. 2001, Andersen et al. 2002).

En función de ello el conocimiento de la abundancia y biodiversidad de las comunidades de artrópodos y de sus patrones espacio-temporales de uso del hábitat, puede ofrecer información importante para la generación de estrategias de conservación y manejo (Tilman y Dowing 1994, Bangert et al. 2006, Lencinas et al. 2007, Noriega et al. 2007).

En Argentina la fauna de artrópodos es una de las más afectadas por el manejo forestal y otras prácticas desarrolladas en el bosque, perdiéndose en promedio una especie cada 11 años (Spagarino et al. 2001).

A pesar de todo lo anterior, son escasos los trabajos que han intentado estudiar las variaciones espacio-temporales de las comunidades de artrópodos de Patagonia (Oliva 1994, Debandi 1999, Flores et al. 2004, Souza 2004, Sackmann et al. 2006, Ruggiero et al. 2009), y en particular de las asociadas a bosques de Nothofagus (Lanfranco 1991, Spagarino et al. 2001, Lencinas et al. 2002, 2003, 2005 y 2008, Vergara y Jerez 2010, Simanonok et al. 2011). 


\subsubsection{Avifauna}

La avifauna se encuentra distribuida la Patagonia en seis ecorregiones biogeográficas denominadas Altos Andes, Bosque Araucano, Estepa Patagónica, Monte patagónico, Espinal patagónico y Costas Patagónicas. El área estudiada se halla en el Bosque Araucano y cubre una franja desde casi el norte de la provincia del Neuquén hasta el sur de Santa Cruz (Di Giacomo et al. 2007).

Debido a su aislamiento y características particulares los bosques patagónicos presentan un elenco propio de aves, la mayoría de las cuales son exclusivas de Argentina y Chile.

En estos bosques se encuentran tres especies de la familia Rhinocryptidae, Huet-Huet (Pteroptochos tarnii), Chucao (Scelorchilus rubecula) y Churrín Andino (Scytalopus magellanicus), cada uno con preferencias de hábitat particulares. Dentro del estrato arbustivo o en sus inmediaciones se observa el Caburé Grande (Glaucidium nanum), Fío Fío Silbón (Elaenia albiceps), Golondrina Patagónica (Tachycineta leucopyga), Zorzal Patagónico (Turdus falklandii), Comesebo Patagónico (Phrygilus patagonicus), Cabecita Negra Austral (Carduelis barbata) y Tordo Patagónico (Curaeus curaeus).

Otras especies de gran relevancia en la dinámica del bosque andino-patagónico son los pájaros carpinteros siendo éstos Carpintero Gigante Patagónico (Campephilus magellanicus), Carpintero Pitío (Colaptes pitius) y Carpintero Bataráz Grande (Picoides lignarius), también se hallan aves rapaces como Aguilucho Cola Rojiza (Buteo ventralis) y Matamico Blanco (Polyborus albogularis) entre otras numerosas especies (Fotos $2.9 ; 2.10 ; 2.11 ; 2.12 ; 2.13 \mathrm{y}$ 2.14). 


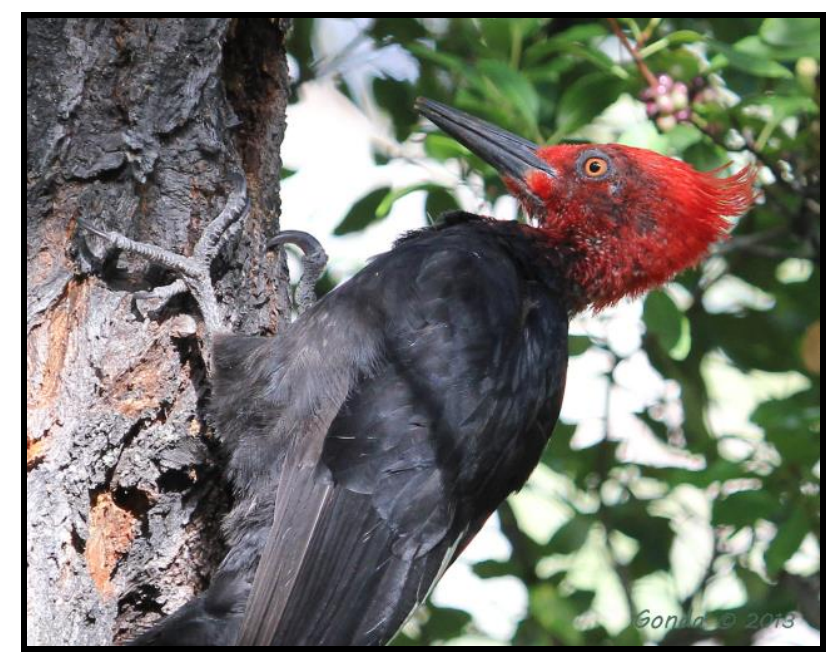

Foto 2.9

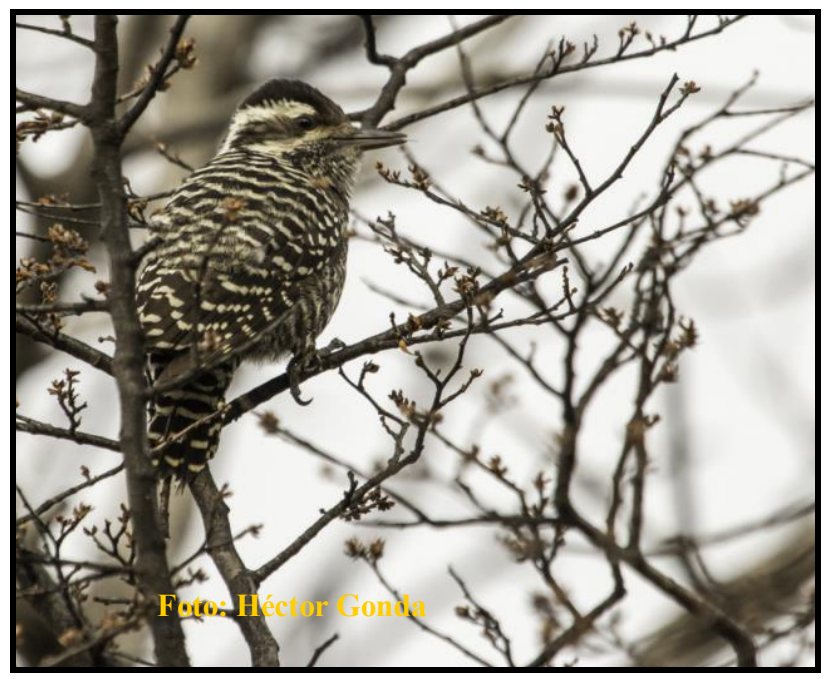

Foto 2.10

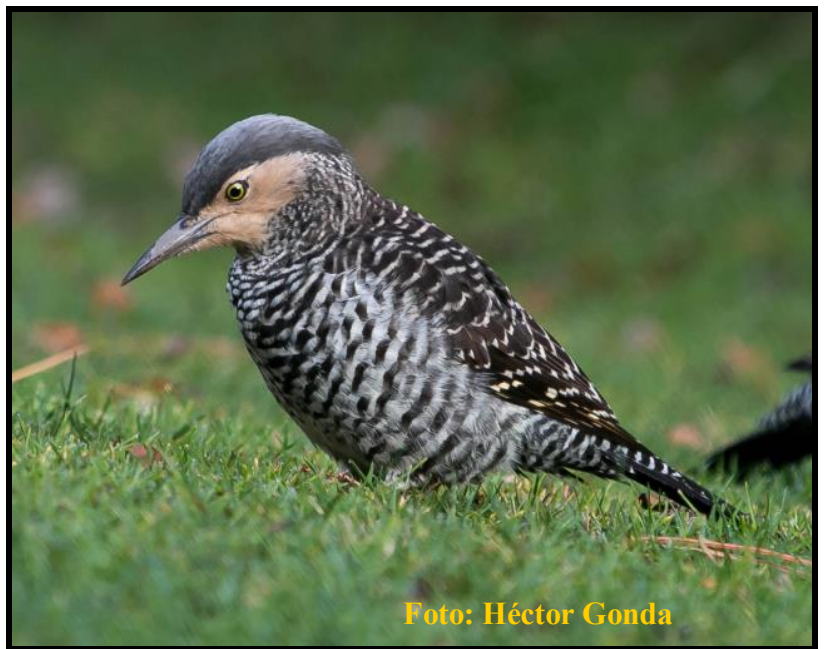

Foto 2.11

Se observan las imágenes de las tres especies de pájaros carpinteros registradas, Foto 2.9: Campephilus magellanicus, Foto 2.10: Picoides lignarius, Foto 2.11: Colaptes pitius, la totalidad de las especies pertenecen a la familia Picidae. Fotos gentileza: Héctor Gonda (Club Observadores de Aves de Esquel Comarca Los Alerces). 

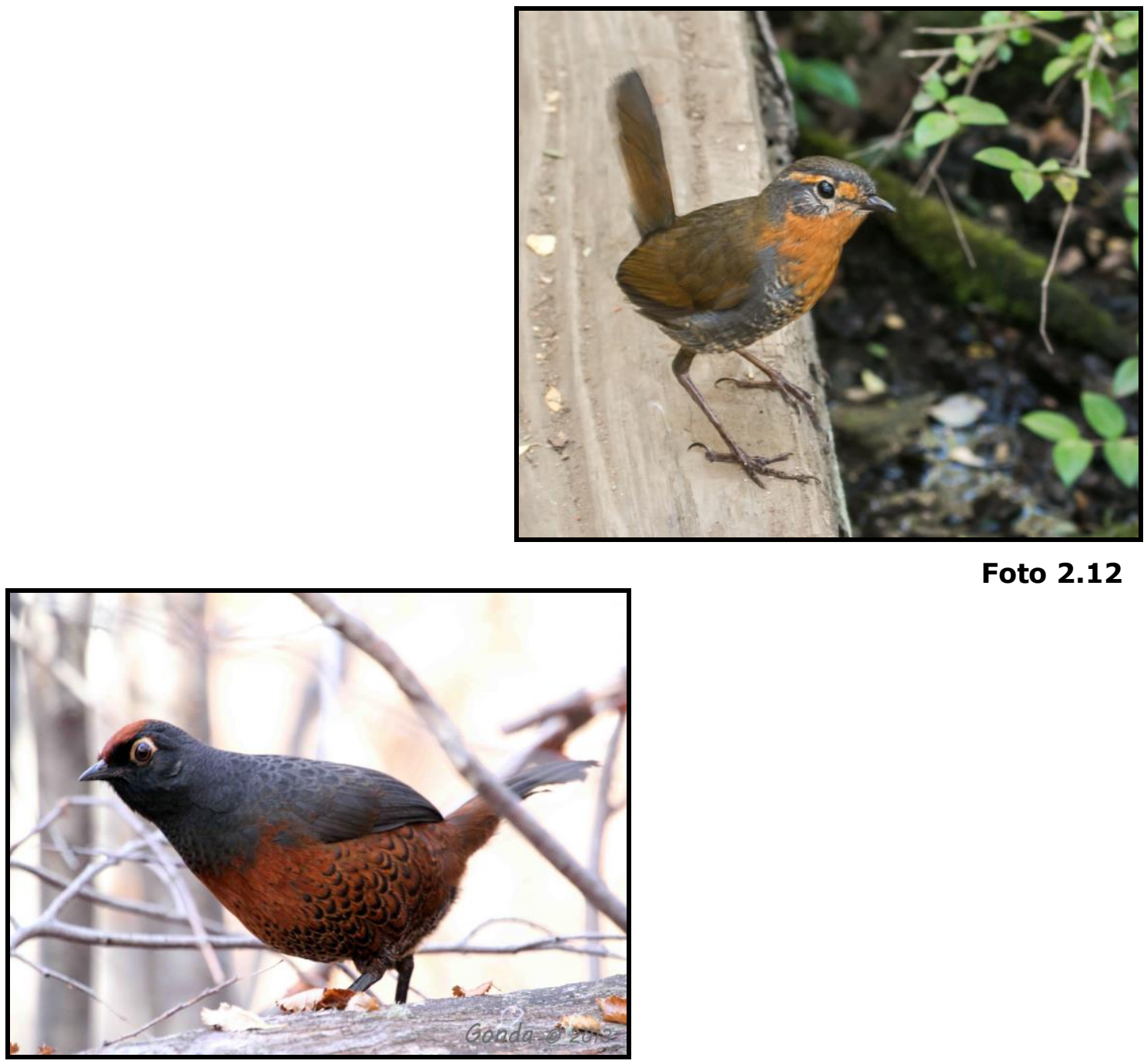

Foto 2.12

Foto 2.13

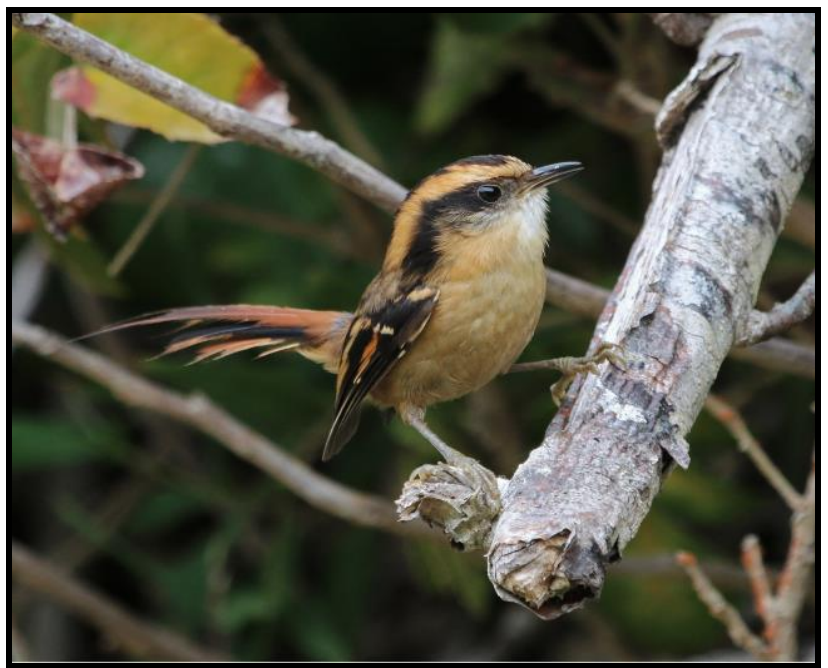

Foto 2.14

Se observan imágenes de tres aves de relevancia en cuanto a su estado de conservación, Foto 2.12: Scelorchilus rubecula, Foto 2.13: Pteroptochos tarnii, ambas pertenecientes a la familia Rhinocryptidae y Foto 2.14: Aphrastura spinicauda pertenecientes a la familia Furnaridae. Foto Gentileza: Héctor Gonda (Club Observadores de Aves de Esquel Comarca Los Alerces). 
Existen agrupamientos supra-específicos (ej. gremios, grupos funcionales), los que son usados como herramientas de manejo para obtener indicadores simples o económicos del estado de los recursos o "salud" de las comunidades en estudio (Milesi et al. 2002). Debido a ello, una de las posibilidades es utilizar gremios de manejo, que agrupan a las especies que tienen la misma respuesta a las perturbaciones de su ambiente (Milesi et al. 2002), ya que son buenos indicadores de la "calidad del hábitat" para los organismos considerados o del estado de sus recursos (Verner 1984, Easton y Martin 1984), conceptos que se fundamentan en la estrecha relación existente entre las aves, la estructura de la vegetación y los recursos asociados (Bock y Webb 1984, Bock y Bock 1999, Canterbury et al. 2000). Así, se ha llegado a la conclusión de que la diversidad específica en zonas templadas está determinada parcialmente por la distribución vertical de la vegetación y la heterogeneidad del perfil del follaje (Recher 1969), por ejemplo, la diversidad de especies en las montañas es especialmente importante debido al pronunciado endemismo, heterogeneidad de hábitats y localización biogeográfica (Paruelo et al. 1998, Morrone 2006).

Los cambios en el uso de los recursos del bosque generan cambios que producen importantes modificaciones en el ambiente, tratándose en muchos casos de cambios rápidos (Miserendino et al. 2010).

Es por ello, que el uso de los gremios como instrumento de predicción, evaluación o como medidas subrogadas del estado de los recursos (por ejemplo, como indicadores) ha sido propuesto para el estudio de ambientes sujetos a perturbaciones humanas, para el monitoreo de ambientes administrados y como sustento de decisiones de manejo y conservación (Johnson 1981, Verner 1984, Block et al. 1986, Roberts 1987), a pesar de ello, las técnicas usadas para formar los grupos no suelen involucrar estudios locales de impacto-respuesta o, análisis de mecanismos subyacente a las modificaciones 
producidas por las perturbaciones sino agremiaciones clásicas a priori (Wiens 1989a), basadas en el conocimiento del uso de los recursos o ciertas porciones del espacio por parte de los organismos (Milesi et al. 2002).

Así, la fragmentación de hábitats continuos (por ej. forestaciones nativas) resulta en pérdida de hábitats y aumento de insolación que podrían afectar a la avifauna por decrecimiento de colonización, incremento de la mortalidad y extinción, reducción de la biodiversidad entre otros potenciales efectos (Wilcox y Murphy 1985, Saunders et al. 1991).

Numerosas investigaciones han utilizado a la comunidad de aves como indicadores de los efectos de las actividades humanas sobre la biodiversidad (e.g., Padoa-Schioppa et al. 2006, Luther et al. 2008, Villegas y Garitano-Zavala 2008). En Europa, sus índices de tendencias poblacionales ya fueron adoptados como uno de los 15 indicadores de desarrollo sostenible del gobierno inglés (Gregory et al. 2005).

Por todo lo mencionado, en el presente estudio se ha abordado principalmente a la comunidad de aves como organismos bioindicadores del estado de conservación del ambiente, la misma supone varias ventajas como modelo de estudio por diversos motivos:

> Responden rápidamente a los cambios del hábitat y estructura paisajística, siendo buenos indicadores biológicos de los cambios ambientales (Furnes y Greenwood 1993).

$>$ Responden a cambios a escala del paisaje (gran escala) debido a la gran distancia de dispersión que pueden alcanzar (Guo et al. 1995).

> Son un grupo ampliamente estudiado, con una ecología bien definida 
> Se sitúan en la parte alta de la cadena trófica siendo especialmente sensibles a las alteraciones de los escalones inferiores

> Cada vez hay mayor disponibilidad de datos obtenidos a partir de sistemas de seguimiento a gran escala (Estrada et al. 2004)

Aunque debe tenerse en cuenta que:

> No todas las especies responden de la misma forma a la fragmentación o degradación del hábitat que utilizan y a la consecuente insularización del mismo.

> La fragmentación de un sitio, tiene relación estrecha con los requerimientos y la capacidad de desplazamiento de las especies involucradas.

> Las especies más abundantes de una comunidad dada tienen mayor probabilidad de ocupar los parches remanentes del bosque, tras la fragmentación, que las especies menos comunes o frecuentes $\mathrm{y}$, por lo tanto, tienden a mantenerse mejor en hábitats fragmentados (Santos y Tellería 1997).

> El tamaño de la isla y/o la cercanía de los parches a grandes bloques de bosque no fragmentados, tiene relación con la probabilidad de extinción y/o recolonización de las especies del área afectada.

Dentro de los indicadores de biodiversidad se ha considerado como sumamente relevante la necesidad de mantener las especies clave y las amenazadas dentro del bosque bajo manejo (Estado et al. 2004).

Por todo lo anterior es remarcable la importancia del presente estudio para generar conocimientos de relevancia para el manejo conservacionista de la avifauna del bosque andino-patagónico. 


\section{MATERIALES Y MÉTODOS}

\section{Área de Estudio}

\subsection{Ubicación}

El área de estudio se encuentra ubicada dentro del sector de bosque andino-patagónico de la provincia de Chubut (Fig. 3.1), la cual se extiende entre los meridianos $71^{\circ} 23^{\prime}$ y $71^{\circ} 36^{\prime}$ y los paralelos $43^{\circ}$ $05^{\prime}$ y $43^{\circ} 14^{\prime}$. El área en estudio está incluida dentro de la mayor cuenca de ñirantales del bosque andino-patagónico argentino denominada cuenca forestal Corcovado-Trevelin.

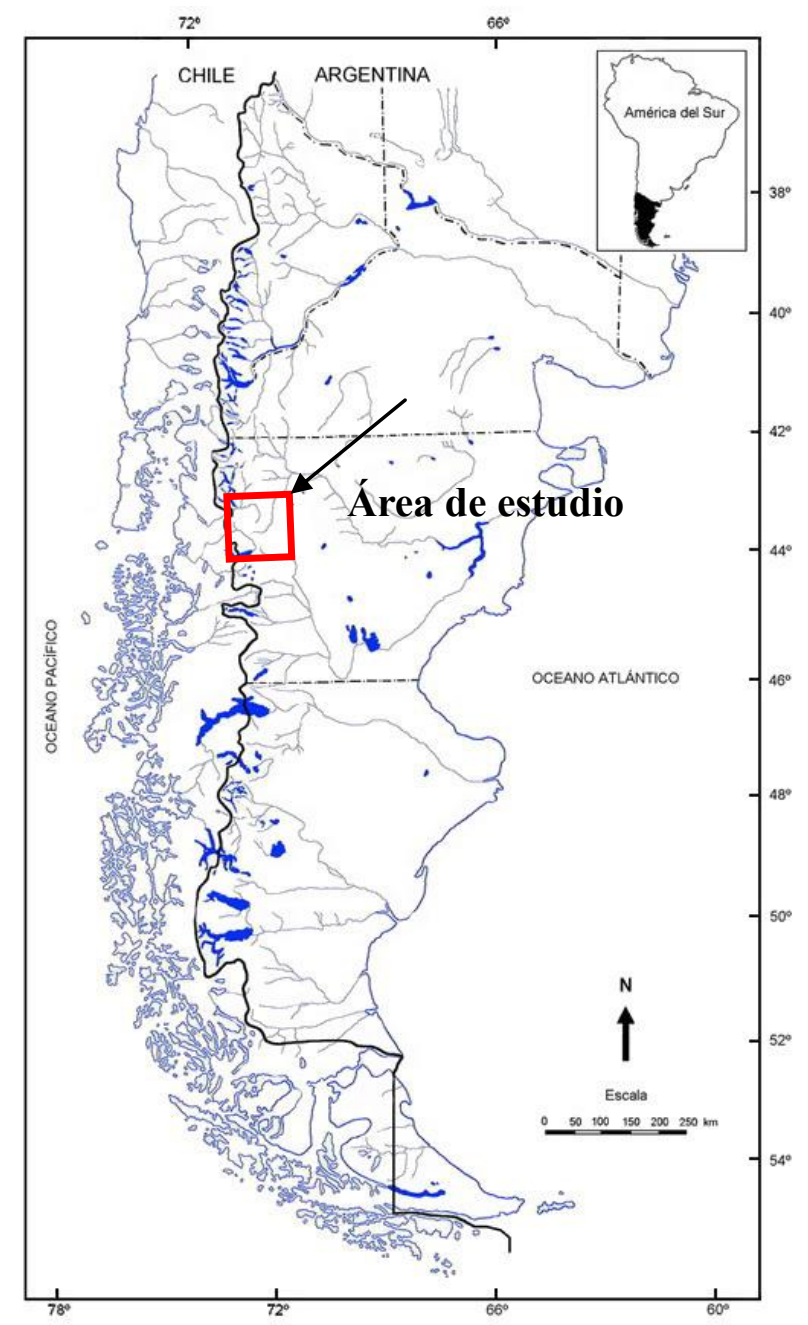

Fig. 3.1: Ubicación del área de estudio. 
El paisaje predominante es de montaña, alcanzando el área en estudio una altura máxima de 855 metros sobre el nivel del mar (m.s.n.m.) en tanto que el punto mínimo se encuentra a una altura mínima de 525 m.s.n.m.

\subsection{Caracterización y síntesis evolutiva del área}

La conformación geomorfológica del área estudiada, finalizó su modelado durante la etapa conocida como período Cuaternario (Era Cenozoica), el que comprendió el último millón y medio de años. Este período ha estado afectado por fenómenos de glaciación y desglaciación cíclica y luego del último gran avance de los glaciares ocurrido entre 15 y 20 mil años antes de la época actual (Bruggen 1948) gruesas capas de hielo cubrieron toda la Patagonia. La retirada final de la mencionada capa de hielo, conjuntamente con una sucesión de erupciones volcánicas, modeló geomorfológicamente la estructura orográfica generando la forma actual de la región andinopatagónica (Bruggen 1948, Auer 1960).

Todo lo mencionado conformó la provincia geológica denominada Cordillera Norpatagónica que se caracteriza por su relieve glaciario y montañas no muy altas, extendiéndose aproximadamente desde los $39^{\circ} 00^{\prime} \mathrm{S}$ hasta alrededor de los $43^{\circ}$ 00 ' S (González Bonorino 1978). Geológicamente está provincia está constituida por dos unidades principales:

a) un "Basamento" que comprende rocas metamórficas y un complejo magmático integrado por cuerpos de distintas edades.

b) una cubierta volcánica sedimentaria de edad entre Mesozoica-Terciaria.

Durante fines del Terciario y en el Cuaternario sobre las dos unidades se depositaron: vulcanitas, sedimentitas, sedimentos glaciogénicos y cenizas volcánicas (González Bonorino y González 
Bonorino 1974). En toda el área predominan los rasgos erosivos resultantes del englazamiento pleistocénico, tales como grandes cuencas lacustres, amplios valles con perfil transversal en " $U$ " y otras formas erosivas menores (Lantschner 2005).

En relación a la cuenca hidrográfica, el área se encuentra inmersa en la denominada Cuenca del Río Futaleufú, la cual posee una superficie de $7346 \mathrm{~km}^{2}$. Ésta cuenca es de vertiente exorreica debido a que vuelca todo su caudal hídrico en el Océano Pacífico (Coronato y del Valle 1988).

Todo lo mencionado determinó que el suelo se originara a partir de cenizas procedentes de erupciones volcánicas que conjuntamente con el aporte de materiales piroclásticos permitió una relativa homogeneidad con alto contenido de "alofanos" (arcillas derivadas de la meteorización del vidrio volcánico) confiriéndole al suelo, elevada capacidad de retención de agua (Rabassa et al. 1981).

En cuanto a la vegetación originaria ésta es poco conocida, aunque el análisis del polen demostró que en la zona donde hoy esta comprendida la estepa patagónica hace 25 millones de años (Terciario, Mioceno) ya existían especies del género Nothofagoxylon, antecesores del actual género Nothofagus (Ragonese 1977). Luego, hace alrededor de 9000 a 10500 años la retirada de los hielos permitió avanzar hacia el Este (entre los $41^{\circ}$ y los $55^{\circ}$ latitud sur) al Ñire y la Lenga (Markgraf 1987) y por ende al bosque andinopatagónico. Finalmente, desde hace 5000 a 6600 años antes del presente, el bosque andino-patagónico alcanzó su distribución actual, aunque varios autores (Auer 1960, Markgraf 1987) expresan que este se encuentra en un franco retroceso como consecuencia del cambio del clima planetario, de la tala del bosque y del sobrepastoreo (Donoso 1995).

Con respecto al origen de la avifauna de los bosques andinopatagónicos, esta provendría de tres posibles fuentes: 
$1^{\circ}$ ) En austro-Sudamérica a comienzos del Cenozoico, hace alrededor de 60 millones de años, se habrían originado los siguientes géneros: Enicognathus (Psittacidae); Aphrastura $y$ Pygarrhichas; Sylviorthorhynchus (Phytotomidae) y; Eugralla, Pteroptochos y Scelorchilus (Rhinocryptidae). Estos géneros habrían sido parte de la fauna andino-patagónica desde el Cenozoico temprano o medio (Araya y Millie 1986). Actualmente las familias Furnariidae y Rhinocryptidae se distribuyen hasta Centro América, en tanto que la familia Phytotomidae está restringida a Sudamérica (Van Tyne y Berger 1959).

$2^{\circ}$ ) Especies ancestrales se originaron de una inmigración sucedida en el Cenozoico tardío, desde otras regiones de Sudamérica a través del cordón andino. Entre los principales representantes de este grupo se encuentran el Carpintero pitio (Colaptes pitius), el Carpintero Gigante Patagónico (Campephilus magellanicus) y el Peutrén (Colorhamphus parvirostris) (Rozzi et al. 1996a).

$3^{\circ}$ ) Un tercer grupo de aves provenientes de otras regiones de Sudamérica, e incluso de Norteamérica, habrían invadido los bosques templados de Sudamérica durante el Pleistoceno el último millón de años. Los procesos de diferenciación genética de estas especies en Sudamérica habrían sido favorecidos por aislamientos poblacionales derivados de la fragmentación de los bosques sudamericanos durante los avances glaciales (Vuilleumier 1971). Dentro de estas especies se encuentran el Aguilucho Cola Rojiza (Buteo ventrales), el Carpintero Bataraz Grande (Picoides lignarius), el Golondrina Patagónica (Tachycineta leucopyga) y el Comesebo Patagónico (Phrygilus patagonicus) (Rozzi et al. 1996a).

Cabe destacar que el proceso de diferenciación genética en la región aún continúa. A modo de ejemplo se puede mencionar al Esparvero Variado (Accipiter bicolor) (Rozzi et al. 1996a). 
Finalmente, cabe mencionar que el alto endemismo de la avifauna de los bosques andino-patagónicos podría originarse de la insularidad que éstos bosques presentan con respecto al resto de los bosques sudamericanos (Vuilleumier 1985).

\subsection{Climatología}

El desarrollo del bosque andino patagónico se ve favorecido por los fuertes vientos húmedos del Pacífico (Jobbagy et al. 1995). Estas masas de aire provenientes del Océano Pacífico atraviesan la cordillera de los Andes e ingresan en las mesetas orientales descargando su humedad a lo largo del trayecto (Walter y Box 1983).

Este fenómeno determina un acentuado gradiente pluviométrico Oeste-Este en la franja oriental de la cordillera y en el sector occidental de las sierras y mesetas patagónicas con las que limita al este (Jobbagy et al. 1995). En la Cuenca Hidrográfica de Futaleufú las lluvias y/o nevadas varían aproximadamente entre 4000 mm y 1000 mm. de precipitación anual (Bertonatti y Corcuera 2000, Christie et al. 2004). La alta variación pluviométrica, sumada a las variaciones topográficas y edáficas determina distintos microclimas, los que explica la existencia de un ambiente boscoso altamente variado (Donoso y Cabello 1978). Las precipitaciones se producen preferentemente durante el invierno, observándose en esta estación valores cuatro veces superiores a los del verano. Claro ejemplo de este contraste estacional invierno-verano son los promedios respectivos de nubosidad $(63 \%$ y $53 \%$ de cobertura respectivamente), de días lluviosos (32\% y $11 \%$ respectivamente) y de días de cielo cubierto ( $38 \%$ y $24 \%$ respectivamente) (Coronato y del Valle 1988).

El gradiente pluviométrico se puede dividir en tres fajas meridianas a fin de lograr un mejor ajuste en el cálculo de los factores climáticos que inciden en el comportamiento de la Cuenca 
hidrográfica de Futaleufú. Estas fajas son: sector occidental húmedo con precipitaciones superiores a los $1500 \mathrm{~mm}$., un sector intermedio subhúmedo donde las precipitaciones anuales fluctúan entre 600 y $1500 \mathrm{~mm}$. de precipitación (donde están ubicados la totalidad de los sitios muestreados), y un sector oriental semiárido con menos de 600 $\mathrm{mm}$. de precipitación anual (Coronato y del Valle 1988). Con respecto a las temperaturas, también se observa una fuerte influencia del Océano Pacífico, siendo las marcas invernales y estivales más bajas en el sector cordillerano que en la estepa.

Debido a las características mencionadas, el clima es templado frío (Chiozza 1976), las lluvias y nevadas se producen fundamentalmente de mayo a agosto (Bustos y Rocchi 1993) y las heladas durante casi todo el año. Los vientos son intensos, originándose principalmente del cuadrante Oeste (Coronato y del Valle 1988).

En lo que respecta al área bajo estudio, la temperatura media anual para el período $1992-2012$ en el NO de Chubut fue de $8,5^{\circ} \mathrm{C}$, en tanto que las temperaturas máximas y mínimas promedio para el mismo período fueron de $14,5^{\circ} \mathrm{C}$ y $2,6^{\circ} \mathrm{C}$ respectivamente (datos obtenidos de www.tutiempo.net y del Sistema Meteorológico Nacional), siendo la precipitación anual promedio de 639,4 mm. (Fig.2.2). En relación al período de muestreo 2008/09 la temperatura media anual y la temperatura máxima y mínima medias fueron $9,0^{\circ} \mathrm{C}, 14,6^{\circ} \mathrm{C}$ y $3,5^{\circ} \mathrm{C}$ respectivamente (datos obtenidos de www.tutiempo.net y del Sistema Meteorológico Nacional; Fig.3.2).

La precipitación total acumulada para el mencionado periodo fue de 992,9 mm., valor considerado normal para el área estudiada, en función de los registros históricos. Con respecto a la temporada 2009/10 las temperaturas: media anual, máxima y mínima promedios fueron de $8,5^{\circ} \mathrm{C}, 14,0^{\circ} \mathrm{C}$ y $3,3^{\circ} \mathrm{C}$ respectivamente, siendo todos valores aproximados a los registrados históricamente. La precipitación anual durante este período fue de 576,8 mm., valor cercano a los 
mínimos de la media histórica, con lo cual presentó una situación diferente al del primer período de muestreo.

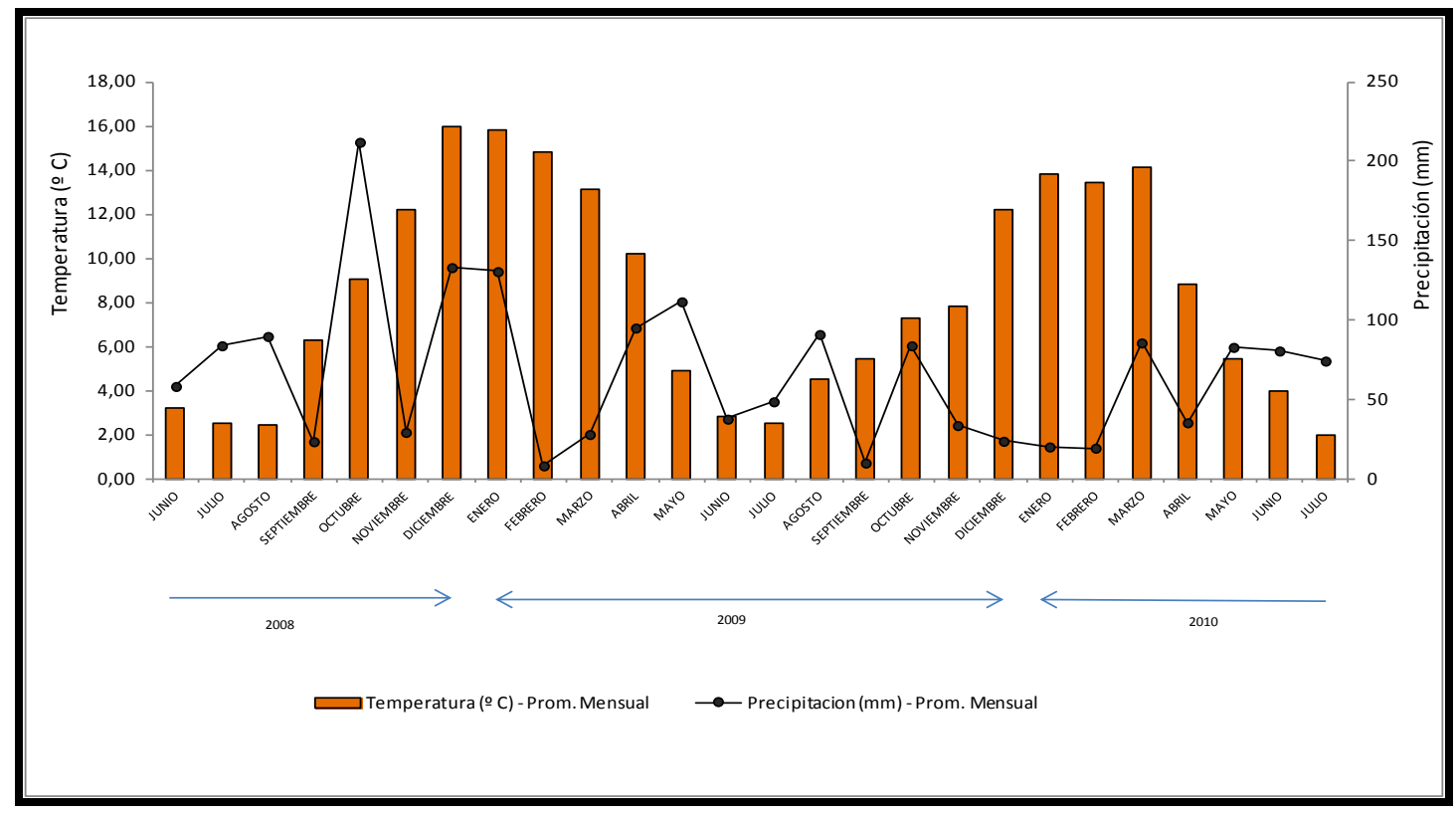

Fig. 3.2: Climatograma para el periodo de estudio (2008/09 y 2009/10)

\subsection{Biogeografía}

Los ñirantales distribuidos dentro del área de estudio presentan la estructura típica de un bosque templado húmedo, semi-deciduo (mezcla de especies deciduas y de follaje persistente). Dependiendo de factores climáticos, edáficos y geográficos, su altura puede alcanzar hasta los 16 metros. Estos ambientes cuentan además con una vegetación de estructura densa que alterna con arbustales y bosques bajos (Hansen et al. 2002).

El área estudiada se ubica geográficamente en la Provincia Altoandina de la Región Neotropical (Distrito Altoandino Austral) (Cabrera 1976), en tanto que a nivel Zoogeográfico se ubica dentro del Dominio Austral-Cordillerano (Ringuelet 1961), y en lo que respecta a la Ornitogeografía, se ubica en la Región Neotropical, Dominio Araucano, Provincia Araucana, Distrito Continental (Narosky y Babarskas 2000, Narosky e Yzurieta 2004) 
La región analizada conforma una isla biogeográfica que se desarrolló desde el período Terciario de modo aislado del resto de los ecosistemas boscosos de la región. El aislamiento conllevó a la generación de numerosos endemismos y de comunidades propias de plantas y animales (Tecklin et al. 2002).

\subsection{Consideraciones Generales}

Para la identificación, localización y tipificación de los sectores de bosque de Ñire afectados por diferentes usos, y por ende sometidos a variados niveles de impacto ambiental, se utilizó un mapeo existente realizado con imágenes satelitales, el cual fue complementado con muestreos a campo propios y de los equipos de trabajo del INTA de la Estación Experimental Agropecuaria (EEA) San Carlos de Bariloche, Río Negro, y EEA Esquel, Chubut (Bran 1991, Hansen et al. 2004).

A los efectos de minimizar el número de variables que pudieran operar sobre las estructuras de las comunidades vegetales, de artrópodos, de aves y, sobre la interrelación entre éstas, los sitios de muestreos seleccionados poseen similitud en las siguientes características fisiométricas:

a) Se ubican dentro de la misma cuenca hidrográfica denominada Cuenca de Futaleufú, sector intermedio, provincia de Chubut (Tabla 3.1).

b) Poseen alturas similares (el rango altimétrico, fluctúa entre 525 y 855 m.s.n.m.)(Tabla 3.1).

c) No poseen exposición al sol definida debido a que en ningún caso la pendiente del terreno supera los $5^{\circ}$ de inclinación (Tabla 3.1).

d) Se ubican en la misma cuenca forestal de ñirantales denominada Cuenca Forestal Corcovado-Trevelin, provincia de Chubut (Tabla 3.1). 
e) La distancia entre los sitios de muestreo no supera los 17 kilómetros de distancia, por lo que están afectados por las mismas condiciones climáticas (Tabla 3.1).

f) Los ñirantales muestreados entre los 4 y 8 metros de altura, correspondiendo todos ellos al estrato intermedio (Hansen 2003).

Para cada una de los seis tipos de usos de los ñirantales (tratamientos) se consideraron 2 réplicas, con lo cual se trabajó con un total de 12 sitios de muestreos. Las réplicas correspondientes a un mismo uso de los ñirantales se encuentran separadas por una distancia mínima de 1.500 metros según la metodología descripta en Ralph (1985) (Fig. 3.1).

En la tabla 3.1 se observa la ubicación geográfica y la altitud de los sitios de muestreos.

Tabla 3.1: Ubicación geográfica, superficie muestreada y altitud de los sitios de muestreo.

\begin{tabular}{|c|c|c|c|}
\hline $\begin{array}{l}\text { SITIOS DE } \\
\text { MUESTREO }\end{array}$ & $\begin{array}{l}\text { TIPO DE } \\
\text { IMPACTO }\end{array}$ & UBICACION & $\begin{array}{c}\text { SUPERFICIE } \\
\text { MUESTREADA }\end{array}$ \\
\hline QIUP & $\begin{array}{c}\text { Ñirantales } \\
\text { quemados hace } 25 \\
\text { años }\end{array}$ & $\begin{array}{c}\text { S } 43^{\circ} 05^{\prime} 24,7^{\prime \prime} \\
\text { O } 71^{\circ} 32^{\prime} 31,8^{\prime \prime} \\
561 \text { m.s.n.m. }\end{array}$ & 5,1 ha. \\
\hline QIDO & $\begin{array}{c}\text { Ñirantales } \\
\text { quemados hace } 25 \\
\text { años }\end{array}$ & $\begin{array}{l}\text { S } 43^{\circ} 06^{\prime}, 2,2^{\prime \prime} \\
\text { O } 71^{\circ} 33^{\prime} 5,7^{\prime \prime} \\
525 \text { m.s.n.m. }\end{array}$ & 9,9 ha. \\
\hline QGUP & $\begin{array}{c}\text { Ñirantales } \\
\text { quemados hace } 15 \\
\text { años }\end{array}$ & $\begin{array}{c}\text { S } 43^{\circ} 14^{\prime} 23,1^{\prime \prime} \\
\text { O } 71^{\circ} 36^{\prime} 22,4^{\prime \prime} \\
786 \text { m.s.n.m. }\end{array}$ & 6,9 ha. \\
\hline QGDO & $\begin{array}{c}\text { Ñirantales } \\
\text { quemados hace } 15 \\
\text { años }\end{array}$ & $\begin{array}{c}\text { S } 43^{\circ} 13^{\prime} 48,3^{\prime \prime} \\
\text { O } 71^{\circ} 36^{\prime} 20,7^{\prime \prime} \\
751 \text { m.s.n.m. }\end{array}$ & 3,2 ha. \\
\hline PAPI & $\begin{array}{l}\text { Ñirantales con } \\
\text { extracción de leña } \\
\text { por parquizado }\end{array}$ & $\begin{array}{l}\mathrm{S} 43^{\circ} 11^{\prime} 41,6^{\prime \prime} \\
\mathrm{O} 71^{\circ} 24^{\prime} 17,9^{\prime \prime} \\
723 \text { m.s.n.m. }\end{array}$ & 7,7 ha. \\
\hline
\end{tabular}




\begin{tabular}{|c|c|c|c|}
\hline PARO & $\begin{array}{l}\text { Ñirantales con } \\
\text { extracción de leña } \\
\text { por parquizado }\end{array}$ & $\begin{array}{c}\text { S } 43^{\circ} 10^{\prime} 44,7^{*} \\
\text { O } 71^{\circ} 24^{\prime} 19,2 \\
663 \text { m.s.n.m. }\end{array}$ & 12,2 ha. \\
\hline TUUP & $\begin{array}{l}\text { Ñirantales con } \\
\text { extracción de leña } \\
\text { por manchones }\end{array}$ & $\begin{array}{c}\mathrm{S} 43^{\circ} 11^{\prime} 51,3^{\prime \prime} \\
\mathrm{O} 71^{\circ} 24^{\prime} 25,4^{\prime \prime} \\
720 \text { m.s.n.m. }\end{array}$ & 9,8 ha. \\
\hline TUDO & $\begin{array}{l}\text { Ñirantales con } \\
\text { extracción de leña } \\
\text { por manchones }\end{array}$ & $\begin{array}{c}\text { S } 43^{\circ} 11^{\prime} 23,2{ }^{*} \\
\text { O } 71^{\circ} 25^{\prime} 2,2 \\
684 \text { m.s.n.m. }\end{array}$ & 7,7 ha. \\
\hline PRPI & $\begin{array}{l}\text { Ñirantales } \\
\text { primarios o } \\
\text { testigos }\end{array}$ & $\begin{array}{c}\text { S } 43^{\circ} 12^{\prime} 26,9^{\circ} \cdot \\
\text { O } 71^{\circ} 23^{\prime} 8,9 \\
855 \text { m.s.n.m. }\end{array}$ & 6,0 ha. \\
\hline PRJO & $\begin{array}{c}\text { Ñirantales } \\
\text { primarios o } \\
\text { testigos }\end{array}$ & $\begin{array}{l}\text { S } 43^{\circ} 12,477^{\prime} \\
\text { O } 71^{\circ} 24,387^{\prime} \\
730 \text { m.s.n.m. }\end{array}$ & 4,1 ha. \\
\hline PAGA & $\begin{array}{c}\text { Ñirantales } \\
\text { convertidos en } \\
\text { pasturas }\end{array}$ & $\begin{array}{c}\mathrm{S} 43^{\circ} 09^{\prime} 41^{\prime \cdot} \\
\mathrm{O} 71^{\circ} 24^{\prime} 8,6 \\
652 \text { m.s.n.m. }\end{array}$ & 4,9 ha. \\
\hline PAPE & $\begin{array}{c}\text { Ñirantales } \\
\text { convertidos en } \\
\text { pasturas }\end{array}$ & $\begin{array}{c}\text { S } 43^{\circ} 10^{\prime} 26,9 \cdot \\
\text { O } 71^{\circ} 25^{\prime} 23,9 \\
626 \text { m.s.n.m. }\end{array}$ & 5,5 ha. \\
\hline
\end{tabular}




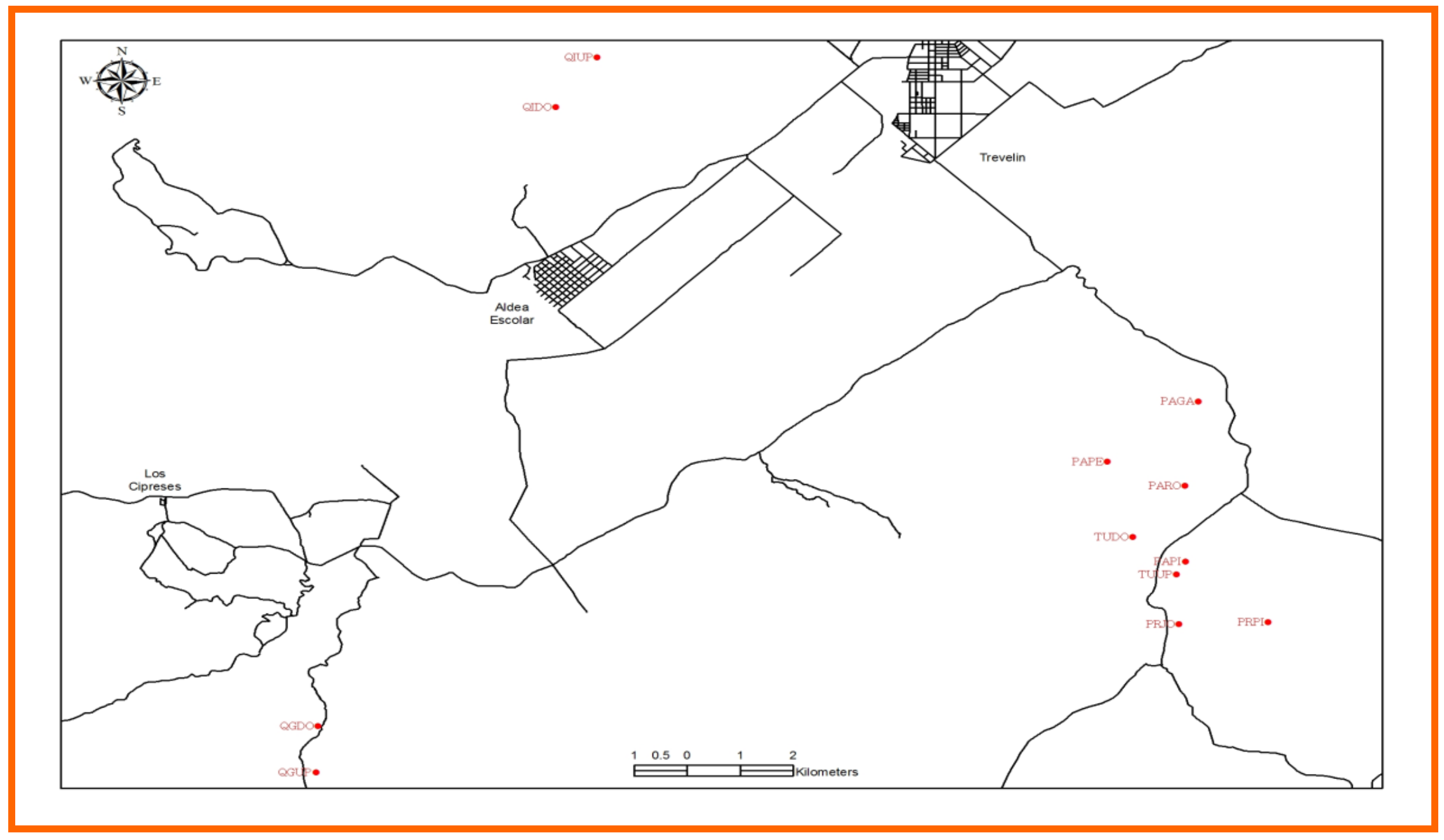

Fig. 3.3: Ubicación de los sitios de muestreo. 
En los doce sitios de muestreo se recolectó información durante cada una de las estaciones en la siguiente secuencia: otoño, invierno, primavera y verano, a lo largo de dos ciclos anuales, 2008/9 y 2009/2010 cada uno de los sitios de muestreos se obtuvo información general de variables climatológicas y sobre las comunidades vegetales, de artrópodos y de aves, los que a continuación se detallan:

\subsection{Datos de variables climáticas}

Conjuntamente con la fecha y hora del muestreo se relevaron las condiciones climáticas principales, siendo éstas las siguientes:

\subsubsection{Nubosidad}

Se realizó la medición en función de los octavos de cielo cubiertos por nubes.

\subsubsection{Intensidad del Viento}

La intensidad del viento se evaluó subjetivamente de acuerdo a la siguiente escala: sin viento, brisa leve, brisa o brisa moderada y viento de baja intensidad. Los niveles del viento mencionados fueron escalados por rangos de tal modo que esta variable era transformada en datos continuos (Tabla 3.2). En los casos donde el viento era superior a los mencionados niveles, la jornada fue considerada no apta para realizar muestreos.

Tabla 3.2: Se indica el valor escalar que corresponde a cada rango de viento

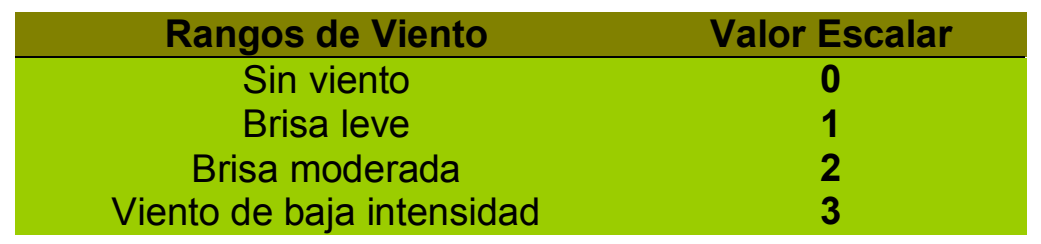




\subsubsection{Visibilidad}

Distancia máxima en que se podía realizar una observación. En los casos donde la visibilidad óptima era menor a los 100 metros de distancia la jornada fue considerada no apta para realizar muestreos.

\subsubsection{Temperatura}

En cada jornada de muestreo, la temperatura fue medida mediante un termómetro de mano marca SUNNTO, cuyo rango de medición fluctúa entre $-30^{\circ} \mathrm{C}$ y $50^{\circ} \mathrm{C}$. Los valores de temperatura obtenidos fueron escalados por rangos de tal modo que la variable temperatura era transformada en datos continuos (Tabla 3.3).

Tabla 3.3: Se indica el valor escalar que corresponde a cada rango de temperatura

\begin{tabular}{ccc} 
Rangos de Temperatura & Rango Cualitativo & Valor Escalar \\
\hline$-10{ }^{\circ} \mathrm{C} \mathrm{a}{ }^{\circ} \mathrm{C}$ & Muy frío & 1 \\
$0{ }^{\circ} \mathrm{C}$ a $10{ }^{\circ} \mathrm{C}$ & Frío & 2 \\
$10^{\circ} \mathrm{C}$ a $20{ }^{\circ} \mathrm{C}$ & Templado & 3 \\
$20^{\circ} \mathrm{C}$ a $30{ }^{\circ} \mathrm{C}$ & Cálido & 4
\end{tabular}

\subsubsection{Presión Atmosférica}

La presión atmosférica se midió en hectopascales mediante un barómetro incorporado a un reloj pulsera, marca Casio PRT - 20.

\subsubsection{Precipitación}

La precipitación se caracterizó como sin precipitación, llovizna o con nevisca leve, cuando los niveles fueron superiores, la jornada fue considerada no apta para realizar muestreos.

La toma de datos generales fue realizada al solo efecto de corroborar que las condiciones fueron las óptimas y/o relativamente estables como para realizar los muestreos. 


\section{7 - Muestreo de Vegetación}

Para el estudio de la vegetación se aplicó el muestreo denominado "estratificado azaroso" debido a que esta metodología es mas efectiva cuando el ambiente a muestrear es heterogéneo (Martella et al. 2012).

En todos los casos la estructura del ñirantal poseía una altura intermedia, la cual fluctúa entre 4 y 8 m. (Fertig 2003, Hansen et al. 2005).

En cada sitio y en cada temporada de muestreo se realizaron tres censos de vegetación de modo azaroso. Para ello, al azar se seleccionaron tres puntos de muestreo en los que se delimitó un área circular con un radio de 5,64 metros la cual abarcó una superficie de $100 \mathrm{~m}^{2}$ y donde se obtuvo información sobre:

\subsubsection{Clasificación Taxonómica de las Especies Vegetales}

Las especies vegetales se identificaron con la ayuda de catálogos o claves para plantas vasculares (Dimitri y Orfila 1985, Zuloaga et al. 2008). Debido a similitudes inter-específicas, para el análisis de los datos los pares de especies Poa ligularis y Poa pratensis, Senecio filaginoide y Senecio neaei, Bromus setifolius y Bromus stamineus, fueron agrupados por género. Las especies vegetales fueron además agrupadas según su origen, en nativas o exóticas.

\subsubsection{Cobertura Vegetal}

La cobertura es la variable mas utilizada para cuantificar la abundancia de especies vegetales (Martella et al. 2012). La cobertura es la proporción de la superficie muestreada recubierta por la proyección vertical de la vegetación (Martella et al. 2012). En base a dicha proyección vertical se contabilizaron las especies que se encontraban en los estratos, 
herbáceo (por debajo de 0,6 metros de altura), arbustivo (entre 0,6 y 4 metros de altura) y arbóreo (entre 4 y 8 metros de altura) con la escala establecida por Braun-Blanquet (1932) y Mueller-Dombois y Ellenberg (1974), estimándose los porcentajes de cobertura mediante la visualización directa acordada por dos observadores.

\subsubsection{Abundancia de Flores y Frutos}

Se muestrearon únicamente las principales especies productoras de flores y frutos:

- Maytenus (Maytenus chubutensis)

- Rosa mosqueta (Elanterea rosa)

- $\quad$ Pillo pillo (Ovidia andina)

- Calafate (Berberis buxifolia)

- Laura (Schinus patagonicus)

El muestreo de flores y frutos (modificado de Alcántara et al. 1997, Doll et al. 2005, Damascos y Llancaqueo 2008) se realizó tomando los tres ejemplares de las mencionadas especies que se encontraban más cercanos al punto central de cada una de las líneas transectas de muestreo de avifauna. Seguidamente, en cada uno de los ejemplares vegetales y a una altura aproximada de 1,5 metros se marcaron con una cinta plástica de color rojo las principales ramas del ejemplar en las que durante las estaciones de primavera y verano se estimó el número de flores y frutos.

\subsubsection{Diámetro a la Altura del Pecho (DAP)}

Se midió el DAP a los diez ñires más cercanos al centro de cada una de las líneas transectas de censado. Para ello, mediante una cinta métrica flexible se les midió el perímetro del tronco del árbol (en cm.) a la altura 
del pecho (Mostacedo y Fredercksen 2000). La medida obtenida fue dividida por 3,1416 obteniéndose de ese modo el DAP de cada uno de los ejemplares.

\subsubsection{Transitabilidad}

Tomándose como referencia el centro de cada una de las líneas transectas de censado de aves, se midió la distancia a los tres árboles más cercanos ubicados en dirección hacia cada uno de los puntos cardinales. De tal modo, que se realizó la medición de 12 ejemplares y así, el promedio de las distancias fue considerado como el área de bosque libre y por ende transitable para las aves (Lantschner 2005).

\subsubsection{Estado Sanitario}

Con el fin de evaluar el estado de los árboles se elaboró una escala de cinco categorías, las que se correspondieron con las siguientes características:

- Nivel 1 - árbol completamente sano

- Nivel 2 - árbol 25\% seco

- Nivel 3 - árbol 50\% seco

- Nivel 4 - árbol 75\% seco o en descomposición

- Nivel 5 - árbol muerto en pie

En base a los datos recolectados, se realizó un ANOVA (estadístico $\mathrm{F}, \mathrm{p}<0,01$ ) con una prueba a posteriori (Tukey, $\mathrm{p}<0,05$ ) para identificar las diferencias de cobertura relativa de especies vegetales según su estrato y origen, para sitios con el mismo tipo de uso y/o perturbación.

Del mismo modo, se realizó un ANOVA para determinar las diferencias entre el porcentaje de cobertura de las especies vegetales, 
entre sitios con diferentes usos, según su estrato, estado sanitario y DAP.

Finalmente, para cada sitio de muestreo se determinaron además, los índices de riqueza específica, Dominancia y diversidad de Simpson, los cuales fueron utilizados para realizar comparaciones entre sitios sometidos al mismo tipo de uso, mediante un ANOVA (estadístico F, $\mathrm{p}<0,01$ ) con prueba a posteriori (Tukey, $\mathrm{p}<0,05$ ).

\subsubsection{Análisis basado en el Modelo de Estados y Transiciones}

El Modelo de Estados y Transiciones es un marco conceptual que permite integrar conocimiento y análisis para el estudio y manejo de bosques productivos (Westoby et al. 1989, López et al. 2014). Este modelo busca conservar la integridad ecológica preservando la capacidad de responder y adaptarse a disturbios y/o cambios futuros con el fin de mantener la generación de bienes y servicios ambientales (López et al. 2014).

En este estudio se sistematizarán ordenadamente los cambios estructurales y funcionales entre un estado y otro con el fin de determinar los estadíos que comprenden cada uno de los diferentes usos a los que fueron sometidos los ñirantales.

\section{8 - Muestreo de Avifauna}

\subsubsection{Metodología de Muestreo}

El censado de la avifauna fue realizado por dos observadores que actuaban simultáneamente. Para la observación de las aves se utilizaron binoculares Bushnell con un aumento de 10 × 50 con ajuste de imagen mediante balancín para un rápido registro. La identificación taxonómica de los ejemplares observados fue realizada mediante la utilización de las 
guías de identificación de aves de De la Peña y Rumboll (1998), Narosky y Babarskas (2000) y, Narosky e Izurieta (2004). Con el objetivo de optimizar el período de observación y de estandarizar los censos, toda la información relacionada con los mismos (fecha, hora de inicio y finalización, condiciones climáticas, identificación del punto de conteo o línea transecta, ejemplares observados, etc.) se registró en una planilla elaborada a tal efecto (ver Anexo). Los censos se realizaron en uno de los momentos de mayor actividad de la avifauna, el que correspondió a las 3 primeras horas siguientes al amanecer (Ralph 1985). En cada censo se contaron e identificaron taxonómicamente los ejemplares registrados. Se estableció si los ejemplares fueron observados en la copa de un árbol o un arbusto, en un tronco, en el suelo o volando (Bibby et al. 1992, Wunderle 1994, Ralph et al. 1996). También se registraron las aves identificadas mediante vocalizaciones con el fin aumentar la eficiencia de los registros (Parker 1991, Angehr et al. 2002). Se respetó la metodología indicada por Wunderle (1994) y Ralph et al. (1996), donde en una sola jornada uno o dos observadores pueden hacer un muestreo de 10 a 30 hectáreas en áreas boscosas o de 50 a 100 hectáreas en áreas abiertas.

Para evitar el doble conteo de aves, los sitios de muestreos debían encontrarse razonablemente espaciados con el fin de que los muestreos sean independientes (Ralph et al. 1996) por ello, en el presente estudio, los mismos fueron ubicados a una distancia entre sí que fluctuó entre 150 y 300 metros. Esta distancia se basa en la metodología propuesta por Ralph et al. (1996) la cual estipula que una distancia adecuada entre sitios de conteo debería fluctuar entre 150-200 m en hábitats cerrados y entre 250-300 metros en hábitats abiertos.

En los hábitats muestreados, el radio estándar o ancho de banda utilizado fue de 25 a $30 \mathrm{~m}$. (Ralph et al. 1996). 
Cabe aclarar, según lo mencionado, que los recuentos de aves recolectados no pueden usarse para estimar densidad (MacGregor-Fors et al. 2010), aunque pueden ser utilizados para medir la riqueza de especies e índices de abundancias relativas (MacGregor-Fors et al. 2010).

Con el objeto de reducir el número de variables a considerar en el análisis de los datos, en cada sitio de muestreo se utilizaron los mismos puntos de muestreo durante todo el período de estudio.

El registro de las aves fue realizado bajo condiciones climáticas adecuadas, puesto que la actividad de las aves podría verse afectadas por las malas condiciones climáticas (Bibby et al. 1992, Wunderle 1994, Ralph et al. 1996).

\section{Técnicas de Muestreo de Avifauna}

Se aplicaron las técnicas mas utilizadas para muestreos de aves: a) líneas transectas y b) puntos de conteo (Blondel et al. 1981, Bibby et al. 1998, Jiménez 2000), siendo esta última la que provee numerosas ventajas para observar aves en ambientes de alta complejidad o de mayor diversidad (Reynolds et al. 1980, Bibby et al. 1998, Drapeau et al. 1999) como es el caso de la mayoría de los ambientes estudiados.

Sin embargo, y dado que otros autores recomiendan la utilización de lineas transectas para muestreos de bosques (Wilson et al. 2000), en este estudio se aplicaron ambos métodos de censados con la finalidad de analizar cual es el más adecuado para muestrear especie/gremio de aves en los ñirantales. 


\subsubsection{Línea Transecta (LT)}

En cada sitio de muestreo se ubicaron tres LT de 350 metros de largo cada una.

Para evitar el doble conteo las transectas fueron separadas entre sí por al menos 150-200 metros en áreas de vegetación cerrada y de 250 a 300 metros en áreas de vegetación abierta (Bibby et al. 1992 y 1998, Wunderle 1994, Ralph et al. 1996, Perovic et al. 2008, González García 2013).

El inicio y el final de cada LT fueron identificados con una marca de color rojo (Foto 3.1), lo que facilitó identificarlas y realizar el mismo recorrido en cada temporada de (Lord 1961, Morales et al. 1981, Mc Cullough 1982, Packard et al. 1986).

Se recorrió lentamente cada una de las distancias de las líneas transectas con el fin de registrar las especies que se encontraban en cada hábitat (González García 2013), siendo la velocidad del recorrido de las transectas de aproximadamente 1 km/hora (Lord 1961, Gómez de Silva et al. 1999) para lo cual fue transitada a paso constante, cubriendo la distancia en un período aproximado que fluctuó entre 15 y 20 minutos aproximadamente, de acuerdo a la metodología descripta por diversos autores (Ralph et al. 1995, Bibby et al. 1998, Codesido y Bilenca 2000).

Se registraron las aves detectadas a una distancia máxima a ambos lados de la línea transecta (ancho de banda) que fluctuó entre 25 y 30 metros (Wunderle 1992, Ralph et al. 1996, Gonzalez Oreja et al. 2007, Mac Gregor-Fors et al. 2010) y a 20 metros de altura (Ralph et al. 1995, Bibby et al. 1998).

En todos los casos se dejó una distancia mínima de $100 \mathrm{~m}$. con respecto al límite de cada hábitat con el fin de evitar el efecto borde (Ralph et al. 1996, Bibby et al. 1998). 


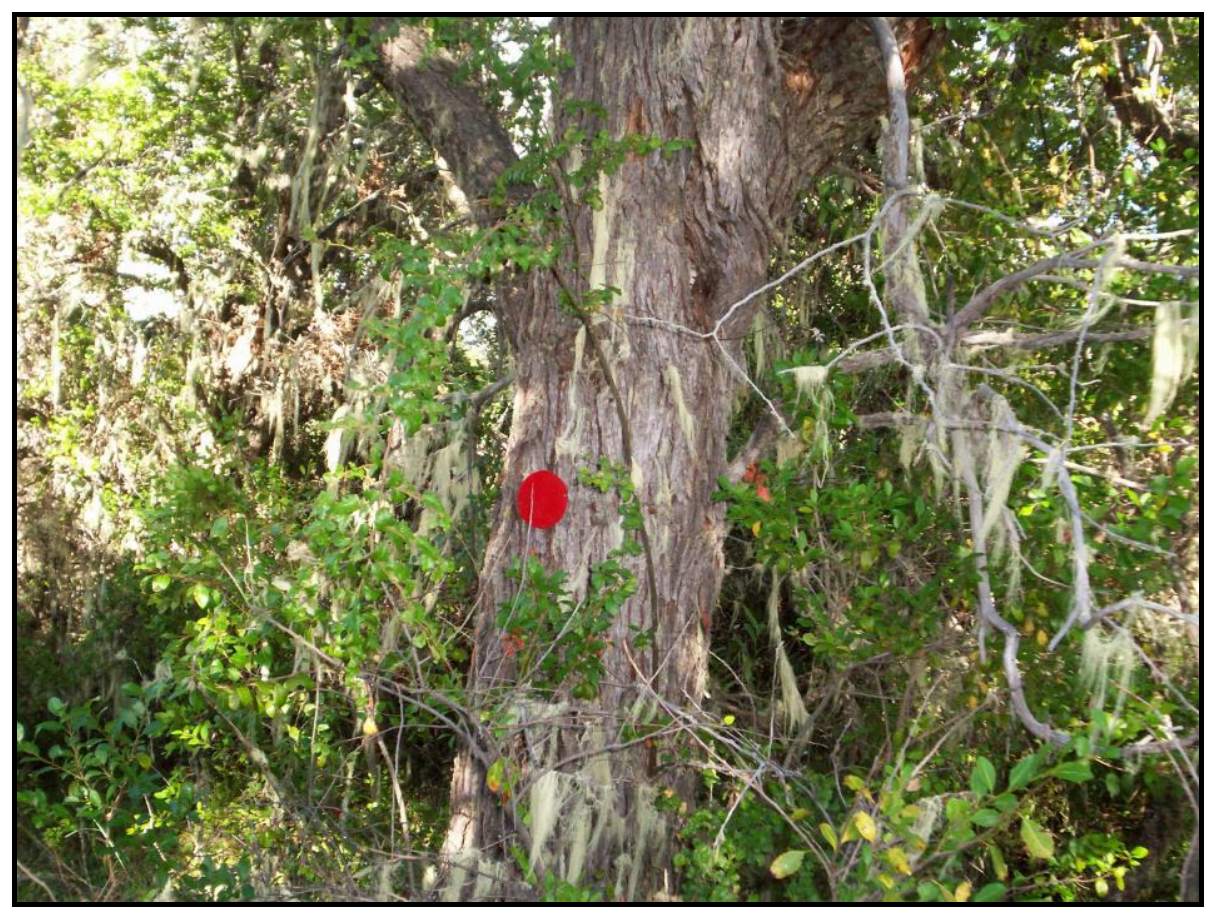

Foto 3.1: Se colocaron chapas de color rojo indicativas del comienzo y el final de cada una de las líneas transectas (LT)

\subsubsection{Punto de Conteo (PC)}

En cada sitio de muestreo se ubicaron seis PC, los que estuvieron identificados con chapas de color amarillo (Foto 3.2), con el objeto de realizar censos en los mismos sitios a lo largo de todos los períodos de muestreo. La distancia mínima entre PC fue de 250 metros (Bibby et al. 1992, Ralph et al. 1996, Mac Gregor-Fors et al. 2010) y, con el objeto de evitar el efecto borde, la distancia mínima entre un PC y el límite de un ambiente diferente fue de 100 metros (Ralph et al. 1996, Bibby et al. 1998).

En los PC se realizaron censos de aves con binoculares durante un lapso total de 10 minutos, siendo los 2 minutos iniciales para el acostumbramiento de las aves al observador y los siguientes 8 minutos de observación corresponden al conteo efectivo (Reynolds 1980, Scott y 
Ramsey 1981, Fuller y Langslow 1984, Verner 1988, Hagar et al. 1996, Deferrari 2001).

En los censos se contabilizaron las aves observadas dentro de un radio de 25 metros (Ralph et al. 1995, Bibby et al. 1998) y a una altura no mayor a 20 metros (Ralph et al. 1995, Bibby et al. 1998).

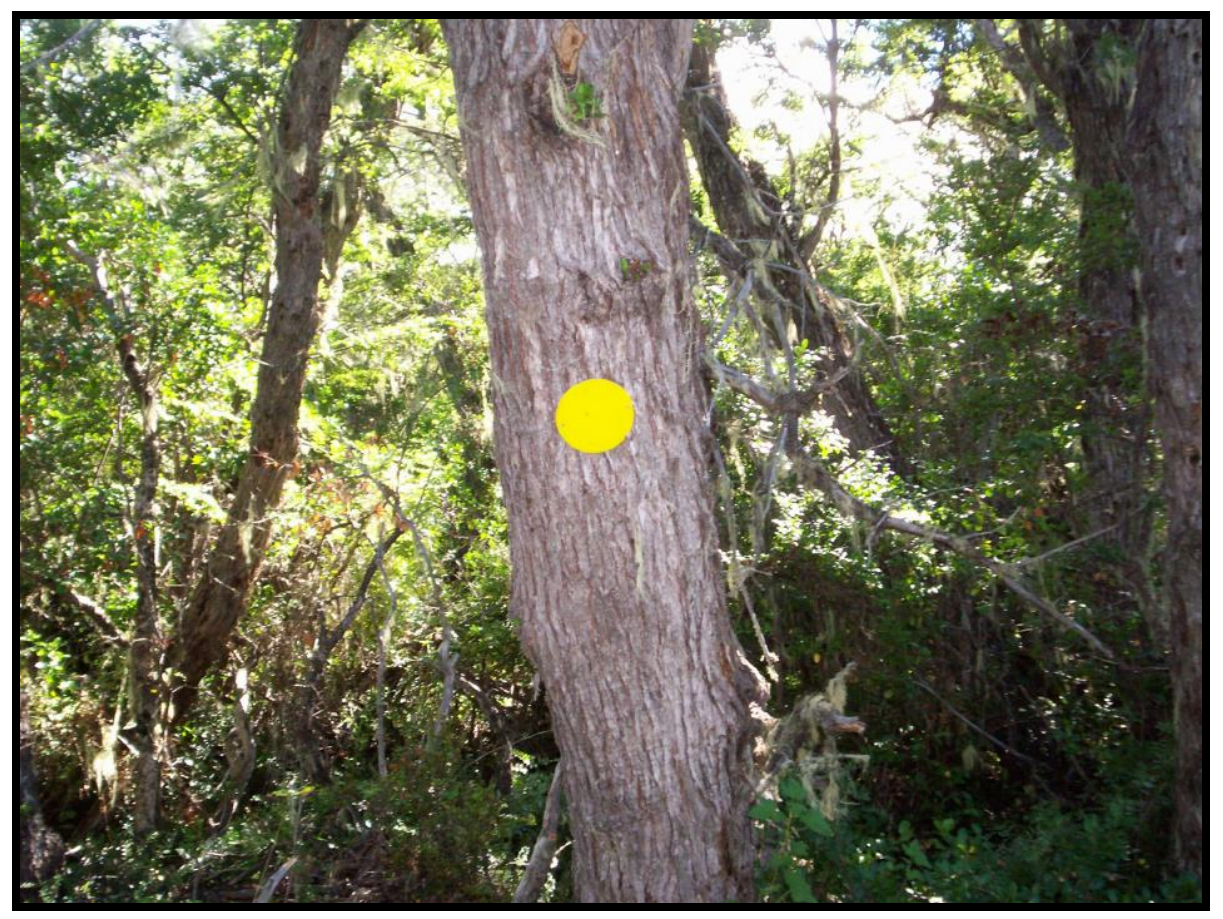

Foto 3.2: Se colocaron chapas de color amarillo indicativas del sitio de ubicación de cada uno de los puntos de conteo (PC)

Conjuntamente a la información derivada de los censos mediante PC y LT, se consideró también la información obtenida circunstancialmente por observación directa de los hábitos de la avifauna estudiada.

\subsubsection{Análisis de los Datos de Avifauna}

Se estimaron los siguientes índices biológicos:

- a) Riqueza específica (S)

- b) Índice de Diversidad de Shannon - Wiener $\left(H^{\prime}\right)$ 
- c) Diversidad de Margaleff (M)

- d) Equitatividad de Pielou (E)

- e) Índice de Dominancia de Berger - Parker (d)

- f) SUMIN (Suma de Índices)

- g) Trofismo

- h) Clasificación de la Red List (IUCN)

Los mencionados índices se describen a continuación:

\section{a) Riqueza específica (S)}

La riqueza específica es el modo más sencillo de medir la biodiversidad, ya que se basa únicamente en el número de especies presentes, sin tomar en cuenta el valor de importancia de las mismas (Magurran 2003, Moreno 2001).

\section{b) Índice de Diversidad de Shannon - Wiener $\left(\mathrm{H}^{\prime}\right)$}

Este índice expresa la uniformidad de los valores de importancia a través de todas las especies de la muestra (Moreno 2001) y mide el grado de incertidumbre en predecir a que especie pertenecerá un individuo escogido al azar perteneciente a una comunidad (Krebs 1985, Magurran 2003, Moreno 2001).

$$
\mathrm{H}^{\prime}=-\Sigma p_{i} * \ln p_{i}
$$

Siendo $p_{i}=\left(n_{i} / N\right)$ y $n_{i}$ el número de individuos de la iésima especie.

\section{c) Índice de Diversidad de Margalef (I)}

El Índice de Margalef, o índice de biodiversidad de Margalef, transforma el número de especies por muestra a una proporción a la cual las 
especies son añadidas por expansión de la muestra (Moreno 2001). Se supone que hay una relación funcional entre el número de especies y el número total de individuos (Magurran 1988 y 2003).

El índice se basa en la siguiente expresión $I=(s-1) / L n N$, donde I es la diversidad, $\mathrm{s}$ es el número de especies presentes, y $\mathrm{N}$ es el número total de individuos encontrados (pertenecientes a todas las especies). La notación $L n$ denota el logaritmo neperiano de un número.

\section{d) Equitatividad de Pielou (E)}

Este índice evalúa la proporción de diversidad observada en relación a la máxima diversidad esperable (Krebs 1985, Magurran 2003, Moreno 2001).

$$
E=H^{\prime} / \ln S
$$

\section{e) Indice de Dominancia de Berger - Parker (d)}

$$
d=\mathrm{N}_{\max } / \mathrm{N}
$$

donde $\mathrm{N}_{\max }$ es el número de individuos de la especie más abundante.

Un incremento en el valor de éste índice se interpreta como una disminución en la equidad y un aumento en la dominancia (Magurran 2003).

\section{f) SUMIN (Suma de Índices) - Estado de Conservación}

El índice SUMIN expresa la importancia de conservación de las especies de aves (Grigera et al. 1996) y es de suma utilidad como insumo para la elaboración de la Guía de Contenidos Mínimos sancionada mediante la Ley 26331, la cual estipula Disposiciones Generales a contemplar para el manejo del Bosque Nativo (SAyDS 2014) siendo una de las 
principales directivas la de registrar la presencia o cercanías de especies amenazadas y/o de valor especial para su conservación (SAyDS 2014).

Para estimar el Índice SUMIN se aplicó la técnica de Reca et al. (1994). Este índice considera con igual ponderación 12 variables que representan factores de importancia para la supervivencia o necesidad de conservación de las especies (por ej. abundancia, puesta de huevos o superficie de ocupación). El valor final del índice para cada especie puede tomar valores entre 0 y 30 . Los valores más altos de SUMIN indican una situación más adversa para la especie y por ende expresaría que requiere una mayor necesidad de conservación.

\section{g) Trofismo}

Con el objetivo de analizar las comunidades de aves desde un punto de vista funcional según los ambientes que habitan, las especies se agruparon en niveles tróficos (Lantschner 2005). Dado que la composición de la dieta puede variar a lo largo del ciclo anual, para la conformación de los gremios se consideró la información obtenida por observación directa durante los censos y la proveniente de la literatura (Rozzi et al. 1996 ayb, Gorgoglione 1997, Reid et al. 2002, Hansen et al. 2004, Rusch et al. 2004, Amico y Aizen 2005, Lantschner 2005, Grigera y Pavic 2007). En función de ello se procedió de la siguiente manera: en los casos donde la totalidad de la información indicaba que una determinada especie era, por ejemplo, insectívora se le asignó un valor de 1 en insectivoría a dicha especie; en los casos en que la información indicaba que, por ejemplo, una especie es insectívora y carnívora, se le asignó un valor de 0,5 a cada nivel trófico; finalmente si una especie era, por ejemplo, principalmente carnívora y ocasionalmente carroñera se le asignó un valor de 0,75 en carnivoría y 0,25 en carroñera. 
h) Clasificación de la Red List (UICN)

Las especies fueron clasificadas según los criterios direccionados por la Unión Internacional para la Conservación de la Naturaleza (UICN) (UICN 2012).

\section{i) Análisis Multivariado de los Datos}

Para examinar la relación entre las asociaciones de aves y las variables ambientales medidas se realizaron dos análisis de correspondencias canónicas ( $\mathrm{ACC}$ ) mediante el paquete estadístico CANOCO para Windows versión 4.02 (Número de serie 6009) (ter Braak y Smilauer 1999). Los dos análisis consideraron la información proveniente de los dos métodos de censado de aves utilizados (LT y PC). Para los ACC se empleó el promedio de la abundancia de cada una de las especies de aves por cada sitio de muestreo, identificando cada sitio y uso. En el modelo se incluyeron descriptores de los sitios de estudio (e.g. temperatura aire, viento, transitabilidad, etc.) como así también las variables que pudieran tener valor predictivo sobre los ensambles de aves (e.g. abundancia de invertebrados terrestres, diversidad, dominancia, diversidad de vegetación, oferta de frutos y semillas, etc.).

El ACC es una técnica de análisis directo de gradientes que asume un modelo unimodal para las relaciones entre las respuestas de cada especie al gradiente ambiental, y los ejes de ordenamiento son combinaciones lineares de las variables ambientales (ter Braak 1986 y 1995). Previo a la selección de este ordenamiento se exploraron mediante diferentes técnicas si la respuesta de las especies de aves era mejor interpretada con modelos lineares o unimodales (ter Braak y Smilauer 1998 y 1999). Antes del análisis todas las variables (excepto diversidad y equitatividad) de las aves fueron transformadas como log $(x+1)$. Cuando una variable está altamente correlacionada con otra, un 
valor alto del factor de inflación $(>15)$ es identificado para cada variable por el programa. Esto ocurre durante el análisis previo lo que permite remover esta variable y volver a correr el programa. Las variables que mostraran covariación fueron entonces removidas y el análisis llevado a cabo nuevamente sobre las variables ambientales remanentes. La función de minimizar la ponderación de presencia de especies raras o de baja ocurrencia y o abundancia a fin de mejorar la visualización de las relaciones especie ambiente fue utilizada.

Se representó gráficamente (biplots) el ordenamiento de las especies y de los sitios de muestreo, sobre los dos primeros ejes del ACC, simultáneamente con las variables ambientales que quedaron seleccionadas en el ordenamiento. Las variables ambientales se representan como vectores y un mayor módulo y cercanía a los ejes representa un mayor grado de correlación. Con el objeto de identificar aquellas variables ambientales que explicaran una parte significativa de la varianza de la densidad de las especies de aves se empleó el test de Monte Carlo (9999 iteraciones). Los ordenamientos finales ACC se obtuvieron empleando el programa con las variables ambientales seleccionadas (ter Braak y Smilauer 1998).

\subsection{Muestreo de Artrópodos}

Los muestreos se realizaron trimestralmente (aproximadamente durante el período central de cada estación) y a lo largo de dos ciclos anuales 2008-2010. Los muestreos se llevaron a cabo en días durante los cuales no hubo precipitación (Iluvia o nevada), neblina, vientos fuertes u otra situación que menoscabe la correcta cuantificación de la microfauna. Los puntos de muestreo se localizaron en el punto central de la segunda línea transecta de censado de aves de cada sitio de 
muestreo y los mismos fueron señalados para su fácil ubicación (Foto 3.3).

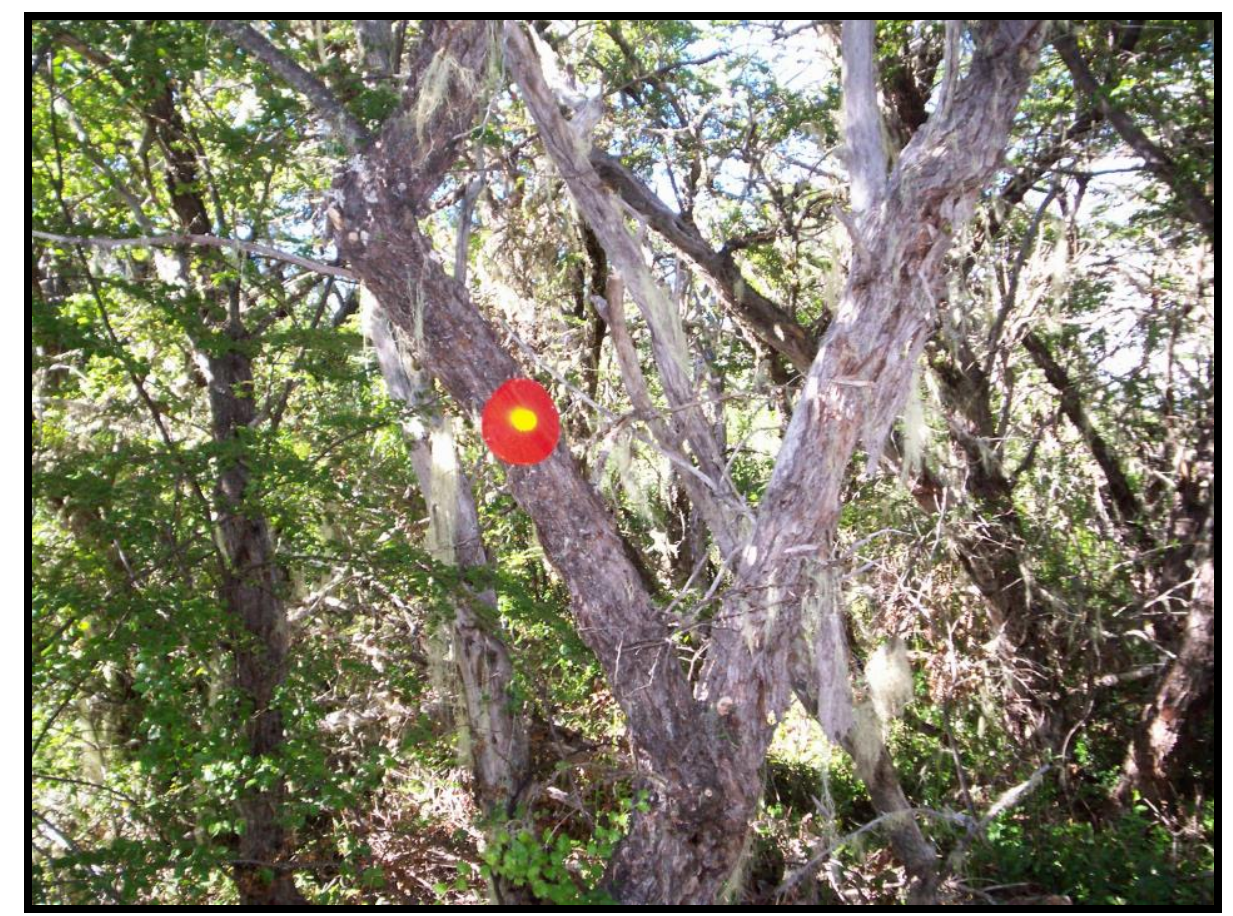

Foto 3.3: Identificación del punto de muestreo de artrópodos

Se obtuvieron muestras de:

1. Artrópodos del suelo

2. Artrópodos voladores

3. Artrópodos del dosel de los árboles

4. Artrópodos del tronco de los árboles

\section{Muestreo de Artrópodos del Suelo}

En cada sitio de muestreo, se tomó una muestra de suelo mediante un sacabocado metálico de $500 \mathrm{~cm}^{3}$ de capacidad $(10 \mathrm{~cm}$. de lado por una profundidad de $5 \mathrm{~cm}$.), se extrajeron 3 muestras de modo azaroso a un metro desde el centro de cada línea transecta (Foto 3.4).

En el laboratorio los artrópodos presentes en las muestras se extrajeron mediante el método Tullgreen. Este método consiste en 
iluminar directamente la muestra de suelo a partir de lo cual, debido a la iluminación y a la acción desecante del calor emitido por la lámpara, los invertebrados salen de los terrones de suelo cayendo en un recipiente que contiene formol al 70\%, donde son fijados. Una vez fijados los artrópodos fueron preservados en alcohol etílico al $70 \%$ hasta su identificación y conteo (Southwood 1989). Cada muestra fue etiquetada con indicación de fecha y sitio de muestreo.

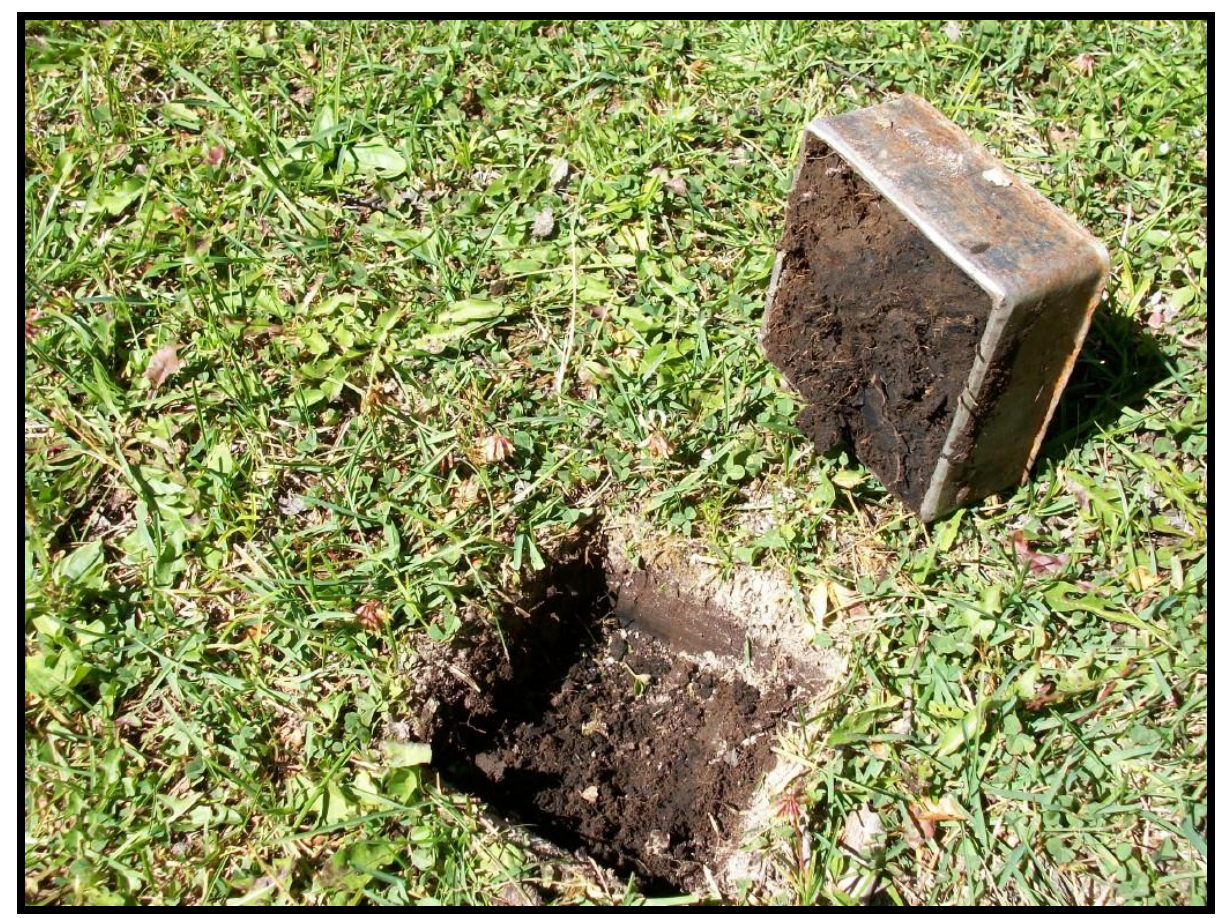

Foto 3.4: Vista de muestreo mediante un sacabocado para artrópodos que habitan en el suelo.

\section{Muestreo de Artrópodos Voladores}

Los artrópodos voladores se muestrearon mediante trampas de intercepción o "Fluid Interception" con un área de intercepción de $1 \mathrm{~m}^{2}$, colocándose una trampa en cada una de las réplicas. Los artrópodos interceptados se recolectaron en cinco bandejas de $400 \mathrm{~cm}^{2}$ cada una, las cuales contenían una solución de agua y anticongelante para evitar: a) el congelamiento del líquido en los meses invernales, b) el escape de 
los ejemplares capturados y para c) retardar su descomposición (Southwood 1989, News 1998).

Las trampas (Foto 3.5) permanecieron en el terreno por un período de 24 horas, luego del cual, los artrópodos fueron extraídos de las trampas y preservados en alcohol etílico al $70 \%$ hasta su traslado al laboratorio. Cada muestra fue etiquetada con indicación de fecha y sitio de muestreo.

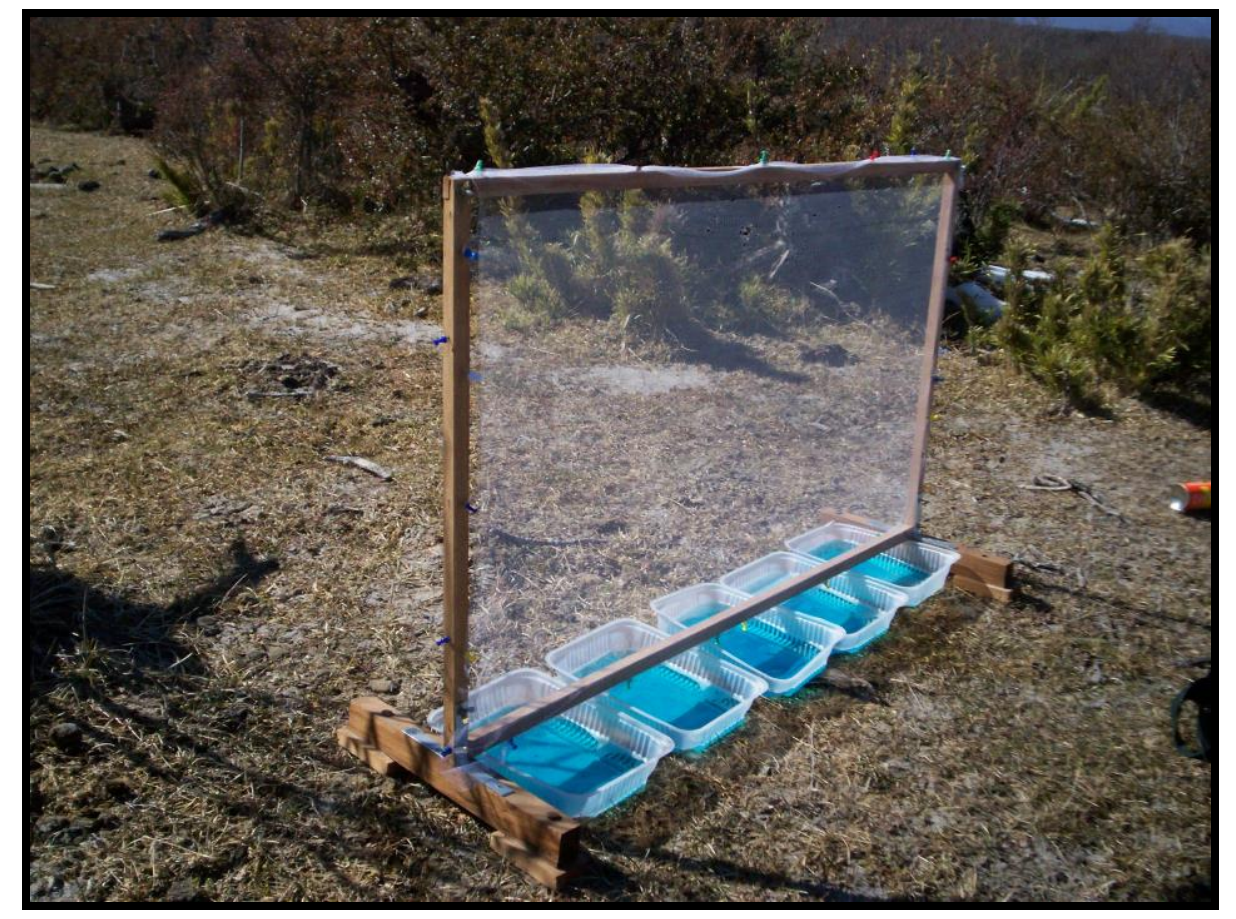

Foto 3.5: Vista de la trampa de intercepción para artrópodos voladores.

\section{Muestreo de Artrópodos del Dosel de los Árboles}

Para el muestreo de artrópodos asociados al dosel, se tomaron ramas de las tres especies mas abundantes de los estratos arbustivo o arbóreo de cada sitio de muestreo fueron rociadas con insecticida (Marca Raid - Casas y Jardines). Luego de 10 segundos de aplicado el insecticida las ramas fueron agitadas y los artrópodos que se desprendían de la mismas fueron recolectados en un bastidor $3600 \mathrm{~cm}^{2}$ y $1 \mathrm{~mm}^{2}$ de malla (Foto 3.6) (Southwood 1989, News 1998). 
Los artrópodos fueron recolectados del bastidor, preservados en alcohol etílico al 70\%, y transportados al laboratorio donde fueron identificados y contados.

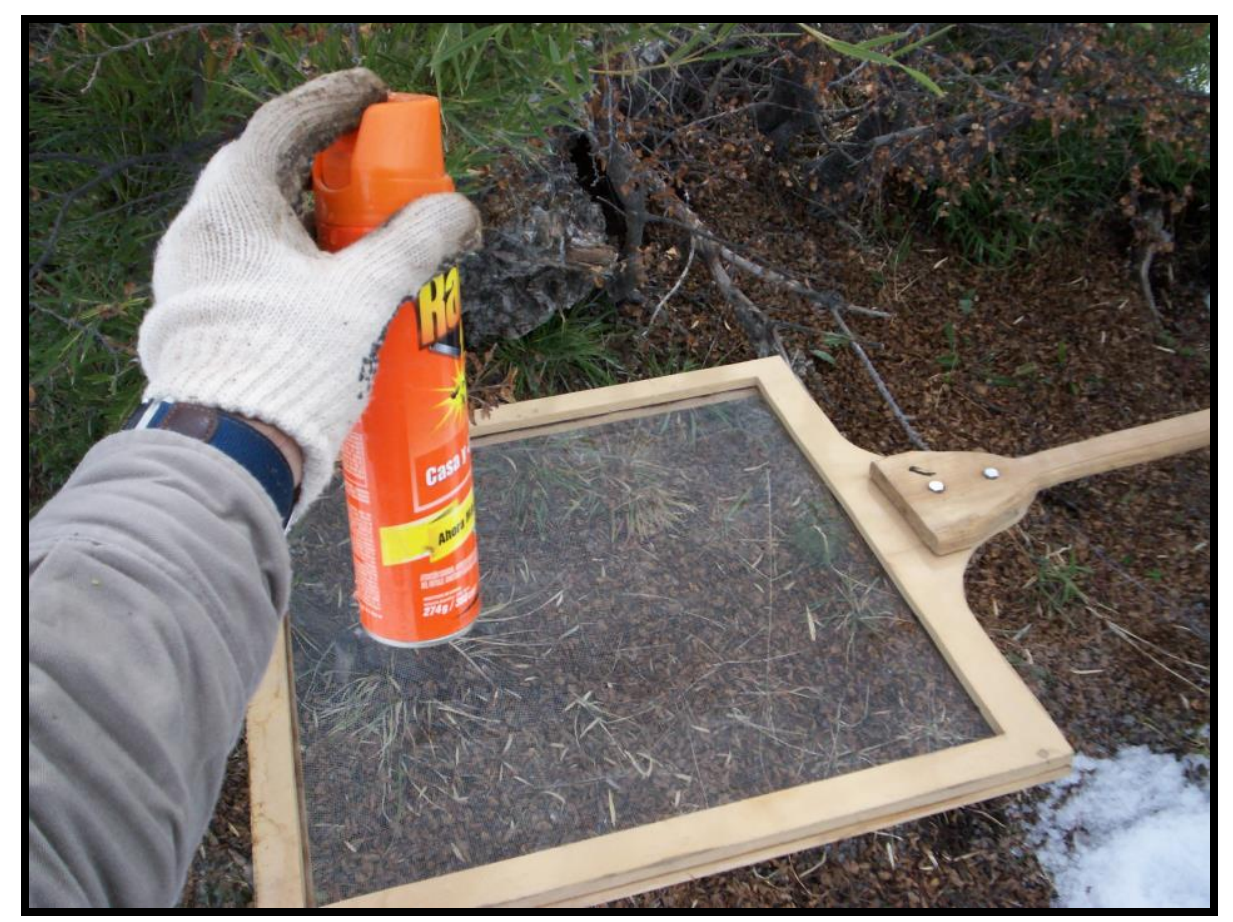

Foto 3.6: Se observa la malla donde los artrópodos eran atrapados.

\section{Muestreo de Artrópodos del Tronco}

Para el muestreo de artrópodos asociados al tronco de los árboles se colocaron trampas denominadas "Sticky-traps" en los tres ejemplares más próximos al punto de muestreo de (Foto 3.7).

Cada trampa consistió en un plástico laminar de 10 micras de espesor y una superficie de $90 \mathrm{~cm}^{2}(30 \mathrm{~cm}$. x $30 \mathrm{~cm}$.). Las trampas fueron fijadas en los árboles con orientaciones distintas. Los plásticos fueron cubiertos con pegamento y permanecieron en el terreno por un período de 24 horas. En el laboratorio los invertebrados fueron extraídos del pegamento mediante la utilización de aguarrás al $100 \%$ y preservados en alcohol etílico al 70\% hasta identificación y conteo (Southwood 1989, News 1998). 


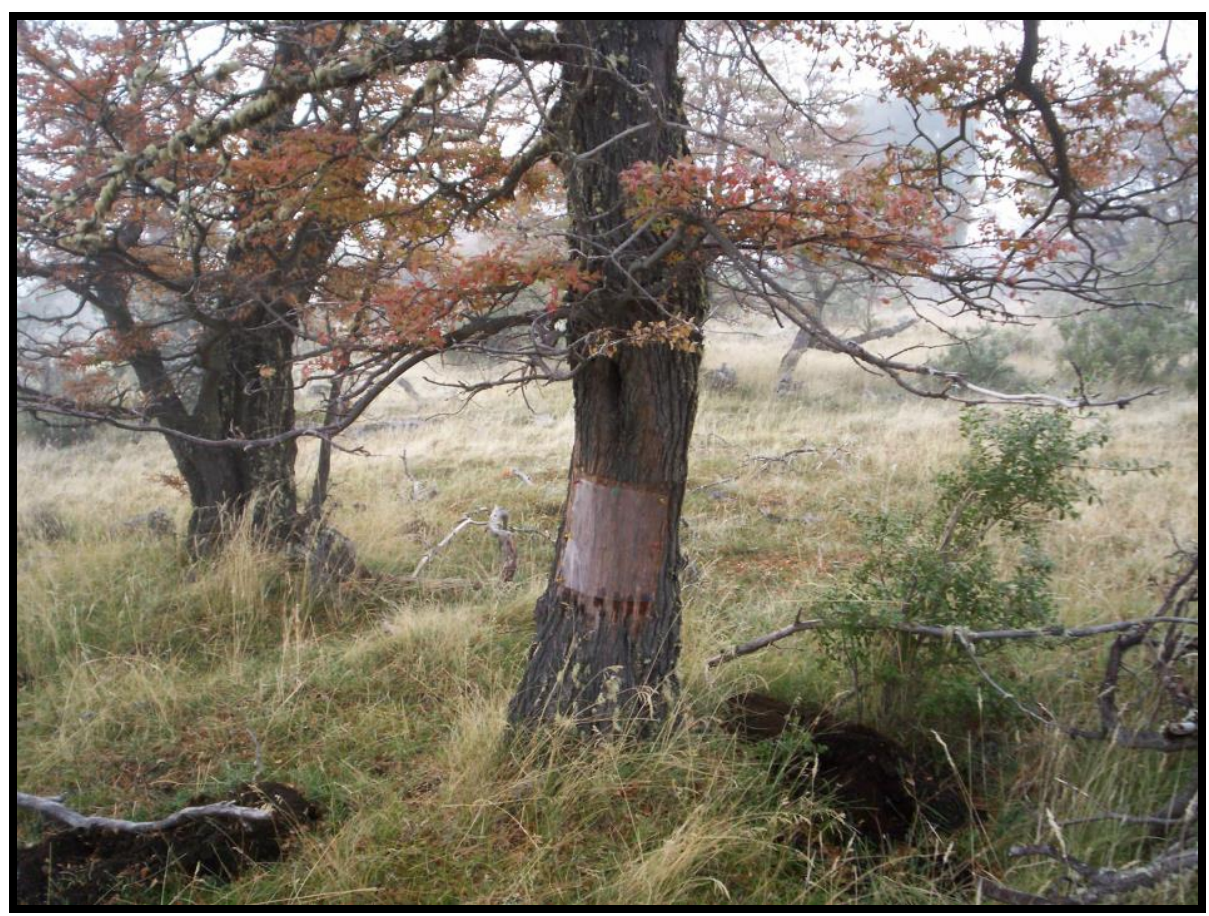

Foto 3.7: Se observa la trama "sticky traps", consistente en una lámina recubierta con un pegamento especial fijada al tronco de los árboles

\section{b) Análisis Taxonómico de Laboratorio}

En el laboratorio de la Universidad Nacional del Comahue Asentamiento Universitario de San Martín de los Andes (AUSMA), Neuquén, los artrópodos fueron identificados hasta el nivel taxonómico más bajo posible con la ayuda de guías y claves de identificación taxonómicas (Ross 1973, Richards y Davies 1984, Morrone y Coscarón 1998, Romoser y Stoffolano 1998, Marvaldi y Lanteri 2005, Claps et al. 2008) y contados.

La información sobre artrópodos se analizó conjuntamente con información adicional, de modo de determinar de qué manera los diferentes tipos de impacto ambiental a los que son sometidos los ñirantales pueden afectar la estructura de las comunidades de artrópodos a través de cambios en la estructura del bosque. Para todos los casos en que se realizaron comparaciones se utilizó el número de especies (S) y el número de individuos (N). Para evaluar si existen 
diferencias entre los atributos de las comunidades de artrópodos de ñirantales sometidos a diferentes impactos se realizaron ANOVAs univariados (programa Infostat versión 2012) con pruebas a posteriori cuando las diferencias fueron significativas (Sokal y Rohlf 1995). Para determinar la existencia de diferencias significativas entre las temporadas de muestreo, entre las diferentes estaciones del año, entre los ñirantales sometidos a diferentes usos y la combinación entre ellos se realizó una prueba ANOVA. Estos análisis permitieron determinar cómo los cambios en la estructura y composición de los sitios de muestreo sometidos a diferentes impactos afectan a las comunidades de artrópodos a través de cambios en la estructura del bosque.

\section{c) Índices Biológicos}

A partir del material recolectado en los muestreos de vegetación, aves y artrópodos se estimaron parámetros tales como: biodiversidad específica mediante la riqueza específica (Magurran 1988, Moreno 2001); índice de Shannon Wiener (Magurran 1988 y 2003); índice de equitatividad (modificado por Pielou)(Krebs 1985, Magurran 1988); índice de Simpson (Moreno 2001); índice de dominancia de BergerParker)(Krebs 1985, Magurran 1988) y composición de los diferentes grupos tróficos de acuerdo a los hábitos alimentarios de los adultos (Moran y Southwood 1982).

Los índices biológicos utilizados fueron (ver Análisis de los datos de Avifauna):

- a) Riqueza específica (S)

- b) Índice de Diversidad de Shannon - Wiener $\left(H^{\prime}\right)$

- d) Equitatividad de Pielou (E)

- e) Índice de Dominancia de Berger - Parker (d) 


\section{RESULTADOS}

\section{1 - Resultados de las Unidades de Vegetación seqún Usos o Perturbaciones}

\subsection{1 Ñirantales convertidos en Pasturas}

(PAPE Y PAGA)

En los pastizales PAGA y PAPE solo estuvieron representados los estratos herbáceos y arbustivos, aunque ambos pastizales estaban rodeados de ñirantales con baja densidad de individuos.

En el estrato arbustivo del sitio PAGA predominó Escalloria rubra, en tanto que en el estrato herbáceo predominaron Stipa sp. y Poa ligularis (Ver Anexo). En el sitio PAPE Escalloria rubra, fue la especie dominante del estrato arbustivo, en tanto que en el estrato herbáceo predominó Stipa sp. Tanto en PAGA $(F=1,96 ; p<0,01)$ como en PAPE $(F=2,41 ; \quad p<0,01)$ se observaron diferencias significativas en la cobertura de ambos estratos, presentando en ambos sitios el estrato herbáceo $(31,00 \% \pm 33,47$ y $24,13 \% \pm 18,82$, respectivamente) mayor cobertura que el estrato arbustivo $(4,5 \% \pm 6,40 ;$ T-t $p<0,05$ y $8,67 \%$ $\pm 10,97$; T-t $p<0,05$, respectivamente) (Fig. 4.1). 


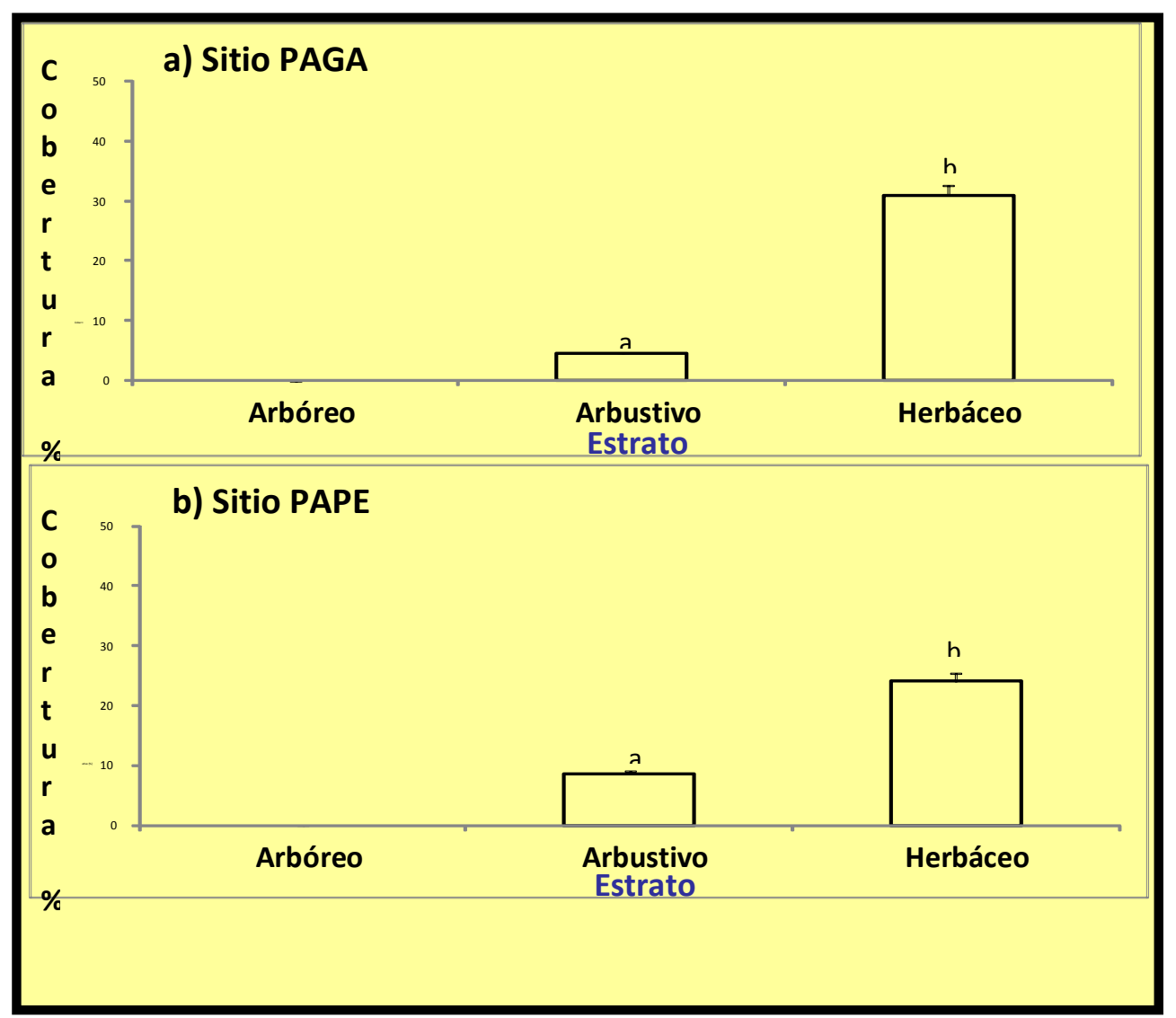

Fig. 4.1: Cobertura relativa de los estratos muestreados en los sitios PAGA (a) y PAPE (b). Las letras diferentes indican que se encontraron diferencias significativas entre los estratos $(p<0,05)$.

En PAGA las especies nativas del estrato herbáceo (31,94\% $\pm 34,50)$ presentaron una mayor cobertura que las de origen exótico $(23,00 \% \pm 31,11 ;$ T-t $p<0,05)$. En el estrato arbustivo solo se observaron especies nativas (Fig. 4.1). En el estrato herbáceo del sitio PAPE las especies nativas $(26,5 \% \pm 19,35)$ también presentaron una mayor cobertura que las exóticas $(14,75 \% \pm 14,97 ; \mathrm{T}$-t $\mathrm{p}<0,05)$ y tal como ocurriera en PAGA, (Fig. 4.2). 


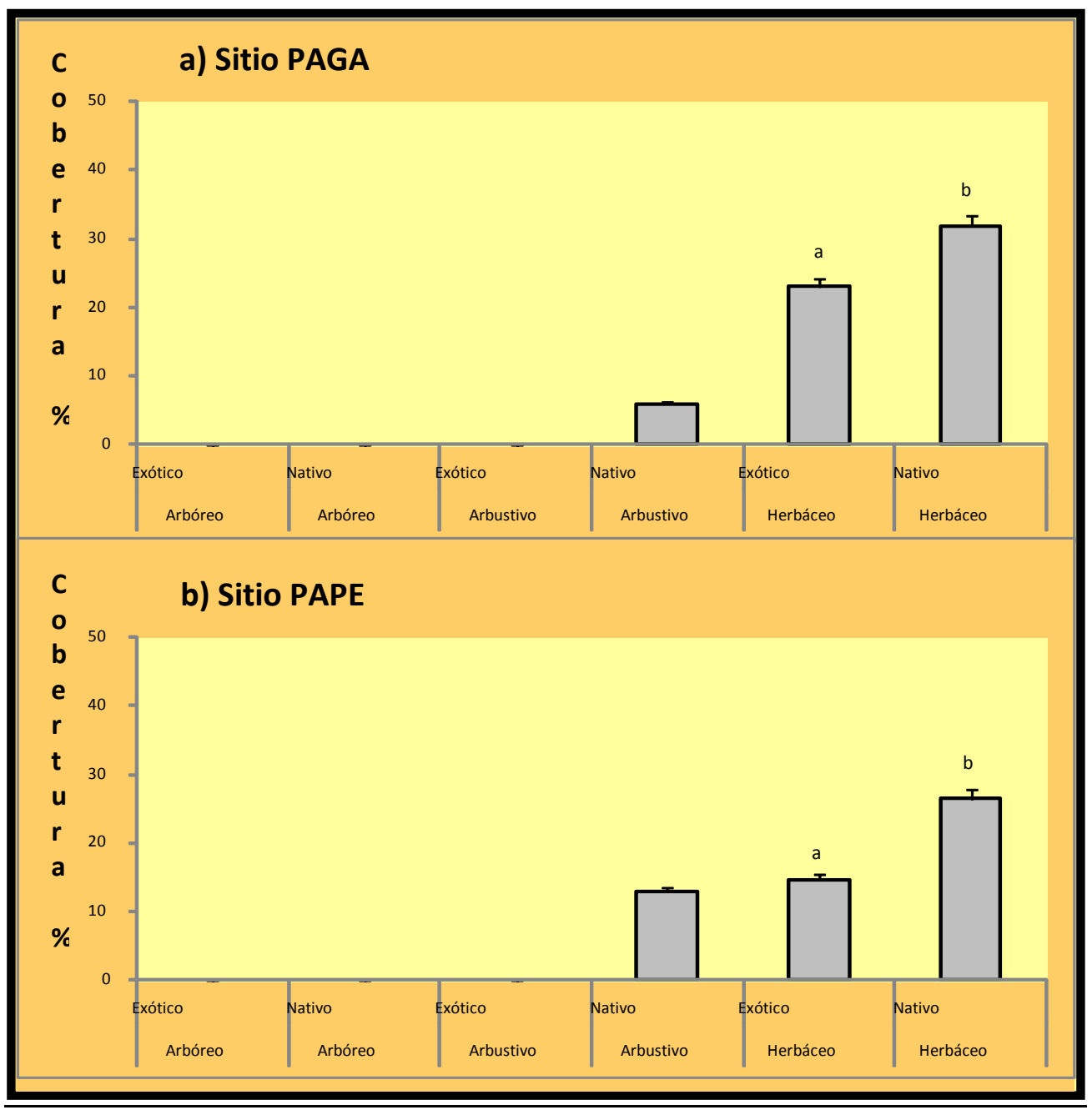

Fig. 4.2: Cobertura relativa de los estratos muestreados según el origen en los sitios PAGA (a) y PAPE (b). Las letras diferentes indican que se encontraron diferencias significativas entre los estratos en relación a su origen $(p<0,05)$.

Se observaron diferencias significativas entre ambos sitios en cuanto a la cobertura relativa de los estratos muestreados $(F=11,02 ; p$ $<0,0001)$, presentando el estrato herbáceo mayor cobertura en el sitio PAGA $(p<0,05)$ y el estrato arbustivo mayor cobertura en el sitio PAPE $(p<0,05)$ (Fig. 4.3). Las diferencias observadas entre los estratos de ambos sitios de muestreo no se debieron a diferencias en la composición de especies de acuerdo a su origen $(p>0,05)$. 


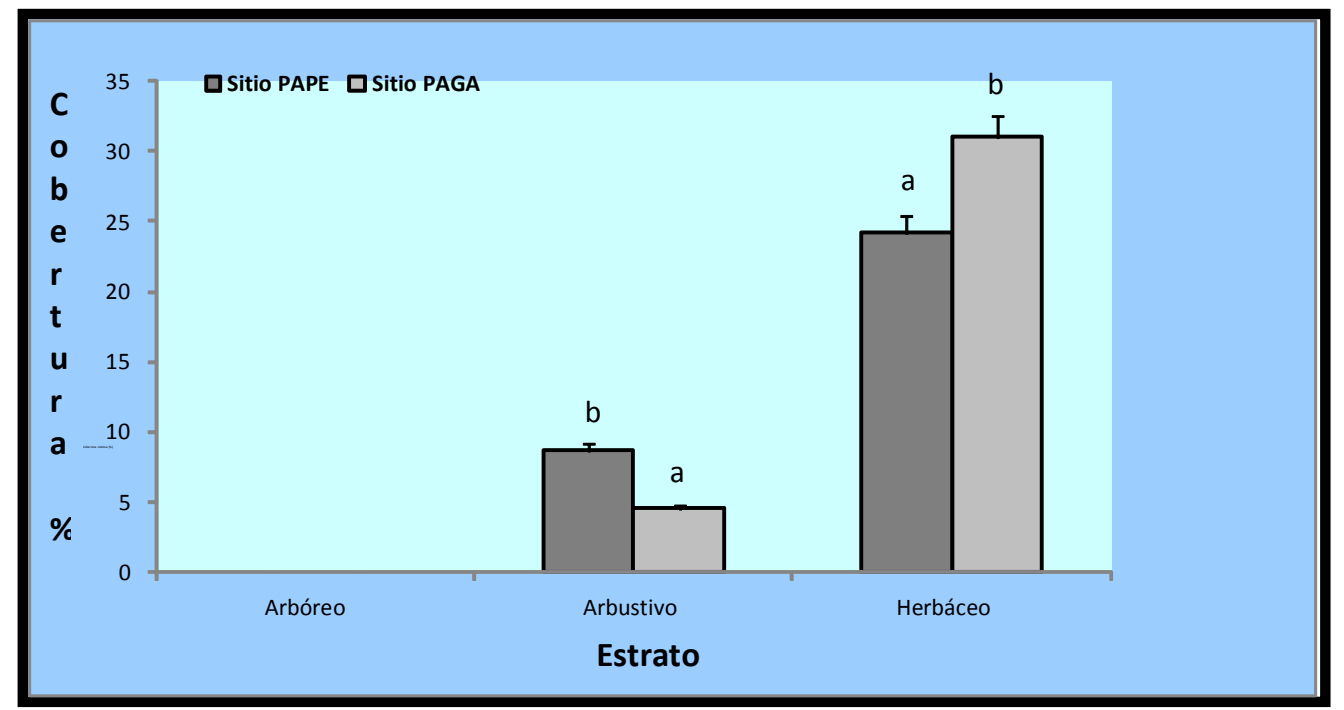

Fig. 4.3: Cobertura relativa de los estratos en los sitios PAPE y PAGA. Las letras diferentes indican que se encontraron diferencias significativas entre los estratos en los sitios muestreados $(p<0,05)$.

La Riqueza, diversidad y dominancia de especies fue similar en ambos sitios (Tabla 4.1).

Tabla 4.1: Riqueza, Dominancia y Diversidad de especies registrada en los sitios PAPE y PAGA. Los valores son expresados como media \pm desvío estándar y rango entre paréntesis.

\begin{tabular}{|l|c|c|c|}
\hline & PAPE & PAGA & P \\
\hline Riqueza & $1,77 \pm 3,16(0,43-0,57)$ & $1,99 \pm 2,35(0,54-7,54)$ & $\mathrm{P}=0,8643$ \\
\hline Dominancia & $0,27 \pm 0,14(0-0,37)$ & $0,25 \pm 0,08(0,10-0,37)$ & $\mathrm{P}=0,5690$ \\
\hline Diversidad & $0,23 \pm 0,38(0,01-1,00)$ & $0,13 \pm 0,25(0,01-0,79)$ & $\mathrm{P}=0,8264$ \\
\hline
\end{tabular}

\subsection{2 Ñirantales con Extracción de Leña por Manchones}

\section{(TUDO y TUUP)}

Se observó que en los estratos arbóreos de ambos sitios, TUDO y TUUP, predominó el Ñire. Las especies vegetales dominantes en los estratos arbustivo (Schinus patagonicus) y herbáceo (Stipa sp.) fueron las mismas en ambos sitios (Ver Anexo). La diferencia en la cobertura de 
los estratos del sitio TUUP se aproximó a la significación ( $F=16,86$; $\mathrm{p}=0,052)$, presentando el estrato arbóreo $(19,92 \% \pm 18,11)$ mayor cobertura que los estratos arbustivo $(10,80 \% \pm 11,73$, T-t $p<0,05)$ y herbáceo $(9,82 \% \pm 14,46, \mathrm{~T}$-t $\mathrm{p}<0,05)$ (Fig. 4.4). Las diferencias en la cobertura de los estratos del sitio TUDO, no fueron significativas $(p=0,280)$.

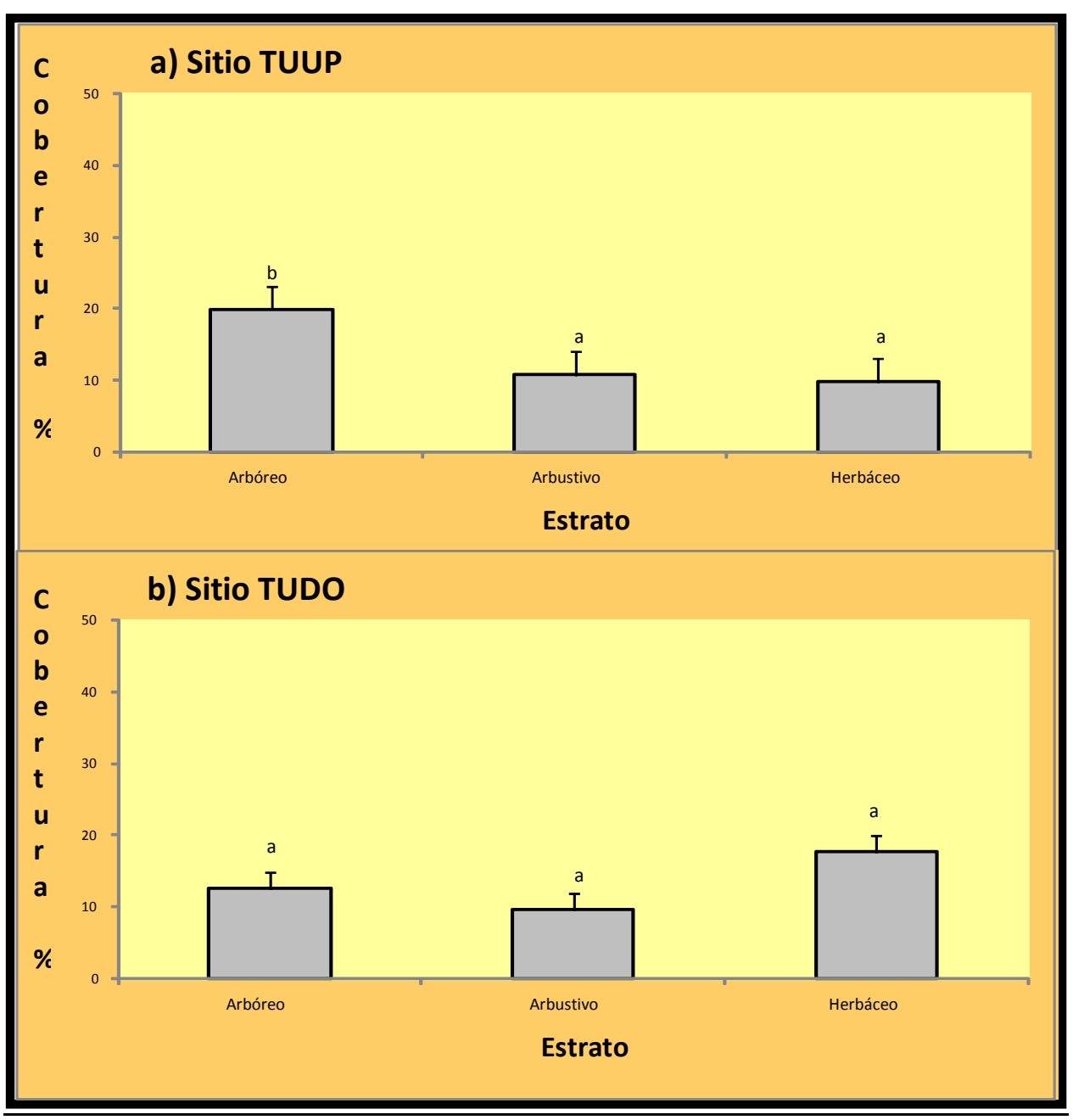

Fig. 4.4: Cobertura relativa de los estratos muestreados en los sitios TUUP (a) y TUDO (b). Las letras diferentes indican que se encontraron diferencias significativas entre los estratos $(p<0,05)$.

En el estrato herbáceo de TUUP, las especies nativas $(13,43 \%$ $\pm 18,50)$ tuvieron mayor cobertura que las exóticas $(6,21 \% \pm 7,97$; T-t $p<0,05)$, en tanto que en los estratos arbóreo y arbustivo solo se observaron especies nativas (Fig. 4.5). Tal como sucedió en TUUP, en el 
estrato herbáceo de TUDO, las especies nativas $(28,5 \% \pm 31,53)$ tuvieron mayor cobertura que las exóticas $(3,22 \% \pm 3,15 ; \mathrm{T}$-t $\mathrm{p}<0,05)$, y solo se observaron especies nativas en los estratos arbóreo y arbustivo (Fig. 4.5).

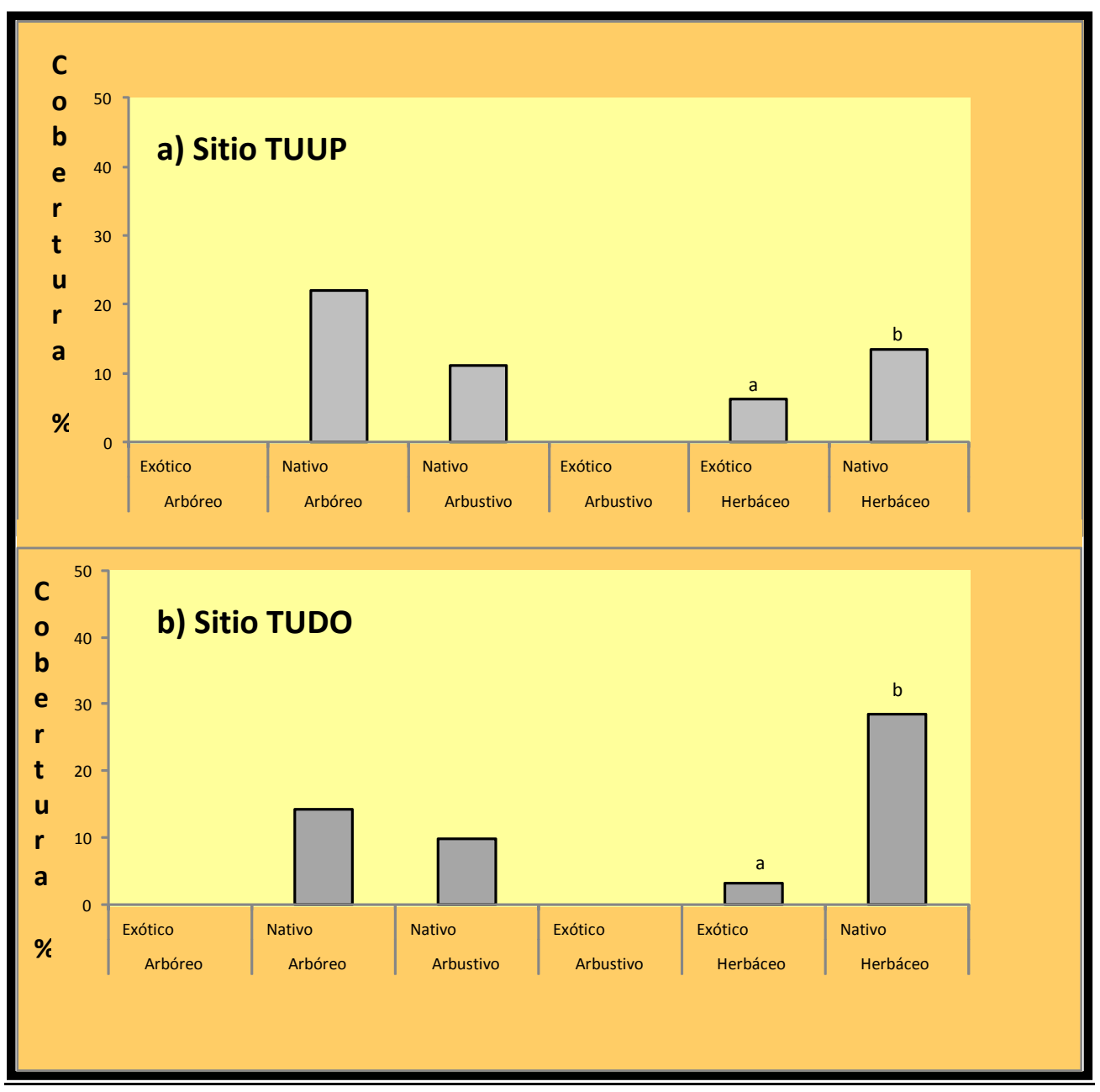

Fig. 4.5: Cobertura relativa de los estratos muestreados según el origen en los sitios TUUP (a) y TUDO (b). Las letras diferentes indican que se encontraron diferencias significativas entre los estratos en relación a su origen $(p<0,05)$.

En lo que respecta al estado sanitario, la totalidad de los ñires representados en los muestreos de ambos sitios se encontraban en muy buen estado sanitario (nivel 1). Si bien el DAP de los ñires de TUUP (media 16,20 cm.; rango 4,77-30,87; d.e. 6,81) fue mayor que el de los ñires de TUDO (media 14,14 cm.; rango 5,09-41,37; d.e. 7,71), las diferencias no fueron estadísticamente significativas $(p>0,05)$. 
La cobertura relativa de los estratos de ambos sitios difirió significativamente $(F=12,05 ; p<0,0001)$, presentando el estrato arbóreo de TUUP $(19,92 \% \pm 18,11)$ mayor cobertura que el de TUDO $(12,61 \%$ $\pm 10,52$; T-t $p<0,05)$ y el estrato herbáceo de TUDO $(17,67 \% \pm 26,74)$ mayor cobertura que el de TUUP $(9,12 \% \pm 14,46 ;$ T-t $p<0,05)$ (Fig. 4.6).

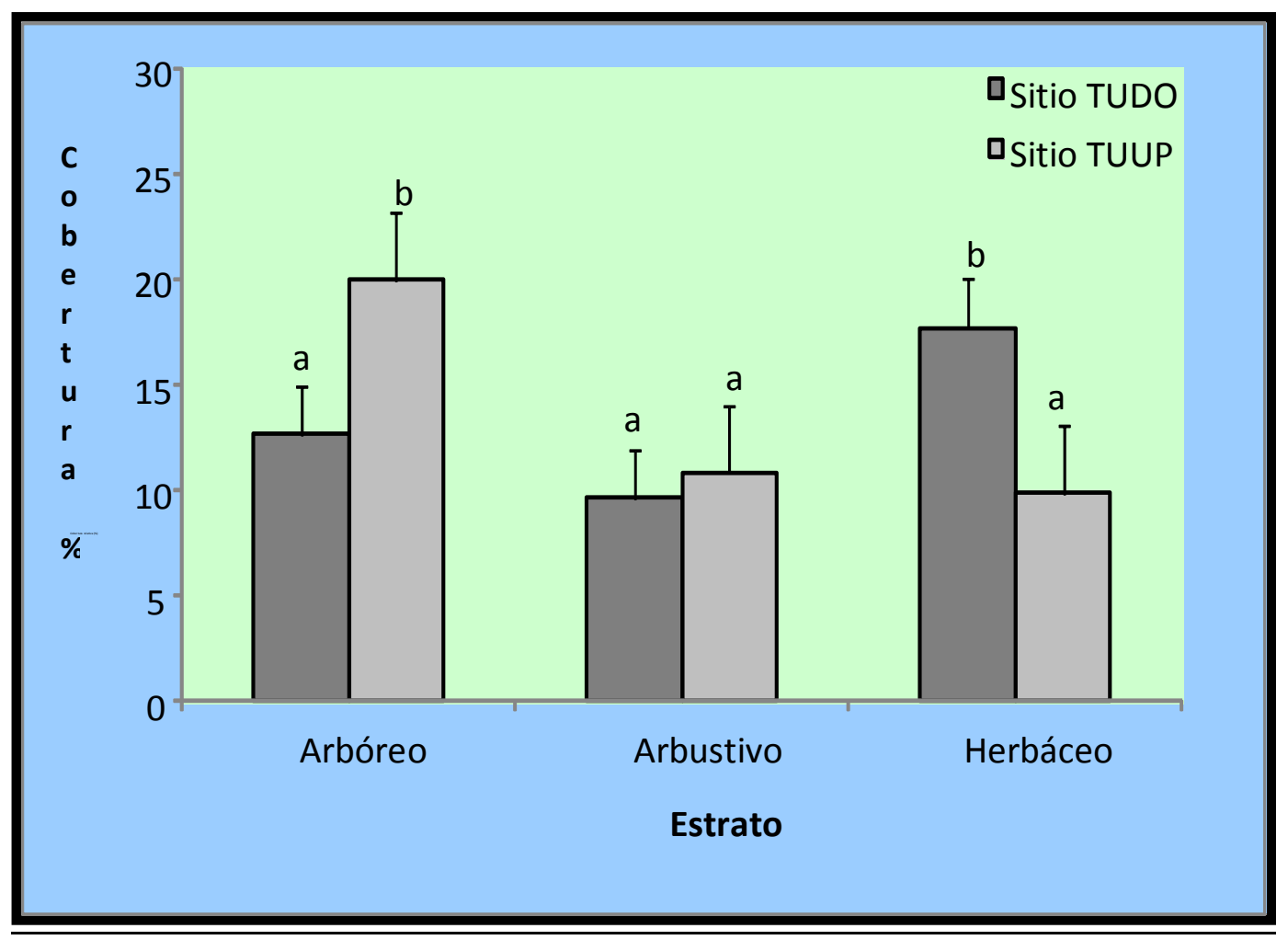

Fig. 4.6: Cobertura relativa (\%) de los estratos en los sitios TUUP y TUDO. Las letras diferentes indican que se encontraron diferencias significativas entre los estratos en los sitios muestreados $(p<0,05)$.

La composición de especies de acuerdo a su origen fue similar en los distintos estratos $(p>0,05)$. Si bien, la riqueza de especies fue significativamente mayor en TUDO $(p<0,05)$, la diversidad y dominancia de especies no difirieron significativamente entre sitios (Tabla 4.2). 
Tabla 4.2: Riqueza, Dominancia y Diversidad de especies registrada en los sitios TUDO y TUUP. Los valores son expresados como media \pm desvío estándar y rango entre paréntesis.

\begin{tabular}{|l|c|c|c|}
\hline & TUDO & TUUP & $\mathbf{p}$ \\
\hline Riqueza & $4,2 \pm 3,61(0,35-12,65)$ & $3,10 \pm 3,82(0,0039-0,77)$ & $\mathrm{p}=0,0332$ \\
\hline Dominancia & $0,08 \pm 0,16(0-0,52)$ & $0,14 \pm 0,22(0,12-0,37)$ & $\mathrm{p}=0,3442$ \\
\hline Diversidad & $0,22 \pm 0,12(0-0,37)$ & $0,27 \pm 0,09(0,64-11,64)$ & $\mathrm{p}=0,1767$ \\
\hline
\end{tabular}

\section{Ñirantales Quemados hace 15 años}

\section{(QGDO Y QGUP)}

El Ñire dominó el estrato arbóreo del sitio QGDO, en tanto que en el estrato arbustivo predominó Berberis parodii y en el herbáceo lo hicieron Stipa sp. y Taraxacum officinale (Ver Anexo). La cobertura relativa de los estratos difirió significativamente $(F=16,86 ; \quad p<0,0001)$, observándose en el estrato herbáceo (media 17,18; rango 3-33; d.e. 9,72 ) mayor cobertura que en los estratos arbóreo (media 4,92; rango 0-8; d.e. 2,40; Tukey test [de aquí en mas referido como $\mathrm{T}-\mathrm{t}$ ] $\mathrm{p}<0,05$ ) y arbustivo (media 7,08; rango 0-20; d.e. 5,82; T-t $p<0,05$ ). El estrato arbóreo no difirió en cobertura con respecto al estrato arbustivo ( $p=$ 0,072) (Fig. 4.7).

El Ñire también dominó el estrato arbóreo del sitio QGUP, en tanto que el estrato arbustivo estuvo dominado por Chusquea culeou y el herbáceo por Stipa sp. (Ver Anexo). Si bien la cobertura relativa de los diferentes estratos no difirió significativamente $(F=1,54 ; p=0,2536)$, en el estrato herbáceo (media 11,76; rango 1-82; d.e. 25,03) se observó una mayor cobertura que en los estratos arbustivos (media 4,25; rango 0-18; d.e. 4,28; T-t $\mathrm{p}<0,05$ ) y arbóreo (media 4,25; rango 0-18; d.e. $4,28 ;$ T-t $p<0,05)$. El estrato arbustivo no difirió en cobertura con el estrato arbóreo ( $p=0,919 ;$ Fig. 4.7). 


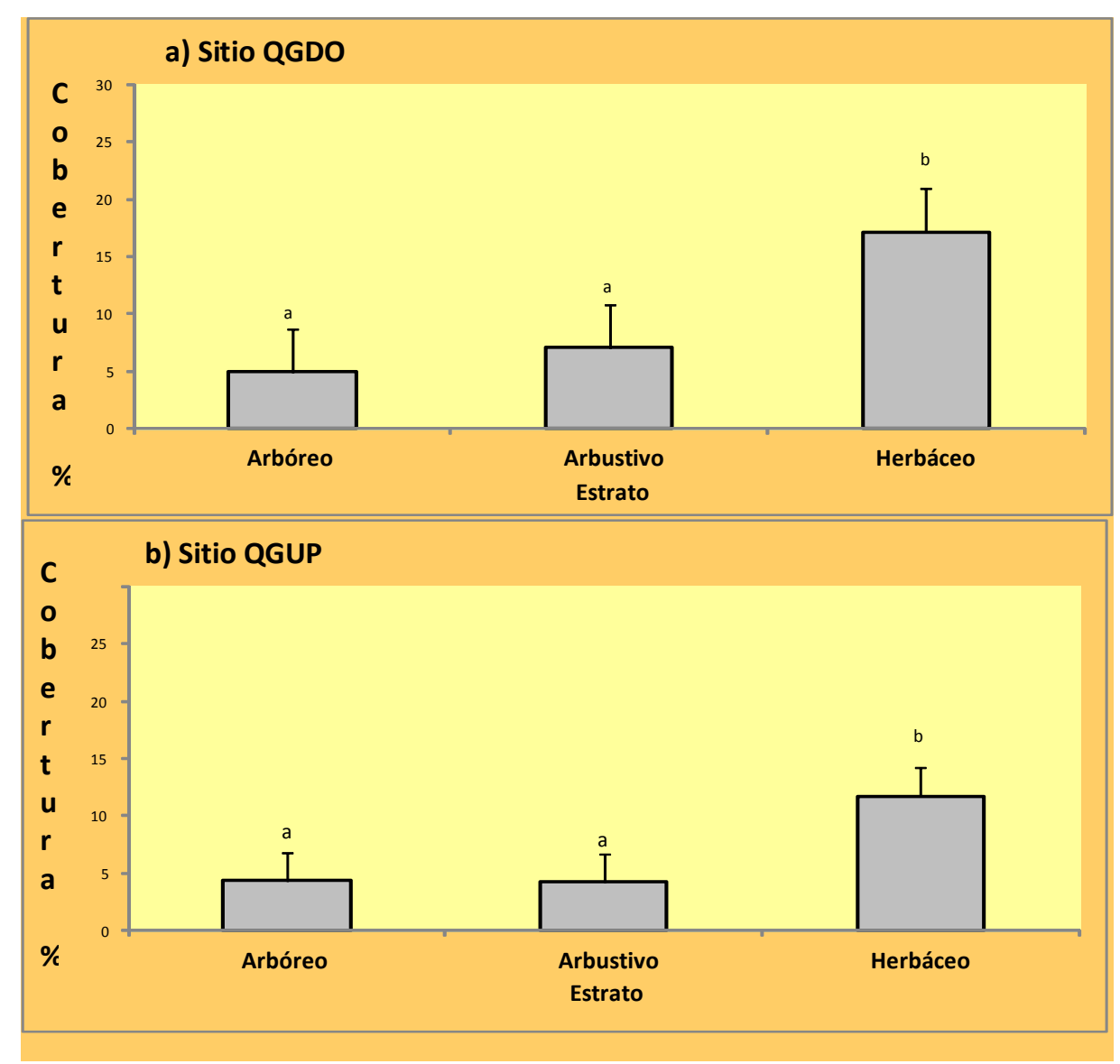

Fig. 4.7: Cobertura relativa de los estratos muestreados en los sitios QGDO (a) y QGUP (b). Las letras diferentes indican diferencias significativas entre los estratos $(p<0,05)$.

En el estrato herbáceo del QGDO las especies exóticas (media $20,7 \mathrm{~cm}$.; rango 6-33; d.e. 10,56) tuvieron mayor cobertura que las nativas (media 12,14 cm.; rango 3-18; d.e. 5,87; T-t p<0,05); en tanto que en los estratos arbóreo y arbustivo solo se registraron especies nativas (Fig. 4.8). En el estrato herbáceo del sitio QGUP la cobertura de las especies nativas (media $12,50 \mathrm{~cm}$; rango 1-82; d.e. 28,12) y exóticas (media 11,11 cm.; rango 1-74; d.e. 23,67) fue similar, en tanto que, como se observara en QGDO, no se registraron especies exóticas en los estratos arbóreo y arbustivo (Fig. 4.8). 


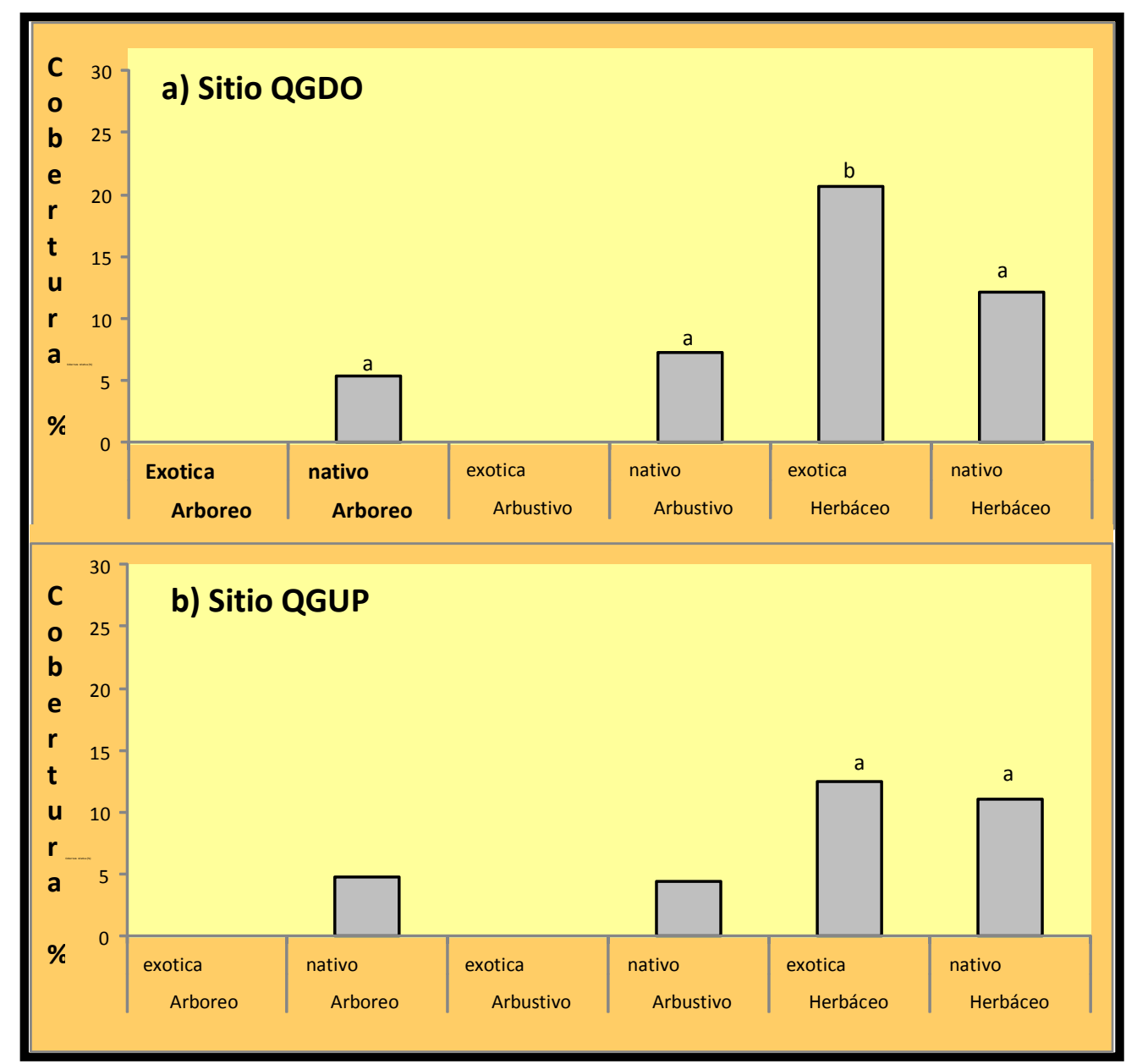

Fig. 4.8: Cobertura relativa de los estratos muestreados según el origen de las especies presentes en los sitios QGDO (a) y QGUP (b). Las letras diferentes indican que se encontraron diferencias significativas en los estratos en relación a su origen $(p<0,05)$.

Los ñires muestreados en ambos sitios poseen estado sanitario 1 , lo que refleja un muy buen estado sanitario de los mismos. Si bien en QGDO el DAP (media 5,09 cm.; rango 0,95-21,64; d.e. 4,76) de los ñires fue mayor que en QGUP (media 3,84cm.; rango 0,32-8,91; d.e. $1,91)$, las diferencias no fueron estadísticamente significativas ( $p>0,05)$. No se encontraron diferencias significativas en cuanto a la cobertura relativa entre los respectivos estratos de cada uno de los sitios $(p=0,803$; Fig. 4.9). 


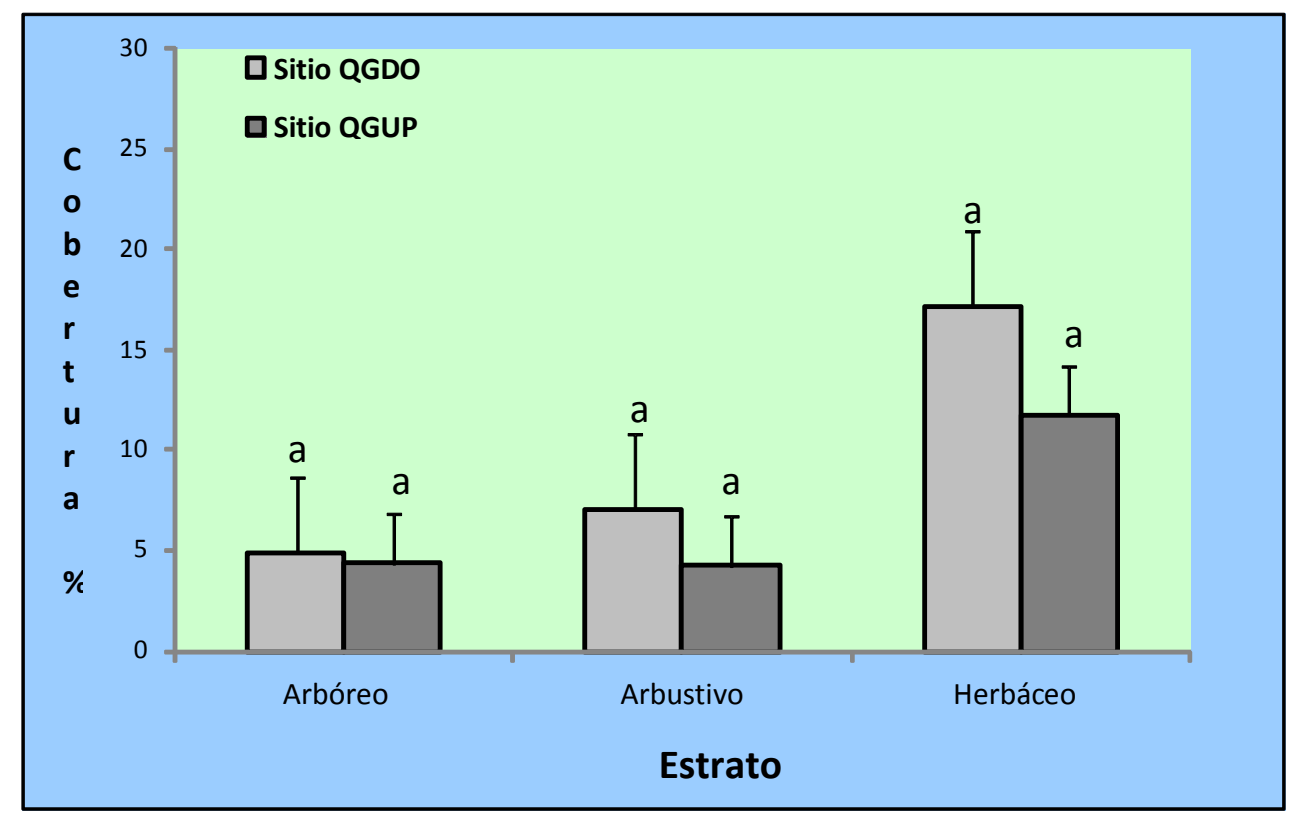

Fig. 4.9: Cobertura de estratos en los sitios QGDO y QGUP. Las letras iguales indican que no se encontraron diferencias significativas entre los estratos en los sitios muestreados $(p>0,05)$.

En el sitio QGDO la riqueza de especies fue significativamente superior a la observada en QGUP $(F=7,09 ; p=0,0134)$, en tanto que la diversidad y la dominancia observadas en ambos sitios fueron similares (Tabla 4.3).

Tabla 4.3: Riqueza, Dominancia y Diversidad de especies registrada en los sitios QGDO y QGUP. Los valores son expresados como media I desvío estándar (rango entre paréntesis)

\begin{tabular}{|l|l|c|c|}
\hline & \multicolumn{1}{|c|}{ QGDO } & QGUP & p \\
\hline Riqueza & $4,07 \pm 4,12(0,61-14,01)$ & $1 \pm 1,27(0-4,55)$ & $p=0,0134$ \\
\hline Dominancia & $0,21 \pm 0,31(0,01-0,36)$ & $0,12 \pm 0,23(0,01-0,86)$ & $p=0,3935$ \\
\hline Diversidad & $0,27 \pm 0,10(0,07-0,36)$ & $0,24 \pm 0,10(0,07-0,37)$ & $p=0,3935$ \\
\hline
\end{tabular}

En este caso las réplicas de las estructuras vegetales fueron estructuralmente semejantes en todas las situaciones analizadas, con la única excepción de la riqueza específica. 


\section{1 .4 \\ Ñirantales Quemados hace 25 años}

(QIDO Y QIUP)

En el sitio QIUP el estrato arbóreo estuvo dominado por Pinus sp. y por Lomatia hirsuta, en el herbáceo predominó Stipa sp., en tanto que en el arbustivo fueron Sthaeroca rethama y Maytenus chubutensis fueron las especies dominantes (ver Anexo). En el estrato arbóreo del sitio QIDO predominaron Maytenus boaria y Lomatia hirsuta, en tanto que en el estrato herbáceo predominó Stipa sp., y en el arbustivo dominó Berberis parodii y Elanterea rosa (ver Anexo). La cobertura de los diferentes estratos difirió significativamente en ambos sitios (QIUP $F=24,57$, $\mathrm{p}<0,01$, QIDO $F=4,83 ; \mathrm{p}=0,05$ ). En QIDO el estrato herbáceo (media 9,38 \%; rango 1-36; d.e. 9,75) presentó mayor cobertura que los estratos arbustivo (media 3,36\%; rango $0-31$; d.e. 5,$28 ;$ T-t $p<0,05$ ) y arbóreo (media 5,20\%; rango 0-10; d.e. 4,55; T-t p<0,05); el estrato arbóreo no presentó diferencias en cobertura respecto del estrato arbustivo $(p=0,466)$ (Fig.4.10). En el sitio QIUP el estrato herbáceo (media 31,00 \%; rango 2-60; d.e. 20,27) también presentó mayor cobertura que los estratos arbustivos (media 6,12 \%; rango 0-36; d.e. 7,76; T-t $\mathrm{p}<0,05$ ) y arbóreo (media 7,56 \%; rango 1-33; d.e. 8,01; Tt $\mathrm{p}<0,05)$, en tanto que el estrato arbóreo no difirió en cobertura del estrato arbustivo ( $p=0,466)$. (Fig.4.10) 


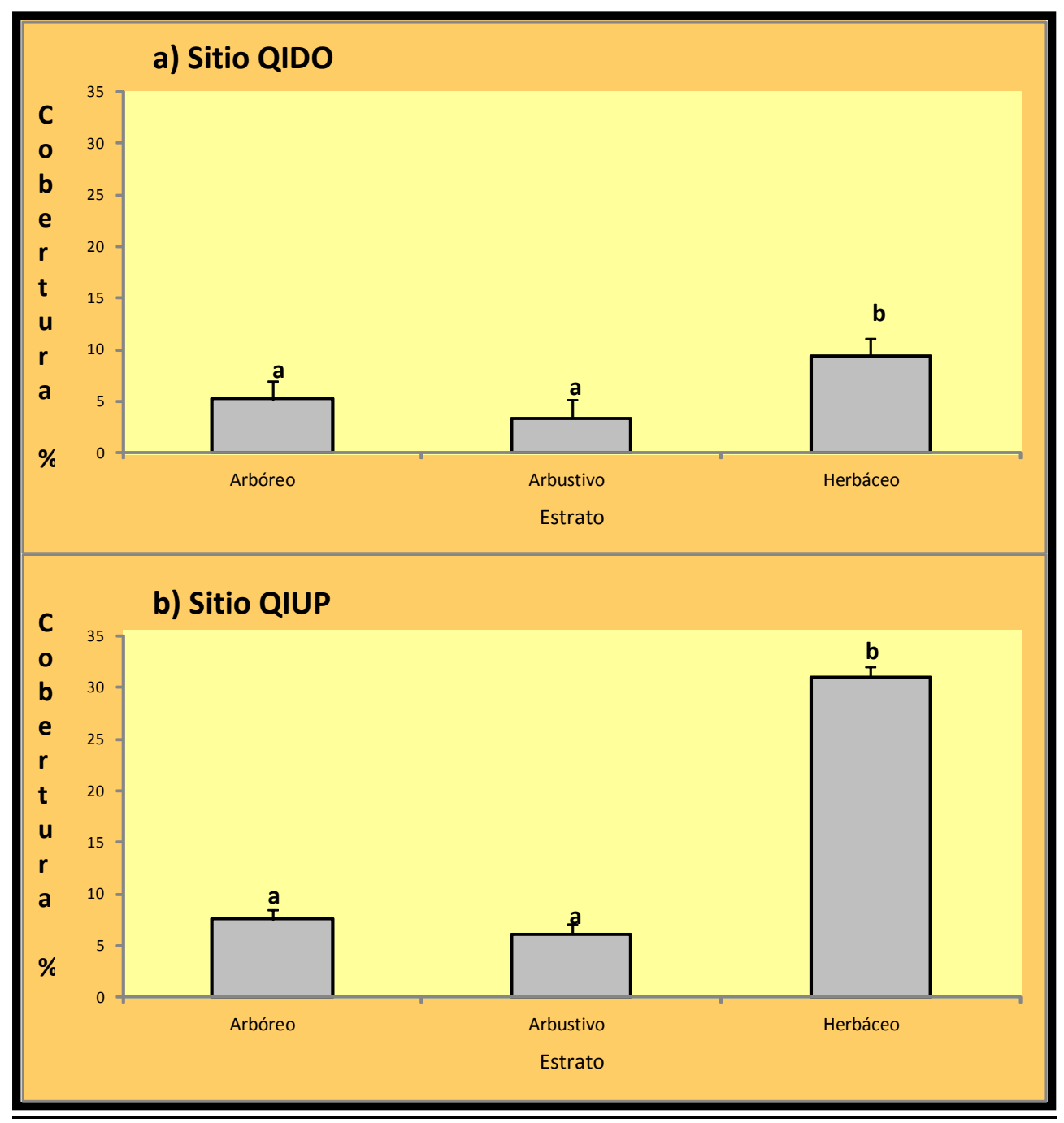

Fig. 4.10: Cobertura relativa de los estratos muestreados en los sitios QIDO (a) e QIUP (b). Las letras diferentes indican diferencias significativas entre los estratos $(p<0,05)$.

En los estratos arbóreo y arbustivo del sitio QIUP, las especies exóticas $(12,33 \% \pm 15,42$ y $6,46 \% \pm 7,80$, respectivamente) tuvieron mayor cobertura que las especies nativas $(6,46 \% \pm 5,03$, T-t $p<0,05$ y 2,0\% $\pm 0,1$, T-t $p<0,05$, respectivamente) (Fig. 4.11). En el estrato herbáceo solo se observaron especies de origen nativo. En los estratos arbustivo y herbáceo del sitio QIDO, no se observaron diferencias significativas en lo que respecta a la cobertura relativa entre las especies nativas y exóticas $(p>0,05)$, en tanto que en el estrato arbóreo solo se observaron especies nativas (Fig. 4.11). 


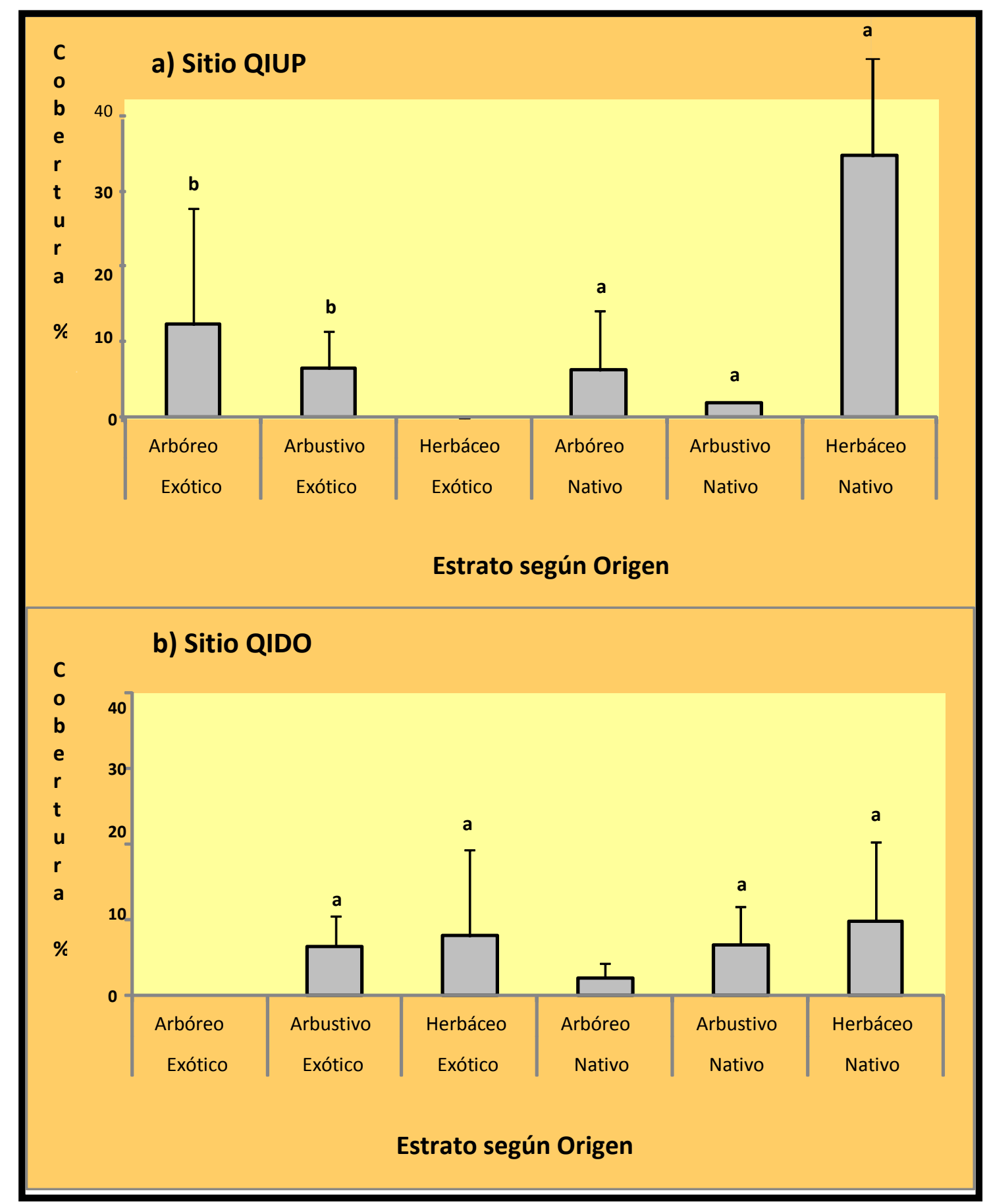

Fig. 4.11: Cobertura relativa de los estratos muestreados según el origen de las especies presentes en los sitios QIUP (a) y QIDO (b). Las letras iguales indican que no se encontraron diferencias significativas en los estratos en relación a su origen $(p<0,05)$.

La totalidad de los ñires relevados en ambos sitios (QIDO y QIUP) presentaron estado sanitario 1 (totalmente sano). El DAP de los ñires 
muestreados en los sitios QIDO (media 10,39 cm.; rango 3,50-22,91; d.e. 5,05) y QIUP (media 7,73 cm.; rango 2,86-28,73; d.e. 5,20) difirió significativamente $(F=4,05 ; p<0,05)$.

Se observaron diferencias significativas entre sitios en cuanto a la cobertura relativa de los diferentes estratos ( $F=11,78 ; p<0,0001)$, presentando el estrato herbáceo mayor cobertura en el sitio QIUP $(31,00 \% \pm 20,27)$ que en el sitio QIDO $(9,38 \% \pm 9,75$; T-t $p<0,05)$ (Fig.4.12), en tanto que la cobertura de los estratos arbustivo y arbóreo de ambos sitios no difirió significativamente ( $p>0,05$; Fig. 4.12). Las diferencias entre los estratos de ambos sitios no se debieron a la composición de especies de acuerdo a su origen (nativa o exótica) $(p>0,05)$.

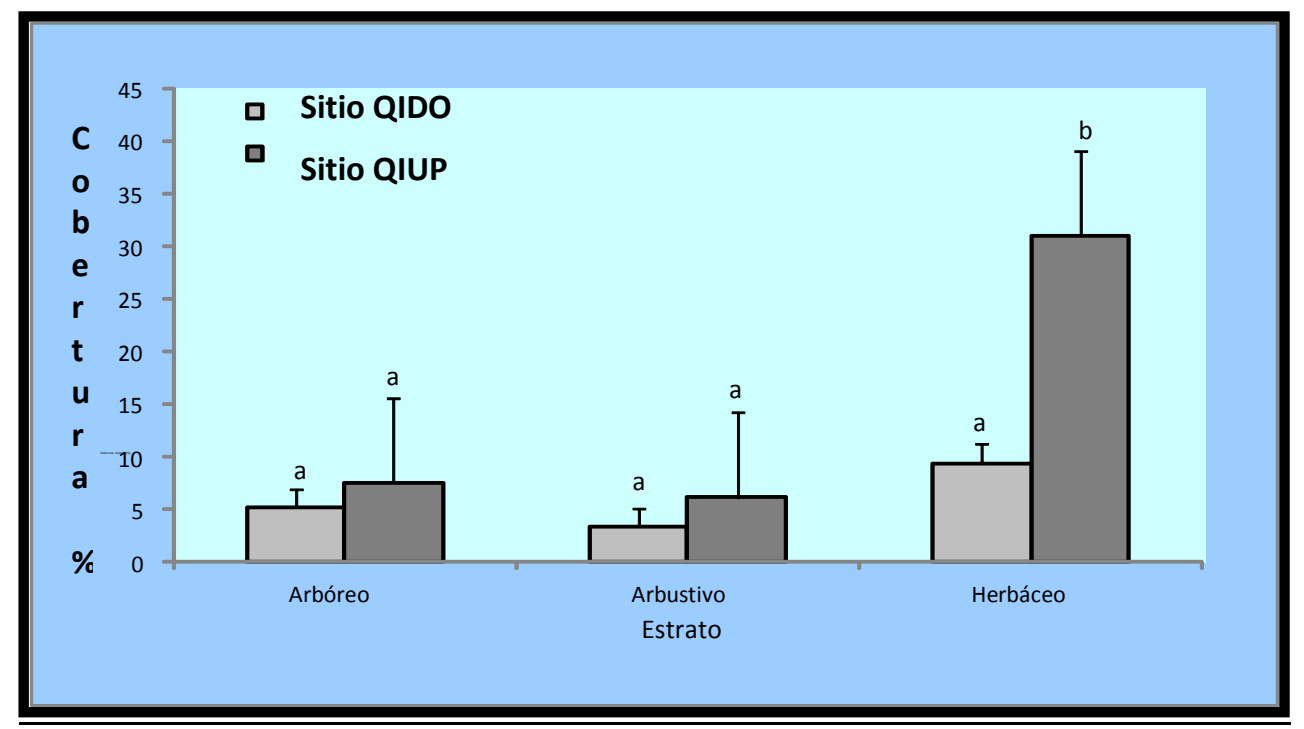

Fig. 4.12: Cobertura de estratos en los sitios QIUP y QIDO. Las letras diferentes indican que se encontraron diferencias significativas entre los estratos en los sitios muestreados $(p<0,05)$.

La riqueza, diversidad y dominancia de especies en ambos sitios (QIDO y QIUP) no difirieron significativamente ( $p>0,05$; Tabla 4.4).

Tabla 4.4: Riqueza, Dominancia y Diversidad de especies registrada en los sitios QIDO e QIUP. Los valores son expresados como media \pm desvío estándar y rango entre paréntesis. 


\begin{tabular}{|l|c|c|c|}
\hline & QIDO & QIUP & p \\
\hline Riqueza & $2,51 \pm 2,06(0,32-7,68)$ & $3,38 \pm 4,2(0,32-12,68)$ & $\mathrm{p}=0,3776$ \\
\hline Dominancia & $0,02 \pm 0,03(0-0,12)$ & $0,06 \pm 0,1(0-0,32)$ & $\mathrm{p}=0,1009$ \\
\hline Diversidad & $0,19 \pm 0,15(0-0,37)$ & $0,220,06(0-0,77)$ & $\mathrm{p}=0,3721$ \\
\hline
\end{tabular}

\subsubsection{Nirantales con Extracción de Leña por Parquizado}

(PAPI y PARO)

En el sitio PAPI, el estrato arbóreo estuvo dominado por Ñire y por Lomatia hirsuta, en tanto que en el arbustivo predominó Schinus patagonicus, y en el herbáceo lo hicieron Stipa sp. y Taraxacum officinale (ver Anexo). En el estrato arbóreo del sitio PARO predominó el Ñire, en tanto que en el estrato arbustivo Schinus patagonicus fue la especie dominante y en el herbáceo prevalecieron Stipa sp., Taraxacum officinale $y$ Bromus sp. (Ver Anexo). En el sitio PARO la cobertura relativa de los estratos difirió significativamente $(F=8,46 ; p<0,001)$, presentando el estrato arbóreo $(42,82 \% \pm 24,40)$ mayor cobertura que los estratos arbustivos $(10,25 \% \pm 14,87$; T-t $\mathrm{p}<0,01)$ y herbáceo $(14,5 \% \pm 13,67 ; \mathrm{T}$-t $\mathrm{p}<0,05)$ (Fig. 4.13). Si bien las diferencias en las coberturas de los diferentes estratos en el sitio PAPI no fueron significativas $(F=1,54 ; p=0,0536)$, los estratos arbóreos $(19,72 \%$ $\pm 22,64)$ y herbáceo $(17,35 \% \pm 16,93$; T-t $p<0,05)$ presentaron mayor cobertura que el estrato arbustivo $(4,85 \% \pm 4,64$; T-t $\mathrm{p}<0,01)$ (Fig. 4.13), característica propia de los ñirantales en parque. 


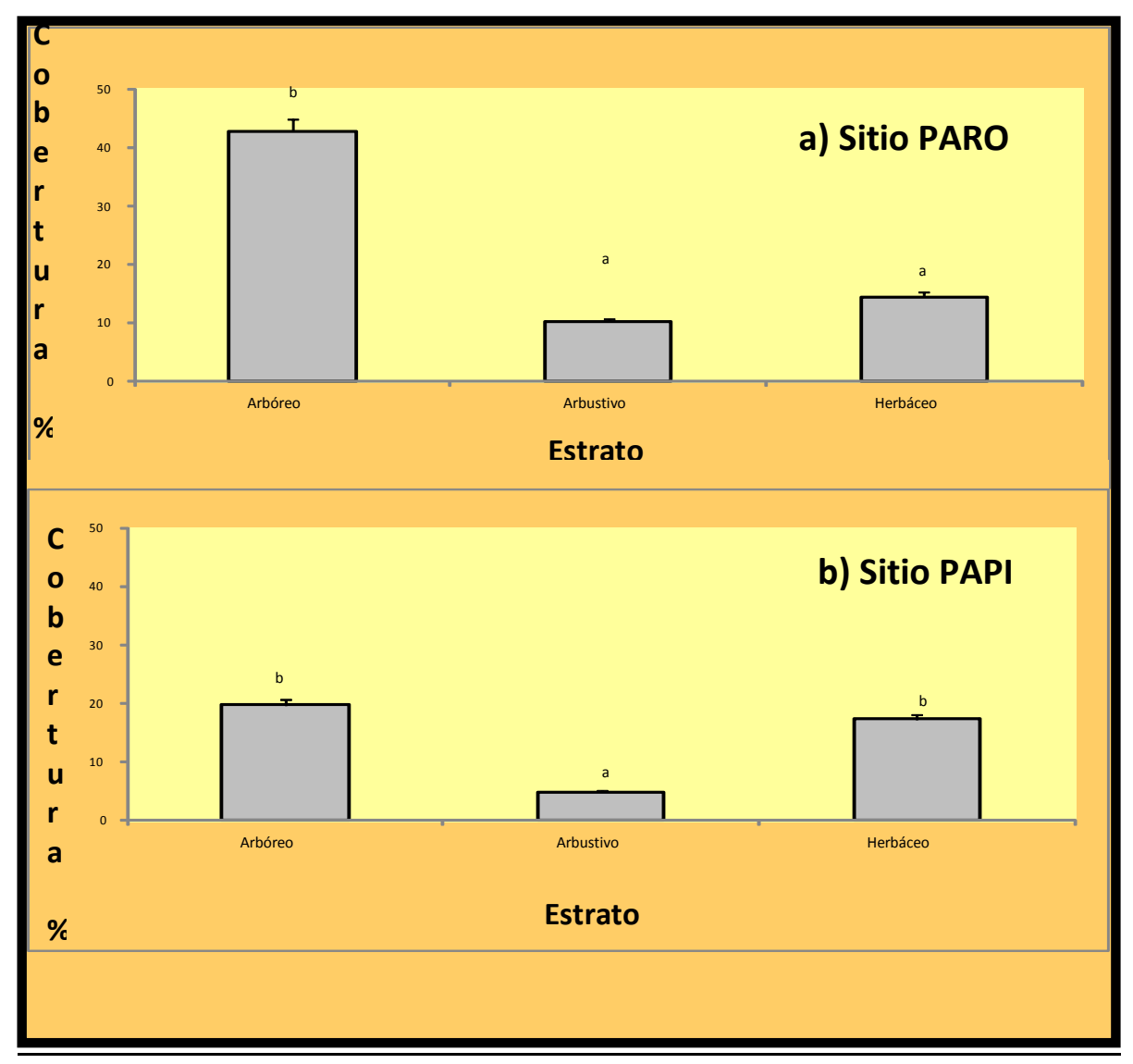

Fig. 4.13: Cobertura relativa de los estratos muestreados en los sitios PARO (a) y PAPI (b). Las letras expresan que se encontraron diferencias significativas entre los estratos $(p<0,05)$.

En el sitio PARO, las especies nativas $(16,81 \% \pm 14,16)$ del estrato herbáceo presentaron mayor cobertura que las exóticas $(10,8 \%$ $\pm 12,65$; T-t $p<0,05)$, en tanto que solo se observaron especies nativas en los estratos arbóreo y arbustivo (Fig. 4.14). Del mismo modo, en el sitio PAPI, las especies nativas $(18,94 \% \pm 18,89)$ del estrato herbáceo tuvieron mayor cobertura que las exóticas $(12,83 \% \pm 9,28 ; \mathrm{T}$-t $\mathrm{p}<0,05)$. $Y$ en los estratos arbóreos solo se observaron especies nativas (Fig. 4.14). 


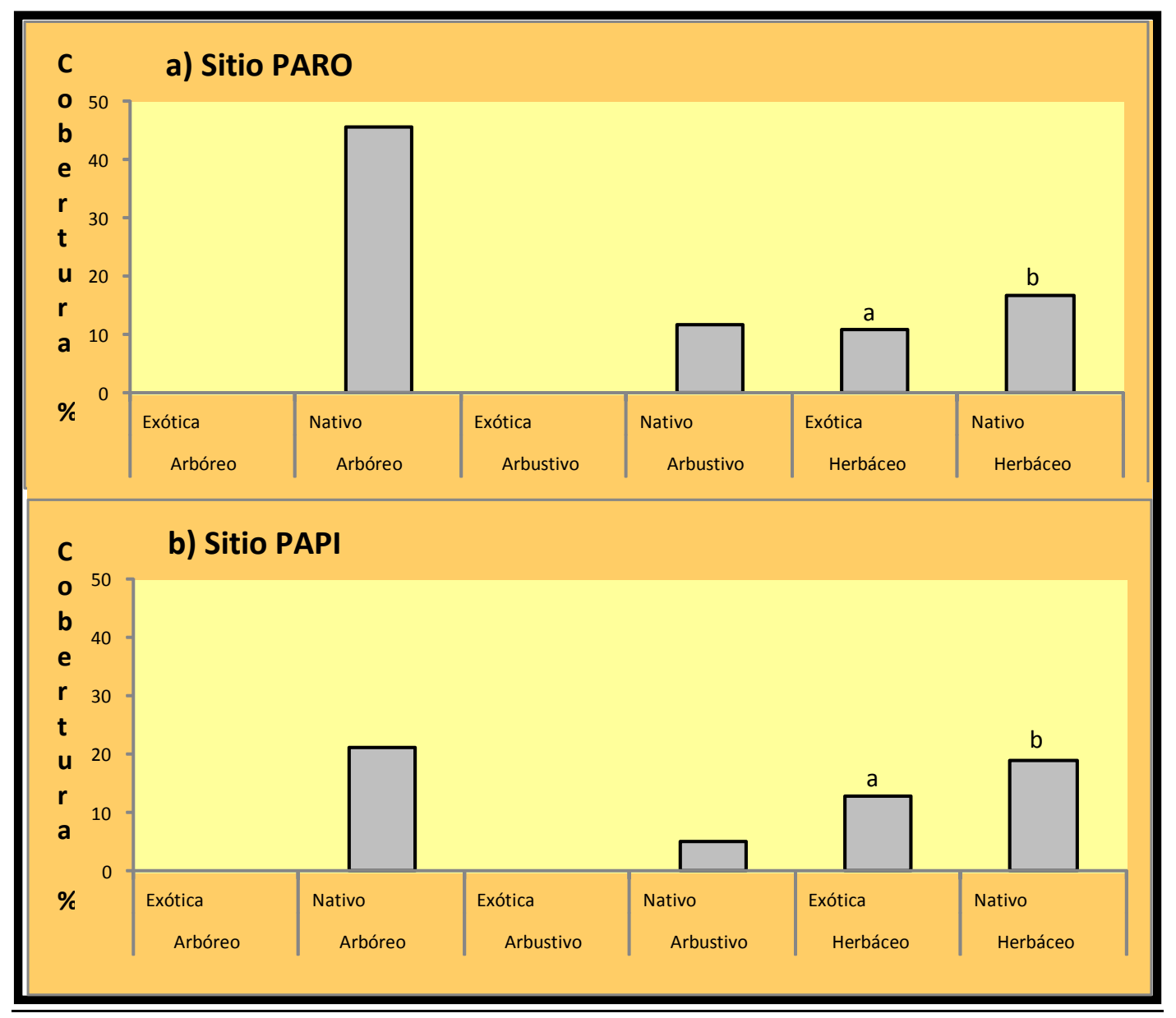

Fig. 4.14: Cobertura relativa de los estratos muestreados según el origen en los sitios PARO (a) y PAPI (b) Las letras diferentes indican que se encontraron diferencias significativas entre los estratos en relación a su origen $(p<0,05)$.

En ambos sitios, la totalidad de los ñires muestreados se encontraban totalmente sanos (estado sanitario 1). En el sitio PARO, el DAP (media 32,12 cm.; rango 6,68-89,10; d.e. 21,29) de los ñires fue mayor que en el sitio PAPI (media 28,84 cm.; rango 0,64-61,10; d.e. $18,19)$, aunque las diferencias no fueron estadísticamente significativas $(p>0,05)$.

La cobertura de los estratos muestreados difirió significativamente entre sitios $(F=7,01 ; p<0,01)$, presentando los estratos arbóreos $(42,82 \% \pm 24,40)$ y arbustivo $(10,25 \% \pm 14,87)$ del sitio PARO mayor cobertura que los de PAPI $(19,72 \% \pm 22,64$; T-t $p<0,01$ y 4,86\% $\pm 4,64$; 
T-t $p<0,01$ (respectivamente) (Fig. 4.15). Las diferencias entre los estratos herbáceos no fueron significativas.

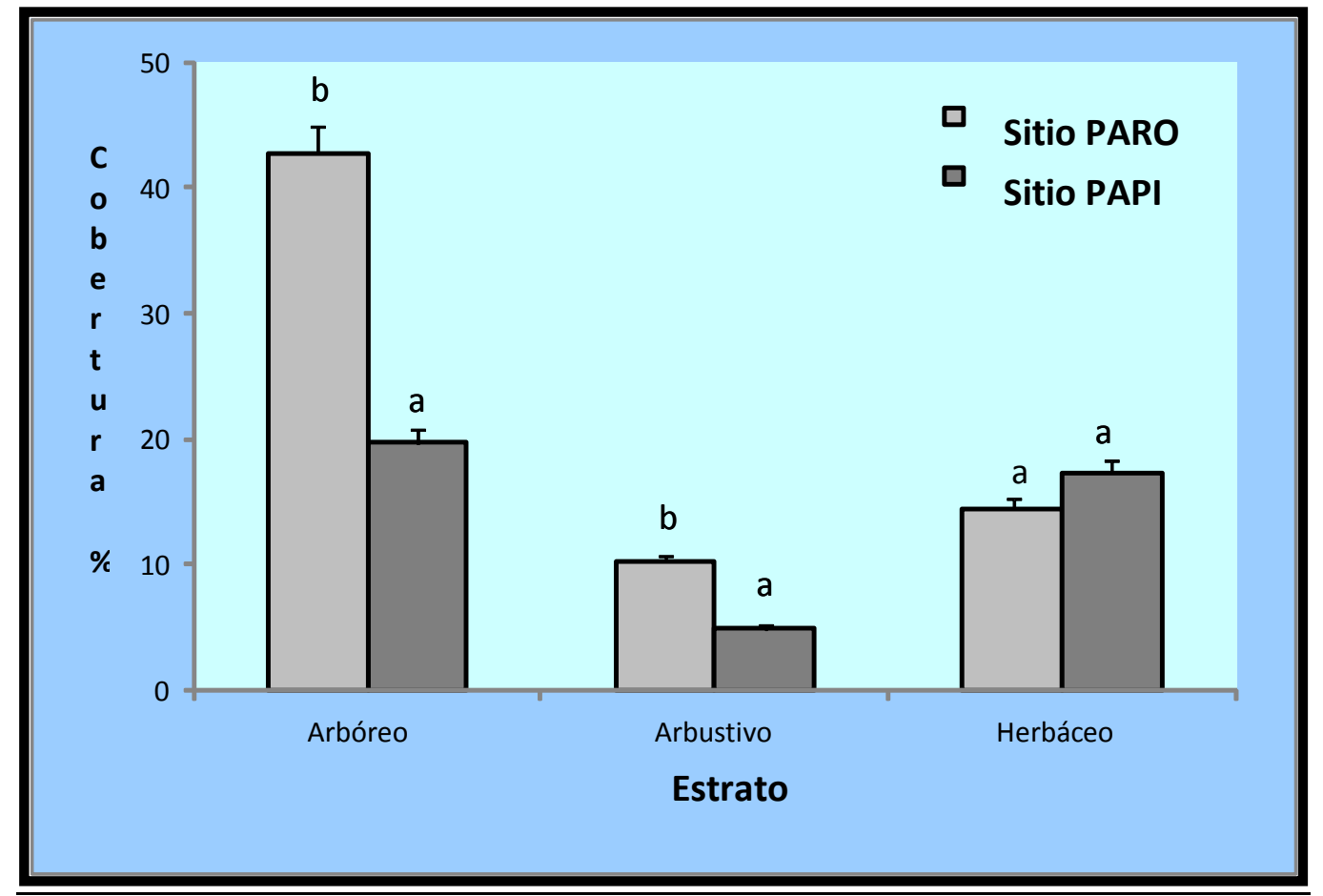

Fig. 4.15: Cobertura relativa de los estratos en los sitios PAPI y PARO. Las letras diferentes indican que se encontraron diferencias significativas entre los estratos en los sitios muestreados $(p<0,05)$.

Al analizar las diferencias entre los estratos de ambos sitios de muestreo, no se observaron diferencias significativas $(p>0,05)$ en cuanto al origen de las especies.

No se observaron diferencias significativas entre los sitios muestreados en cuanto a la riqueza, diversidad y dominancia de especies (Tabla 4.5). 
Tabla 4.5: Riqueza, Dominancia y Diversidad de especies registrada en los sitios PARO y PAPI. Los valores son expresados como media \pm desvío estándar y rango entre paréntesis.

\begin{tabular}{|l|c|c|c|}
\hline & PAPI & PARO & P \\
\hline \multirow{2}{*}{ Riqueza } & $\begin{array}{c}3,33 \pm 4,01 \\
(3,32-16,68)\end{array}$ & $\begin{array}{c}3,19 \pm 3,34 \\
(0,62-15,62)\end{array}$ & $\mathrm{p}=0,1978$ \\
\hline \multirow{2}{*}{ Dominancia } & $\begin{array}{c}0,05 \pm 0,34 \\
(0-0,27)\end{array}$ & $\begin{array}{c}3,33 \pm 4,01 \\
(0,01-1,31)\end{array}$ & $\mathrm{p}=0,7095$ \\
\hline \multirow{2}{*}{ Diversidad } & $0,24 \pm 0,12$ & $\begin{array}{c}0,23 \pm 0,12 \\
(0,15-0,37)\end{array}$ & $\mathrm{p}=0,3678$ \\
& $(0-0,37)$ & & \\
\hline
\end{tabular}

4.1.6

Ñirantales Primarios

(PRPI y PRJO)

Con respecto al sitio PRPI, el estrato arbóreo estuvo dominado por Ñire $y$ en segundo lugar por Maitén (Maytenus boaria), en tanto que en el estrato arbustivo predominaron Ribes sp. y Schinus patagonicus, y en el herbáceo lo hicieron Bromus sp. y Stipa sp. (Ver Anexo). En tanto que en el sitio PRJO, el estrato arbóreo también tuvo como especie dominante también al Ñire ( $N$. antarctica) y al Maitén ( $M$. boaria), en el estrato arbustivo predominó $S$. patagonicus, y en el herbáceo $T$. officinale y Stipa sp. (Ver Anexo).

Tanto en PRPI $(F=8,62 ; p<0,001)$ como en PRJO ( $F=13,52$; $p<0,0001$ ) se observaron diferencias significativas en cada uno con respecto a la cobertura relativa de los estratos, presentando el estrato arbóreo $(31,28 \% \pm 21,23$ y $35,35 \% \pm 36,17$, respectivamente) mayor cobertura que los estratos arbustivos $(14,12 \% \pm 18,41$, T-t $p<0,05$ y $8,45 \% \pm 11,24, p<0,05$, respectivamente) y herbáceo $(9,10 \% \pm 14,51$, T-t $p<0,05$ y $8,38 \% \pm 5,59, p<0,05$, respectivamente) (Fig. 4.16). 


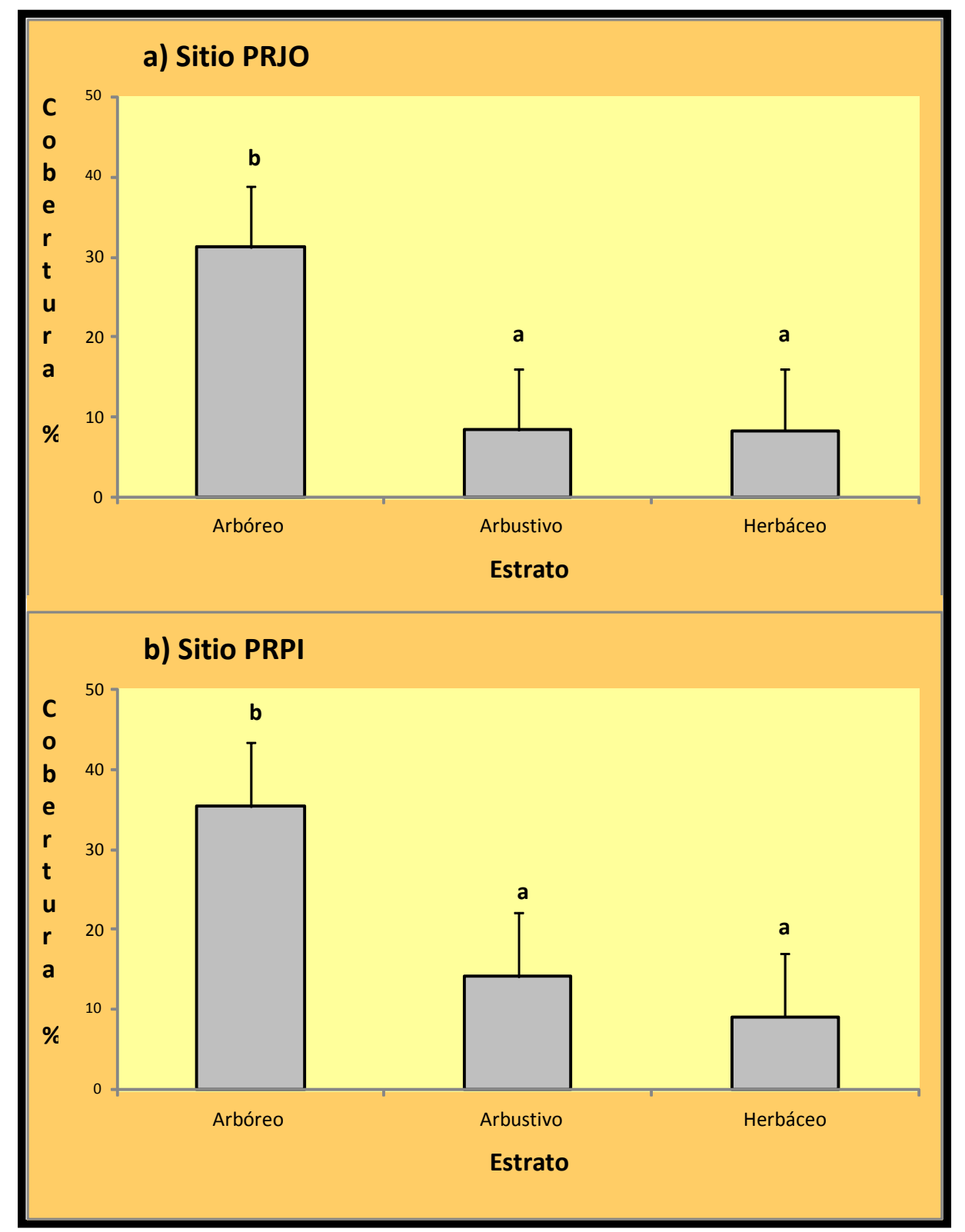

Fig.4.16: Cobertura relativa de los estratos muestreados en los sitios PRJO (a) y PRPI (b). Las letras diferentes indican diferencias significativas entre los estratos $(p<0,05)$.

En el estrato herbáceo del PRJO no se observaron diferencias significativas en cuanto a la cobertura relativa de las especies nativas y exóticas ( $p>0,05$, Fig. 4.17), en tanto que en los estratos arbustivo y arbóreo de dicho sitio solo se observaron especies nativas. En el estrato herbáceo del sitio PRPI, la cobertura relativa de especies nativas $(10,76 \% \pm 15,74)$ fue mayor que la de las exóticas $(2,17 \% \pm 1,60 ; \mathrm{T}$-t 
$p<0,05$ ) (Fig. 4.17) y, al igual que lo observado en PRJO, en los estratos arbóreo y arbustivo solo se visualizaron especies nativas.

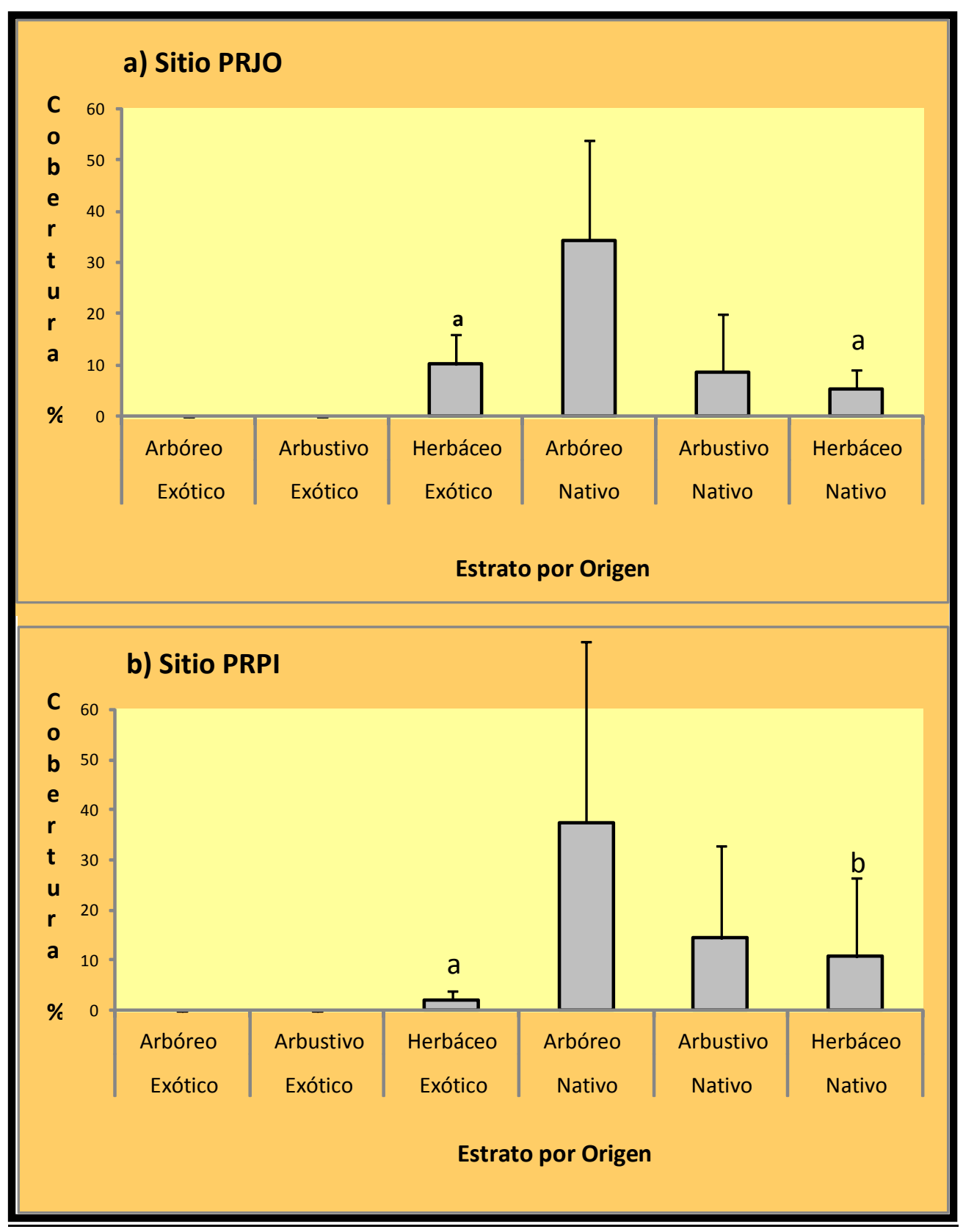

Fig. 4.17: Cobertura relativa de los estratos muestreados según el origen en los sitios PRJO (a) y PRPI (b) Las letras diferentes indican diferencias significativas en los estratos en relación a su origen $(p<0,05)$.

En el sitio PRJO predominaron los ñires de excelente estado sanitario correspondientes al Nivel $1(30 \%)$, seguidos por los ñires de 
estado sanitario $2(25 \%)$ y, en tercer lugar los de nivel sanitario 5 (25\%) (Fig. 4.18). En PRPI también predominaron los ñires con muy buen estado sanitario (nivel $1,36,66 \%$ ), pero estos fueron seguidos en abundancia por árboles con estado sanitario 5 (26,66\%) y, 3 (20\%). Las diferencias en el estado sanitario de los ñires de ambos sitios no fueron significativas $(p>0,05)$. Si bien las diferencias no fueron estadísticamente significativas ( $p>0,05)$, el DAP de los ñires de PRPI (media 21,13 cm.; rango 6,05-38,82; d.e. 8,96) fue mayor que el de los de PRJO (media 17,93 cm.; rango 3,50-45,50; d.e. 9,62) (Fig. 4.18).

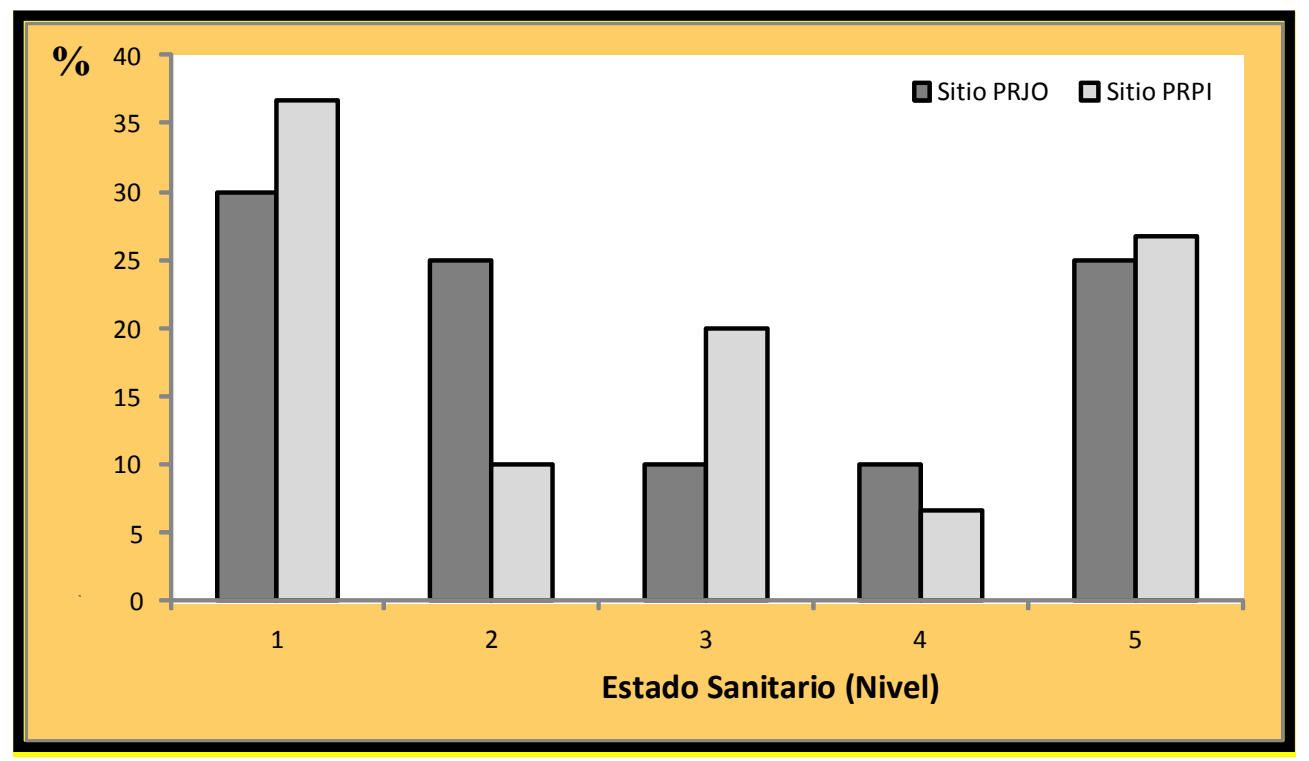

Fig. 4.18: Estado sanitario de los ñires muestreados en los sitios PRJO y PRPI.

Al comparar la cobertura de ambos sitios de los estratos herbáceo, arbustivo y arbóreo de los sitios PRPI y PRJO no se encontraron diferencias significativas ( $p>0,05$; Fig. 4.19). Finalmente, al comparar la riqueza, diversidad y dominancia de especies no se observaron diferencias significativas entre ambos sitios (Tabla 4.6). 


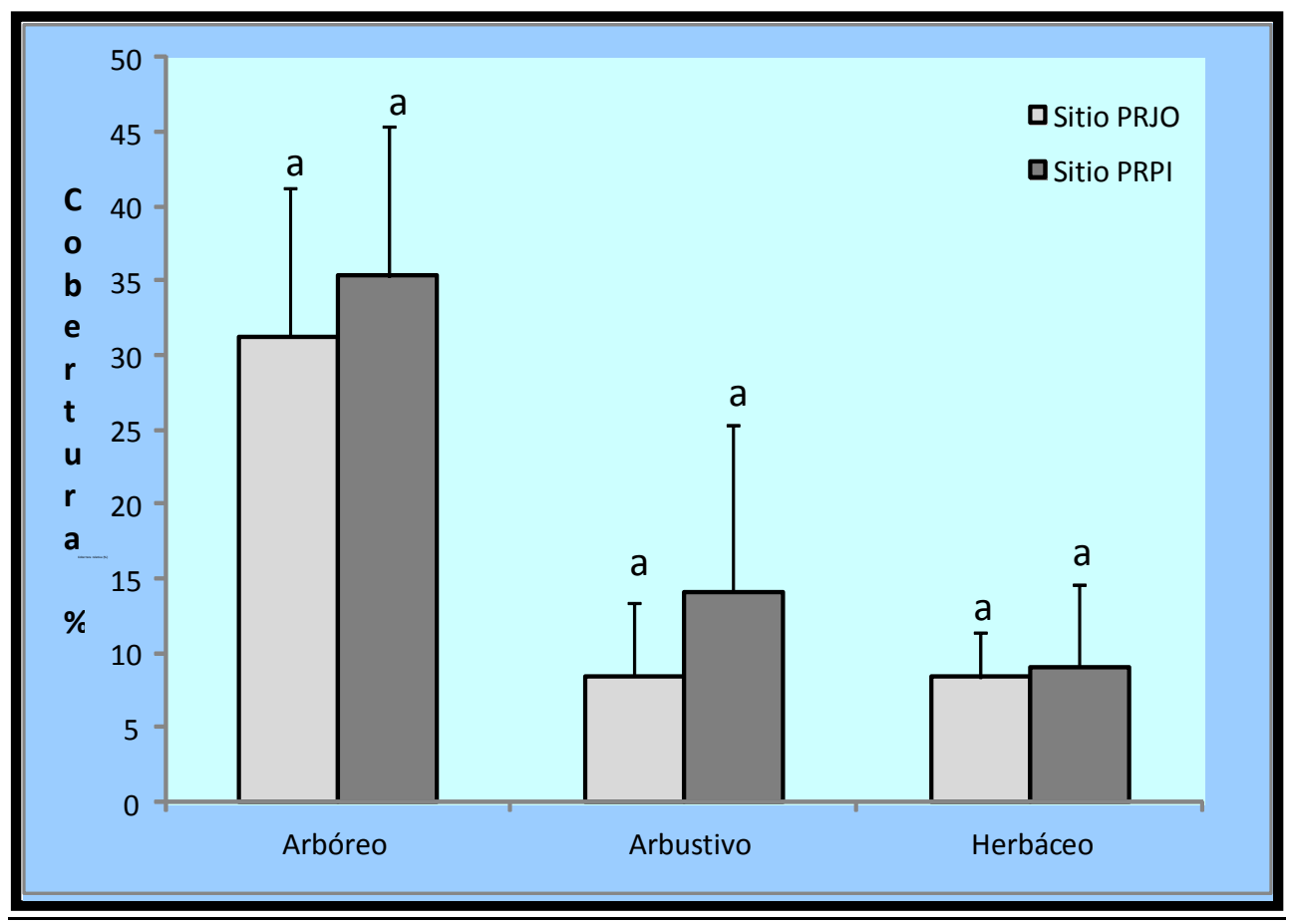

Fig. 4.19: Cobertura relativa de los estratos en los sitios PRJO y PRPI. Las letras iguales indican que no se encontraron diferencias significativas entre los estratos en sitios muestreados $(p>0,05)$.

Tabla 4.6: Riqueza, Dominancia y Diversidad de especies registrada en los sitios PRJO y PRPI. Los valores son expresados como media \pm desvío estándar y rango entre paréntesis.

\begin{tabular}{|l|c|c|c|}
\hline & PRJO & PRPI & p \\
\hline Riqueza & $0,21 \pm 0,15(0,06-0,56)$ & $0,17 \pm 0,05(0,04-0,61)$ & $p=0,2385$ \\
\hline Dominancia & $0,28 \pm 0,07(0,16-0,37)$ & $0,25 \pm 0,06(0,14-0,37)$ & $p=0,2220$ \\
\hline Diversidad & $0,07 \pm 0,1\left(3,1 \times 10^{-3}-0,31\right)$ & $0,05 \pm 0,1\left(1,9 \times 10^{-3}-0,37\right)$ & $p=0,6798$ \\
\hline
\end{tabular}

\section{2 - Comparación entre sitios con diferentes usos}

En base al análisis estadístico, a continuación, se desarrollan los resultados obtenidos del estudio de los ñirantales sometidos a diferentes usos, siendo las variables analizadas las siguientes: cobertura relativa de cada uno de los estratos, riqueza específica, diversidad, equitatividad, nivel de sanidad, diámetro a la altura del pecho (DAP) y transitabilidad. 


\subsubsection{Cobertura Relativa}

\section{Estrato herbáceo}

La mayor cobertura del estrato herbáceo se registró en los sitios convertidos a pasturas (PAPE $24,13 \% \pm 18,82$; T-t $\mathrm{p}<0,05$ y PAGA $31,00 \% \pm 33,47$; T-t $p<0,05$ ) (ver Tabla 4.7 y Fig. 4.20 ) y le siguieron en importancia los sitios con extracción de leña por parquizado. La cobertura del estrato herbáceo fue similar en los ñirantales primarios, los quemados hace 15 y 25 años y en los que se realizó extracción de leña por manchones $(p>0,05)$. Las diferencias observadas entre los estratos de los sitios de muestreo no se debieron a diferencias en la composición de especies de acuerdo a su origen $(p>0,05)$.

Tabla 4.7: Cobertura (media y desvío estándar (D.E.)) del estrato herbáceo de cada sitio de muestreo. Las letras diferentes indican que se encontraron diferencias significativas en los estratos muestreados entre los sitios $(p<0,05)$.

\begin{tabular}{|c|c|c|c|}
\hline Estrato & Sitio & $\begin{array}{c}\text { Media } \pm \\
\text { D.E. }\end{array}$ & $\begin{array}{c}\text { Nivel de } \\
\text { Significación }\end{array}$ \\
\hline Herbáceo & QGDO & $17,18 \pm 9,72$ & $\mathrm{a}$ \\
\hline Herbáceo & QGUP & $11,76 \pm 25,03$ & $\mathrm{a}$ \\
\hline Herbáceo & QIDO & $9,38 \pm 9,75$ & $\mathrm{a}$ \\
\hline Herbáceo & PRJO & $8,38 \pm 5,59$ & $\mathrm{a}$ \\
\hline Herbáceo & PRPI & $9,1 \pm 14,51$ & $\mathrm{a}$ \\
\hline Herbáceo & TUUP & $9,82 \pm 14,46$ & $\mathrm{a}$ \\
\hline Herbáceo & PARO & $14,5 \pm 13,67$ & $\mathrm{a}$ \\
\hline Herbáceo & PAPI & $17,35 \pm 16,93$ & $\mathrm{a}$ \\
\hline Herbáceo & TUDO & $9,12 \pm 14,46$ & $\mathrm{a}$ \\
\hline Herbáceo & QIUP & $9,10 \pm 14,51$ & $\mathrm{a}$ \\
\hline Herbáceo & PAPE & $24,13 \pm 18,82$ & $\mathrm{~b}$ \\
\hline Herbáceo & PAGA & $31,00 \pm 33,47$ & $\mathrm{~b}$ \\
\hline
\end{tabular}




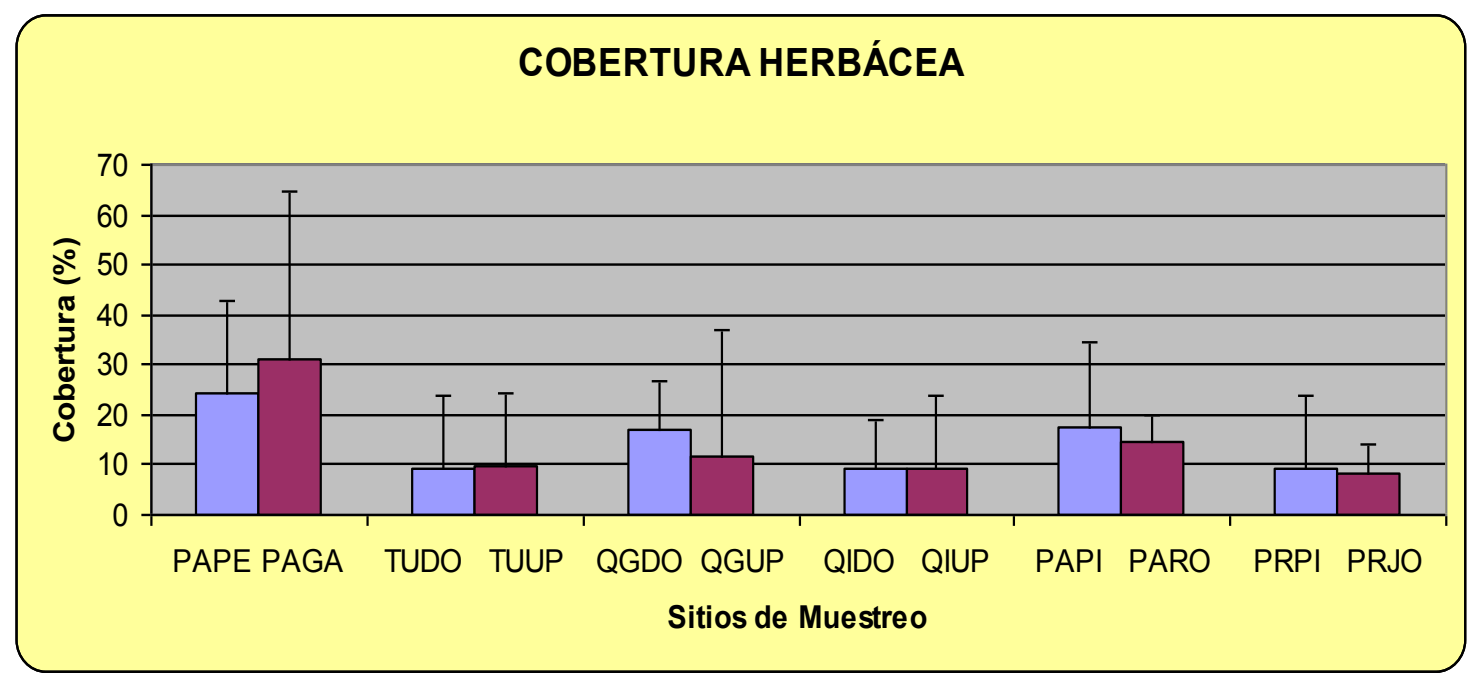

Fig. 4.20: Cobertura relativa herbácea de los diferentes sitios según usos de los ñirantales

\section{Estrato arbustivo}

La mayor cobertura del estrato arbustivo se observó en los sitios PRJO $(14,42 \% \pm 18,49 ; \mathrm{T}-\mathrm{t} \mathrm{p}<0,05)$, TUUP $(10,80 \% \pm 11,73 ; \mathrm{T}$-t $\mathrm{p}<0,05)$, PARO $(10,25 \% \pm 14,87 ;$ T-t $\mathrm{p}<0,05)$ y PRPI $(8,45 \% \pm 11,24 ; \mathrm{T}$-t $\mathrm{p}<0,05)$ (ver Tabla 4.8 y Fig.4.21).

Tabla 4.8: Cobertura (media y desvío estándar (D.E.)) del estrato arbustivo de cada sitio de muestreo. Las letras diferentes indican que se encontraron diferencias significativas en los estratos muestreados entre los sitios $(p<0,05)$.

\begin{tabular}{|c|c|c|c|}
\hline Estrato & Sitio & $\begin{array}{c}\text { Media } \pm \\
\text { D.E. }\end{array}$ & $\begin{array}{c}\text { Nivel de } \\
\text { Significación }\end{array}$ \\
\hline Arbustivo & QGDO & $7,08 \pm 5,82$ & $\mathrm{a}$ \\
\hline Arbustivo & QIDO & $3,36 \pm 5,28$ & $\mathrm{a}$ \\
\hline Arbustivo & QGUP & $4,25 \pm 4,28$ & $\mathrm{a}$ \\
\hline Arbustivo & PAPI & $4,85 \pm 4,64$ & $\mathrm{a}$ \\
\hline Arbustivo & PAGA & $4,5 \pm 6,40$ & $\mathrm{a}$ \\
\hline Arbustivo & PAPE & $8,67 \pm 10,97$ & $\mathrm{a}$ \\
\hline Arbustivo & QIUP & $6,12 \pm 7,76$ & $\mathrm{a}$ \\
\hline Arbustivo & TUDO & $9,87 \pm 10,29$ & $\mathrm{a}$ \\
\hline Arbustivo & TUUP & $10,80 \pm 11,73$ & $\mathrm{~b}$ \\
\hline Arbustivo & PARO & $10,25 \pm 14,87$ & $\mathrm{~b}$ \\
\hline Arbustivo & PRJO & $14,12 \pm 18,41$ & $\mathrm{~b}$ \\
\hline Arbustivo & PRPI & $8,45 \pm 11,24$ & $\mathrm{~b}$ \\
\hline
\end{tabular}




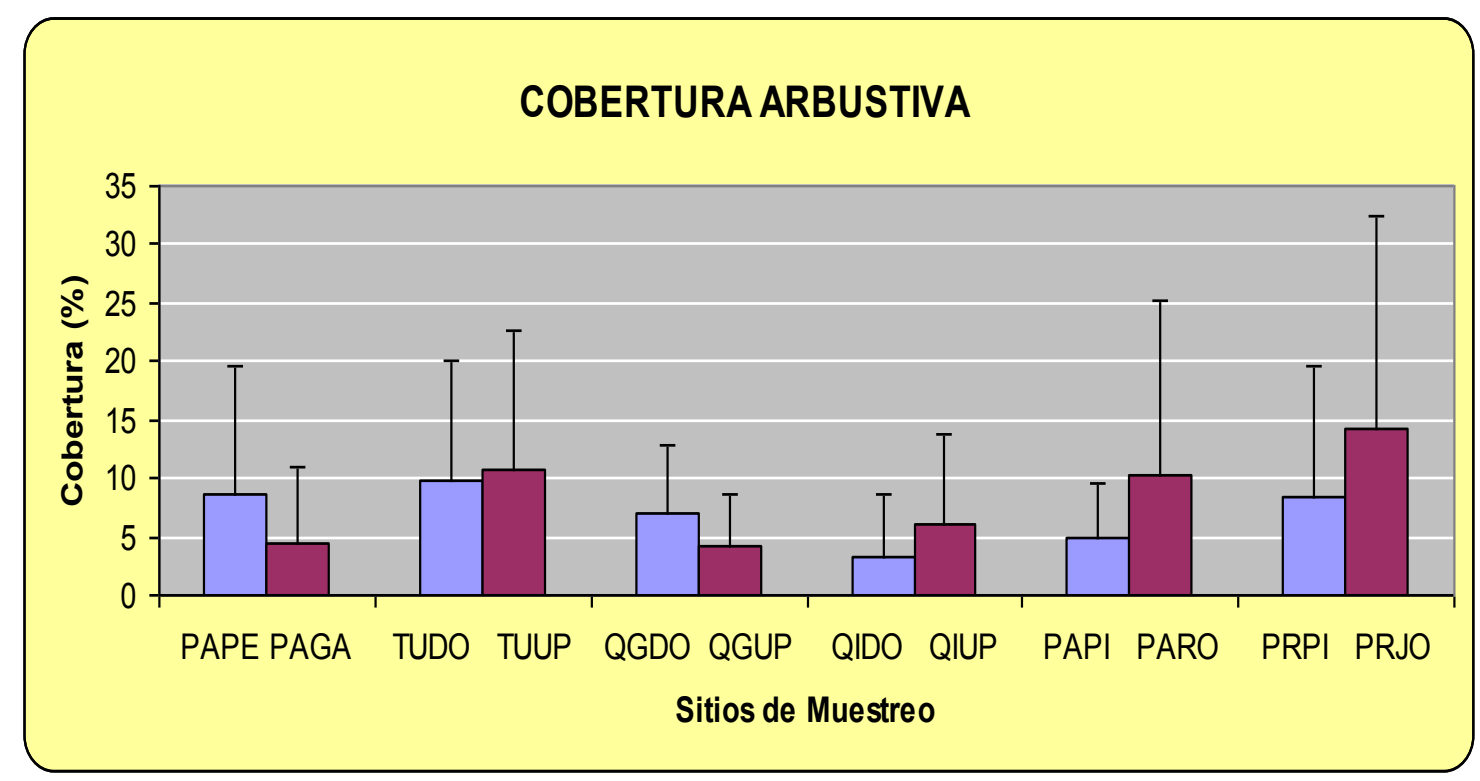

Fig. 4.21: Cobertura relativa arbustiva de los diferentes sitios según usos de los ñirantales

\section{Estrato arbóreo}

La mayor cobertura arbórea fue observada en los bosques primarios o testigos (PRJO 31,28\% $\pm 21,23$; T-t $\mathrm{p}<0,05$ y PRPI $35,35 \% \pm 36,17$; T-t $p<0,05)$ y en uno de los ambientes en los que se extrajo leña por parquizado (PARO 42,82\% $\pm 24,40 ;$ T-t $\mathrm{p}<0,05$ ) (ver Tabla 4.9 y Fig. 4.22). La cobertura relativa de los diferentes estratos no difirió significativamente entre los diferentes sitio de muestreo $(F=5,32$; $p<0,0001)$.

Tabla 4.9: Cobertura (media y desvío estándar (D.E.)) del estrato arbóreo de cada sitio de muestreo. Las letras diferentes indican que se encontraron diferencias significativas en los estratos muestreados entre los sitios $(p<0,05)$.

\begin{tabular}{|c|c|c|c|}
\hline Estrato & Sitio & Media \pm D.E. & $\begin{array}{c}\text { Nivel de } \\
\text { Significación }\end{array}$ \\
\hline Arbóreo & QGDO & $4,92 \pm 2,40$ & $a$ \\
\hline Arbóreo & QGUP & $4,25 \pm 4,28$ & $a$ \\
\hline Arbóreo & QIDO & $5,20 \pm 4,55$ & $a$ \\
\hline Arbóreo & QIUP & $7,56 \pm 8,01$ & $a$ \\
\hline Arbóreo & TUDO & $12,61 \pm 10,52$ & $a$ \\
\hline Arbóreo & PAPI & $19,72 \pm 22,64$ & $a$ \\
\hline Arbóreo & TUUP & $19,92 \pm 18,11$ & a \\
\hline
\end{tabular}




\begin{tabular}{|c|c|c|c|}
\hline Arbóreo & PRJO & $31,28 \pm 21,23$ & $b$ \\
\hline Arbóreo & PRPI & $35,35 \pm 36,17$ & $b$ \\
\hline Arbóreo & PARO & $42,82 \pm 24,40$ & $b$ \\
\hline
\end{tabular}

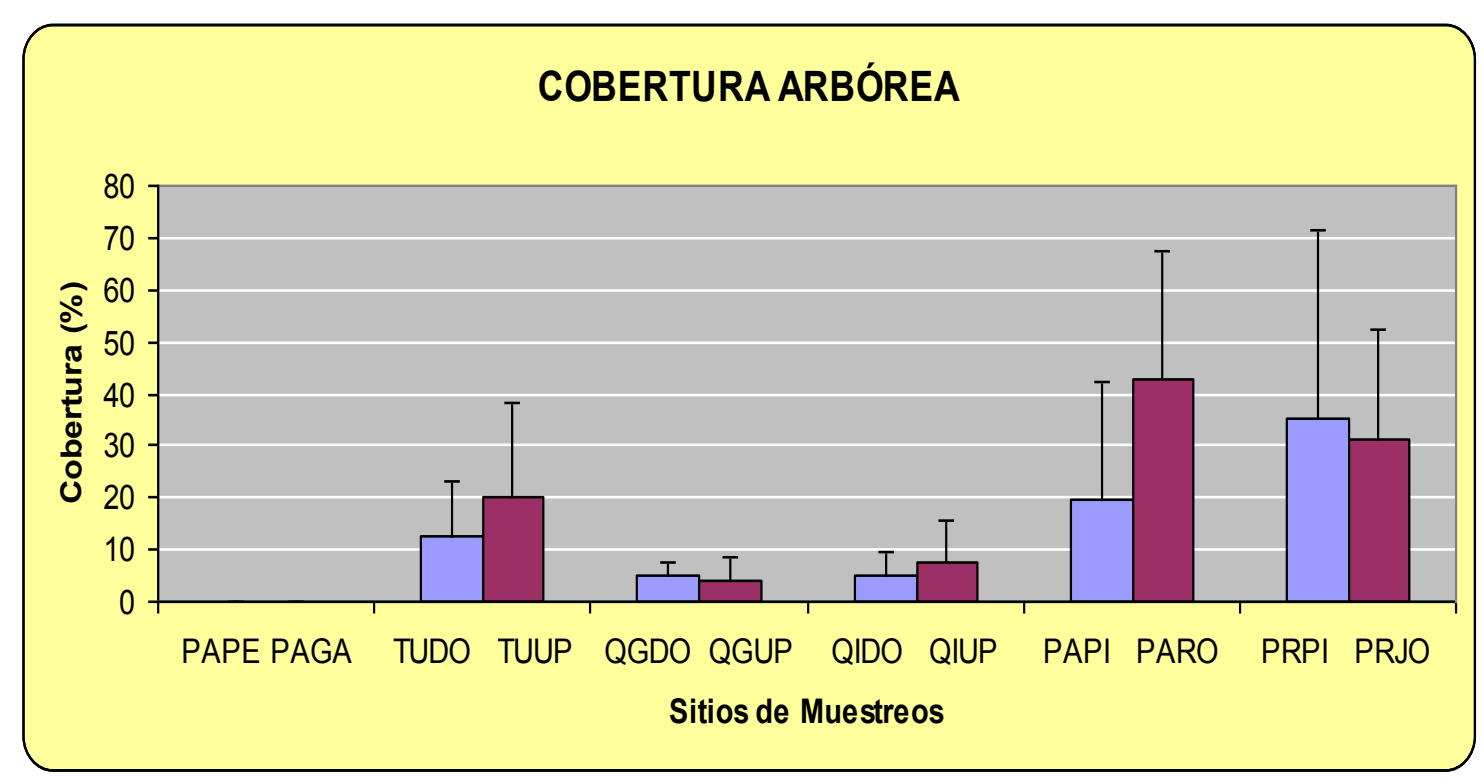

Fig. 4.22: Cobertura arbórea de los diferentes sitios según usos de los ñirantales

\subsubsection{Diámetro a la Altura del Pecho (DAP)}

El DAP de los ñires varió entre los diferentes sitios de muestreo $(F=24,05 ; p<0,0001)$. Los mayores diámetros se observaron en los sitios con extracción de leña por parquizado (PAPI y PARO; T-t $p<0,05$ ) $y$ en los ñirantales primarios (PRPI y PRJO; T-t $p<0,01$ ) y no hubo diferencias significativas entre los individuos de estos sitios. Los ñirantales afectados por incendios (QIUP, QIDO, QGUP y QGDO) presentaron los especímenes con menor diámetro ( $T$ - $t \quad p<0,01)$ (Fig.4.23). 


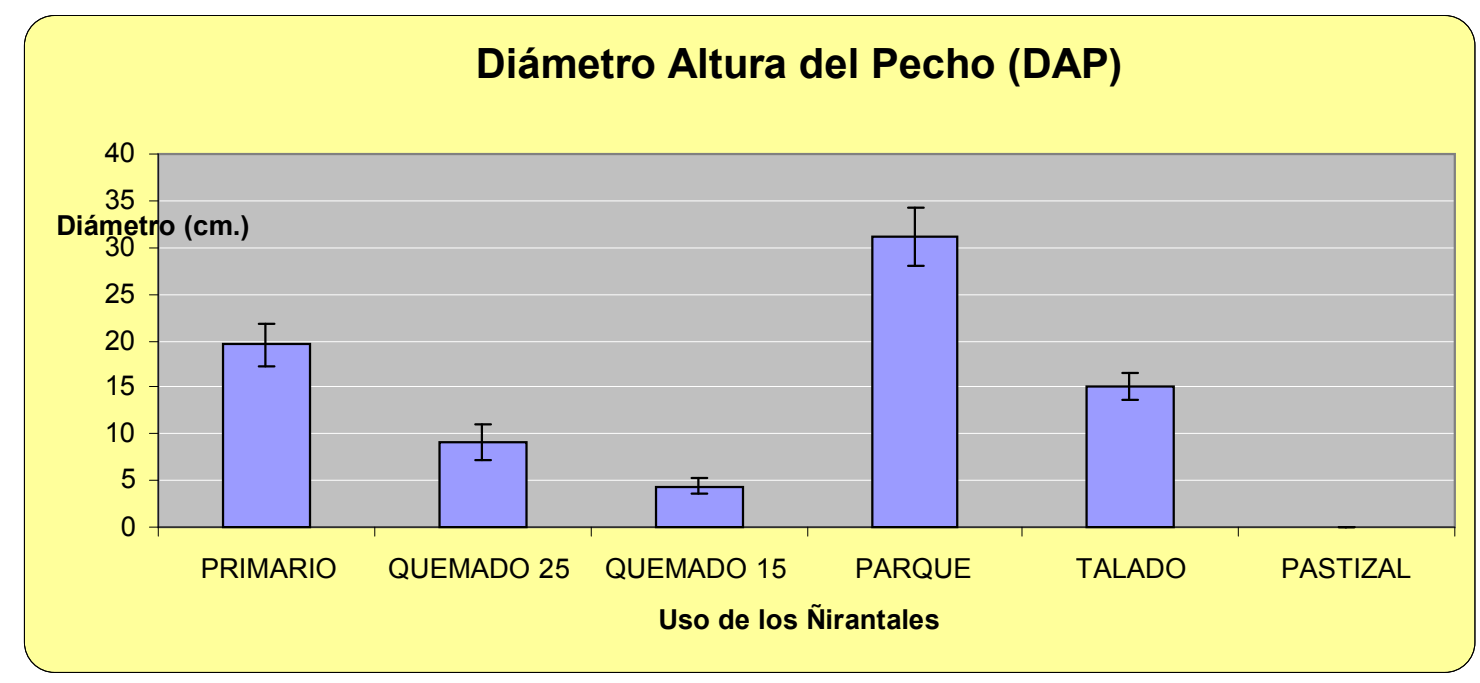

Fig. 4.23: Diámetro altura de pecho (DAP) de los diferentes sitios según usos de los ñirantales.

\subsubsection{Riqueza Específica}

La riqueza de especies varió significativamente entre los sitios de muestreo $(F=3,76 ; p<0,0001)$, observándose los mayores valores en los sitios PRPI y PRJO ( $p<0,0001$ en ambos casos) (Tabla 4.10 y Fig. 24). Los mayores valores se observaron en los ñirantales primarios, seguido por los sitios donde se desarrolló extracción de leña por manchones y por parquizado; la menor riqueza se observó en los ñirantales transformados en pasturas (Fig. 4.24).

Tabla 4.10: Riqueza de especies observadas en los sitios de muestreo. Las letras indican los niveles de significancias entre los sitios de muestreo $(p<0,05)$.

\begin{tabular}{|c|c|c|}
\hline ÍNDICE & Sitio & $\begin{array}{c}\text { Nivel de } \\
\text { Significación }\end{array}$ \\
\hline \multirow{4}{*}{$\begin{array}{c}\text { Riqueza } \\
\text { Específica }\end{array}$} & PAGA y PAPE & $\mathrm{a}$ \\
\cline { 2 - 3 } & QGDO y QGUP & $\mathrm{a}$ \\
\cline { 2 - 3 } & QIDO y QIUP & $\mathrm{a}$ \\
\cline { 2 - 3 } & PAPI y PARO & $\mathrm{b}$ \\
\cline { 2 - 3 } & TUDO y TUUP & $\mathrm{b}$ \\
\cline { 2 - 3 } & PRPI y PRJO & $\mathrm{c}$ \\
\hline
\end{tabular}




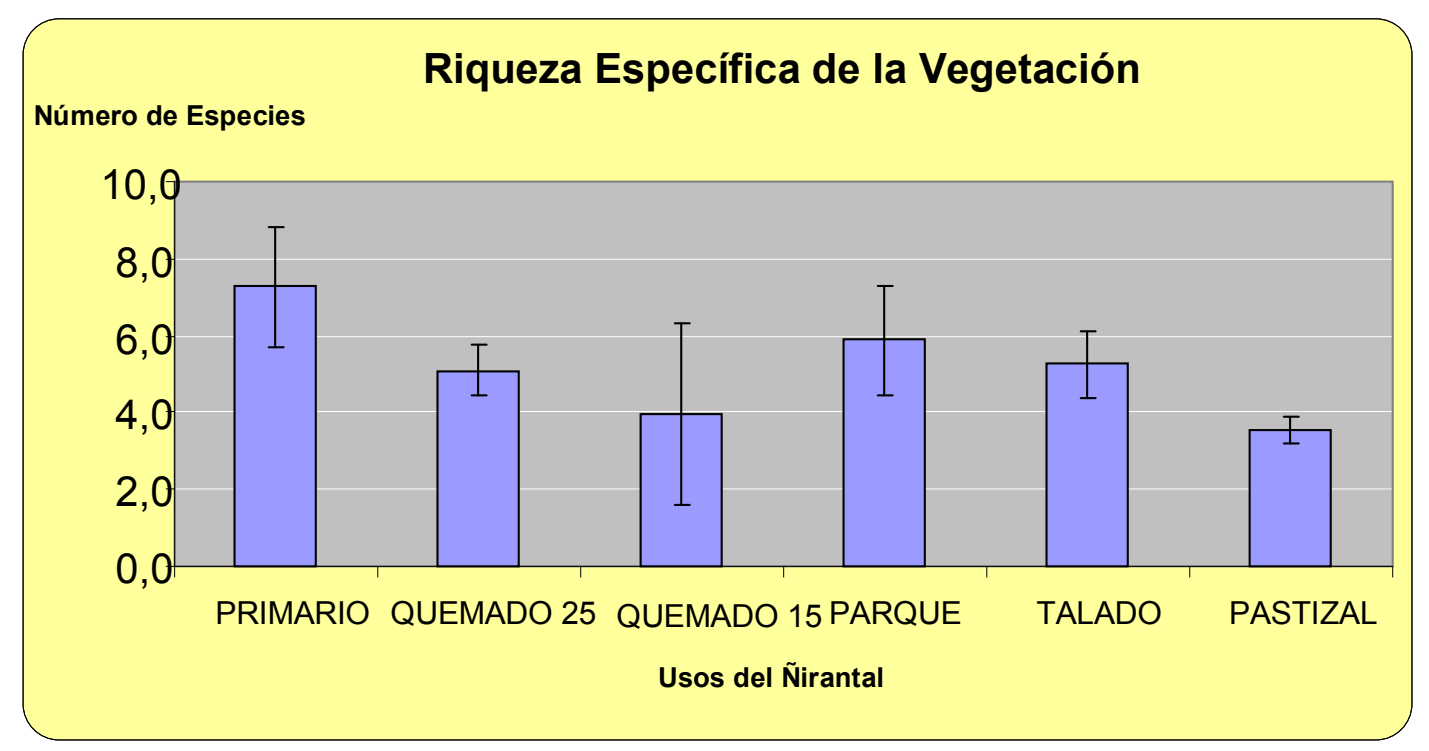

Fig. 4.24: Riqueza específica de la vegetación de los diferentes sitios según usos de los ñirantales.

\subsubsection{Diversidad de Shannon-Wiener}

Tal como ocurriera con la riqueza específica, la mayor diversidad de Shannon-Wiener se observó en los ñirantales primarios y en los afectados por extracción de leña por parquizado, en tanto que los menores valores se observaron en los ñirantales transformados en pasturas (Tabla 4.11). La diversidad entre los sitios no difirió en general significativamente ( $p>0,05)$ (ver Fig. 4.25).

Tabla 4.11: Diversidad observadas en los sitios de muestreo. Las letras indican los niveles de significancias entre los sitios de muestreo $(p<0,05)$.

\begin{tabular}{|c|c|c|}
\hline Índice & Sitio & Nivel de Significación \\
\hline \multirow{4}{*}{ Diversidad } & PAGA y PAPE & $\mathrm{b}$ \\
\cline { 2 - 3 } & QGDO y QGUP & $\mathrm{a}$ \\
\cline { 2 - 3 } & QIDO y QIUP & $\mathrm{a}$ \\
\cline { 2 - 3 } & PAPI y PARO & $\mathrm{a}$ \\
\cline { 2 - 3 } & TUDO y TUUP & $\mathrm{a}$ \\
\cline { 2 - 3 } & PRPI y PRJO & $\mathrm{a}$ \\
\hline
\end{tabular}




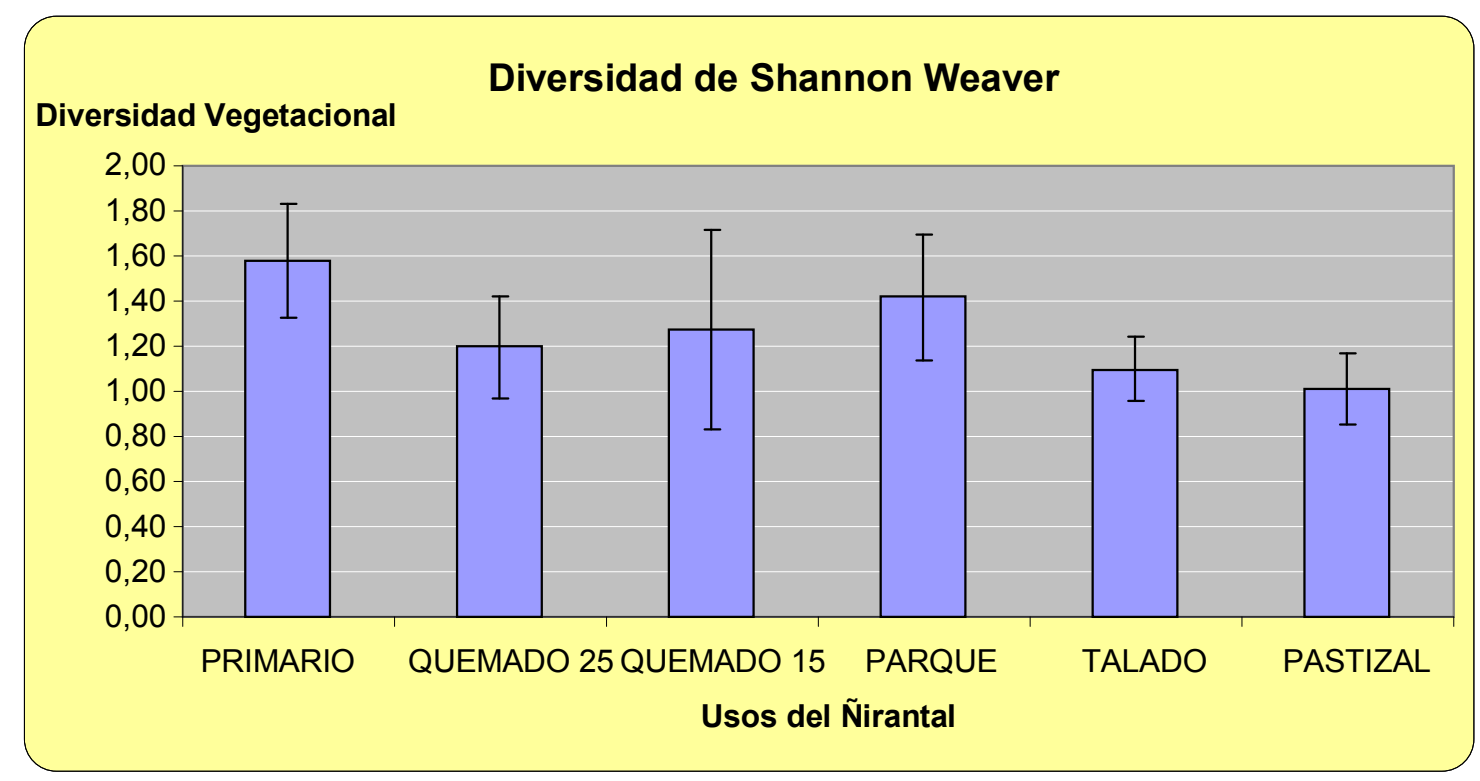

Fig. 4.25: Diversidad vegetal de los diferentes sitios según tipos de explotación de los ñirantales

\subsubsection{Equitatividad (modificado por Pielou)}

La equitatividad (modificada por Pielou) de la estructura vegetal no difirió significativamente $(p>0,05)$ entre los ñirantales sometidos a los diferentes usos (ver Tabla 4.12 y Fig. 4.26).

Tabla 4.12: Equitatividad calculada según los usos de los ñirantales. Las letras indican los niveles de significancias entre los sitios de muestreo $(p<0,05)$.

\begin{tabular}{|c|c|c|}
\hline Índice & Sitio & $\begin{array}{c}\text { Nivel de } \\
\text { Significación }\end{array}$ \\
\hline \multirow{4}{*}{ Equitatividad } & PAGA y PAPE & $\mathrm{a}$ \\
\cline { 2 - 3 } & QGDO y QGUP & $\mathrm{a}$ \\
\cline { 2 - 3 } & QIDO y QIUP & $\mathrm{a}$ \\
\cline { 2 - 3 } & PAPI y PARO & $\mathrm{a}$ \\
\cline { 2 - 3 } & TUDO y TUUP & $\mathrm{a}$ \\
\cline { 2 - 3 } & PRPI y PRJO & $\mathrm{a}$ \\
\hline
\end{tabular}




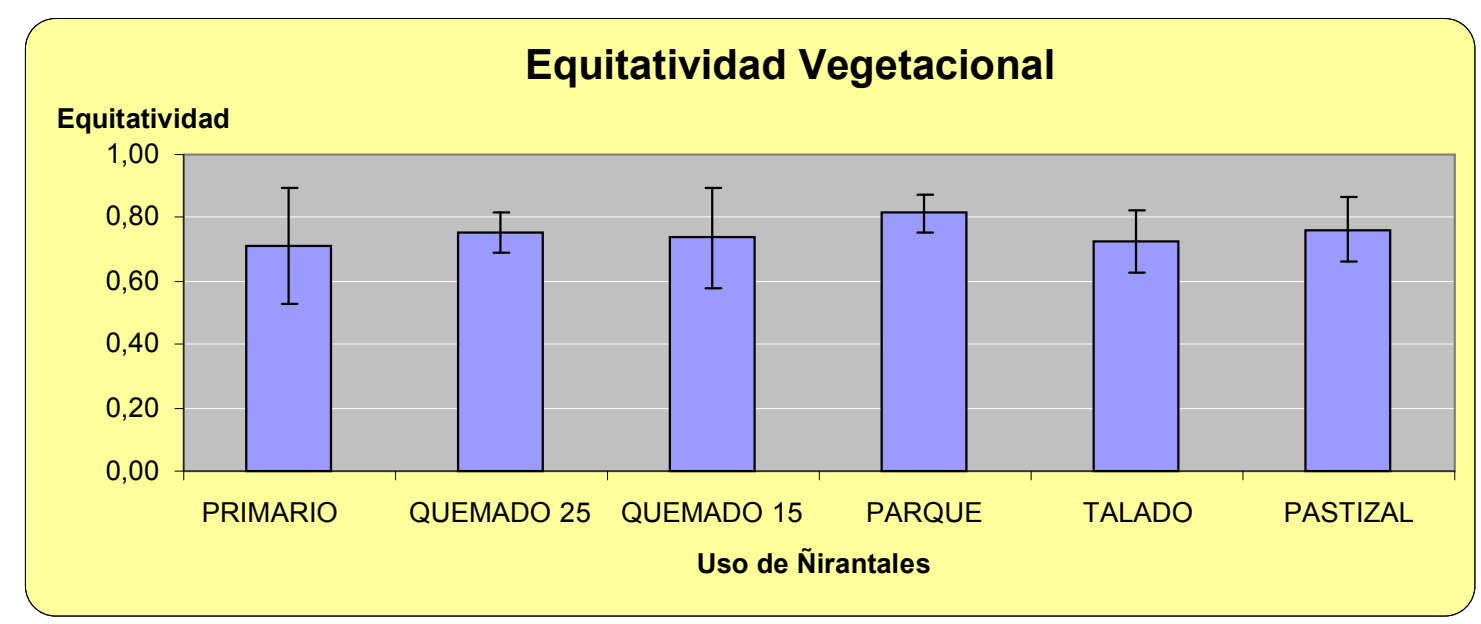

Fig. 4.26: Equitatividad de la estructura vegetal de los ñirantales sometidos a diferentes usos

\subsubsection{Estado Sanitario}

Se observó una marcada diferencia en el estado sanitario de los individuos entre los ñirantales primarios y los afectados por el resto de los usos $(F=3,76 ; p<0,0001)$, no observándose diferencias $(p>0,05)$ entre los individuos de estos últimos tratamientos (Ver Tabla 4.13 y Fig. 4.27).

Tabla 4.13: Estado sanitario calculado según los usos de los ñirantales. Las letras indican los niveles de significancias entre los sitios de muestreo $(p<0,05)$.

\begin{tabular}{|c|c|c|}
\hline Índice & Sitio & $\begin{array}{c}\text { Nivel de } \\
\text { Significación }\end{array}$ \\
\hline \multirow{4}{*}{$\begin{array}{c}\text { Estado } \\
\text { Sanitario }\end{array}$} & PAGA y PAPE & $\mathrm{a}$ \\
\cline { 2 - 3 } & QGDO y QGUP & $\mathrm{a}$ \\
\cline { 2 - 3 } & QIDO y QIUP & $\mathrm{a}$ \\
\cline { 2 - 3 } & PAPI y PARO & $\mathrm{a}$ \\
\cline { 2 - 3 } & TUDO y TUUP & $\mathrm{a}$ \\
\cline { 2 - 3 } & PRPI y PRJO & $\mathrm{b}$ \\
\hline
\end{tabular}




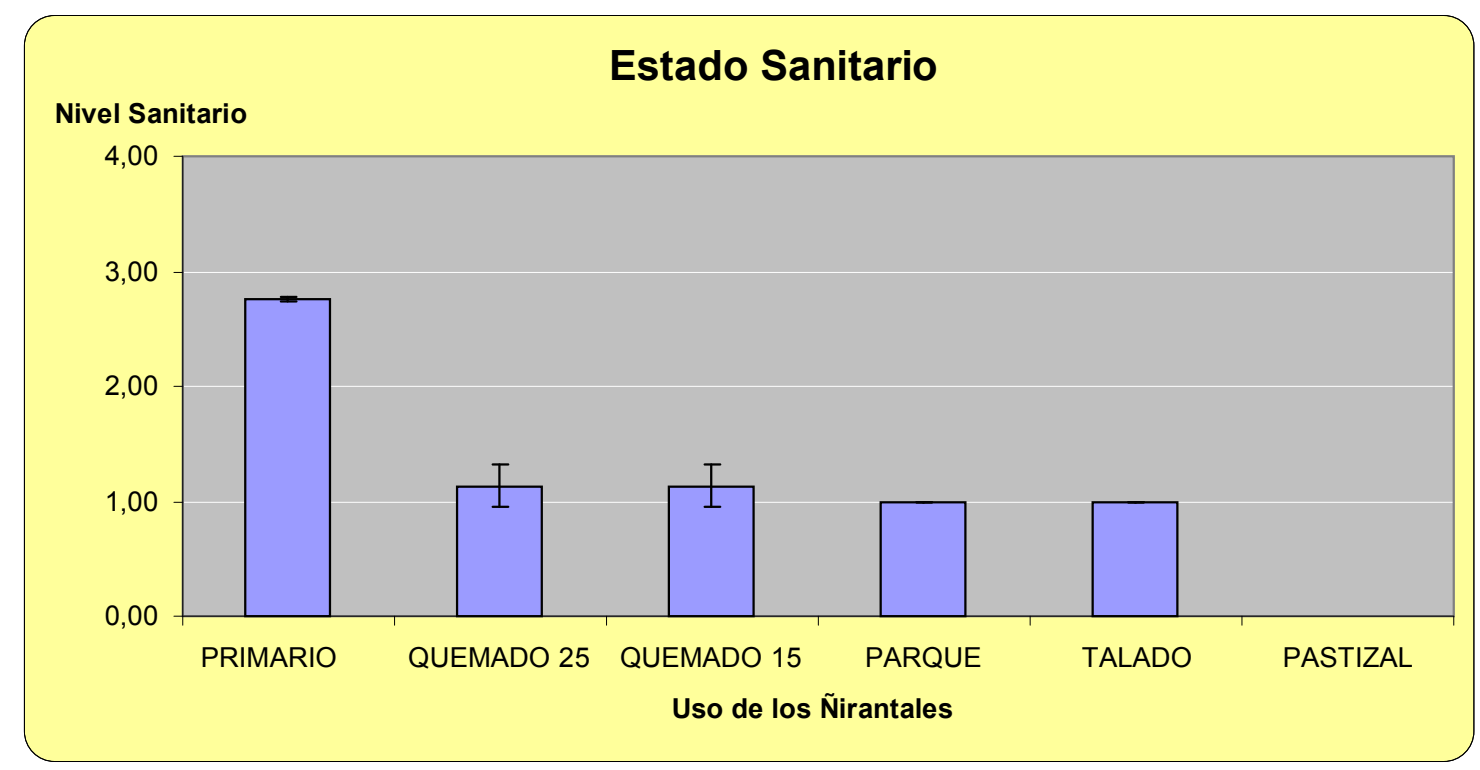

Fig. 4.27: Estado sanitario arbóreo de los diferentes sitios según usos de los Ñirantales

\subsubsection{Transitabilidad}

Los ñirantales convertidos en pasturas presentaron la mayor transitabilidad, seguidos por los ñirantales incendiados hace 25 años. La menor transitabilidad se observó en los ñirantales primarios, lo que se debió a la gran densidad de renovales, latizales y de árboles de gran porte (Fig. 4.28). 


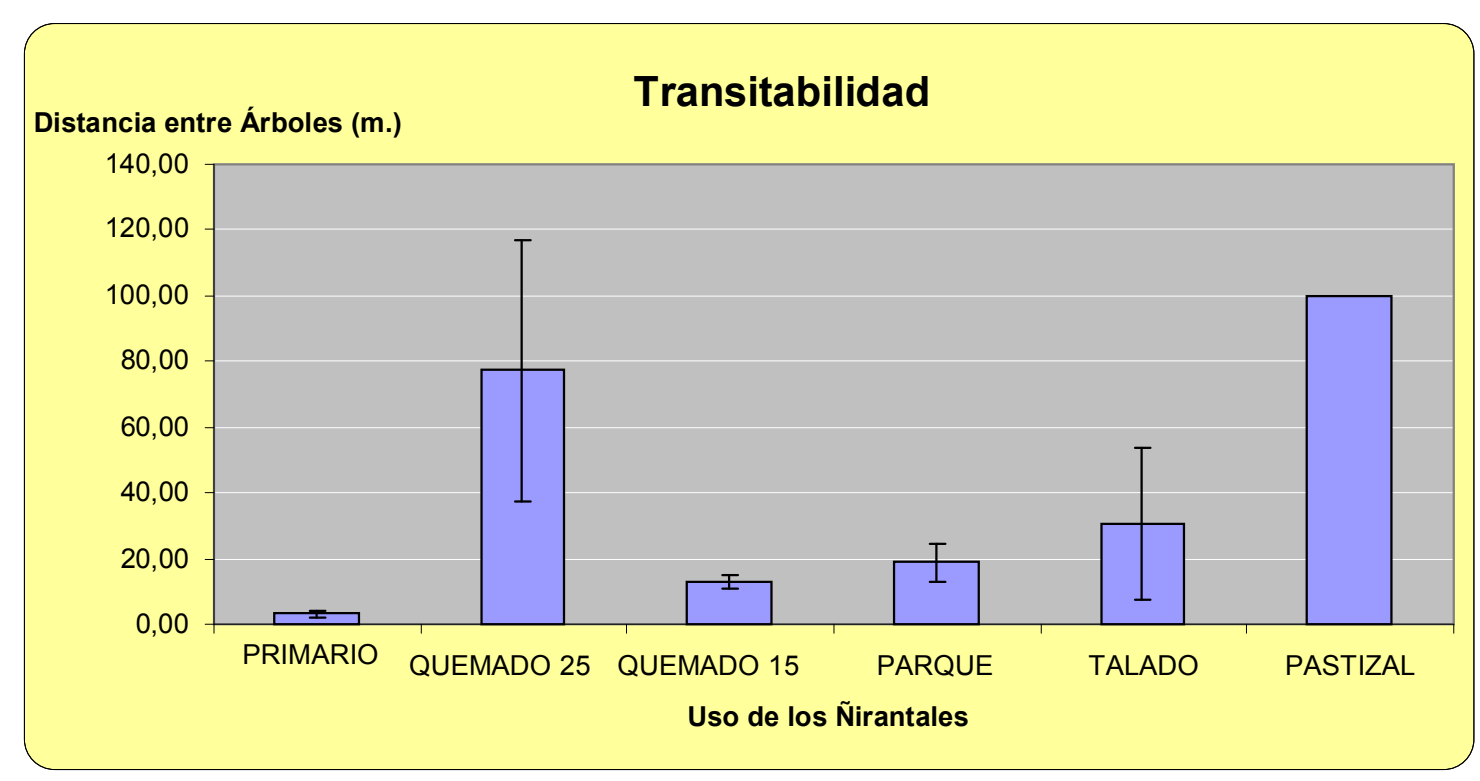

Fig. 4.28: Transitabilidad de los diferentes sitios según usos de los ñirantales.

\section{3 - Resultados de las comunidades de artrópodos de los ñirantales sometidos a diferentes usos}

\subsection{1 Ñirantales convertidos en pasturas}

(PAPE Y PAGA)

Sitio PAGA

Se capturó un total de 57 individuos pertenecientes a 8 órdenes y 20 familias, entre las cuales la familia Cecidomyidae fue la más abundante, seguida por Cicadellidae y Muscidae (ver Anexo). El número de individuos difirió significativamente entre los órdenes $(F=3,71$; $\mathrm{p}<0,05)$, siendo Ortoptera $(4,00 \pm 1,73)$ el más abundante ( $N-K$ $\mathrm{p}<0,01$ ) (Tabla 4.14). La cantidad de ejemplares capturados varió estacionalmente $(F=1,45 ; p<0,01)$, obteniéndose las mayores tasas de captura durante las estaciones cálidas (N-K p<0,01; Fig. 4.29). 
Tabla 4.14: Órdenes de artrópodos representados en el sitio PAGA. Los valores son expresados como media \pm desvío estándar (D.E.) y rango.

\begin{tabular}{|c|c|c|}
\hline Órdenes & $\begin{array}{c}\text { Media } \pm \\
\text { D.E. }\end{array}$ & Rango \\
\hline ARANEAE & $1,00 \pm 0,00$ & $1-1$ \\
\hline LEPIDOPTERA & $1,00 \pm 0,00$ & $1-1$ \\
\hline HYMENOPTERA & $1,20 \pm 0,45$ & $1-2$ \\
\hline COLEOPTERA & $1,33 \pm 0,52$ & $1-2$ \\
\hline HEMIPTERA & $2,00 \pm 0,00$ & $2-2$ \\
\hline DIPTERA & $3,92 \pm 3,39$ & $1-12$ \\
\hline ORTOPTERA & $4,00 \pm 1,73$ & $2-5$ \\
\hline HOMOPTERA & $5,50 \pm 6,86$ & $1-18$ \\
\hline
\end{tabular}



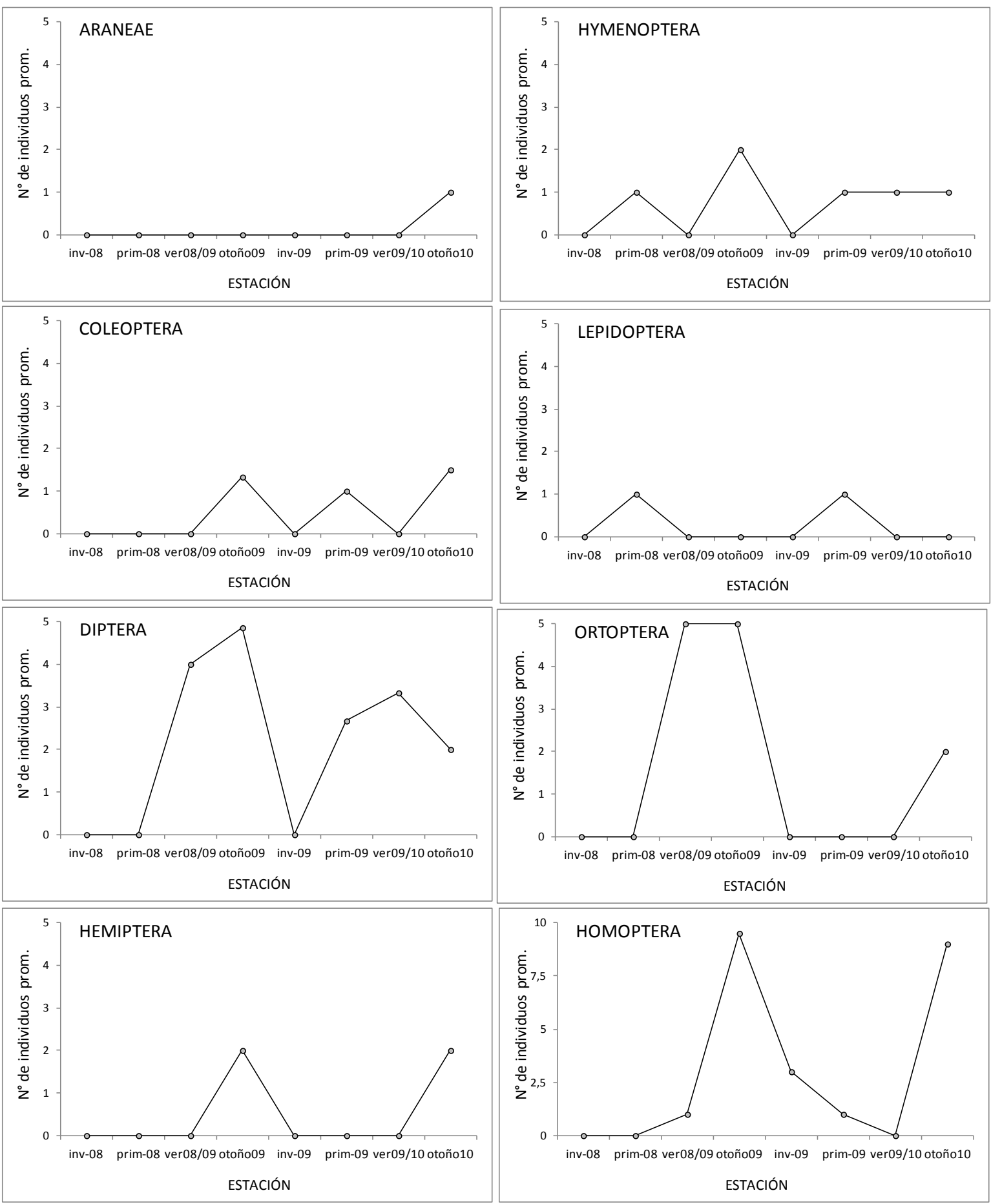

Fig. 4.29: Variación estacional en el número de individuos (promedio) pertenecientes a los órdenes representados en las capturas de sitio PAGA. 


\section{Sitio PAPE}

En PAPE se capturó un total de 49 individuos pertenecientes a 7 órdenes y 27 familias, de las cuales Cecidomyidae fue la más abundante (Ver Anexo). La abundancia de los órdenes representados en las capturas difirió significativamente $(\mathrm{F}=2,44 ; \mathrm{p}<0,05)$, siendo Ortoptera $(5,00$ $\pm 0,00)$ el más abundante $(\mathrm{N}-\mathrm{K} \mathrm{p}<0,01)$ (Tabla 4.15). El número de los diferentes órdenes varió significativamente entre estaciones $(F=1,63$; $\mathrm{p}<0,01)$, observándose las mayores abundancias en las estaciones cálidas ( $\mathrm{N}-\mathrm{K} \mathrm{p}<0,01$; Fig. 4.30). 

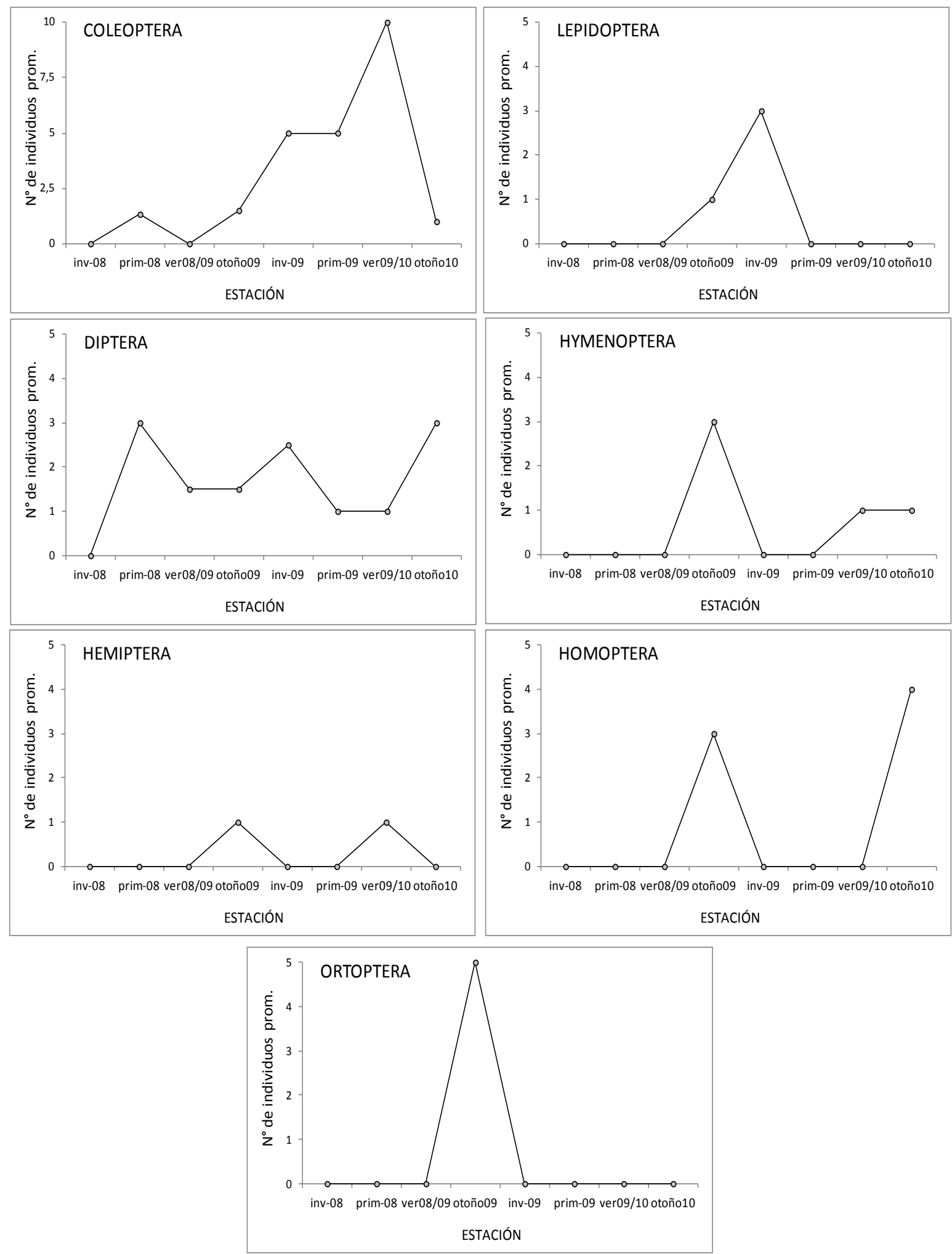

Fig. 4.30: Variación estacional en el número de individuos (promedio) pertenecientes a los órdenes representados en las capturas de sitio PAPE 
Tabla 4.15: Órdenes de artrópodos representados en el sitio PAPE. Los valores son expresados como media \pm desvío estándar (D.E.) y rango.

\begin{tabular}{|c|c|c|}
\hline Órdenes & $\begin{array}{c}\text { Media } \pm \\
\text { D.E }\end{array}$ & Rango \\
\hline HEMIPTERA & $1,00 \pm 0,00$ & $1-1$ \\
\hline HYMENOPTERA & $1,80 \pm 1,30$ & $1-4$ \\
\hline LEPIDOPTERA & $2,00 \pm 1,41$ & $1-3$ \\
\hline DIPTERA & $2,10 \pm 2,10$ & $1-10$ \\
\hline COLEOPTERA & $2,67 \pm 2,13$ & $1-7$ \\
\hline HOMOPTERA & $3,50 \pm 0,71$ & $3-4$ \\
\hline ORTOPTERA & $5,00 \pm 0,00$ & $5-5$ \\
\hline
\end{tabular}

\section{Comparación PAGA vs. PAPE}

La abundancia de los diferentes ordenes no difirió significativamente entre sitios ( $F=1,22 ; p=0,3007 ;$ Tabla 4.16). Tampoco se observaron diferencias significativas entre sitios al comparar la riqueza, y los índices de diversidad, dominancia y equitatividad ( $p>0,05$; Tabla 4.16 y 4.17 ).

Tabla 4.16: Órdenes de artrópodos representados en los sitios PAGA y PAPE. Los valores son expresados como media \pm desvío estándar (D.E.) y rango. Las letras iguales indican que no se encontraron diferencias significativas en los órdenes entre sitios de muestreo.

\begin{tabular}{|c|c|c|c|c|}
\hline Sitios & Órdenes & Media \pm D.E. & Rango & Significación \\
\hline PAGA & ARANEAE & $1,00 \pm 0,00$ & $1-1$ & - \\
\hline PAGA & COLEOPTERA & $1,33 \pm 0,52$ & $1-2$ & $\mathrm{a}$ \\
\hline PAPE & COLEOPTERA & $2,67 \pm 2,13$ & $1-7$ & $\mathrm{a}$ \\
\hline PAGA & DIPTERA & $3,92 \pm 3,39$ & $1-12$ & $\mathrm{a}$ \\
\hline PAPE & DIPTERA & $2,10 \pm 2,10$ & $1-10$ & $\mathrm{a}$ \\
\hline PAGA & HEMIPTERA & $2,00 \pm 0,00$ & $2-2$ & $\mathrm{a}$ \\
\hline PAPE & HEMIPTERA & $1,00 \pm 0,00$ & $1-1$ & $\mathrm{a}$ \\
\hline PAGA & HOMOPTERA & $5,50 \pm 6,86$ & $1-18$ & $\mathrm{a}$ \\
\hline PAPE & HOMOPTERA & $3,50 \pm 0,71$ & $3-4$ & $\mathrm{a}$ \\
\hline PAGA & HYMENOPTERA & $1,20 \pm 0,45$ & $1-2$ & $\mathrm{a}$ \\
\hline PAPE & HYMENOPTERA & $1,80 \pm 1,30$ & $1-4$ & $\mathrm{a}$ \\
\hline
\end{tabular}




\begin{tabular}{|c|c|c|c|c|}
\hline PAGA & LEPIDOPTERA & $1,00 \pm 0,00$ & $1-1$ & $\mathrm{a}$ \\
\hline PAPE & LEPIDOPTERA & $2,00 \pm 1,41$ & $1-3$ & $\mathrm{a}$ \\
\hline PAGA & ORTOPTERA & $4,00 \pm 1,73$ & $2-5$ & $\mathrm{a}$ \\
\hline PAPE & ORTOPTERA & $5,00 \pm 0,00$ & $5-5$ & $\mathrm{a}$ \\
\hline
\end{tabular}

Tabla 4.17: Riqueza, dominancia, diversidad y equitatividad de órdenes representados en los sitios PAGA y PAPE. Los valores son expresados como media \pm desvío estándar y rango entre paréntesis.

\begin{tabular}{|c|c|c|c|}
\hline Sitios & Índice & Media \pm D.E. & Significación \\
\hline PAGA & \multirow{2}{*}{ Equitatividad } & $\begin{array}{c}0,16 \pm 0,08(0,00- \\
0,25)\end{array}$ & \multirow{2}{*}{$p=0,7516$} \\
\hline PAPE & & $\begin{array}{c}0,14 \pm 0,11(0,00- \\
0,28)\end{array}$ & \\
\hline PAGA & \multirow{2}{*}{ Riqueza } & $\begin{array}{c}0,06 \pm 0,01(0,39- \\
0,48)\end{array}$ & \multirow{2}{*}{$p=0,7783$} \\
\hline PAPE & & $\begin{array}{c}0,10 \pm 0,01(0,49- \\
0,51)\end{array}$ & \\
\hline PAGA & \multirow{2}{*}{ Dominancia } & $\begin{array}{c}0,25 \pm 0,13(0,00- \\
0,37)\end{array}$ & \multirow{2}{*}{$p=0,9630$} \\
\hline PAPE & & $\begin{array}{c}0,25 \pm 0,16(0,00- \\
0,36)\end{array}$ & \\
\hline PAGA & \multirow{2}{*}{ Diversidad } & $\begin{array}{c}0,26 \pm 0,28(0,00- \\
0,77)\end{array}$ & \multirow{2}{*}{$p=0,9616$} \\
\hline PAPE & & $\begin{array}{c}0,25 \pm 0,33(0,00- \\
1,00)\end{array}$ & \\
\hline
\end{tabular}

\subsubsection{Nirantales con extracción de leña por manchones}

(TUDO y TUUP)

Sitio TUDO

Se capturó un total de 78 individuos pertenecientes a 9 órdenes y 33 familias, siendo Muscidae y Cecidomyidae las familias mejor representadas en las capturas, seguidas por Cicadellidae (Ver Anexo). 
La abundancia de los diferentes ordenes difirió significativamente $(F=2,33 ; p<0,05)$, siendo Homóptera el orden mas abundante (media 9,00; rango 1-23; d.e. 8,88; $\mathrm{N}-\mathrm{K} \mathrm{p}<0,01$ ) (Tabla 4.18). No se observaron diferencias significativas entre el resto de los órdenes $(p>0,05)$. La abundancia de los órdenes varió a lo largo del año $(F=3,15 ; p<0,01)$, observándose los mayores valores durante las estaciones cálidas (N-K p<0,01; Fig. 4.31). 

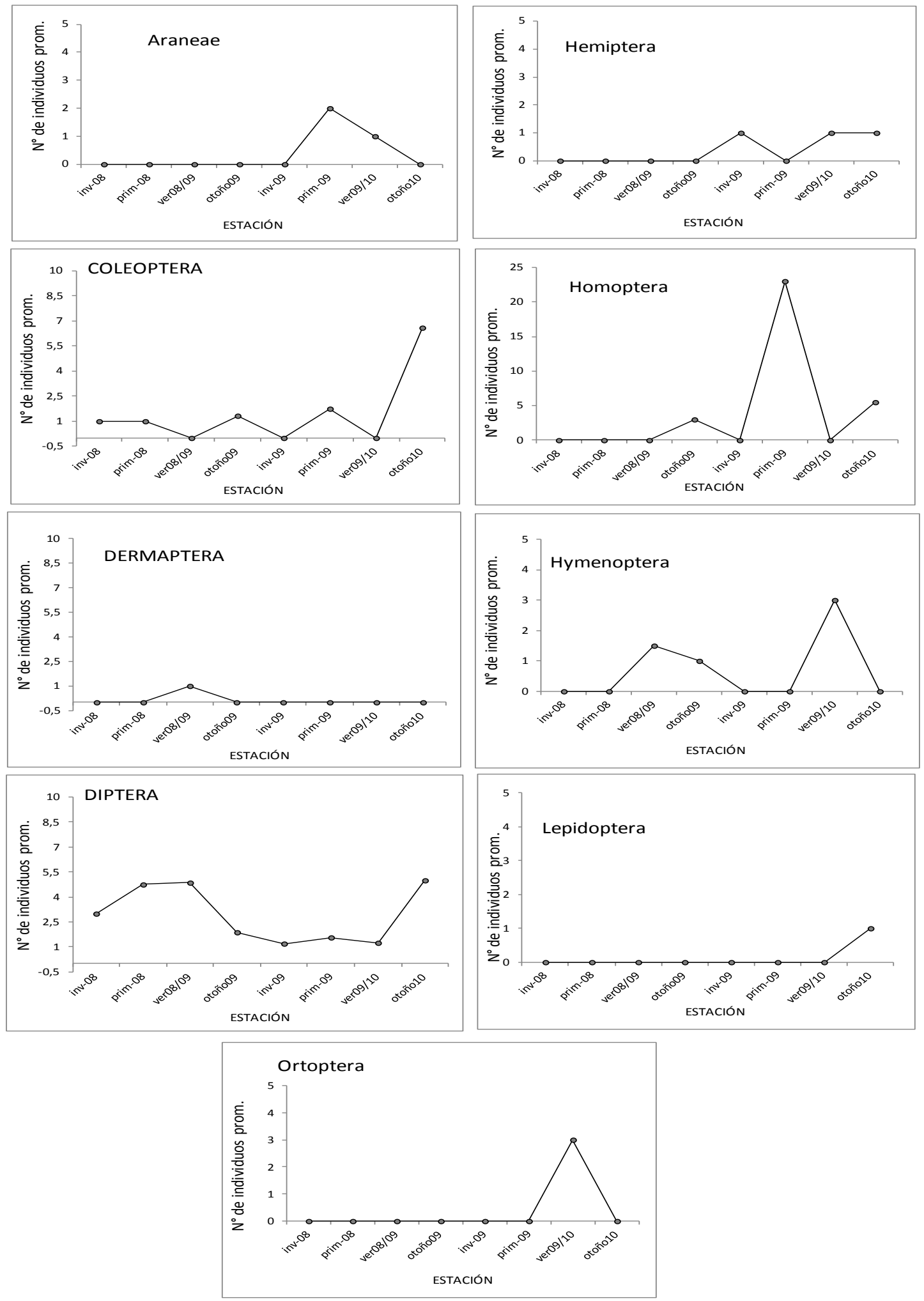

Fig. 4.31: Variación estacional en el número de individuos (promedio) pertenecientes a los órdenes representados en las capturas de sitio TUDO.

132 
Tabla 4.18: Órdenes de artrópodos representados en el sitio TUDO. Los valores son expresados como media \pm desvío estándar (D.E.) y rango.

\begin{tabular}{|c|c|c|}
\hline Órdenes & $\begin{array}{c}\text { Media } \pm \\
\text { D.E. }\end{array}$ & Rango \\
\hline DERMAPTERA & $1,00 \pm 0,00$ & $1-1$ \\
\hline HEMIPTERA & $1,00 \pm 0,00$ & $1-1$ \\
\hline LEPIDOPTERA & $1,00 \pm 0,00$ & $1-1$ \\
\hline ARANEAE & $1,50 \pm 0,71$ & $1-2$ \\
\hline HYMENOPTERA & $2,00 \pm 1,15$ & $1-4$ \\
\hline DIPTERA & $2,73 \pm 3,15$ & $1-15$ \\
\hline ORTOPTERA & $3,00 \pm 0,00$ & $3-3$ \\
\hline COLEOPTERA & $3,13 \pm 6,12$ & $1-25$ \\
\hline HOMOPTERA & $9,00 \pm 8,88$ & $1-23$ \\
\hline
\end{tabular}

\section{Sitio TUUP}

En el sitio TUUP se capturó un total de 111 individuos pertenecientes a 9 órdenes y 32 familias, siendo Cecidomyidae la familia mejor representada, seguida por Curculionidae, Muscidae y Mycetophilidae (Ver Anexo). La abundancia de los diferentes órdenes varió significativamente $(F=3,62 ; p<0,0001)$, siendo Diptera más abundante (media 7,31; rango 1-50; d.e. 10,40) que el resto de los órdenes $(\mathrm{N}-\mathrm{K} \quad \mathrm{p}<0,01)$ (Tabla 4.19). No se observaron diferencias significativas entre el resto de los órdenes $(p>0,05)$. La abundancia de los órdenes varió estacionalmente $(F=2,16 ; p<0,01)$, observándose los mayores los mayores valores durante las estaciones cálidas ( $\mathrm{N}-\mathrm{K}$ $\mathrm{p}<0,01$; Fig. 4.32). 

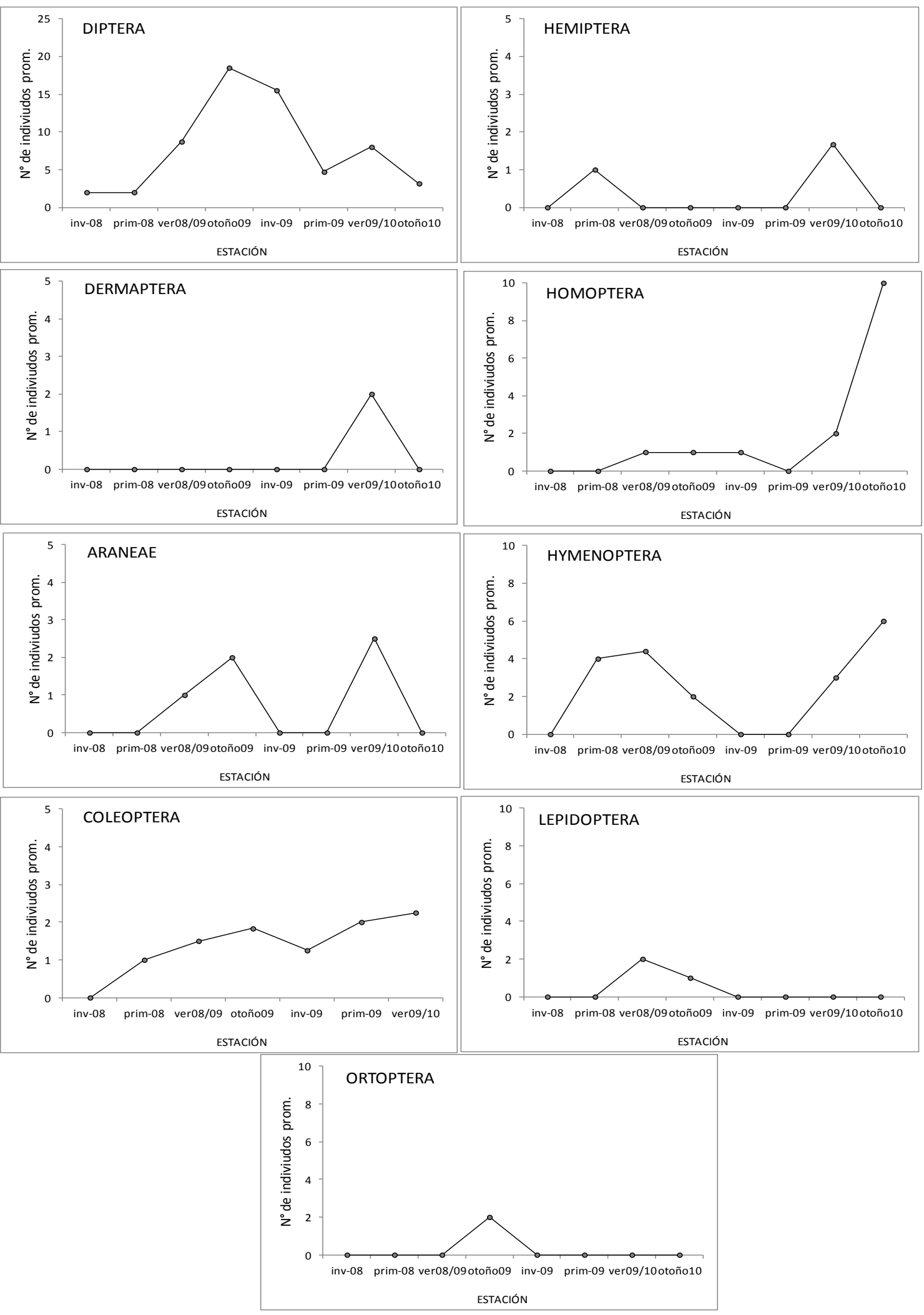

Fig. 4.32: Variación estacional en el número de individuos (promedio) pertenecientes a los órdenes representados en las capturas de sitio TUUP. 
Tabla 4.19: Órdenes de artrópodos representados en el sitio TUUP. Los valores son expresados como media \pm desvío estándar (D.E.) y rango.

\begin{tabular}{|c|c|c|}
\hline Órdenes & $\begin{array}{c}\text { Media } \mathbf{\pm} \\
\text { D.E. }\end{array}$ & Rango \\
\hline HEMIPTERA & $1,50 \pm 1,00$ & $1-3$ \\
\hline LEPIDOPTERA & $1,67 \pm 1,15$ & $1-3$ \\
\hline COLEOPTERA & $1,78 \pm 1,34$ & $1-6$ \\
\hline ARANEAE & $1,80 \pm 1,30$ & $1-4$ \\
\hline DERMAPTERA & $2,00 \pm 0,00$ & $2-2$ \\
\hline ORTOPTERA & $2,00 \pm 0,00$ & $2-2$ \\
\hline HOMOPTERA & $2,57 \pm 3,36$ & $1-10$ \\
\hline HYMENOPTERA & $4,00 \pm 2,58$ & $1-9$ \\
\hline DIPTERA & $7,31 \pm 10,40$ & $1-50$ \\
\hline
\end{tabular}

Comparación TUDO vs. TUUP

Los órdenes registrados en las capturas de cada sitio difirieron significativamente $(F=2,27 ; p<0,05 ;$ Tabla 4.20). Homóptera fue más abundante en TUDO $(9,00 \pm 8,88)$ que en TUUP $(2,57 \pm 3,36 ; \mathrm{N}-\mathrm{K}$ $p<0,01)$, en tanto que Diptera fue más abundante en TUUP $(7,31$ $\pm 10,40)$ que en TUDO $(2,73 \pm 3,15 ; \mathrm{N}-\mathrm{K} \mathrm{p}<0,01)$. No se observaron diferencias significativas al comparar la riqueza, y los índices de diversidad, dominancia y equitatividad entre los sitios de muestreo ( $p>0,05 ;$ Tabla 4.20 y 4.21 ). 
Tabla 4.20: Órdenes de artrópodos representados en los sitios TUDO y TUUP. Los valores son expresados como media \pm desvío estándar (D.E.) y rango. Las letras iguales indican que no se encontraron diferencias significativas en los órdenes entre sitios de muestreo.

\begin{tabular}{|c|c|c|c|c|}
\hline Sitios & Órdenes & Media \pm D.E. & Rango & Significación \\
\hline TUDO & ARANEAE & $1,50 \pm 0,71$ & $1-2$ & $a$ \\
\hline TUUP & ARANEAE & $1,80 \pm 1,30$ & $1-4$ & a \\
\hline TUDO & COLEOPTERA & $3,13 \pm 6,12$ & $1-25$ & $a$ \\
\hline TUUP & COLEOPTERA & $1,78 \pm 1,34$ & $1-6$ & $a$ \\
\hline TUDO & DERMAPTERA & $1,00 \pm 0,00$ & $1-1$ & a \\
\hline TUUP & DERMAPTERA & $2,00 \pm 0,00$ & $2-2$ & $a$ \\
\hline TUDO & DIPTERA & $2,73 \pm 3,15$ & $1-15$ & $a$ \\
\hline TUUP & DIPTERA & $7,31 \pm 10,40$ & $1-50$ & $b$ \\
\hline TUDO & HEMIPTERA & $1,00 \pm 0,00$ & $1-1$ & $a$ \\
\hline TUUP & HEMIPTERA & $1,50 \pm 1,00$ & $1-3$ & $a$ \\
\hline TUDO & HOMOPTERA & $9,00 \pm 8,88$ & $1-23$ & $b$ \\
\hline TUUP & HOMOPTERA & $2,57 \pm 3,36$ & $1-10$ & $a$ \\
\hline TUDO & HYMENOPTERA & $2,00 \pm 1,15$ & $1-4$ & $a$ \\
\hline TUUP & HYMENOPTERA & $4,00 \pm 2,58$ & $1-9$ & $a$ \\
\hline TUDO & LEPIDOPTERA & $1,00 \pm 0,00$ & $1-1$ & $a$ \\
\hline TUUP & LEPIDOPTERA & $1,67 \pm 1,15$ & $1-3$ & $a$ \\
\hline TUDO & ORTOPTERA & $3,00 \pm 0,00$ & $3-3$ & $a$ \\
\hline TUUP & ORTOPTERA & $2,00 \pm 0,00$ & $2-2$ & $a$ \\
\hline
\end{tabular}

Tabla 4.21: Riqueza, dominancia, diversidad y equitatividad de los órdenes representados en los sitios TUDO y TUUP. Los valores son expresados como media \pm desvío estándar y rango entre paréntesis.

\begin{tabular}{|c|c|c|c|}
\hline Sitios & Índice & Media \pm D.E. & Significación \\
\cline { 1 - 1 } TUDO & \multirow{3}{*}{ Equitatividad } & $\begin{array}{r}0,16 \pm 0,06 \\
(0,08-0,23)\end{array}$ & \multirow{2}{*}{$\mathrm{p}=0,7602$} \\
\cline { 1 - 1 } TUUP & & $\begin{array}{r}0,17 \pm 0,05 \\
(0,08-0,23)\end{array}$ & \\
\cline { 1 - 1 } TUDO & \multirow{2}{*}{ Riqueza } & $\begin{array}{r}0,05 \pm 0,02 \\
(0,21-0,34)\end{array}$ & $\mathrm{p}=0,3766$ \\
\hline
\end{tabular}




\begin{tabular}{|c|c|c|c|}
\hline TUUP & & $\begin{array}{l}0,02 \pm 0,24 \\
(0,32-0,34) \\
\end{array}$ & \\
\hline TUDO & \multirow{2}{*}{ Dominancia } & $\begin{array}{l}0,32 \pm 0,04 \\
(0,24-0,36)\end{array}$ & \multirow{2}{*}{$p=0,4396$} \\
\hline TUUP & & $\begin{array}{l}0,30 \pm 0,06 \\
(0,20-0,37)\end{array}$ & \\
\hline TUDO & \multirow{2}{*}{ Diversidad } & $\begin{array}{l}0,20 \pm 0,15 \\
(0,01-0,44)\end{array}$ & \multirow{2}{*}{$p=0,5324$} \\
\hline TUUP & & $\begin{array}{l}0,27 \pm 0,21 \\
(0,01-0,60)\end{array}$ & \\
\hline
\end{tabular}

\subsection{3 Ñirantales quemados hace 15 años}

(QGDO y QGUP)

\section{Sitio QGDO}

En el sitio QGDO se capturó un total de 90 individuos pertenecientes a 8 órdenes y 28 familias, siendo Cecidomyidae la familia mejor representada, seguida por Cicadellidae y Curculionidae (Ver Anexo).

La abundancia de los órdenes representados en las capturas presentaron diferencias significativas $(F=2,94 ; p<0,01)$, siendo Díptera (media 6,49; rango 1-50; d.e. 9,41; N-K p<0,01). (Tabla 4.22) y Lepidóptero (media 3,00; rango 1-6; d.e. 2,16) los más abundante en $(\mathrm{N}-\mathrm{K} \mathrm{p}<0,01)$. No se observaron diferencias significativas entre el resto de los órdenes ( $p>0,05$; Tabla 4.22). La abundancia de los individuos de los distintos órdenes existieron diferencias significativas durante las estaciones del año en lo que respecta al número de individuos de los órdenes representados $(F=1,45 ; p<0,01)$. En general, como se observa en la Fig. 4.33, el número de individuos aumentó durante las estaciones cálidas y disminuyó durante las más frías $(\mathrm{N}-\mathrm{K} \mathrm{p}<0,01)$. 
Tabla 4.22: Órdenes de artrópodos representados en el sitio QGDO. Los valores son expresados como media \pm desvío estándar (D.E.) y rango.

\begin{tabular}{|l|c|c|}
\hline \multicolumn{1}{|c|}{ Órdenes } & $\begin{array}{c}\text { Media } \pm \\
\text { D.E. }\end{array}$ & Rango \\
\hline ARANEAE & $1,00 \pm 0,00$ & $1-1$ \\
\hline ORTOPTERA & $1,00 \pm 0,00$ & $1-1$ \\
\hline HEMIPTERA & $2,75 \pm 2,87$ & $1-7$ \\
\hline LEPIDOPTERA & $3,00 \pm 2,16$ & $1-6$ \\
\hline HOMOPTERA & $2,22 \pm 1,39$ & $1-5$ \\
\hline HYMENOPTERA & $2,00 \pm 1,73$ & $1-7$ \\
\hline COLEOPTERA & $1,83 \pm 0,83$ & $1-3$ \\
\hline DIPTERA & $6,49 \pm 9,41$ & $1-50$ \\
\hline
\end{tabular}



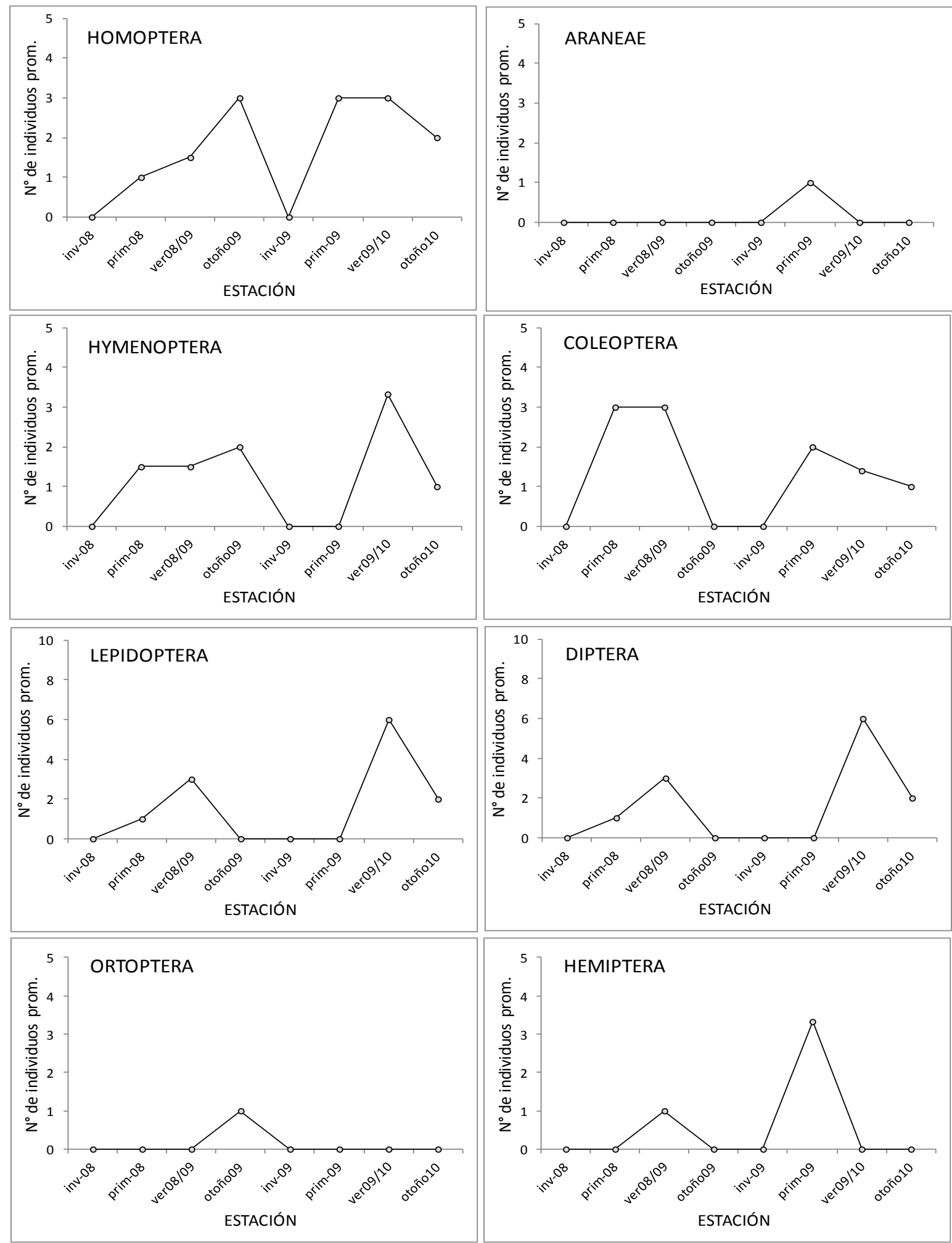

Fig. 4.33: Variación estacional en el número de individuos (promedio) pertenecientes a los órdenes representados en las capturas del sitio QGDO. 


\section{Sitio QGUP}

En el sitio QGUP se capturó un total de 70 individuos pertenecientes a 9 órdenes y 27 familias, siendo Cecidomyidae la familia mejor representada, seguida por Cicadellidae y Mycetophilidae (Ver Anexo). La abundancia de los órdenes difirió significativamente $(F=2,27$; $\mathrm{p}<0,05$ ), siendo los dípteros mas abundantes (media 4,55; rango 1-23; d.e. 5,$23 ; \mathrm{N}-\mathrm{K} \mathrm{p}<0,01$; Tabla 4.23) que el resto de los órdenes, los que no difirieron entre sí. La abundancia de los ordenes varió a lo largo del año $(F=2,64 ; \quad p<0,01)$, observándose los mayores números de individuos en las estaciones más cálidas (N-K p<0,01; Fig. 4.34).

Tabla 4.23: Órdenes de artrópodos representados en el sitio QGUP. Los valores son expresados como media \pm desvío estándar (D.E.) y rango.

\begin{tabular}{|c|c|c|}
\hline Órdenes & $\begin{array}{c}\text { Media } \pm \\
\text { D.E. }\end{array}$ & Rango \\
\hline ARANEAE & $1,00 \pm 0,00$ & $1-1$ \\
\hline HETEROPTERA & $1,00 \pm 0,00$ & $1-1$ \\
\hline LEPIDOPTERA & $1,00 \pm 0,00$ & $1-1$ \\
\hline NEUROPTERA & $1,00 \pm 0,00$ & $1-1$ \\
\hline HYMENOPTERA & $1,00 \pm 0,00$ & $1-1$ \\
\hline HEMIPTERA & $1,00 \pm 0,00$ & $1-1$ \\
\hline HOMOPTERA & $2,00 \pm 2,45$ & $1-7$ \\
\hline COLEOPTERA & $1,50 \pm 0,97$ & $1-4$ \\
\hline DIPTERA & $4,55 \pm 5,23$ & $1-23$ \\
\hline
\end{tabular}



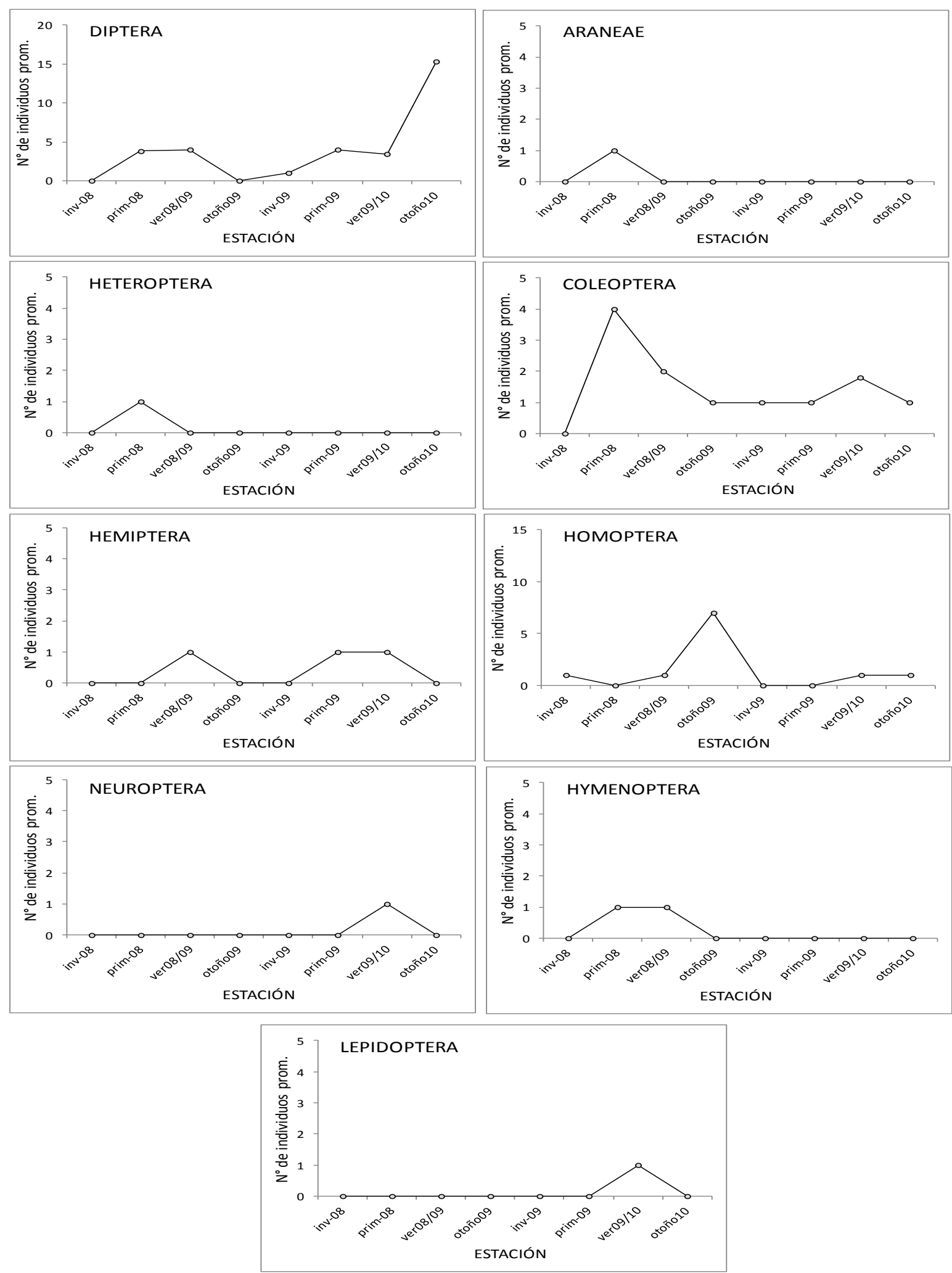

Fig. 4.34: Variación estacional en el número de individuos (promedio) pertenecientes a los órdenes representados en las capturas de sitio QGUP. 
No se observaron diferencias entre sitios en las abundancias de los diferentes ordenes $(F=0,16 \mathrm{p}=0,9921$; Tabla 4.24) ni en la riqueza, diversidad, dominancia y equitatividad ( $p>0,05$; Tabla 4.25).

Tabla 4.24: Órdenes de artrópodos representados en los sitios QGDO y QGUP. Los valores son expresados como media \pm desvío estándar (D.E.) y rango. Las letras iguales indican que no se encontraron diferencias significativas en los órdenes entre sitios de muestreo.

\begin{tabular}{|c|c|c|c|c|}
\hline Sitios & Órdenes & $\begin{array}{c}\text { Media } \\
\mathbf{\pm D . E .}\end{array}$ & Rango & Significación \\
\hline QGDO & ARANEAE & $1,00 \pm 0,00$ & $1-1$ & $\mathrm{a}$ \\
\hline QGUP & ARANEAE & $1,00 \pm 0,00$ & $1-1$ & $\mathrm{a}$ \\
\hline QGDO & COLEOPTERA & $1,83 \pm 0,83$ & $1-3$ & $\mathrm{a}$ \\
\hline QGUP & COLEOPTERA & $1,50 \pm 0,97$ & $1-4$ & $\mathrm{a}$ \\
\hline QGDO & DIPTERA & $6,49 \pm 9,41$ & $1-50$ & $\mathrm{a}$ \\
\hline QGUP & DIPTERA & $4,55 \pm 5,23$ & $1-23$ & $\mathrm{a}$ \\
\hline QGDO & HEMIPTERA & $2,75 \pm 2,87$ & $1-7$ & $\mathrm{a}$ \\
\hline QGUP & HEMIPTERA & $1,00 \pm 0,00$ & $1-1$ & $\mathrm{a}$ \\
\hline QGUP & HETEROPTERA & $1,00 \pm 0,00$ & $1-1$ & - \\
\hline QGDO & HOMOPTERA & $2,22 \pm 1,39$ & $1-5$ & $\mathrm{a}$ \\
\hline QGUP & HOMOPTERA & $2,00 \pm 2,45$ & $1-1$ & $\mathrm{a}$ \\
\hline QGDO & HYMENOPTERA & $2,00 \pm 1,73$ & $1-7$ & $\mathrm{a}$ \\
\hline QGUP & HYMENOPTERA & $1,00 \pm 0,00$ & $1-1$ & $\mathrm{a}$ \\
\hline QGDO & LEPIDOPTERO & $3,00 \pm 2,16$ & $1-6$ & $\mathrm{a}$ \\
\hline QGUP & LEPIDOPTERO & $1,00 \pm 0,00$ & $1-1$ & $\mathrm{a}$ \\
\hline QGDO & NEUROPTERO & $1,00 \pm 0,00$ & $1-1$ & - \\
\hline QGUP & ORTOPTERO & $1,00 \pm 0,00$ & $1-1$ & - \\
\hline & & & & \\
\hline
\end{tabular}


Tabla 4.25: Riqueza, dominancia, diversidad y equitatividad de órdenes representados en los sitios QGDO y QGUP. Los valores son expresados como media \pm desvío estándar y rango entre paréntesis.

\begin{tabular}{|c|c|c|c|}
\hline Sitios & Índice & Media \pm D.E. & Significación \\
\hline QGDO & \multirow{2}{*}{ Riqueza } & $\begin{array}{l}0,06 \pm 0,15 \\
(0,23-0,28)\end{array}$ & \multirow{2}{*}{$p=0,1660$} \\
\hline QGUP & & $\begin{array}{l}0,05 \pm 0,17 \\
(0,21-0,23)\end{array}$ & \\
\hline QGDO & \multirow{2}{*}{ Dominancia } & $\begin{array}{l}0,27 \pm 0,12 \\
(0,00-0,35)\end{array}$ & \multirow{2}{*}{$p=0,2517$} \\
\hline QGUP & & $\begin{array}{l}0,34 \pm 0,03 \\
(0,27-0,37)\end{array}$ & \\
\hline QGDO & \multirow{2}{*}{ Diversidad } & $\begin{array}{l}0,19 \pm 0,15 \\
(0,05-0,44)\end{array}$ & \multirow{2}{*}{$p=0,1276$} \\
\hline QGUP & & $\begin{array}{l}0,29 \pm 0,19 \\
(0,00-0,56)\end{array}$ & \\
\hline QGDO & \multirow{2}{*}{ Equitatividad } & $\begin{array}{l}0,13 \pm 0,07 \\
(0,00-0,24)\end{array}$ & \multirow{2}{*}{$p=0,0878$} \\
\hline QGUP & & $\begin{array}{l}0,18 \pm 0,03 \\
(0,14-0,23)\end{array}$ & \\
\hline
\end{tabular}

\subsection{4 Ñirantales quemados hace $\mathbf{2 5}$ años}

(QIDO y QIUP)

\section{$\underline{\text { Sitio QIDO }}$}

En el sitio QIDO se capturó un total de 75 individuos pertenecientes a 8 órdenes y 25 familias, siendo Muscidae y Cecidomyidae las familias mejor representadas, seguidas por Cicadellidae y Ligaeidae (Ver Anexo). Las abundancias de los ordenes difirieron significativamente $(F=3,47 ; p<0,01)$, presentando Homóptera mayor número de individuos (media 7,50; rango 1-20; d.e. 7,7) que el resto de los órdenes ( $\mathrm{N}-\mathrm{K} \mathrm{p}<0,01$; Tabla 4.26), cuyas abundancias no difirieron entre sí $(p>0,05)$. Las abundancias de los órdenes variaron a 
lo largo del año $(F=2,53 ; p<0,01)$, observándose el mayor número de individuos durante las estaciones más cálidas ( $\mathrm{N}-\mathrm{K} \mathrm{p}<0,01$; Fig. 4.35).

Tabla 4.26: Órdenes de artrópodos representados en el sitio QIDO. Los valores son expresados como media \pm desvío estándar (D.E.) y rango.

\begin{tabular}{|c|c|c|}
\hline Órdenes & Media \pm D.E. & Rango \\
\hline ARANEAE & $3,00 \pm 0,00$ & $3-3$ \\
\hline COLEOPTERA & $2,07 \pm 2,06$ & $1-8$ \\
\hline DIPTERA & $3,55 \pm 4,29$ & $1-20$ \\
\hline HEMIPTERA & $1,67 \pm 1,21$ & $1-4$ \\
\hline HOMOPTERA & $7,50 \pm 7,77$ & $1-20$ \\
\hline HYMENOPTERA & $3,38 \pm 2,97$ & $1-10$ \\
\hline LEPIDOPTERA & $1,00 \pm 0,00$ & $1-1$ \\
\hline ORTOPTERA & $1,33 \pm 0,58$ & $1-2$ \\
\hline
\end{tabular}



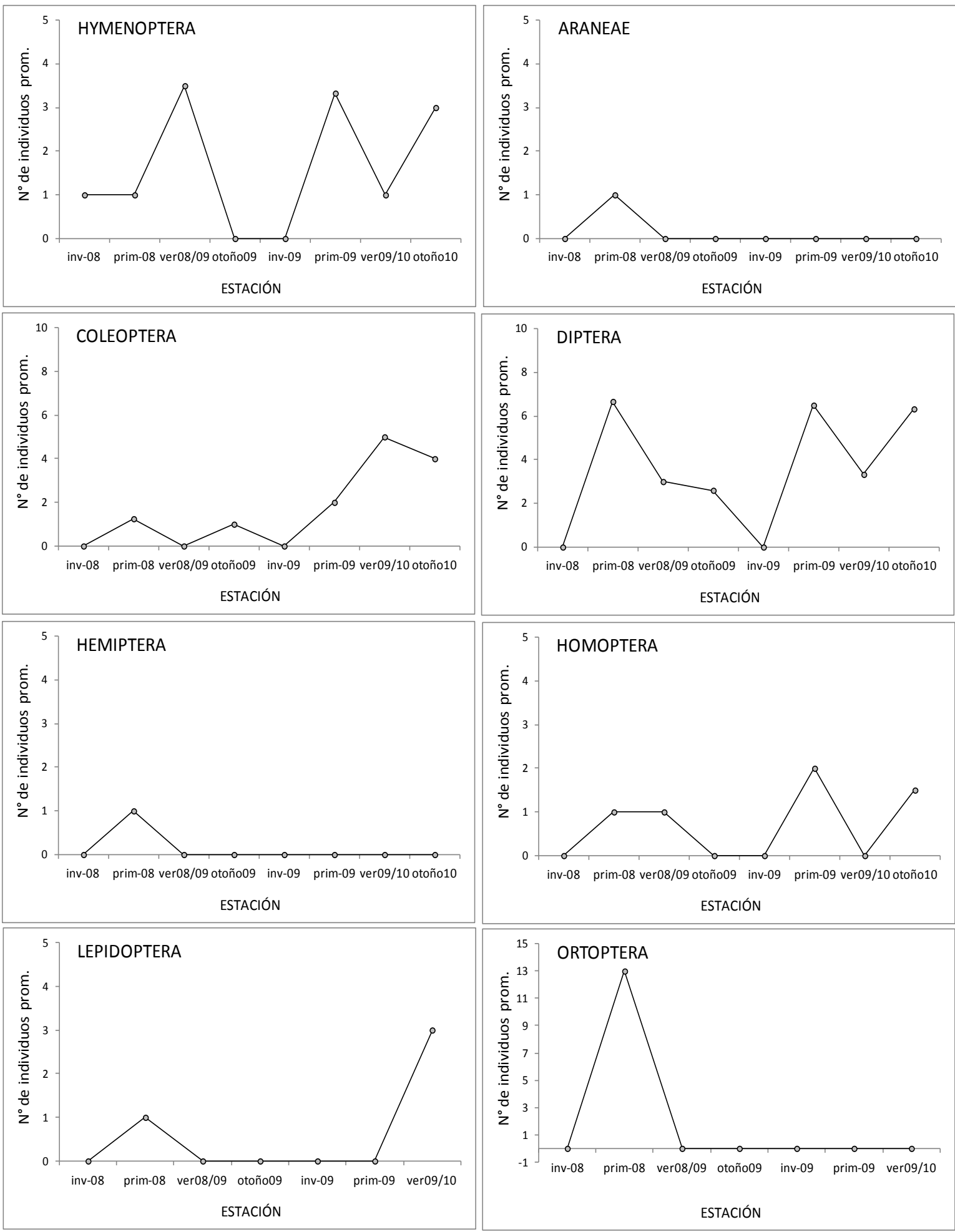

Fig. 4.35: Variación estacional en el número de individuos (promedio) pertenecientes a los órdenes representados en las capturas del sitio QIDO. 


\section{Sitio QIUP}

En el sitio QIUP se capturó un total de 75 individuos pertenecientes a 8 órdenes y 25 familias, siendo Muscidae y Cecidomyidae las familias mejor representadas en las capturas, seguidas por Cicadellidae y Ligaeidae (Ver Anexo). Las abundancias de los ordenes difirieron significativamente $(F=6,51 ; p<0,0001)$ siendo Ortoptera mas abundante representado por un mayor número de individuos (media 13,00; rango 13-0; d.e.13) que el resto de los órdenes ( $\mathrm{N}-\mathrm{K} \mathrm{p}<0,01$; Tabla 4.27). Los que no difirieron entre sí $(p>0,05)$. Las abundancias de los ordenes variaron a lo largo del año $(F=2,53 ; p<0,01)$, observándose el mayor número de individuos durante las estaciones mas cálidas (N-K p<0,01; Fig. 4.36).

Tabla 4.27: Órdenes de artrópodos representados en el sitio QIUP. Los valores son expresados como media \pm desvío estándar (D.E.) y rango.

\begin{tabular}{|c|c|c|}
\hline Órdenes & Media \pm D.E. & Rango \\
\hline ARANEAE & $1,00 \pm 0,00$ & $1-1$ \\
\hline COLEOPTERA & $2,25 \pm 1,98$ & $1-6$ \\
\hline DIPTERA & $4,26 \pm 4,81$ & $1-20$ \\
\hline HEMIPTERA & $1,00 \pm 0,00$ & $1-1$ \\
\hline HOMOPTERA & $1,50 \pm 0,76$ & $1-3$ \\
\hline HYMENOPTERA & $2,60 \pm 2,55$ & $1-8$ \\
\hline LEPIDOPTERA & $2,00 \pm 1,41$ & $1-3$ \\
\hline ORTOPTERA & $13,00 \pm 0,00$ & $13-13$ \\
\hline
\end{tabular}



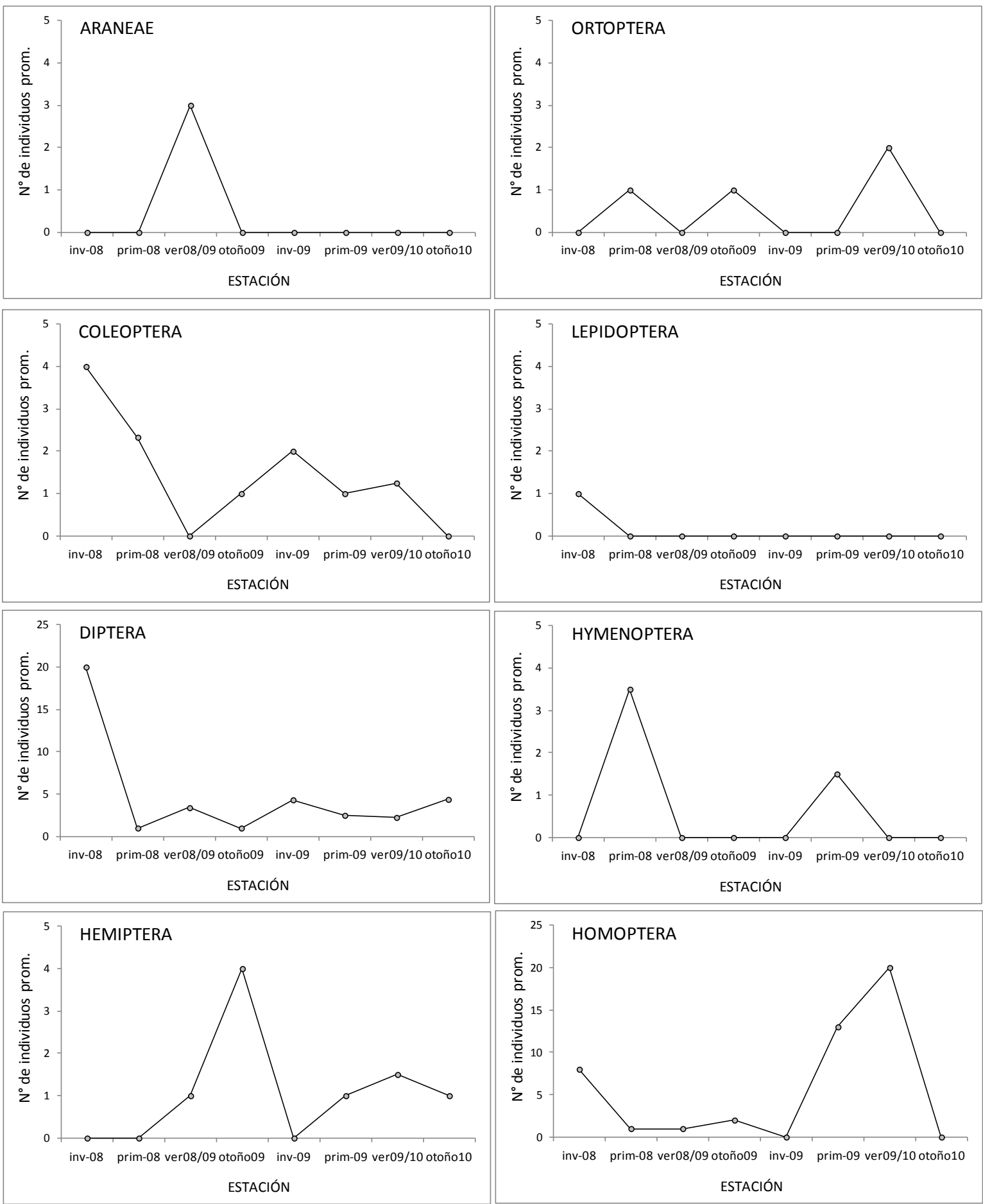

Fig.4.36: Variación estacional en el número de individuos (promedio) pertenecientes a los órdenes representados en las capturas de sitio QIUP. 
Las diferencias entre sitios en las abundancias de losmordenes fueron significativas $(F=2,02 ; p<0,05)$, siendo Ortoptera mas abundante en $\operatorname{QIUP}(13,00 \pm 0,00)$ que en $\operatorname{QIDO}(1,33 \pm 0,58 ; \mathrm{N}-\mathrm{K} \mathrm{p}<0,01)$ y Homóptera mas abundante en QIDO $(7,50 \pm 7,77)$ que en QIUP $(1,50$ $\pm 0,76 ; N-K p<0,01)$. El resto de los órdenes no presentaron estas diferencias entre sitios $(p>0,05)$ (Tabla 4.28). No se observaron diferencias entre sitios en riqueza específica, ni en los índices de diversidad, dominancia y equitatividad ( $p>0,05$; Tabla 4.29).

Tabla 4.28: Órdenes de artrópodos representados en los sitios QIDO e QIUP. Los valores son expresados como media \pm desvío estándar (D.E.) y rango. Las letras iguales indican que no se encontraron diferencias significativas en los órdenes entre sitios de muestreo.

\begin{tabular}{|l|c|c|c|c|}
\hline Sitios & Órdenes & Media \pm D.E. & Rango & Significación \\
\hline QIDO & ARANEAE & $3,00 \pm 0,00$ & $3-3$ & $\mathrm{a}$ \\
QIUP & ARANEAE & $1,00 \pm 0,00$ & $1-1$ & $\mathrm{a}$ \\
\hline QIDO & COLEOPTERA & $2,07 \pm 2,06$ & $1-8$ & $\mathrm{a}$ \\
QIUP & COLEOPTERA & $2,25 \pm 1,98$ & $1-6$ & $\mathrm{a}$ \\
\hline QIDO & DIPTERA & $3,55 \pm 4,29$ & $1-20$ & $\mathrm{a}$ \\
QIUP & DIPTERA & $4,26 \pm 4,81$ & $1-20$ & $\mathrm{a}$ \\
\hline QIDO & HEMIPTERA & $1,67 \pm 1,21$ & $1-4$ & $\mathrm{a}$ \\
QIUP & HEMIPTERA & $1,00 \pm 0,00$ & $1-1$ & $\mathrm{a}$ \\
\hline QIDO & HOMOPTERA & $7,50 \pm 7,77$ & $1-20$ & $\mathrm{~b}$ \\
QIUP & HOMOPTERA & $1,50 \pm 0,76$ & $1-3$ & $\mathrm{a}$ \\
\hline QIDO & HYMENOPTERA & $3,38 \pm 2,97$ & $1-10$ & $\mathrm{a}$ \\
QIUP & HYMENOPTERA & $2,60 \pm 2,55$ & $1-8$ & $\mathrm{a}$ \\
\hline QIDO & LEPIDOPTERA & $1,00 \pm 0,00$ & $1-1$ & $\mathrm{a}$ \\
QIUP & LEPIDOPTERA & $2,00 \pm 1,41$ & $1-3$ & $\mathrm{a}$ \\
\hline QIDO & ORTOPTERA & $1,33 \pm 0,58$ & $1-2$ & $\mathrm{a}$ \\
\cline { 2 - 5 } QIUP & ORTOPTERA & $13,00 \pm 0,00$ & $13-13$ & $\mathrm{~b}$ \\
\hline
\end{tabular}


Tabla 4.29: Riqueza, dominancia, diversidad y equitatividad de órdenes representados en los sitios QIDO e QIUP. Los valores son expresados como media \pm desvío estándar y rango entre paréntesis.

\begin{tabular}{|c|c|c|c|}
\hline Sitios & Índice & Media \pm D.E. & Significación \\
\hline QGDO & \multirow{2}{*}{ Riqueza } & $\begin{array}{c}0,17 \pm 0,05(0,09- \\
0,24)\end{array}$ & \multirow{2}{*}{$p=0,9614$} \\
\hline QGUP & & $\begin{array}{c}0,17 \pm 0,11(0,00- \\
0,32) \\
\end{array}$ & \\
\hline QGDO & \multirow{2}{*}{ Dominancia } & $\begin{array}{c}0,07 \pm 0,20(0,23- \\
0,27)\end{array}$ & \multirow{2}{*}{$p=0,2420$} \\
\hline QGUP & & $\begin{array}{c}0,30 \pm 0,32(0,39- \\
0,44)\end{array}$ & \\
\hline QGDO & \multirow{2}{*}{ Diversidad } & $\begin{array}{c}0,29 \pm 0,05(0,22- \\
0,35)\end{array}$ & \multirow{2}{*}{$p=0,6273$} \\
\hline QGUP & & $\begin{array}{c}0,24 \pm 0,12(0,00- \\
0,37)\end{array}$ & \\
\hline QGDO & \multirow{2}{*}{ Equitatividad } & $\begin{array}{c}0,33 \pm 0,20(0,06- \\
0,56)\end{array}$ & \multirow{2}{*}{$p=0,6516$} \\
\hline QGUP & & $\begin{array}{c}0,41 \pm 0,36(0,03- \\
1,00)\end{array}$ & \\
\hline
\end{tabular}

\subsubsection{Nirantales con extracción de leña por parquizado}

(PAPI y PARO)

\section{$\underline{\text { Sitio PARO }}$}

En el sitio PARO se capturó un total de 90 individuos pertenecientes a 9 órdenes y 33 familias, de las cuales Cecidomyidae fue la más abundante, seguida por Muscidae (Ver Anexo) esta abundancia de los ordenes difirió significativamente $(F=4,08 ; p<0,0001)$, presentando Díptera (media 3,40; rango 1-25; d.e. 5,35) el mayor número de individuos $(\mathrm{N}-\mathrm{K} \mathrm{p}<0,01)$ (Tabla 4.30). Las abundancias de los ordenes variaron estacionalmente $(F=3,15 ; p<0,01)$, observándose el mayor número de individuos durante las estaciones cálidas ( $\mathrm{N}-\mathrm{K} \mathrm{p}<0,01$; Fig. 4.37). 
Tabla 4.30: Órdenes de artrópodos representados en el sitio PARO. Los valores son expresados como media \pm desvío estándar (D.E.) y rango.

\begin{tabular}{|c|c|c|}
\hline Órdenes & $\begin{array}{c}\text { Media } \mathbf{\pm} \\
\text { D.E. }\end{array}$ & Rango \\
\hline DERMAPTERA & $1,00 \pm 0,00$ & $1-1$ \\
\hline ORTOPTERA & $1,00 \pm 0,00$ & $1-1$ \\
\hline HEMIPTERA & $1,25 \pm 0,50$ & $1-2$ \\
\hline LEPIDOPTERA & $1,25 \pm 0,50$ & $1-2$ \\
\hline HYMENOPTERA & $1,29 \pm 0,49$ & $1-2$ \\
\hline COLEOPTERA & $1,50 \pm 0,78$ & $1-4$ \\
\hline ARANEAE & $2,00 \pm 0,00$ & $2-2$ \\
\hline HOMOPTERA & $2,80 \pm 2,17$ & $1-6$ \\
\hline DIPTERA & $3,40 \pm 5,35$ & $1-26$ \\
\hline
\end{tabular}



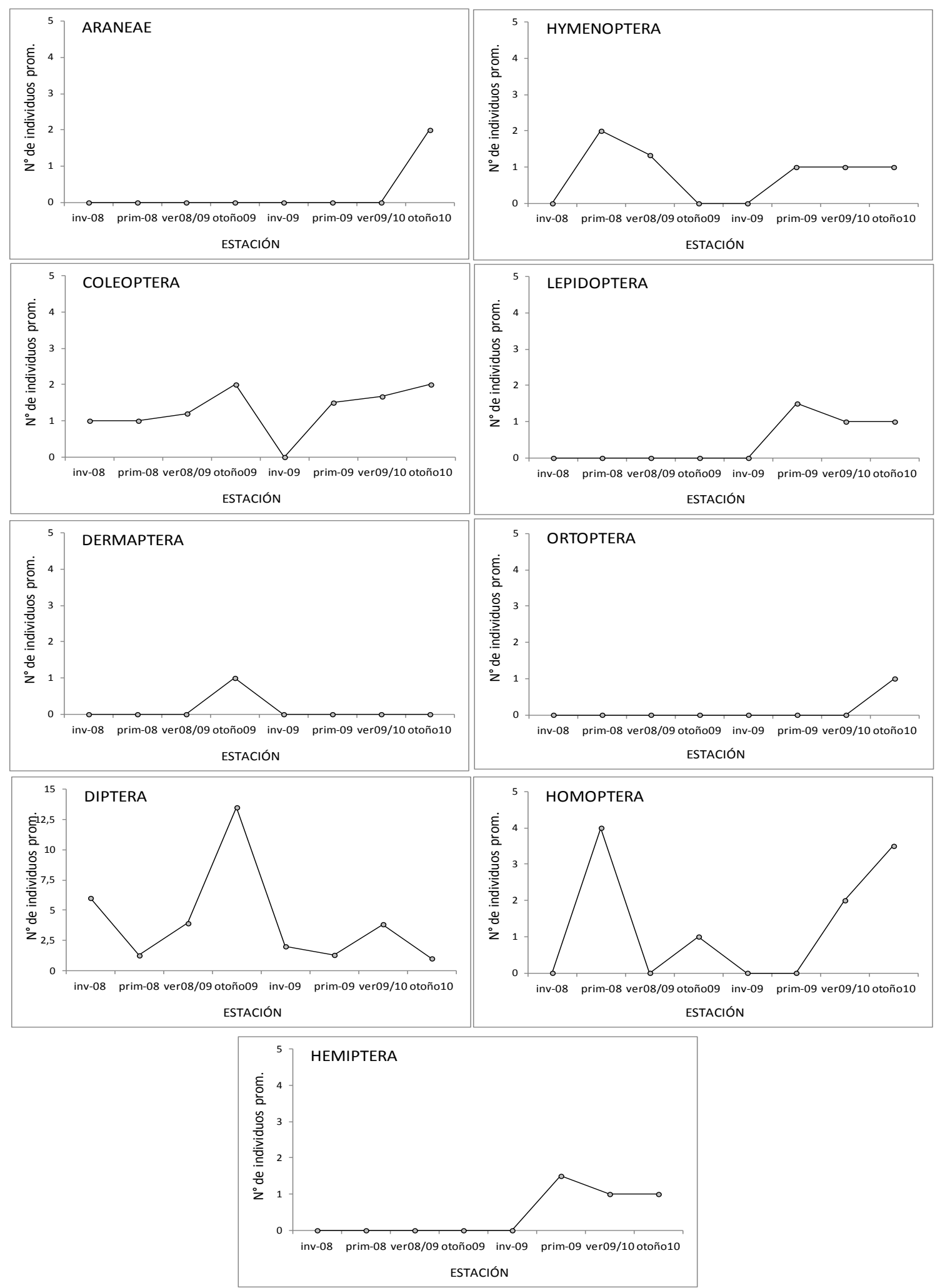

Fig. 4.37: Variación estacional en el número de individuos (promedio) pertenecientes a los órdenes representados en las capturas de sitio PARO. 
En el sitio PAPI se capturó un total de 96 individuos, pertenecientes a 9 órdenes y 32 familias, de las cuales Cecidomyidae fue la más abundante, seguida por Curculionidae y Mycetophylidae (Ver Anexo). La abundancia de individuos pertenecientes a los distintos órdenes difirió significativamente $(F=4,33 ; p<0,0001)$, presentando Hymenoptera (media 5,63; rango $1-25$; d.e. 8,02 ) el mayor número de individuos ( $\mathrm{N}$ $\mathrm{K} \mathrm{p}<0,01$ ) (Tabla 4.31). La abundancia de los ordenes varió estacionalmente a lo largo del año $(F=2,23 ; p<0,01)$, observándose los mayores números de individuos durante las estaciones más cálidas ( $\mathrm{N}-\mathrm{K}$ p $<0,01$; Fig. 4.38).

Tabla 4.31: Órdenes de artrópodos representados en el sitio PAPI. Los valores son expresados como media \pm desvío estándar (D.E.) y rango.

\begin{tabular}{|c|c|c|}
\hline Órdenes & $\begin{array}{c}\text { Media } \pm \\
\text { D.E. }\end{array}$ & Rango \\
\hline ARANEAE & $1,00 \pm 0,00$ & $1-1$ \\
\hline HETEROPTERA & $1,00 \pm 0,00$ & $1-1$ \\
\hline COLEOPTERA & $1,48 \pm 0,85$ & $1-4$ \\
\hline HEMIPTERA & $1,50 \pm 1,00$ & $1-3$ \\
\hline LEPIDOPTERA & $1,50 \pm 1,00$ & $1-3$ \\
\hline HOMOPTERA & $2,33 \pm 2,31$ & $1-5$ \\
\hline DERMAPTERA & $3,00 \pm 3,83$ & $1-5$ \\
\hline DIPTERA & $4,76 \pm 6,28$ & $1-26$ \\
\hline HYMENOPTERA & $5,63 \pm 8,02$ & $1-25$ \\
\hline
\end{tabular}



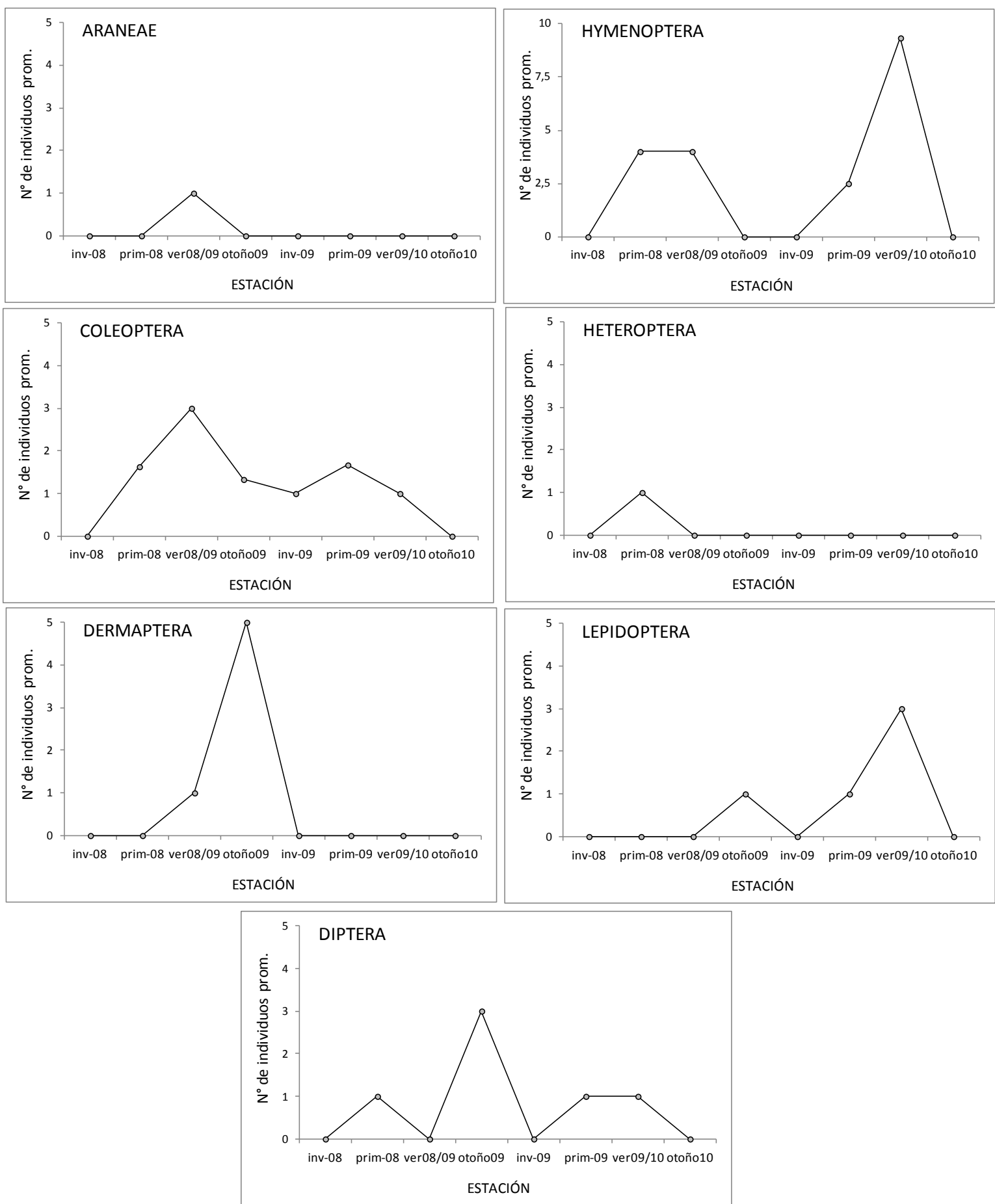

Fig. 4.38: Variación estacional en el número de individuos (promedio) pertenecientes a los órdenes representados en las capturas de sitio PAPI. 
Las abundancias de los ordenes no difirieron entre sitios ( $F=0,76$; $p=0,6566$; Tabla 4.32), aunque Hymenoptera presentó un mayor número de individuos en el sitio PAPI $(5,63 \pm 8,02)$ que en PARO $(1,29$ $\pm 0,49 ; N-K p<0,01)$. No se observaron diferencias significativas entre sitios al comparar la riqueza, y los índices de diversidad, dominancia y equitatividad ( $p>0,05$; Tabla 4.33).

Tabla 4.32: Órdenes de artrópodos representados en los sitios PAPI y PARO. Los valores son expresados como media, desvío estándar (D.E.) y rango. Las letras diferentes indican que se encontraron diferencias significativas en los órdenes entre sitios de muestreo $(p<0,01)$.

\begin{tabular}{|c|c|c|c|c|}
\hline Sitios & Órdenes & Media \pm D.E. & Rango & Significación \\
\hline PARO & ARANEAE & $2,00 \pm 0,00$ & $2-2$ & a \\
\hline PAPI & ARANEAE & $1,00 \pm 0,00$ & $1-1$ & $a$ \\
\hline PARO & COLEOPTERA & $1,50 \pm 0,78$ & $1-4$ & $a$ \\
\hline PAPI & COLEOPTERA & $1,48 \pm 0,85$ & $1-4$ & $a$ \\
\hline PARO & DERMAPTERA & $1,00 \pm 0,00$ & $1-1$ & a \\
\hline PAPI & DERMAPTERA & $3,00 \pm 2,83$ & $1-5$ & $a$ \\
\hline PARO & DIPTERA & $3,40 \pm 5,35$ & $1-26$ & $a$ \\
\hline PAPI & DIPTERA & $4,76 \pm 6,28$ & $1-26$ & $a$ \\
\hline PARO & HEMIPTERA & $1,25 \pm 0,50$ & $1-2$ & $a$ \\
\hline PAPI & HEMIPTERA & $1,50 \pm 1,00$ & $1-3$ & $\mathrm{a}$ \\
\hline PAPI & HETEROPTERA & $1,00 \pm 0,00$ & $1-1$ & - \\
\hline PARO & HOMOPTERA & $2,80 \pm 2,17$ & $1-6$ & $a$ \\
\hline PAPI & HOMOPTERA & $2,33 \pm 2,31$ & $1-5$ & $a$ \\
\hline PARO & HYMENOPTERA & $1,29 \pm 0,49$ & $1-2$ & a \\
\hline PAPI & HYMENOPTERA & $5,63 \pm 8,02$ & $1-25$ & $b$ \\
\hline PARO & LEPIDOPTERA & $1,25 \pm 0,50$ & $1-2$ & $a$ \\
\hline PAPI & LEPIDOPTERA & $1,50 \pm 1,00$ & $1-3$ & $\mathrm{a}$ \\
\hline PARO & ORTOPTERA & $1,00 \pm 0,00$ & $1-1$ & - \\
\hline
\end{tabular}


Tabla 4.33: Riqueza, dominancia, diversidad y equitatividad de los órdenes representados en los sitios PARO y PAPI. Los valores son expresados como media \pm desvío estándar y rango entre paréntesis.

\begin{tabular}{|c|c|c|c|}
\hline Sitios & Índice & Media \pm D.E. & Significación \\
\hline PARO & \multirow{2}{*}{ Equitatividad } & $\begin{array}{c}0,17 \pm 0,05(0,08- \\
0,23)\end{array}$ & \multirow{2}{*}{$p=0,3528$} \\
\hline PAPI & & $\begin{array}{c}0,17 \pm 0,06(0,08- \\
0,23) \\
\end{array}$ & \\
\hline PARO & \multirow{2}{*}{ Riqueza } & $\begin{array}{c}0,32 \pm 0,26(0,34- \\
0,43)\end{array}$ & \multirow{2}{*}{$p=0,7109$} \\
\hline PAPI & & $\begin{array}{c}0,05 \pm 0,27(0,32- \\
0,34)\end{array}$ & \\
\hline PARO & \multirow{2}{*}{ Dominancia } & $\begin{array}{c}0,29 \pm 0,09(0,10- \\
0,37)\end{array}$ & \multirow{2}{*}{$p=0,820$} \\
\hline PAPI & & $\begin{array}{c}0,28 \pm 0,06(0,20- \\
0,36)\end{array}$ & \\
\hline PARO & \multirow{2}{*}{ Diversidad } & $\begin{array}{c}0,27 \pm 0,27(0,01- \\
0,79)\end{array}$ & \multirow{2}{*}{$p=0,6791$} \\
\hline PAPI & & $\begin{array}{c}0,22 \pm 0,22(0,01- \\
0,60)\end{array}$ & \\
\hline
\end{tabular}

\subsubsection{Nirantales primarios}

(PRPI y PRJO)

\section{Sitio PRPI}

En el sitio PRPI se capturó un total de 68 individuos pertenecientes a 7 órdenes y 23 familias, siendo Cecidomyidae la familia mejor representada, seguida por Formicidae y Muscidae (Ver Anexo). Las abundancias de los ordenes difirieron significativamente $(F=4,46$; $\mathrm{p}<0,0001)$, presentando Homóptera un mayor número de individuos (media 7,67; rango $1-33$; d.e. 6,43 ) que el resto de los órdenes ( $\mathrm{N}-\mathrm{K}$ $p<0,01)$ (Tabla 4.34), los que no difirieron entre sí $(p>0,05)$. Las abundancias de los órdenes variaron a lo largo del año $(F=4,82$; 
$\mathrm{p}<0,01)$, observándose los mayores números de individuos durante las estaciones más cálidas ( $\mathrm{N}-\mathrm{K} \mathrm{p}<0,01)$ (Fig. 4.39).

Tabla 4.34: Órdenes de artrópodos representados en el sitio PRPI. Los valores son expresados como media \pm desvío estándar (D.E.) y rango.

\begin{tabular}{|c|c|c|}
\hline Órdenes & $\begin{array}{c}\text { Media } \pm \\
\text { D.E. }\end{array}$ & Rango \\
\hline DERMAPTERA & $1,00 \pm 0,00$ & $1-1$ \\
\hline ARANEAE & $1,33 \pm 0,58$ & $1-2$ \\
\hline LEPIDOPTERA & $1,33 \pm 0,52$ & $1-2$ \\
\hline COLEOPTERA & $1,80 \pm 0,84$ & $1-3$ \\
\hline HYMENOPTERA & $5,00 \pm 6,55$ & $1-20$ \\
\hline DIPTERA & $5,94 \pm 7,67$ & $1-33$ \\
\hline HOMOPTERA & $7,67 \pm 6,43$ & $3-15$ \\
\hline
\end{tabular}



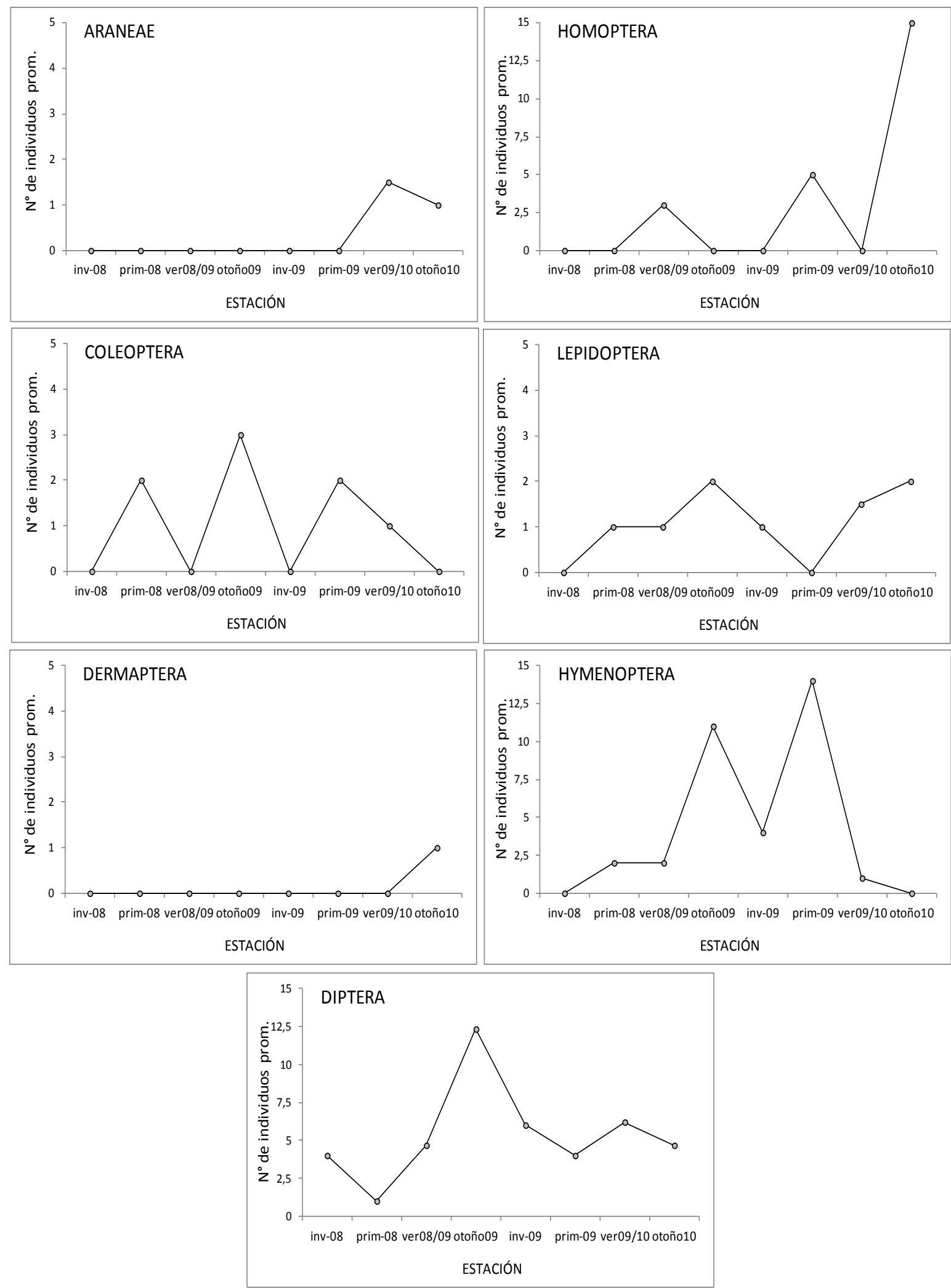

Fig. 4.39: Variación estacional en el número de individuos (promedio) pertenecientes a los órdenes representados en las capturas de sitio PRPI 


\section{Sitio PRJO}

En el sitio PRJO se capturó un total de 83 individuos pertenecientes a 7 órdenes y 24 familias, entre las que Cecidomyidae fue la más abundante, seguida por Cicadellidae y Mycetophilidae (Ver Anexo). Las abundancias de los ordenes variaron significativamente $(F=4,64 ; p<0,0001)$, presentando Díptera un mayor número de individuos (media 6,53; rango 1-46; d.e. 9,95) que el resto de los órdenes ( $\mathrm{N}-\mathrm{K} \quad \mathrm{p}<0,01)$ (Tabla 4.35), los que no difirieron entre sí $(p>0,05)$. Las abundancias de los órdenes variaron a lo largo del año $(F=4,11 ; p<0,01)$, observándose el mayor número de individuos durante las estaciones más cálidas ( $\mathrm{N}-\mathrm{K} \mathrm{p}<0,01)$ (Fig. 4.40).

Tabla 4.35: Órdenes de artrópodos representados en el sitio PRJO. Los valores son expresados como media \pm desvío estándar (D.E.) y rango.

\begin{tabular}{|c|c|c|}
\hline Órdenes & $\begin{array}{c}\text { Media } \pm \\
\text { D.E. }\end{array}$ & Rango \\
\hline ARANEAE & $1,00 \pm 0,00$ & $1-1$ \\
\hline HEMIPTERA & $1,00 \pm 0,00$ & $1-1$ \\
\hline NEUROPTERA & $1,00 \pm 0,00$ & $1-1$ \\
\hline COLEOPTERA & $1,62 \pm 0,87$ & $1-3$ \\
\hline HYMENOPTERA & $2,22 \pm 2,95$ & $1-10$ \\
\hline HOMOPTERA & $3,43 \pm 2,15$ & $1-7$ \\
\hline DIPTERA & $6,53 \pm 9,95$ & $1-46$ \\
\hline
\end{tabular}



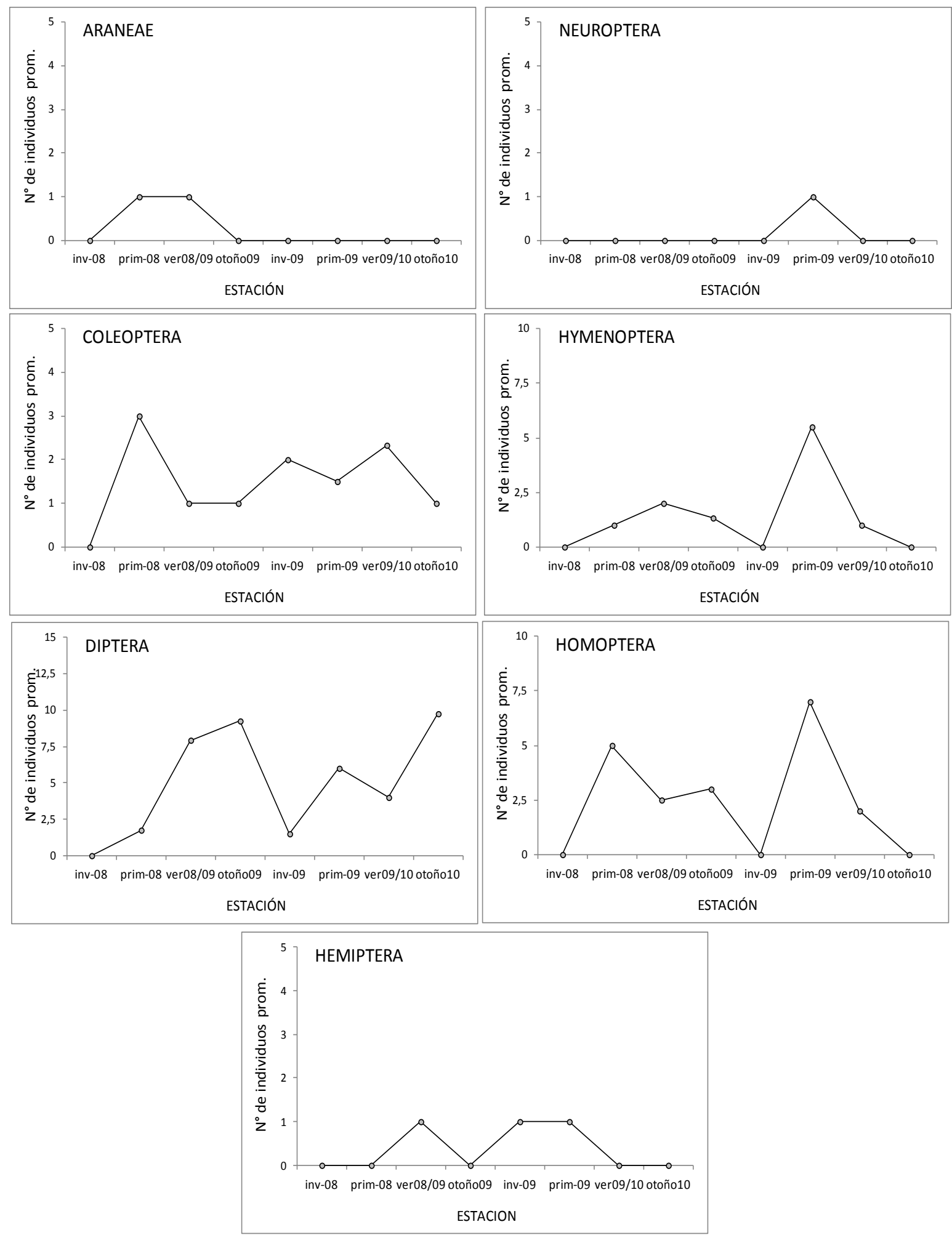

Fig. 4.40: Variación estacional en el número de individuos (promedio) pertenecientes a los órdenes representados en las capturas de sitio PRJO. 


\section{Comparación entre PRPI y PRJO}

Si bien en términos generales no hubo diferencias entre sitios de muestreo en la abundancia de los órdenes ( $F=0,40 ; p=0,8464 ;$ Tabla 4.56), Homóptera e Hymenoptera fueron más abundantes en PRPI $(5,00$ $\pm 6,55$ y $5,00 \pm 6,55$ respectivamente) que en PRJO $(3,43 \pm 2,15$ y 2,22 $\pm 2,95$ respectivamente; $\mathrm{N}-\mathrm{K} \mathrm{p}<0,01$ en ambos casos) (Tabla 4.36). No se observaron diferencias significativas entre sitios en la riqueza, y en los índices de diversidad, dominancia y equitatividad ( $p>0,05 ;$ Tabla 4.37).

Tabla 4.36: Órdenes de artrópodos representados en los sitios PRPI y PRJO. Los valores son expresados como media \pm desvío estándar (D.E.) y rango. Las letras iguales indican que no se encontraron diferencias significativas en los órdenes entre sitios de muestreo.

\begin{tabular}{|l|c|c|c|c|}
\hline Sitios & Órdenes & Media \pm D.E. & Rango & Significación \\
\hline PRJO & ARANEAE & $1,00 \pm 0,00$ & $1-1$ & $\mathrm{a}$ \\
PRPI & ARANEAE & $1,33 \pm 0,58$ & $1-2$ & $\mathrm{a}$ \\
\hline PRJO & COLEOPTERA & $1,62 \pm 0,87$ & $1-3$ & $\mathrm{a}$ \\
PRPI & COLEOPTERA & $1,80 \pm 0,84$ & $1-3$ & $\mathrm{a}$ \\
\hline PRPI & DERMAPTERA & $1,00 \pm 0,00$ & $1-1$ & - \\
\hline PRJO & DIPTERA & $6,53 \pm 9,95$ & $1-46$ & $\mathrm{a}$ \\
PRPI & DIPTERA & $5,94 \pm 7,67$ & $1-33$ & $\mathrm{a}$ \\
\hline PRJO & HEMIPTERA & $1,00 \pm 0,00$ & $1-1$ & - \\
\hline PRJO & HOMOPTERA & $3,43 \pm 2,15$ & $1-7$ & $\mathrm{a}$ \\
\cline { 2 - 5 } PRPI & HOMOPTERA & $7,67 \pm 6,43$ & $3-15$ & $\mathrm{~b}$ \\
\hline PRJO & HYMENOPTERA & $2,22 \pm 2,95$ & $1-10$ & $\mathrm{a}$ \\
\cline { 2 - 5 } PRPI & HYMENOPTERA & $5,00 \pm 6,55$ & $1-20$ & $\mathrm{~b}$ \\
\hline PRPI & LEPIDOPTERO & $1,33 \pm 0,52$ & $1-2$ & - \\
\hline PRJO & NEUROPTERA & $1,00 \pm 0,00$ & $1-1$ & - \\
\hline
\end{tabular}


Tabla 4.37: Riqueza, dominancia, diversidad y equitatividad de órdenes representados en los sitios PRJO y PRPI. Los valores son expresados como media \pm desvío estándar y rango entre paréntesis.

\begin{tabular}{|c|c|c|c|}
\hline Sitios & Índice & Media \pm D.E. & Significación \\
\hline PRJO & \multirow{2}{*}{ Riqueza } & $\begin{array}{c}0,13 \pm 0,07 \\
(0,09-0,24)\end{array}$ & \multirow{2}{*}{$p=0,6190$} \\
\hline PRPI & & $\begin{array}{l}0,14 \pm 0,06 \\
(0,11-0,28)\end{array}$ & \\
\hline PRJO & \multirow{2}{*}{ Dominancia } & $\begin{array}{l}0,02 \pm 0,29 \\
(0,34-0,51)\end{array}$ & \multirow{2}{*}{$p=0,1349$} \\
\hline PRPI & & $\begin{array}{l}0,04 \pm 0,17 \\
(0,20-0,37)\end{array}$ & \\
\hline PRJO & \multirow{2}{*}{ Diversidad } & $\begin{array}{l}0,23 \pm 0,13 \\
(0,00-0,36)\end{array}$ & \multirow{2}{*}{$p=0,5428$} \\
\hline PRPI & & $\begin{array}{l}0,31 \pm 0,04 \\
(0,24-0,36)\end{array}$ & \\
\hline PRJO & \multirow{2}{*}{ Equitatividad } & $\begin{array}{l}0,36 \pm 0,28 \\
(0,00-0,73)\end{array}$ & \multirow{2}{*}{$p=0,8836$} \\
\hline PRPI & & $\begin{array}{l}0,29 \pm 0,14 \\
(0,02-0,51)\end{array}$ & \\
\hline
\end{tabular}

\subsubsection{Comparación entre sitios asociados a diferentes impactos}

No se observaron diferencias significativas entre sitios afectados por los diferentes impactos en la abundancia de los diferentes $(F=0,77$; $p=0,9358)$. Del mismo modo, tampoco se observaron diferencias significativas entre temporadas en la abundancia de los órdenes representados en las capturas de los diferentes sitios de muestreo $(\mathrm{F}=0,72 ; \mathrm{p}=0,98 ; \mathrm{Fig} .4 .41)$. La riqueza y los índices de diversidad, dominancia y equitatividad fueron similares en los sitios de muestreo sometidos a diferentes tipos de impactos $(p>0,05)$. 


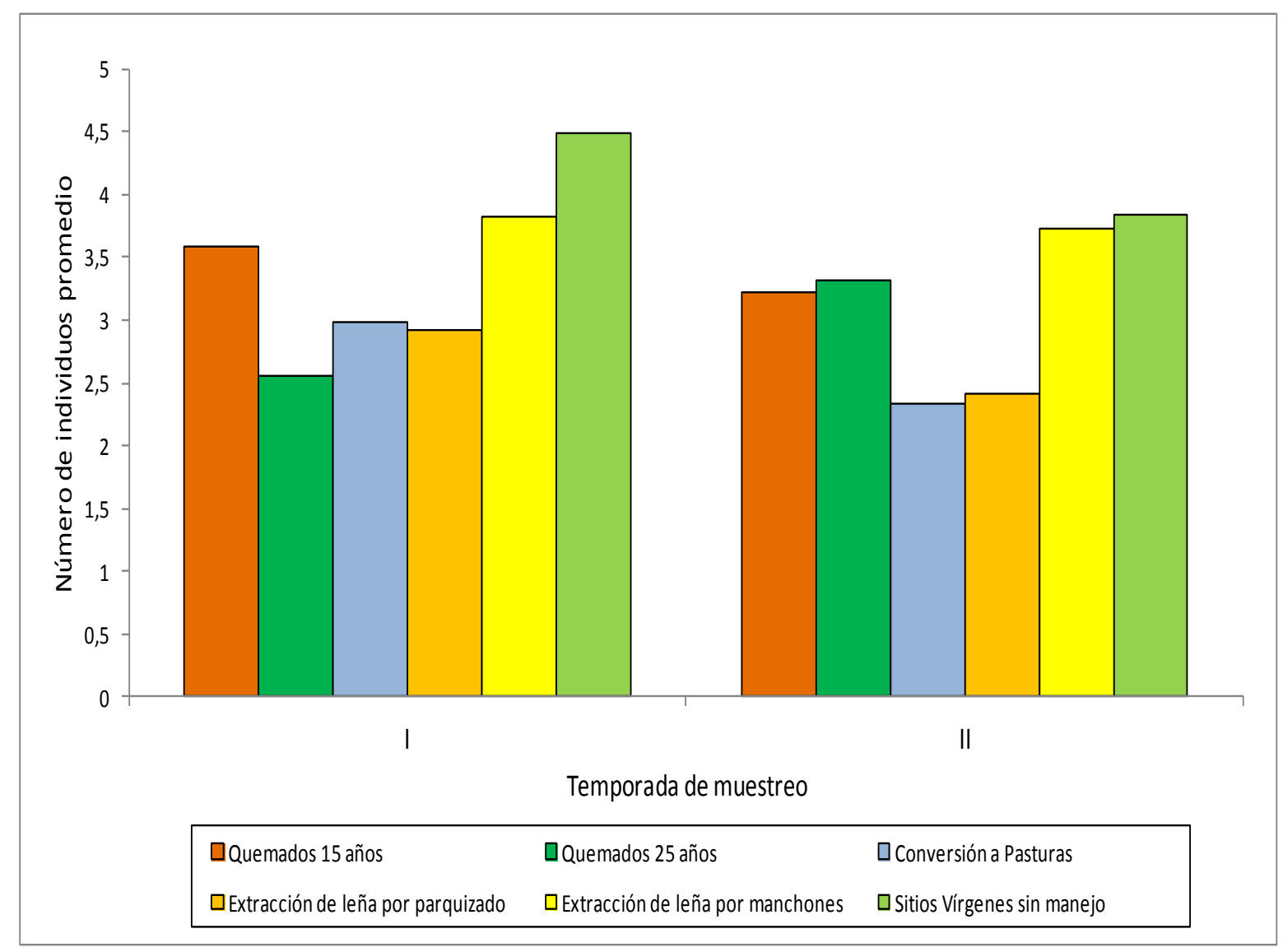

Fig. 4.41: Número de individuos promedio sobre el total de artrópodos capturados en los sitios según las temporadas de muestreo.

\subsubsection{Eficiencia de las Técnicas de Muestreo}

El número de individuos capturados por los diferentes tipos de muestreo difirió significativamente $(F=38,18 ; p<0,0001)$. Las muestras mas abundantes fueron las provenientes de las trampas "fluid interception" (media 4,25; rango 0-46; d.e. 6,06) (Fig. 4.43), seguidas por las trampas "sticky traps" (media 4,49; rango 0-50; d.e. 7,$30 ; \mathrm{N}-\mathrm{K} \mathrm{p}<0,01$ ) (Fig. 4.44), luego las obtenidas del suelo (obtenidas con sacabocado)(media 1,92 ; rango $0-25$; d.e. 2,67 )(Fig. $4.45)$ y finalmente, las provenientes del dosel de las plantas (media 1,21; rango 0-7; d.e.1,0; N-K p<0,01) (Fig. 4.42).

El número de individuos capturados pertenecientes a cada orden varió con la técnica de muestreo implementada $(F=3,17$; 
$\mathrm{p}<0,0001)$. En las muestras de dosel se capturó mayor cantidad de individuos pertenecientes a los órdenes Diptera $(1,92 \pm 1,83)$ y Coleóptera $(1,66 \pm 1,15)$ que del resto de los órdenes representados $(\mathrm{N}-\mathrm{K} \mathrm{p}<0,01 ;$ Fig. 4.42). Con las trampas "Fluid interception" se capturaron mas individuos pertenecientes a los órdenes Homóptera $(5,62 \pm 5,6)$ y Díptera $(5,55 \pm 7,45)$ que al resto de los órdenes ( $\mathrm{N}-\mathrm{K}$ $\mathrm{p}<0,01$; Fig. 4.43). Las trampas "Sticky traps" capturaron mayor cantidad de individuos del orden Díptera $(5,59 \pm 7,93)$ que del resto de los órdenes ( $\mathrm{N}-\mathrm{K} \mathrm{p}<0,01 ; \mathrm{Fig} .4 .44$ ), en tanto que, comparado con el resto de los órdenes, Coleóptero $(5,64 \pm 5,04)$ fue el orden más abundante en las muestras de suelo ( $\mathrm{N}-\mathrm{K} \mathrm{p}<0,01$; Fig. 4.45).

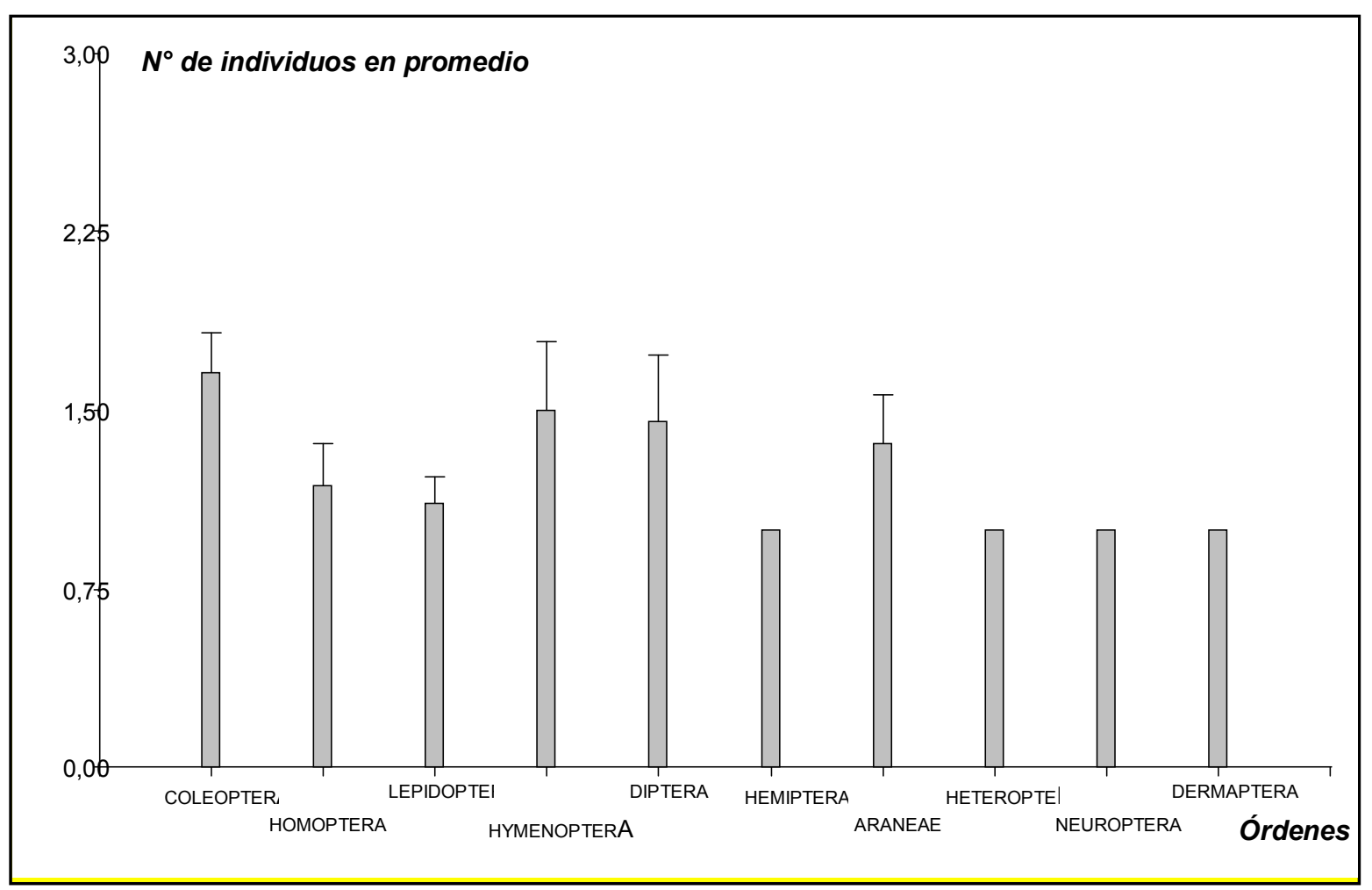

Fig. 4.42: Número de individuos promedio de los órdenes de artrópodos capturados en las muestras del dosel de la vegetación. 


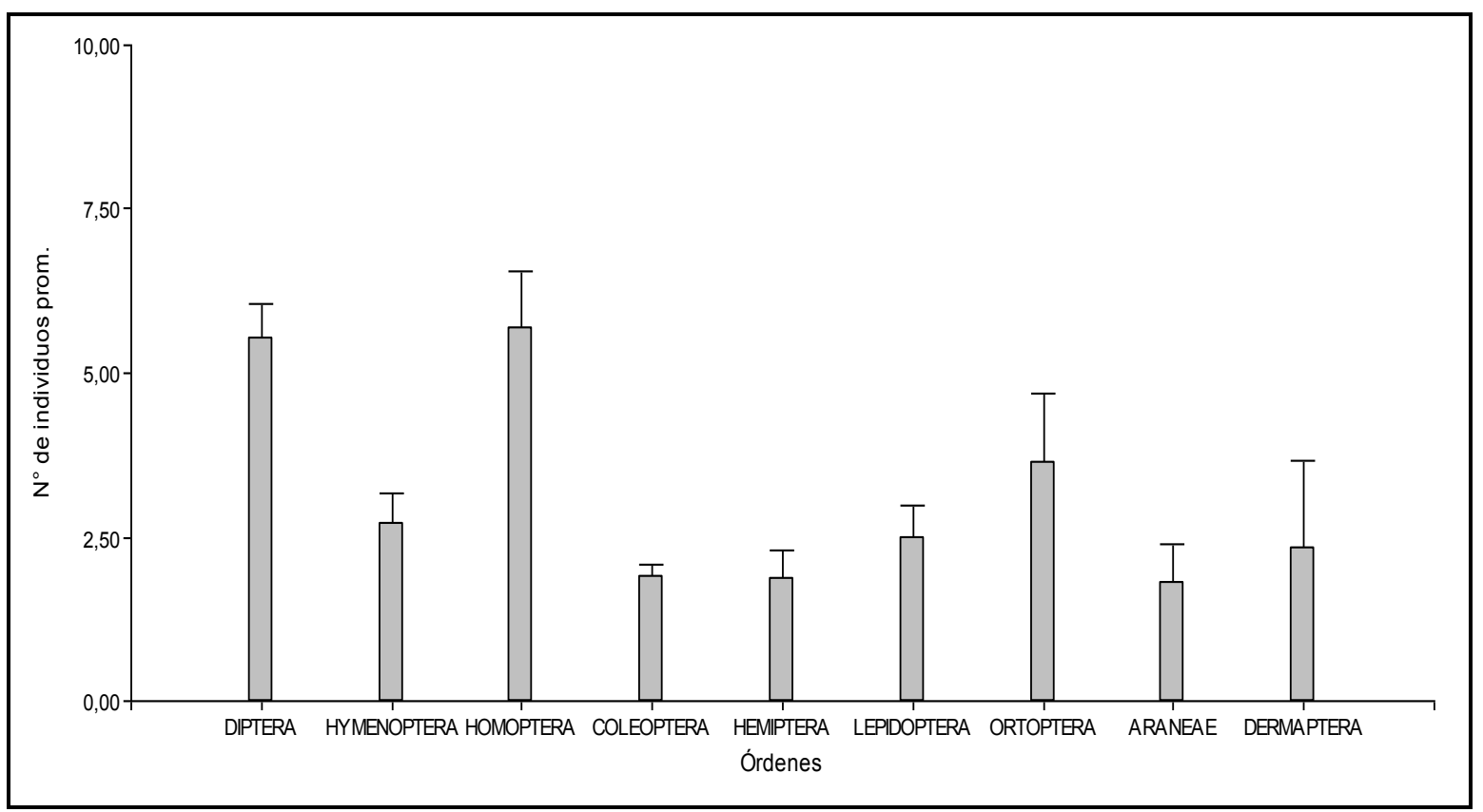

Fig. 4.43: Número de individuos promedio de los órdenes de artrópodos capturados con las trampas "Fluid interception".

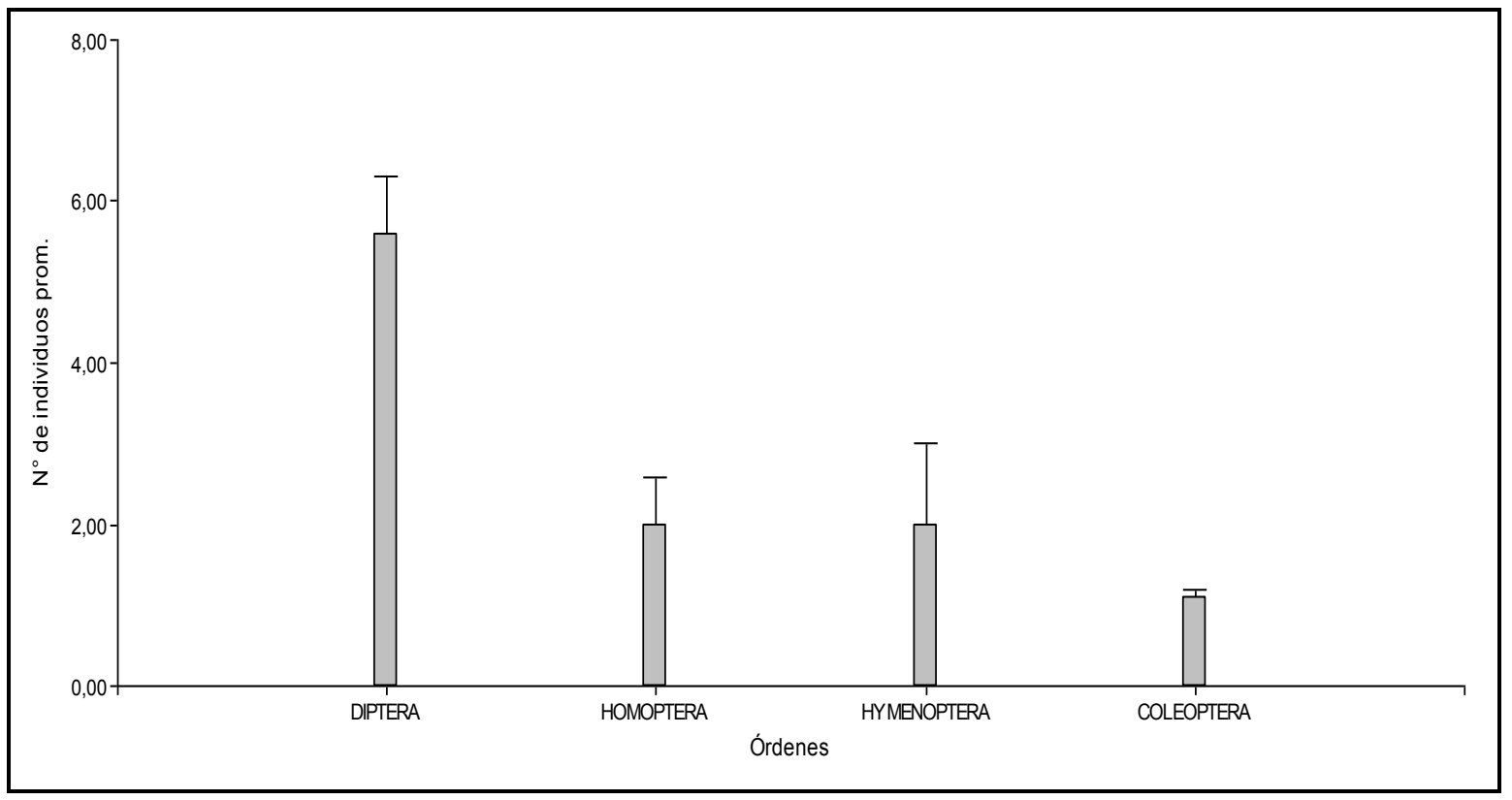

Fig. 4.44: Número de individuos promedio de los órdenes capturados con las trampas "Sticky traps". 


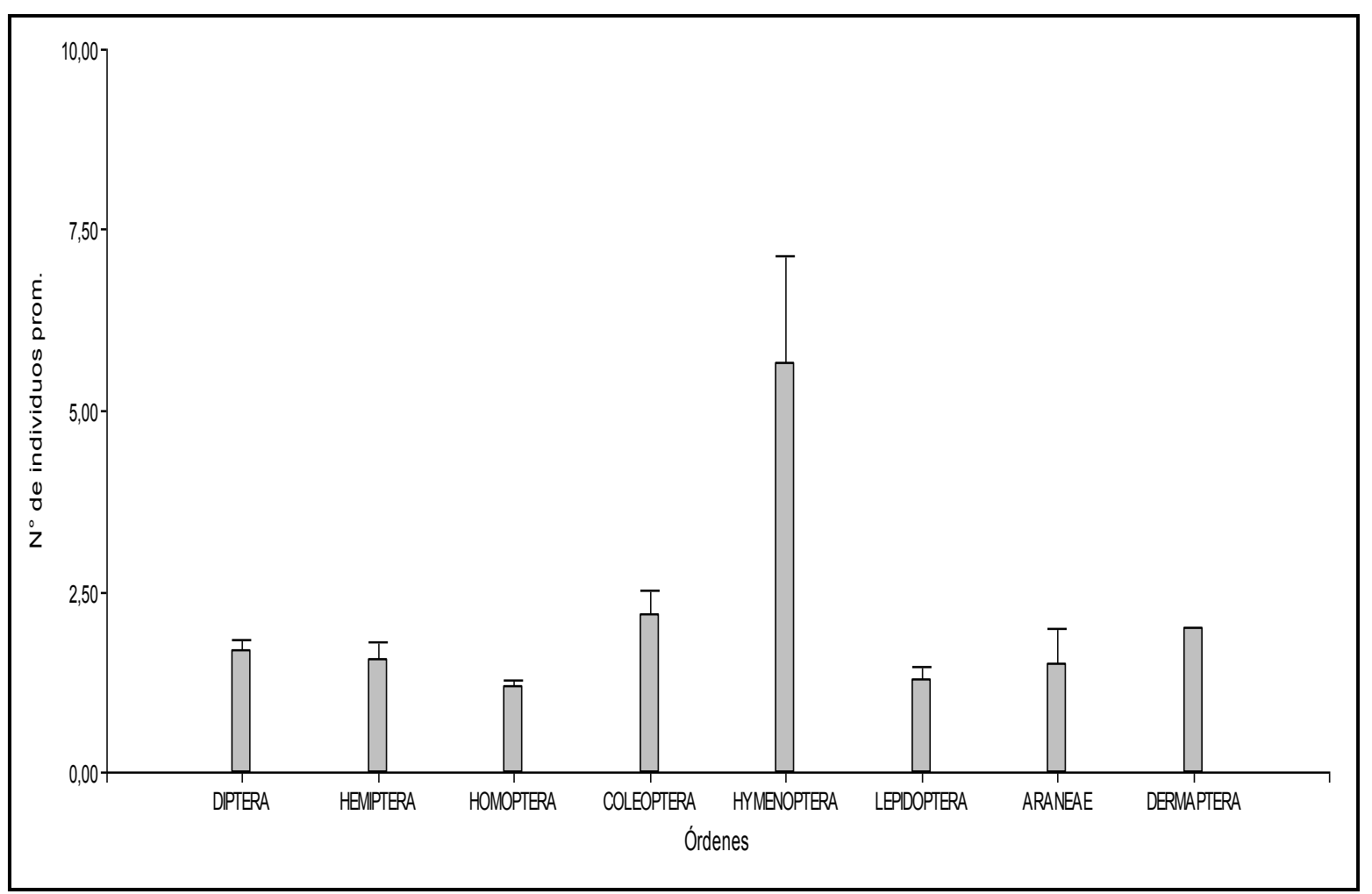

Fig. 4.45: Número de individuos promedio de los órdenes capturados en las muestras de suelo obtenidas con sacabocados. 


\section{4 - Resultados de la comunidad de aves asociadas a bosques de Ñire}

\subsubsection{Composición Específica de la Comunidad}

El número de especies observado en la totalidad de los sitios muestreados fue de 56 que correspondieropn a 25 familias y 11 órdenes (Fig. 4.46 y Tabla 4.38). El número de especies identificadas mediante la metodologías de punto de conteo (PC) y de línea transecta (LT) fue de 49 y 44 especies respectivamente (Tabla 4.38); estas diferencias no fueron significativas (Kruskal-Wallis; $p>0,05$ ).

Dieciocho de las 56 especies identificadas con ambos métodos son endémicas del bosque andino-patagónico y en el caso de cuatro especies se constató que únicamente la subespecie es catalogada como endémica. Por último, solamente se observó una especie exótica (Tabla 4.38).

Tabla 4.38: Lista de especies, familia y órdenes, identificadas a través del censado por línea transecta y punto de conteo en la totalidad de los ñirantales sometidos a diferentes usos. La presencia o ausencia de especies son indicadas mediante $+y-$ respectivamente. La simbología para la tipología de especie es: * especie endémica; * s subespecie endémica; + especie introducida.

\begin{tabular}{|c|c|c|c|c|c|c|}
\hline Orden & Familia & Nombre científico & Nombre Común & PC & LT & Sp \\
\hline \multirow{2}{*}{ Anseriformes } & \multirow{2}{*}{ Anatidae } & Anas flavirostris & Pato Barcino & - & + & + \\
\hline & & Chloephaga picta & Cauquén Común & + & + & + \\
\hline Ardeiformes & Threskiornithidae & Theristicus melanopis & Bandurria Baya & + & + & + \\
\hline \multirow{3}{*}{ Charadriiformes } & Charadriidae & Vanellus chilensis & Tero & + & + & + \\
\hline & Laridae & Larus dominicanus & Gaviota Cocinera & + & - & + \\
\hline & Scolopacidae & Gallinago gallinago & Becasina & + & - & + \\
\hline Columbiformes & \begin{tabular}{|l|} 
Columbidae \\
\end{tabular} & Zenaida auriculata & Torcaza & + & + & + \\
\hline \multirow{9}{*}{ Falconiformes } & \multirow{4}{*}{ Accipitridae } & Accipiter bicolor * $\mathrm{s}$ & Esparvero Variado & + & - & + \\
\hline & & Buteo polyosoma & Aguilucho Común & + & + & + \\
\hline & & Circus cinereus & Gavilán Ceniciento & + & + & + \\
\hline & & Geranoaetus melanoleucus & Águila Mora & + & + & + \\
\hline & Cathartidae & Coragyps atratus & Jote Cabeza Negra & + & + & + \\
\hline & \multirow{4}{*}{ Falconidae } & Falco peregrinus * $\mathrm{s}$ & Halcón Peregrino & - & + & + \\
\hline & & Falco sparverius & Halconcito Colorado & + & + & + \\
\hline & & Polyborus chimango & Chimango & + & + & + \\
\hline & & Polyborus plancus & Carancho & + & + & + \\
\hline Galliformes & Phasianidae & Callipepla californicus $†$ & Codorníz Califórnica & + & + & + \\
\hline \multirow{3}{*}{ Passeriformes } & \multirow{3}{*}{ Emberizidae } & Diuca diuca & Diuca & + & + & + \\
\hline & & Melanodera xanthogramma * & Yal Andino & + & - & + \\
\hline & & Phrygilus gayi & Comesebo Andino & + & + & + \\
\hline
\end{tabular}




\begin{tabular}{|c|c|c|c|c|c|c|}
\hline & & Phrygilus patagonicus * & Comesebo Patagónico & + & + & + \\
\hline & & Phrygilus unicolor & Yal Plomizo & + & + & + \\
\hline & & Zonotrichia capensis & Chingolo & + & + & + \\
\hline & Fringillidae & Carduelis barbata * & Cabecita Negra Austral & + & + & + \\
\hline & & Aphrastura spinicauda * & Rayadito & + & + & + \\
\hline & & Asthenes modesta & Canastero Pálido & + & + & + \\
\hline & Furnariidae & Asthenes pyrrholeuca & Canastero Coludo & + & - & + \\
\hline & & Leptasthenura aegithaloides & Coludito Cola Negra & + & + & + \\
\hline & & Pygarrhichas albogularis * & Picolezna & + & - & + \\
\hline & & Upucerthia dumetaria & Bandurrita Común & + & + & + \\
\hline & Hirundinidae & Pigochelidon cyanoleuca & Golondrina Barranquera & + & - & + \\
\hline & 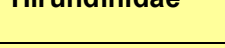 & Tachicineta leucopiga & Golondrina Patagónica & + & + & + \\
\hline & & Curaeus curaeus * & Tordo Patagónico & + & + & + \\
\hline & Icteridae & Molothrus bonariensis & Tordo Renegrido & + & - & + \\
\hline & & Sturnella loyca & Loica & + & + & + \\
\hline & Motaciliidae & Anthus correndera & Cachirla Común & - & + & + \\
\hline & 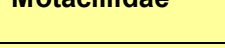 & Anthus hellmayri ${ }^{*} \mathrm{~s}$ & Cachirla Pálida & - & + & + \\
\hline & Phytotomidae & Phytotoma rara & Rara & + & + & + \\
\hline & & Pteroptochos tarnii * & Huet Huet & + & + & + \\
\hline & Rhinocryptidae & Scelorchilus rubecula * & Chucao & + & + & + \\
\hline & & Scytalopus magellanicus * & Churrín Andino & + & + & + \\
\hline & Troglodytidae & Troglodites aedon & Ratona Común & + & + & + \\
\hline & \begin{tabular}{|l|} 
Turdidae \\
\end{tabular} & Turdus falklandii & Zorzal Patagónico & + & + & + \\
\hline & & Agriornis lividus * $\mathrm{s}$ & Gaucho Grande & + & + & + \\
\hline & & Agriornis montanus & Gaucho Serrano & + & - & + \\
\hline & Tyrannidae & Anairetes parulus & Cachudito Pico Negro & - & + & + \\
\hline & Priaminat & Colorhamphus parvirostris * & Peutrén & + & - & + \\
\hline & & Elaenia albiceps & Fío Fío Silbón & + & + & + \\
\hline & & Xolmis pyrope * & Diucón & + & + & + \\
\hline & & Campephilus magellanicus * & Carp. Gigante Patag. & + & - & + \\
\hline Piciformes & Picidae & Colaptes pitius * & Carpintero Pitío & + & + & + \\
\hline & & Picoides lignarius & Carp. Bataráz Grande & + & + & + \\
\hline Psittaciformes & Psittacidae & Enicognathus ferrugineus & Cachaña & + & - & + \\
\hline Striaiformes & Strigidae & Bubo virginianus & Ñacurutú & - & + & + \\
\hline onginmes & otingiar & Glacidium nanum * & Caburé Grande & - & + & + \\
\hline Trochiliformes & Trochilidae & Oreotrochilus leucopleurus & Picaflor Andino & + & + & + \\
\hline & & Total & & 49 & 44 & 56 \\
\hline
\end{tabular}

Las familias mejor representadas en los censos fueron Embericidae, Tyrannidae y Furnaridae ( 6 especies cada una), todas pertenecientes al órden Passeriformes. Accipitridae y Falconidae (4 especies cada una) ambas familias, pertenecientes al órden Falconiformes, les siguieron en importancia (Tabla 4.38). Si bien el número de familias identificadas a través de censos de LT y PC fue similar (Kruskal-Wallis; $p>0,05$; Tabla 4.38 y 4.39), la familia Strigidae solo estuvo representada cuando el censo fue realizado mediante $L T$, en tanto que Laridae solamente estuvo representada en 
los PC (Fig. 4.46). Los órdenes con el mayor número de especies representadas fueron Passeriformes (32 especies) y Falconiformes (9 especies)(Fig. 4.47). Los ordenes identificados a través de ambos métodos de censado fueron coincidentes. En la Tabla 4.39 se resumen los datos de especies, familias y ordenes resgistrados mediante ambos métodos de conteo de avifauna (línea transecta y punto de conteo) en los ñirantales sometidos a diferentes usos.

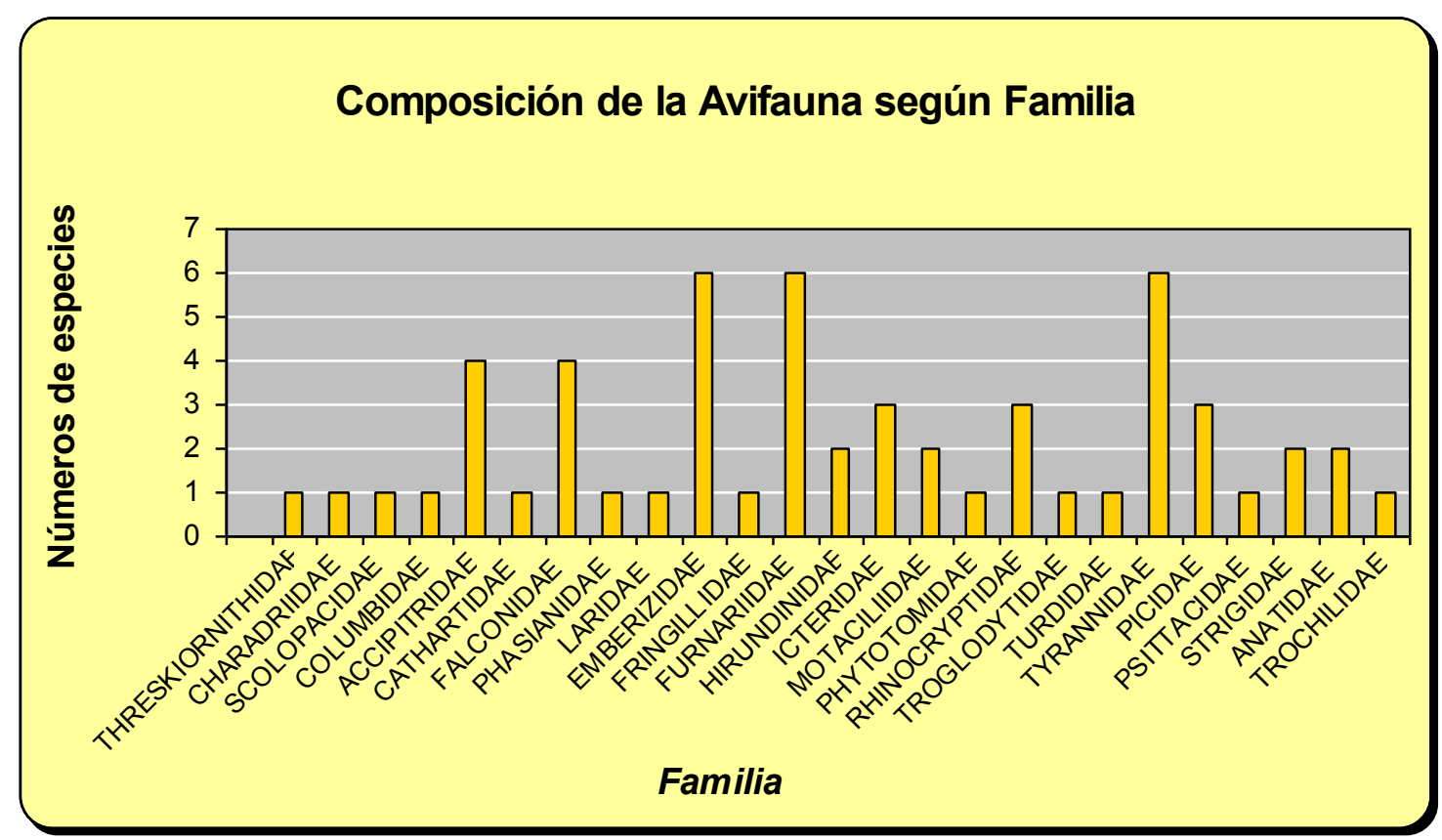

Fig. 4.46: Abundancia de especies por familias en los ñirantales sometidos a diferentes usos durante el período 2008 - 2010.

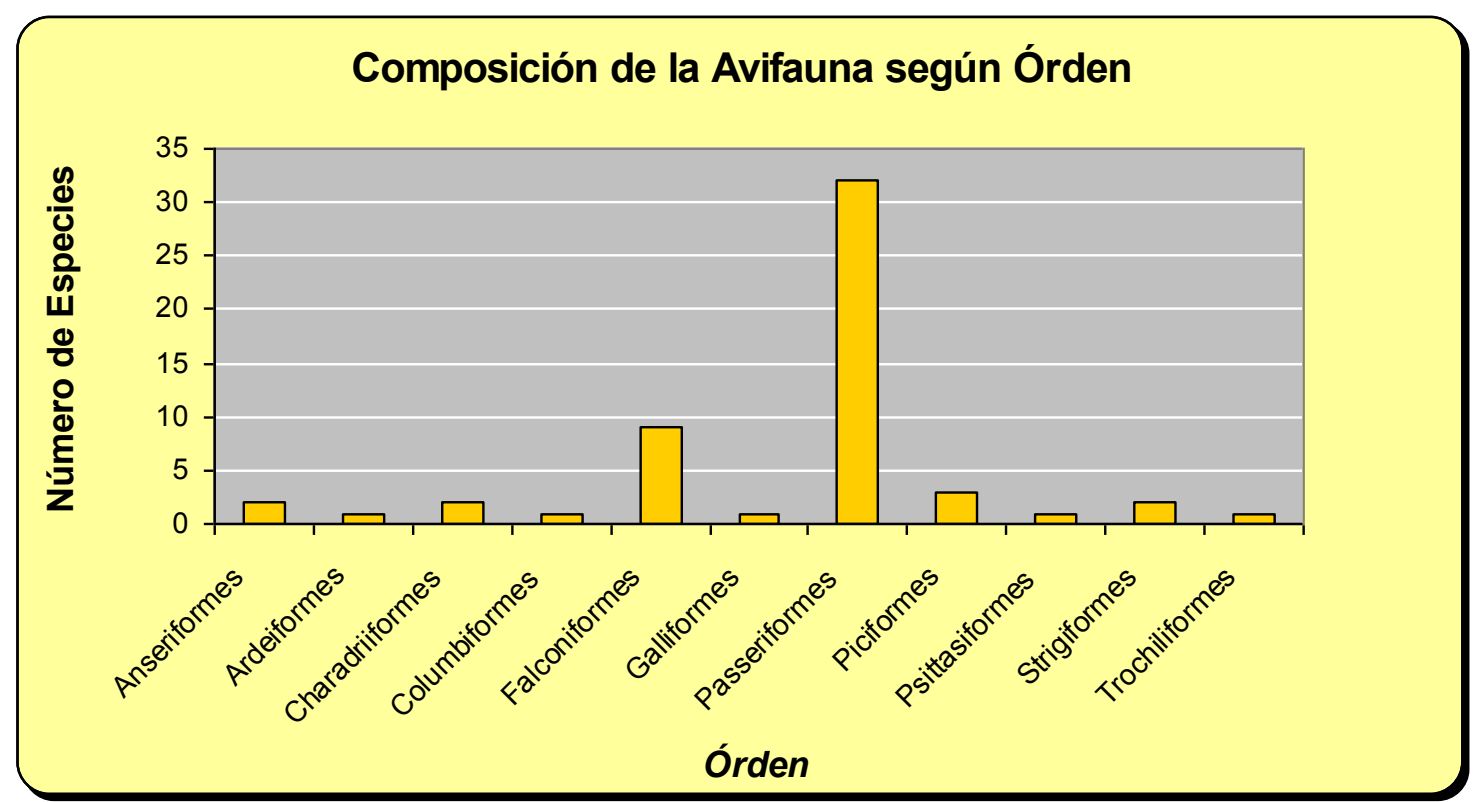

Fig. 4.47: Órdenes de aves representados en la totalidad de los ñirantales sometidos a diferentes usos durante el período 2008 - 2010. 
Tabla 4.39: Se indica el número de especies, familias y órdenes totales registrados mediante línea transecta y punto de conteo durante el período de muestreo en la totalidad de los ñirantales sometidos a diferentes usos.

\begin{tabular}{|c|c|c|c|}
\hline Nivel Taxonómico & PC & LT & Total \\
\hline Especies & 49 & 43 & 56 \\
\hline Familias & 24 & 24 & 25 \\
\hline Órdenes & 11 & 11 & 11 \\
\hline
\end{tabular}

\subsubsection{Riqueza Específica}

Las riquezas específicas observada en los ñirantales primarios y en los convertidos a pasturas difirieron de las del resto de los sitios (Kruskal-Wallis; $p=0,0058$ mediante PC, $p=0,0039$ mediante LT) (Fig. 4.48).

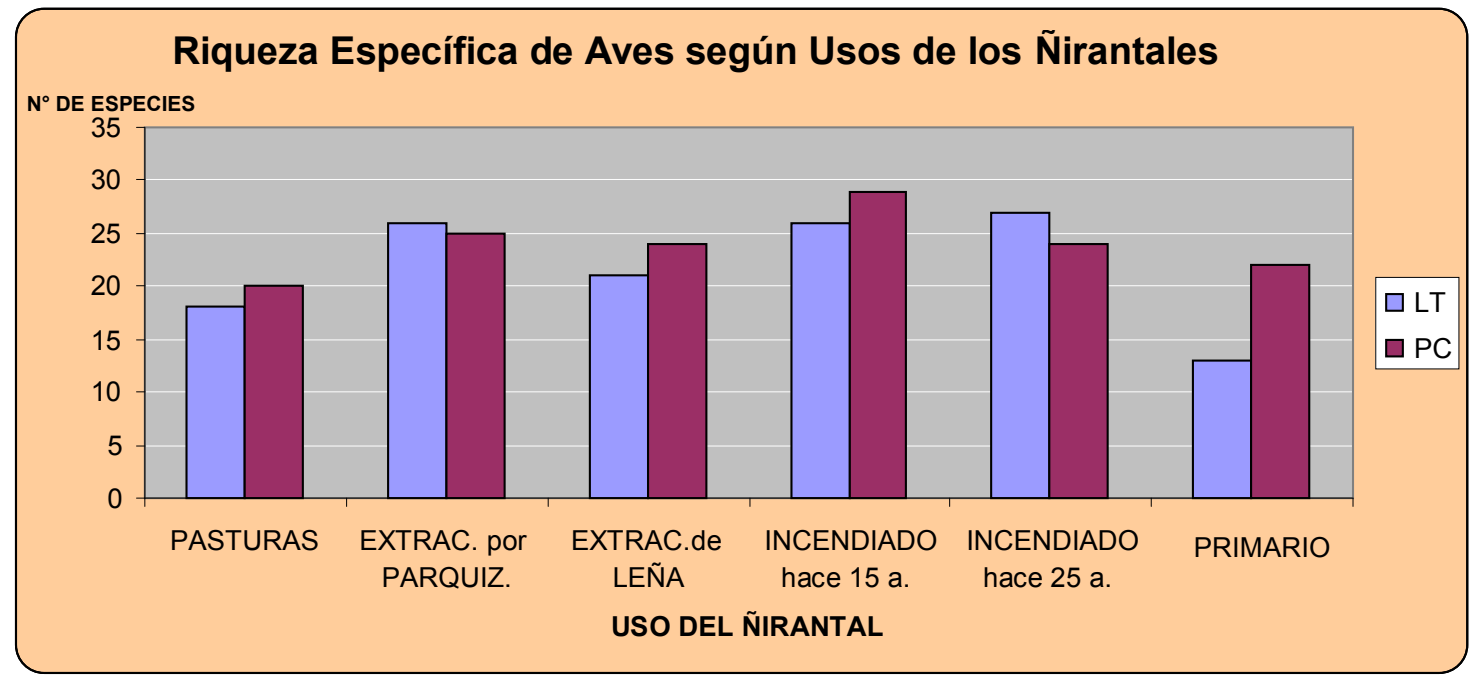

Fig. 4.48: Número de especies identificadas a través de las técnicas de LT y PC en ñirantales sometidos a diferentes usos durante el período 2008 - 2010.

\subsubsection{Abundancia Absoluta}

Mediante las técnicas de LT y PC se detectó un total de 2948 y 3752 especímenes respectivamente. El $81 \%$ y $87 \%$ de los especímenes identificados mediante línea transecta y puntos de conteo fueron observados, en tanto que los restantes especímenes fueron distinguidos mediante la identificación de sus vocalizaciones. 


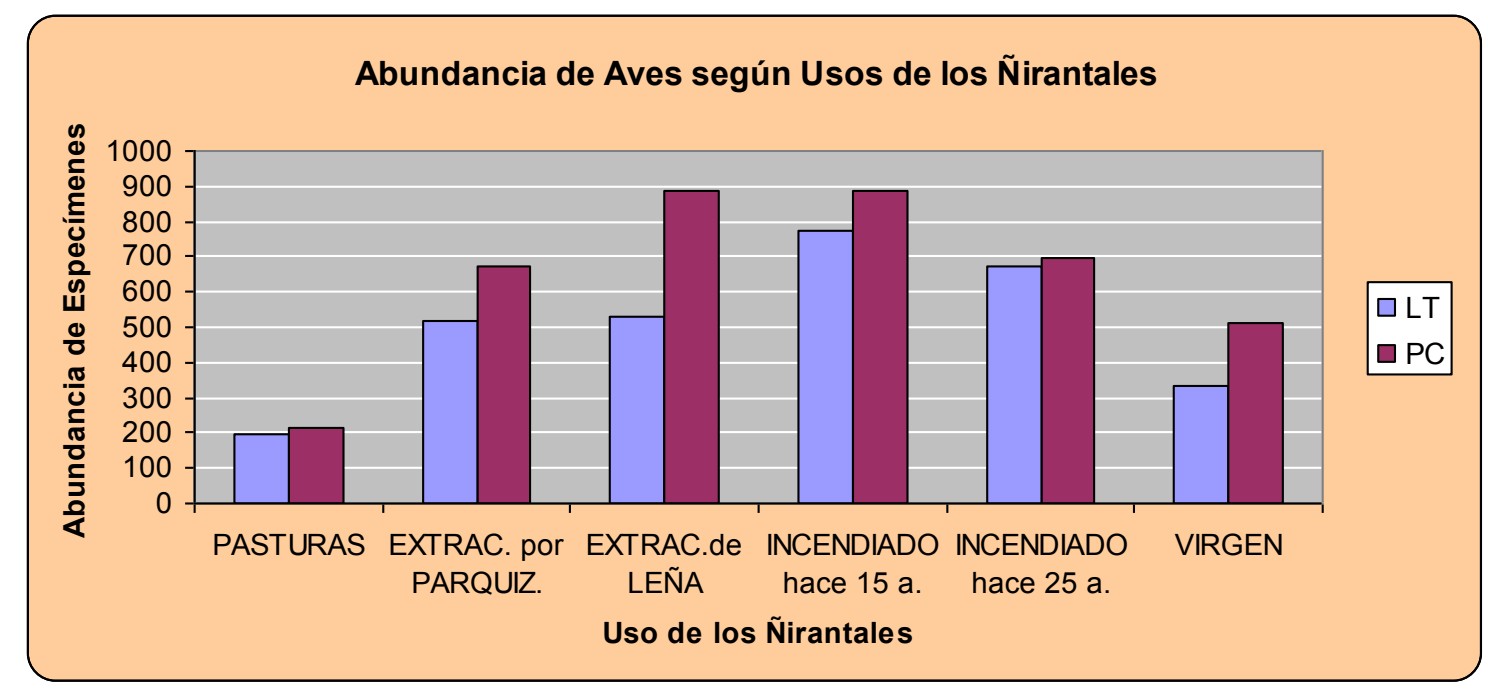

Fig. 4.49 Número de especímenes observados mediante puntos de conteo y línea transecta en la totalidad de los ñirantales sometidos a diferentes usos durante el período bianual $2008-2010$.

En los ñirantales primarios y en los convertidos a pasturas se observaron las menores abundancias (Fig. 4.49). Las abundancias observadas en los PC de los diferentes tipos de ñirantales difirieron significativamente (Kruskal-Wallis: Chí $\left.^{2}=18,5 ; \mathrm{gl}=5 ; \mathrm{p}<0,0024\right)$, hecho que no ocurrió en relación a las (Kruskal-Wallis: Chí $^{2}=8 ; \mathrm{gl}=5$; $p<0,1562)$.

La mayoría de los especímenes fueron observados posados en copas de árboles o volando (Fig. 4.50) y el número de individuos identificados en los distintos sustratos difirió según el método de censado (Kruskal-Wallis; $p=0,00001$ mediante PC y $p=0,0017$ mediante LT) (Fig. 4.50). 


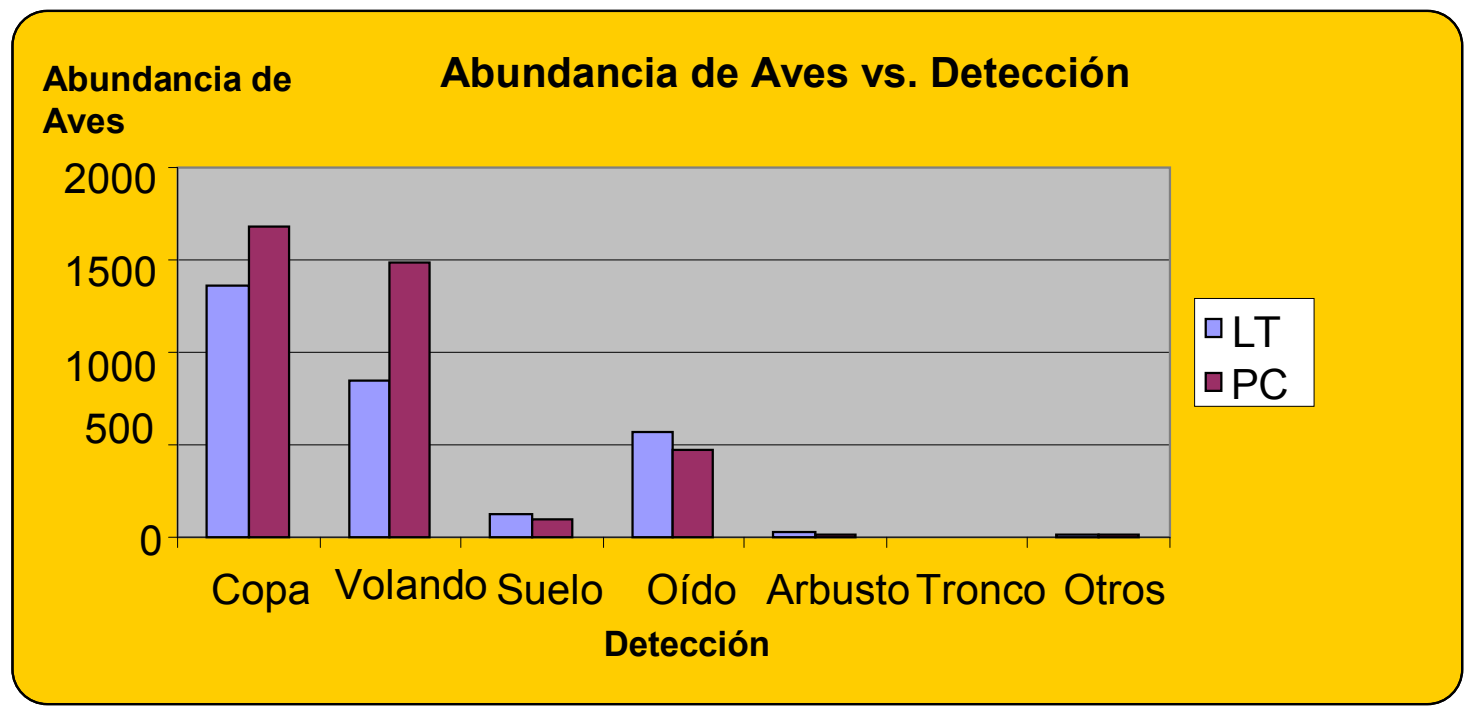

Fig. 4.50: Número de especímenes observados en base al modo de detección mediante línea transecta o punto de conteo durante el período bianual 2008 - 2010 en la totalidad de los ñirantales sometidos a diferentes usos.

\subsubsection{Abundancia Relativa}

Las abundancias relativas de los individuos observados en los diferentes sustratos mediante ambas metodologías de censado (Tabla 4.40), no difirieron significativamente comparando ambas metodologías (Kruskal-Wallis; p>0,05)(Fig. 4.49).

Tabla 4.40: Abundancias relativas según sitios o modos de detección, durante el período bianual 2008 - 2010, basados en el relevamiento mediante puntos de conteo y línea transecta en todos los hábitats de los ñirantales sometidos a los diferentes modos de explotación.

\begin{tabular}{ccccccccccc} 
Met. & Conteo & Total & Copa & Volando & Suelo & Oído & Arbusto & Tronco & Otros \\
\cline { 4 - 11 } & TOTAL & 2948 & 1362 & 853 & 131 & 564 & 27 & 2 & 9 \\
\hline & $\%$ & 100 & 46,2 & 28,9 & 4,4 & 19,1 & 0,9 & 0,2 & 0,3 \\
PC & TOTAL & 3752 & 1675 & 1480 & 99 & 468 & 17 & 4 & 9 \\
\hline & $\%$ & 100 & 44,6 & 39,4 & 2,6 & 12,4 & 0,5 & 0,2 & 0,3
\end{tabular}


Tabla 4.41: Abundancias relativas en los diferentes muestreos estacionales durante el período bianual 2008 - 2010, basados en el relevamiento por puntos de conteo y línea transecta en la totalidad de los ñirantales sometidos a diferentes modos de explotación

\begin{tabular}{|c|c|c|c|c|}
\hline Metod. & \multicolumn{2}{|c|}{$L T$} & \multicolumn{2}{|c|}{$P C$} \\
\hline Estación & Total & $\%$ & Total & $\%$ \\
\hline $\begin{array}{l}I_{1} \\
P_{1} \\
V_{1} \\
O_{1}\end{array}$ & $\begin{array}{l}144 \\
346 \\
508 \\
221 \\
\end{array}$ & $\begin{array}{c}4,8 \\
11,7 \\
17,2 \\
7,4\end{array}$ & $\begin{array}{l}142 \\
372 \\
638 \\
503\end{array}$ & $\begin{array}{c}3,7 \\
9,9 \\
17 \\
13,4\end{array}$ \\
\hline $\begin{array}{c}I_{2} \\
P_{2} \\
V_{2} \\
O_{2} \\
\text { TOTAL }\end{array}$ & $\begin{array}{l}133 \\
775 \\
697 \\
124 \\
2948\end{array}$ & $\begin{array}{c}4,5 \\
26,2 \\
23,6 \\
4,2 \\
100\end{array}$ & $\begin{array}{l}194 \\
776 \\
842 \\
285 \\
3752\end{array}$ & $\begin{array}{c}5,1 \\
20,6 \\
22,4 \\
7,6 \\
100\end{array}$ \\
\hline
\end{tabular}

\subsubsection{Nivel de Conservación}

Con respecto al estado de conservación y en base a los procedimientos de Acosta y Murúa (1998 y 1999), se detectaron tres especies (mediante ambos métodos PC y LT) con rango de Vulnerable (abreviado como VU), se la denomina así cuando, tras ser evaluada por la UICN, es clasificada en esta categoría de la Lista Roja tras determinarse que presenta una alta probabilidad de convertirse en "especie en peligro de extinción" (IUCN 2001)(Fig. 4.51): Carpintero Gigante Patagónico (Campephilus magellanico), Picolezna (Pygarrhichas albogularis) y, Cauquén Común (Chloephaga picta), y solo una especie introducida Codorniz californica (Callipepla californicus).

En la Fig. 4.51 se observa el número de especies categorizadas para cada uno de los niveles de conservación: 


\section{Composición de la avifauna según el Estado de Conservación}

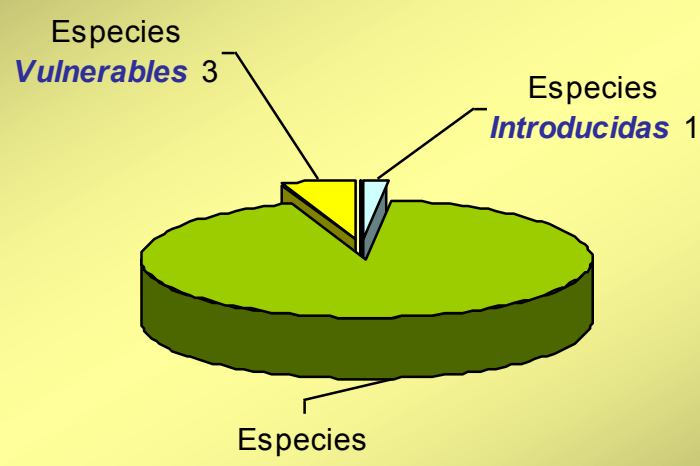

No amenazadas

52

Fig. 4.51: Número de especies según estado de riesgo, durante el período bianual de relevamientos observados en todos los hábitats de los ñirantales estudiados.

En la Fig. 4.52 se discrimina las especies vulnerables observadas con ambos métodos en los diferentes ñirantales sometidos a diferentes usos.

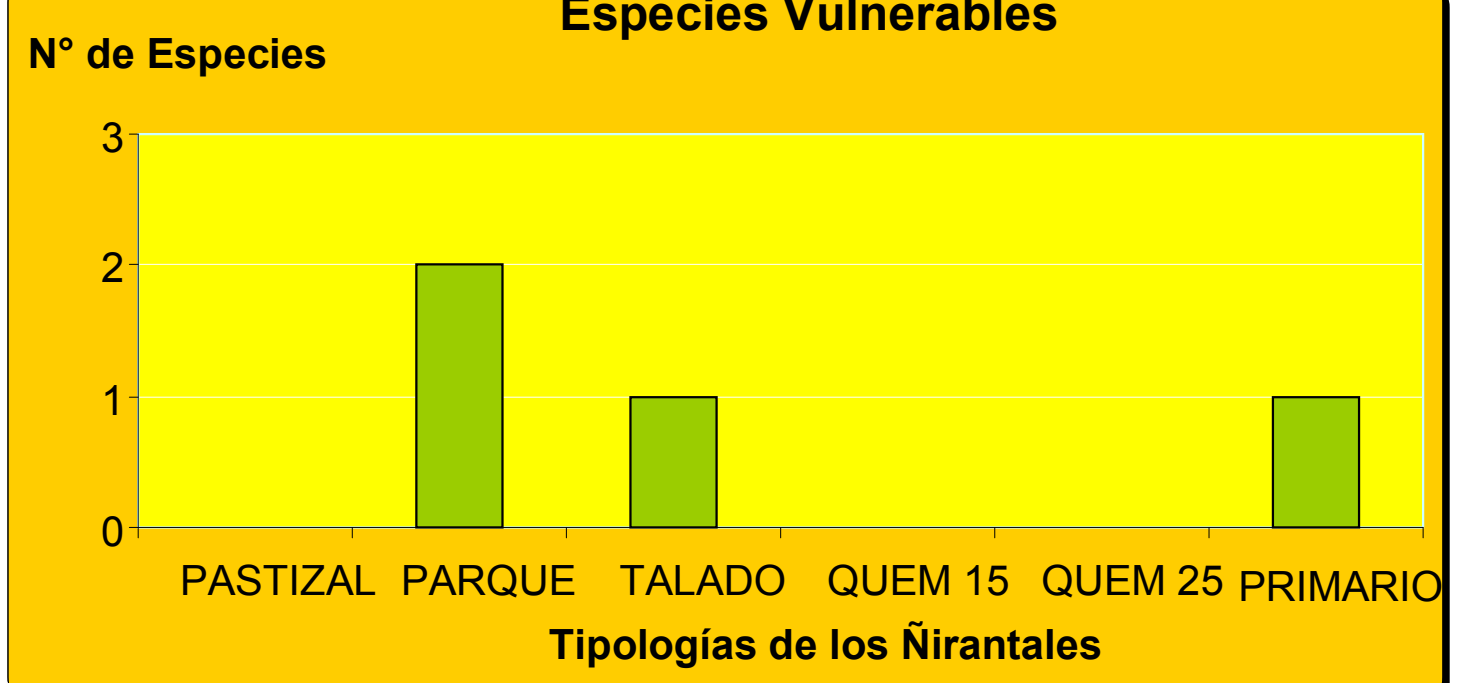

Fig. 4.52: Número de especies vulnerables según los diferentes usos de los ñirantales durante el período bianual 2008 - 2010 en los diferentes muestreos estacionales. 


\subsection{6 Índice SUMIN (Suma de Índices)}

Los valores SUMIN correspondientes a las especies observadas durante los censos fluctuaron entre 19 (Carpintero Gigante Patagónico) y 0 (Codorníz califórnica) (Tabla 4.42). Solo tres especies (Carpintero Gigante Patagónico, Churrín Andino y Picolezna) presentaron niveles de SUMIN por encima del valor medio de la escala (el índice fluctúa entre 0 y 30 ). El valor promedio de SUMIN de las especies observadas fue 8,91 (tercio menor de la escala, Fig. 4.53).

Tabla 4.42: Valores de SUMIN (Suma de Índices de Conservación) y estatus de conservación de las especies representadas en los censos desarrollados durante el período bianual de estudio 2008-2010. (Abreviaturas: NA no amenazada, IN introducida y VU vulnerable) (Se indican en la $5^{\circ}$ columna los códigos de cada una de las especies de aves).

\begin{tabular}{|c|c|c|c|c|}
\hline Especie & Nombre científico & SUMIN & Estatus & Código \\
\hline Carpintero gigante patagónico & Campephilus magellanicus & 19 & VU & CAMA \\
\hline Churrin andino & Scytalopus magellanicus & 17 & NA & SCMA \\
\hline Picolezna & Pygarrhichas albogularis & 15 & VU & PYAL \\
\hline Peutrén & Colorhamphus parvirostris & 14 & NA & COPA \\
\hline Rara & Phitotoma rara & 14 & NA & PHRA \\
\hline Chucao & Scelorchilus rubecula & 13 & NA & SCRU \\
\hline Picaflor andino & Oreotrochilus leucopleurus & 13 & NA & ORLE \\
\hline Carpintero bataráz grande & Picoides lignarius & 13 & NA & PILI \\
\hline Esparvero variado & Accipiter bicolor & 13 & NA & ACBI \\
\hline Gaucho grande & Agriornis lividus & 12 & NA & AGLI \\
\hline Halcón peregrino & Falco peregrinus & 12 & NA & FAPE \\
\hline Cauquén común & Chloephaga picta & 11 & VU & CHPI \\
\hline Huet huet & Pteroptochos tarnii & 11 & NA & HUHU \\
\hline Águila mora & Geranoaetus melanoleucus & 11 & NA & GEME \\
\hline Caburé grande & Glacidium nanum & 11 & NA & GLNA \\
\hline Carpintero pitío & Colaptes pitius & 11 & NA & COPI \\
\hline Comesebo patagónico & Phrigilus patagonicus & 11 & NA & PHPA \\
\hline Diucón & Xolmis pyrope & 11 & NA & XOPY \\
\hline Pato barcino & Anas flavirostris & 11 & NA & ANFL \\
\hline Rayadito & Aphrastura spinicauda & 11 & NA & APSP \\
\hline Yal plomizo & Phrygilus unicolor & 11 & NA & PHUN \\
\hline Bandurria baya & Theristicus melanopis & 10 & NA & THME \\
\hline Bandurrita común & Upucerthia dumetaria & 10 & NA & UPDU \\
\hline Cachaña & Enicognathus ferrugineus & 10 & NA & ENFE \\
\hline Cachirla pálida & Anthus hellmayri & 10 & NA & ANHE \\
\hline Canastero pálido & Asthenes modesta & 10 & NA & ASMO \\
\hline Diuca común & Diuca diuca & 10 & NA & DIDI \\
\hline Gaucho serrano & Agriornis montanus & 10 & NA & AGMO \\
\hline Yal andino & Melanodera xanthogramma & 10 & NA & MEXA \\
\hline Canastero coludo & Asthenes pyrrholeuca & 9 & NA & ASPY \\
\hline Coludito cola negra & Leptasthenura aegithaloides & 9 & NA & LEAE \\
\hline
\end{tabular}




\begin{tabular}{|l|l|l|l|c|}
\cline { 4 - 5 } Gavilán ceniciento & Circus cinereus & $\mathbf{9}$ & NA & CICI \\
\hline Aguilucho común & Buteo polyosoma & $\mathbf{8}$ & NA & BUPO \\
\hline Cachudito pico negro & Anairetes parulus & $\mathbf{8}$ & NA & ANPA \\
\hline Comesebo andino & Phrigilus galli & $\mathbf{8}$ & NA & PHGA \\
\hline Golondrina patagónica & Tachicineta leucopiga (T. meyeni) & $\mathbf{8}$ & NA & TALE \\
\hline Nacurutú & Buvo virginianus & $\mathbf{8}$ & NA & BUVI \\
\hline Tordo patagónico & Curaeus curaeus & $\mathbf{8}$ & NA & CUCU \\
\hline Zorzal patagónico & Turdus falklandii & $\mathbf{8}$ & NA & TUFA \\
\hline Becasina común & Gallinago gallinago (G. paraguaiae) & $\mathbf{7}$ & NA & GAGA \\
\hline Gaviota cocinera & Larus dominicanus & $\mathbf{7}$ & NA & LADO \\
\hline Cabecita negra austral & Carduelis barbata & $\mathbf{6}$ & NA & CABA \\
\hline Fiofío silbón & Elaenia albiceps & $\mathbf{6}$ & NA & ELAL \\
\hline Loica común & Sturnella loyca & $\mathbf{6}$ & NA & STLO \\
\hline Cachirla común & Anthus correndera & $\mathbf{5}$ & NA & ANCO \\
\hline Carancho & Poliborus plancus & $\mathbf{5}$ & NA & POPL \\
\hline Chimango & Milvago chimango & $\mathbf{5}$ & NA & MICH \\
\hline Golondrina barranquera & Pigochelidon cyanoleuca & $\mathbf{5}$ & NA & PICY \\
\hline Jote cabeza negra & Coragyps atratus & $\mathbf{5}$ & NA & COAT \\
\hline Halconcito colorado & Falco sparverius & $\mathbf{4}$ & NA & FASP \\
\hline Tero & Vanellus chilensis & $\mathbf{4}$ & NA & VACH \\
\hline Torcaza & Zenaida auriculata & $\mathbf{4}$ & NA & ZEAU \\
\hline Chingolo & Zonotrichia capensis & $\mathbf{2}$ & NA & ZOCA \\
\hline Ratona común & Troglodites aedon & $\mathbf{1}$ & NA & TRAE \\
\hline Tordo renegrido & Molothrus bonariensis & $\mathbf{1}$ & NA & MOBO \\
\hline Codorníz califórnica & Lophortyx caliplepla & IN & LOCA \\
\hline
\end{tabular}

El valor promedio de SUMIN, contabilizadas todas las aves observadas durante el estudio, arrojó un valor de 8,91 el cual corresponde al tercio menor de la escala, este resultado refleja una comunidad de avifauna de relevancia intermedia a baja en cuanto al nivel de conservación. En el siguiente gráfico se observa la distribución de las aves según el índice SUMIN (Fig. 4.53):

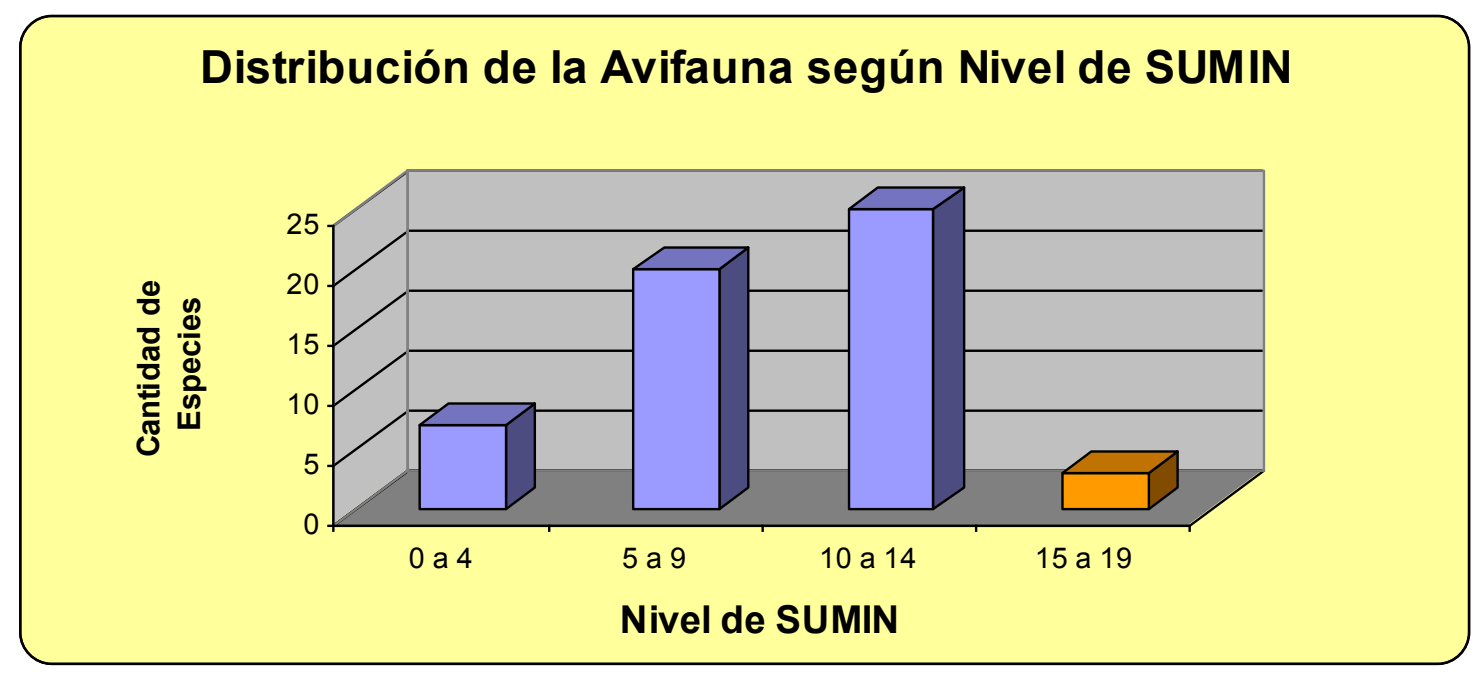

Fig. 4.53: Agrupamiento de las especies de avifauna según el nivel del índice SUMIN registrados durante la totalidad del período bianual de estudio. 


\subsubsection{SUMIN vs. Usos de los ñirantales}

Los valores SUMIN promedios del índice de las comunidades de aves representadas según los censos de PC (Kruskal-Wallis: Chí $^{2}=6 ; \mathrm{gl}=5$; p<0,3062; Fig. 4.54) y LT (Kruskal-Wallis: Chí $^{2}=5,48 ; \quad g l=5$; $\mathrm{p}<0,3595$; Fig. 4.55).

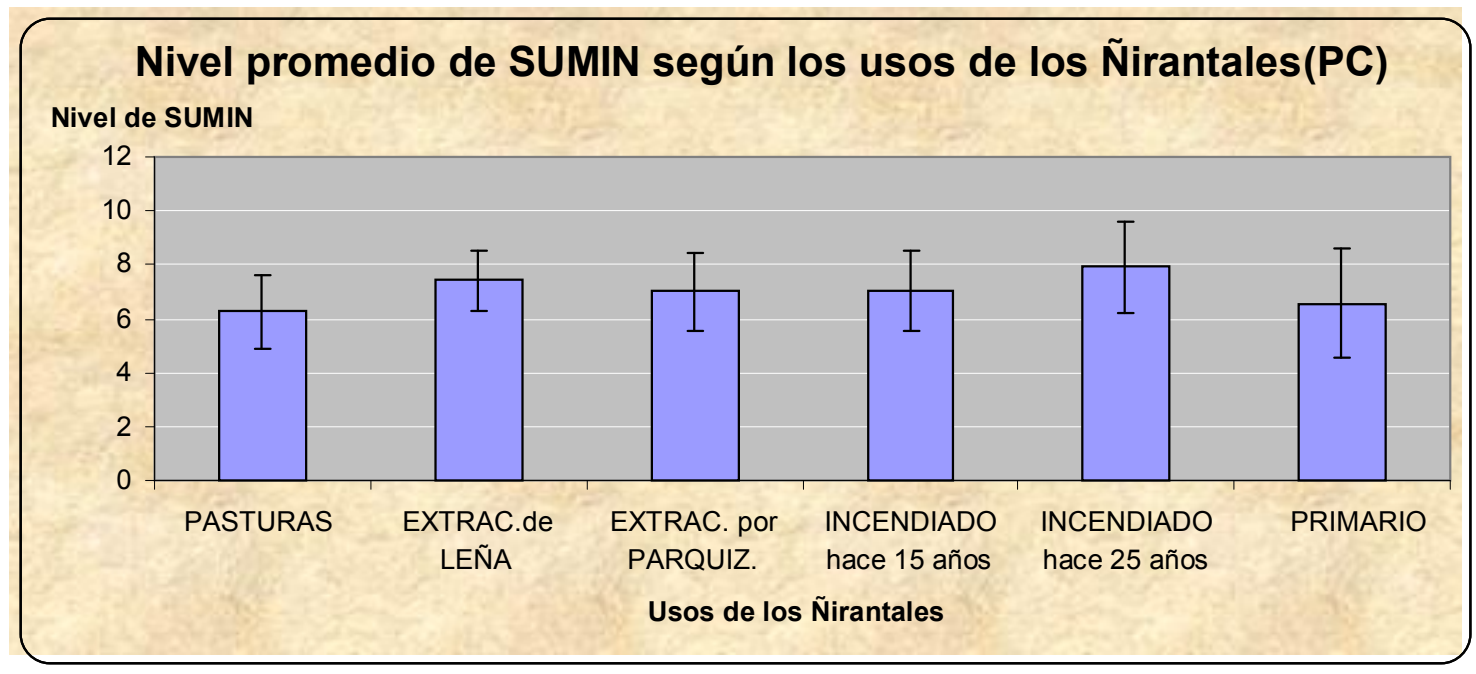

Fig. 4.54: Nivel promedio de SUMIN (Suma de Índices) de la comunidades de aves relevadas mediante la aplicación de puntos de conteo, en los ñirantales sometidos a los diferentes usos y que estuvieron bajo estudio durante el período bianual 2008-2010.

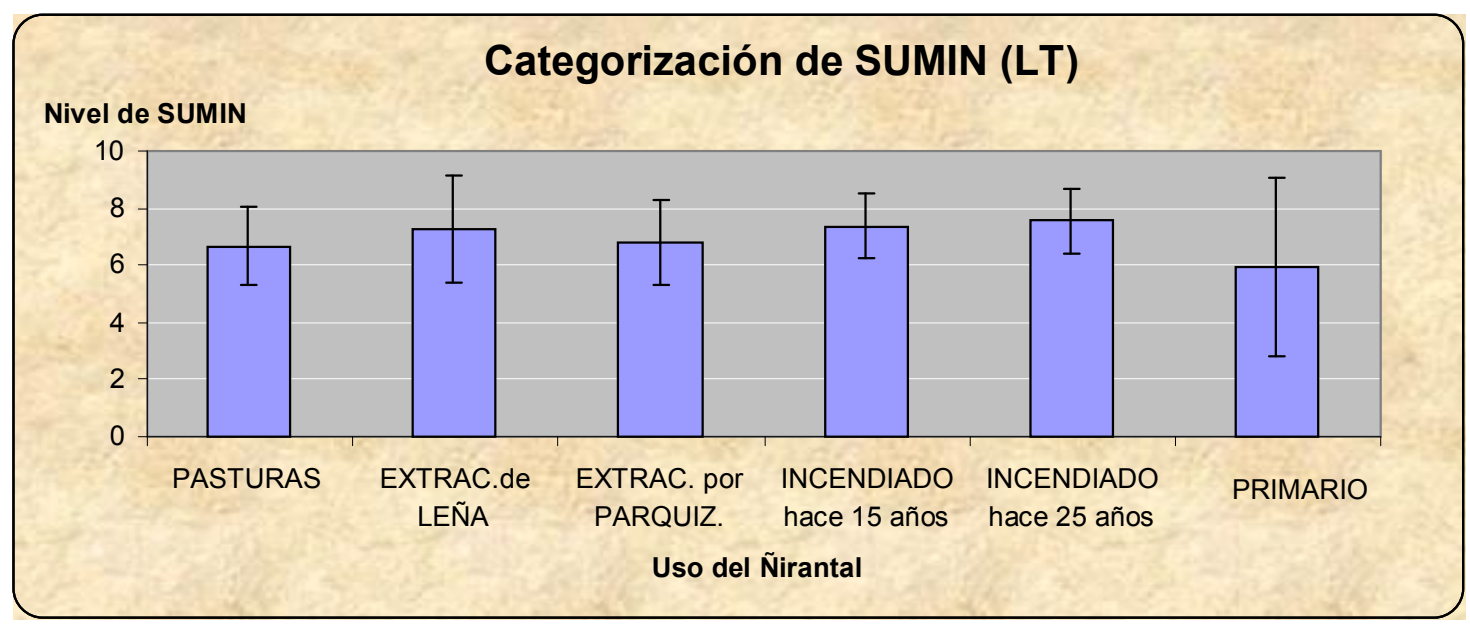

Fig. 4.55: Nivel promedio de SUMIN (Suma de Índices) de la comunidades de aves relevadas mediante la aplicación de línea transecta, en los ñirantales sometidos a los diferentes usos y que estuvieron bajo estudio durante el período bianual 20082010. 


\subsubsection{SUMIN máximo}

Los valores promedios del índice SUMIN máximo de las comunidades de aves correspondientes a cada una de las estructuras según usos de los ñirantales y relevadas mediante PC variaron estadísticamente (Kruskal-Wallis: Chí $^{2}=25,33 ; g l=5 ; p<0,0001$ ), hecho que no ocurrió al analizar la información derivada de los censos por LT (KruskalWallis: Chí $^{2}=9,10 ; g l=5 ; p<0,1011$ )(Fig. 4.56).

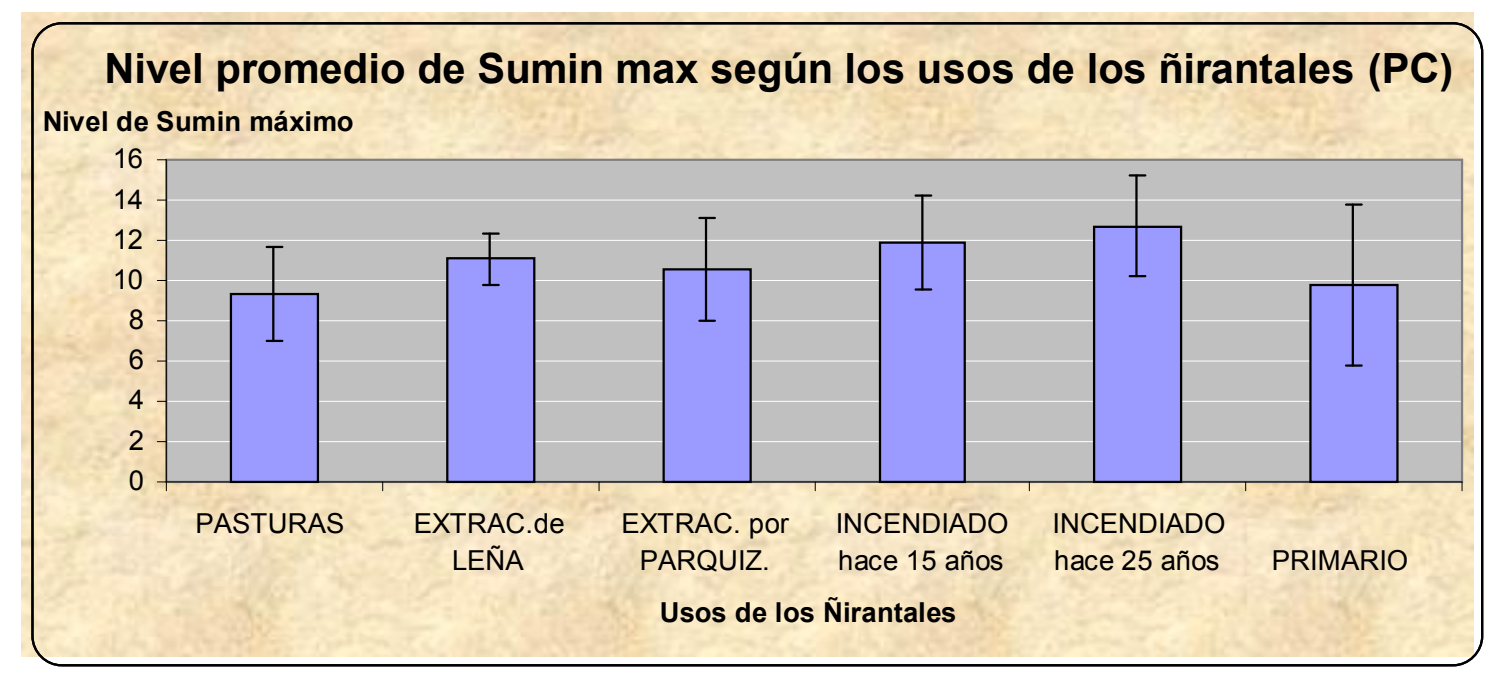

Fig. 4.56: Nivel promedio de SUMIN (Suma de Índices) máximo de las comunidades de aves relevadas mediante la aplicación del método de puntos de conteo, en los ñirantales sometidos a los diferentes usos y que estuvieron bajo estudio durante el período bianual 2008-2010.

El resultado de los valores promedios del índice SUMIN máximo de las comunidades de aves correspondientes a cada una de las estructuras según usos de los ñirantales y relevadas mediante línea transecta (Fig. 4.57) no arrojó diferencias significativas entre los diferentes usos (Kruskal-Wallis: Chí $^{2}=9,10 ; \mathrm{gl}=5 ; \mathrm{p}<0,1011$ ). 


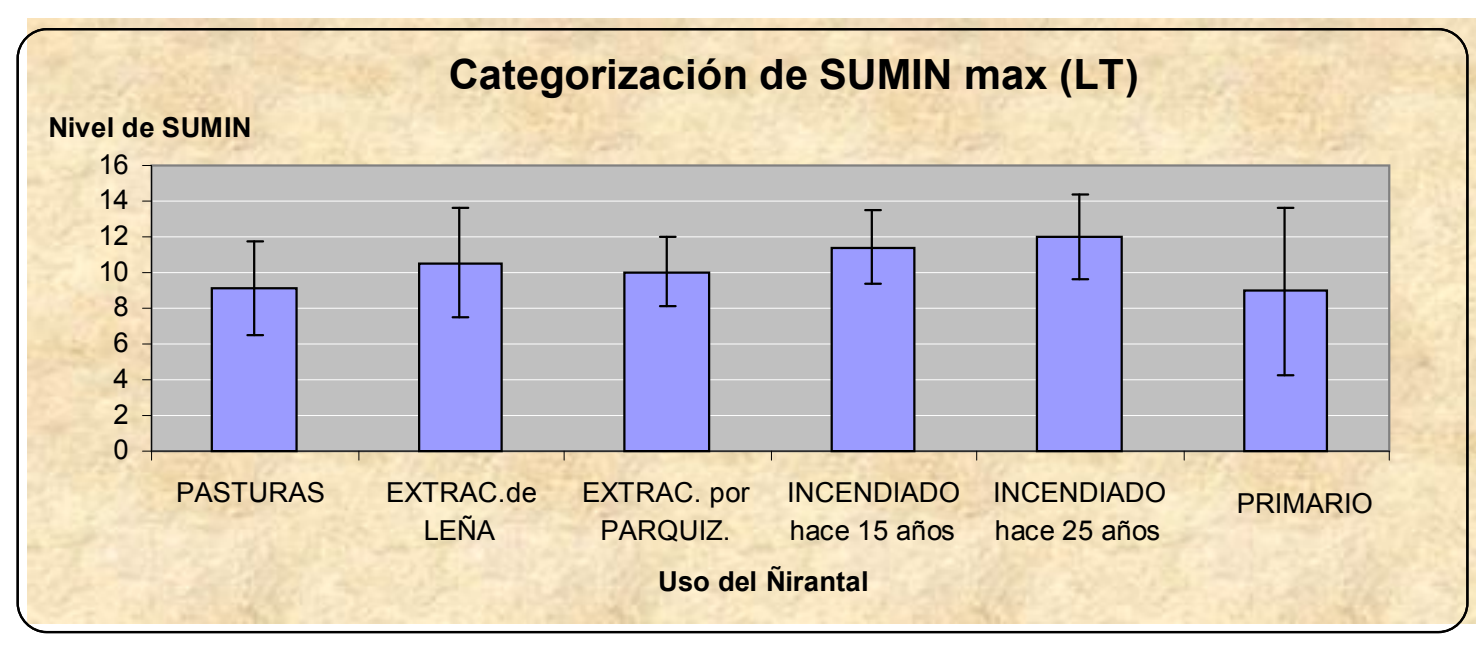

Fig. 4.57: Nivel promedio de SUMIN (Suma de Índices) máximo de las comunidades de aves relevadas mediante la aplicación del método de líneas transectas, en los ñirantales sometidos a los diferentes usos y que estuvieron bajo estudio durante el período bianual 2008-2010.

\subsection{9 Índice de Diversidad de Shannon-Wiener}

De acuerdo a los censos por PC, el Índice de Diversidad de Shannon Wiener (Fig. 4.58) varió estadísticamente entre ñirantales sometidos a diferentes usos realizándose el relevamiento de datos mediante puntos de conteo (Prueba no paramétrica de Kruskal-Wallis: Chí $^{2}=$ 11,5; $\mathrm{gl}=5 ; \mathrm{p}<0,0423)$, hecho que no ocurrió de acuerdo a la información derivada de las LT (Kruskal-Wallis: Chí $^{2}=10,09 ; \mathrm{gl}=5$; $p<0,0727$ ) (Fig. 4.59).

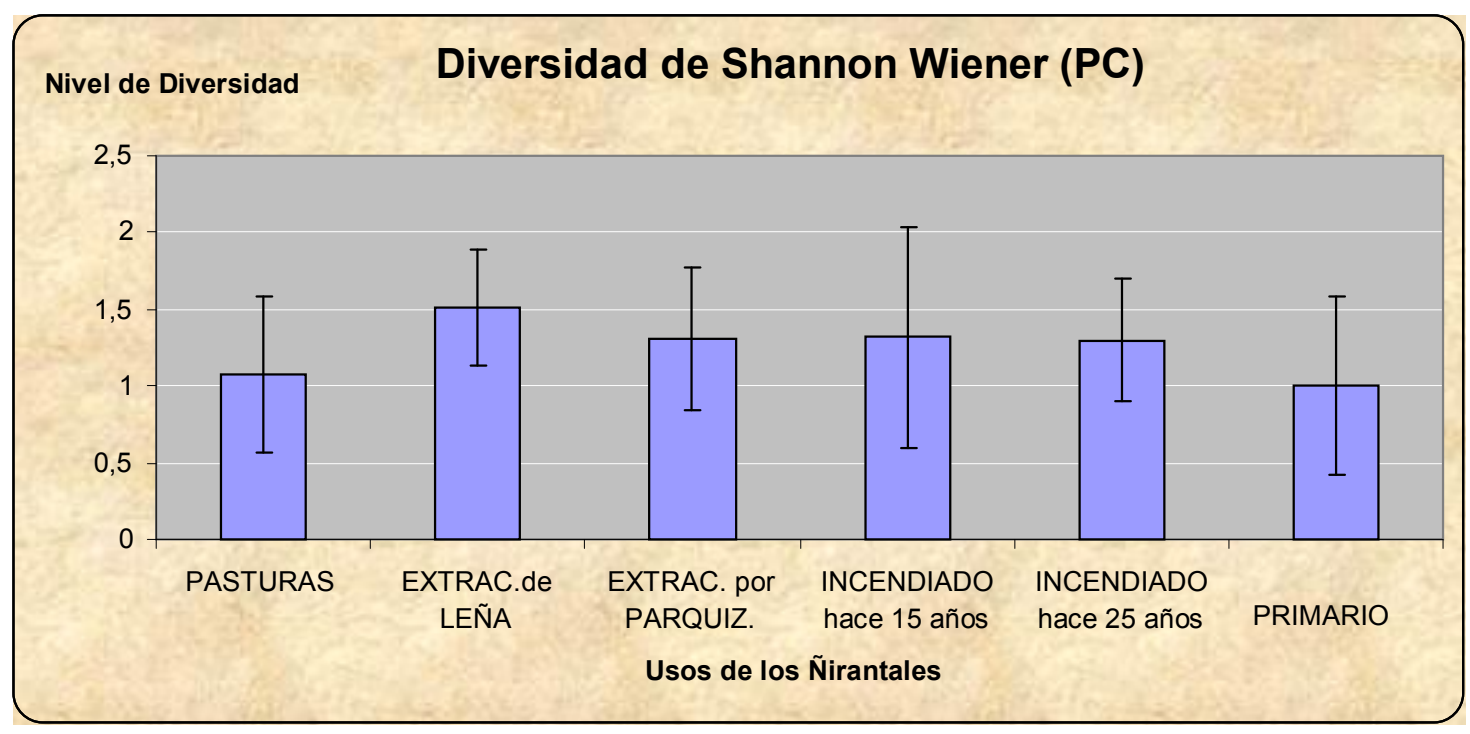

Fig. 4.58: Índice de Diversidad de Shannon-Wiener de las comunidades de aves asociados a los ñirantales sometidos a diferentes usos. Los datos fueron relevados mediante el método de puntos de conteo durante el período bianual 2008-2010. 


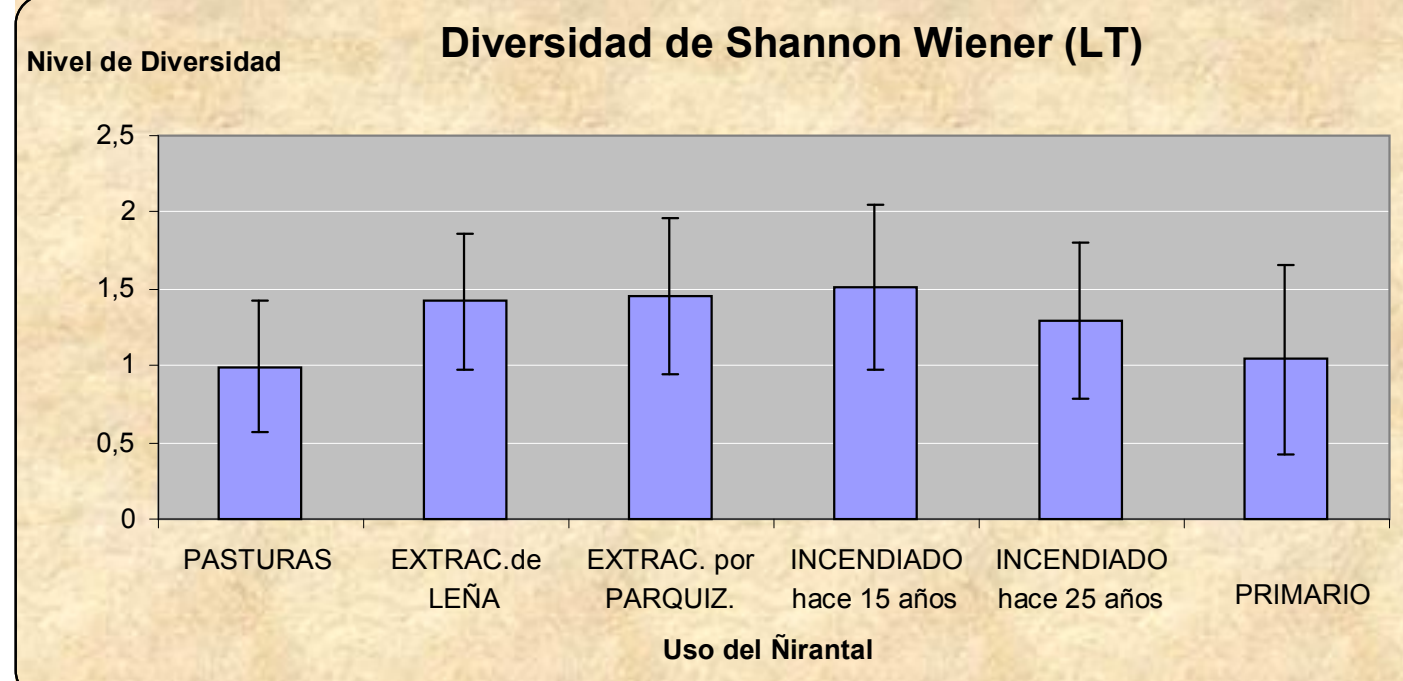

Fig. 4.59: Índice de Diversidad de Shannon-Wiener de las comunidades de aves asociados a los ñirantales sometidos a diferentes usos. Los datos fueron relevados mediante el método línea transecta durante el período bianual 2008-2010.

\subsubsection{0 Índice de Diversidad de Margaleff}

El Índice de Diversidad de Margaleff, estimado a partir de la información derivada de los censos por PC (Kruskal-Wallis: Chí $^{2}=5,5$; $g l=5 ; p<0,3579$ )(Fig. 4.60) y LT (Kruskal-Wallis: Chi $^{2}=10 ; \mathrm{gl}=5$; $\mathrm{p}<0,0752)$ no difirieron estadísticamente entre comunidades asociadas a ñirantales sometidos a diferentes usos)(Fig. 4.61).

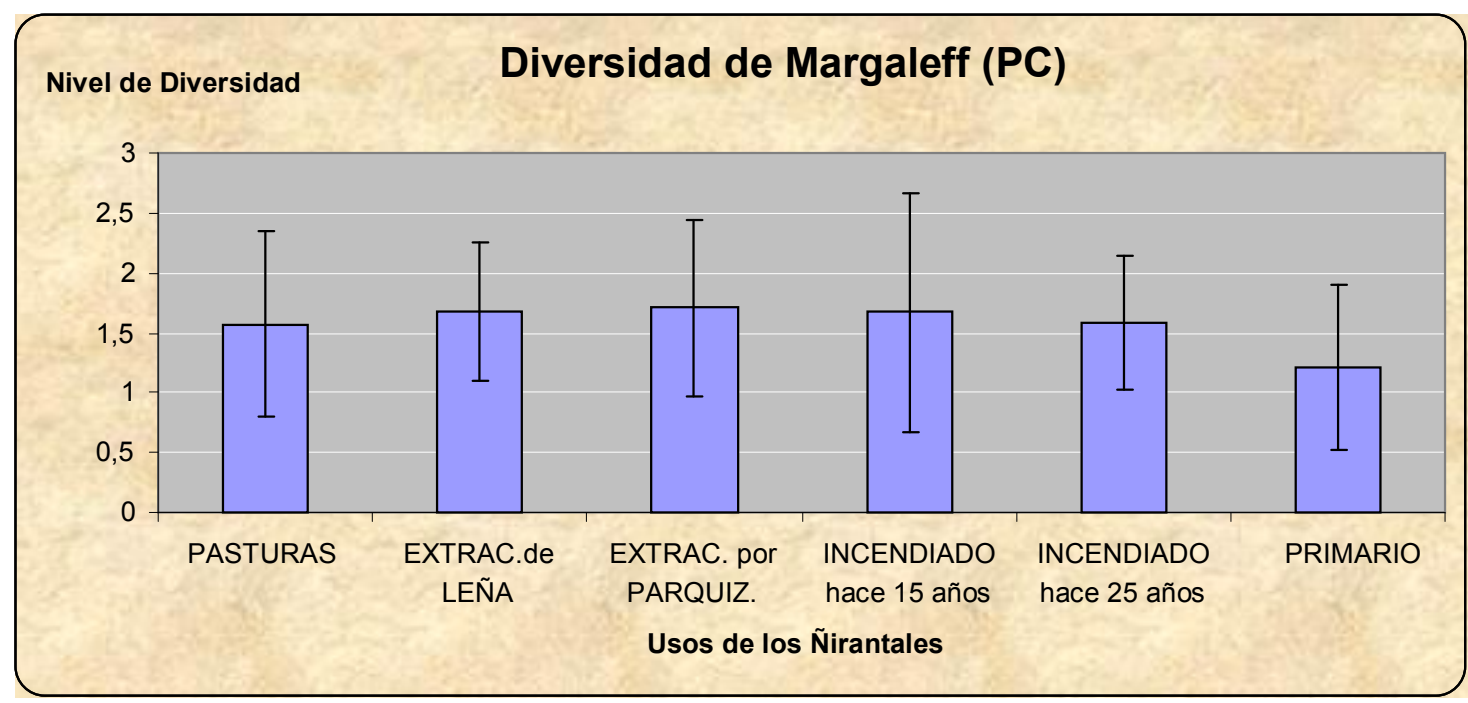

Fig. 4.60: Índice de Diversidad de Margaleff de las comunidades de aves asociadas a los ñirantales sometidos a diferentes usos. Los datos fueron relevados mediante el método puntos de conteo durante el período bianual 2008-2010. 


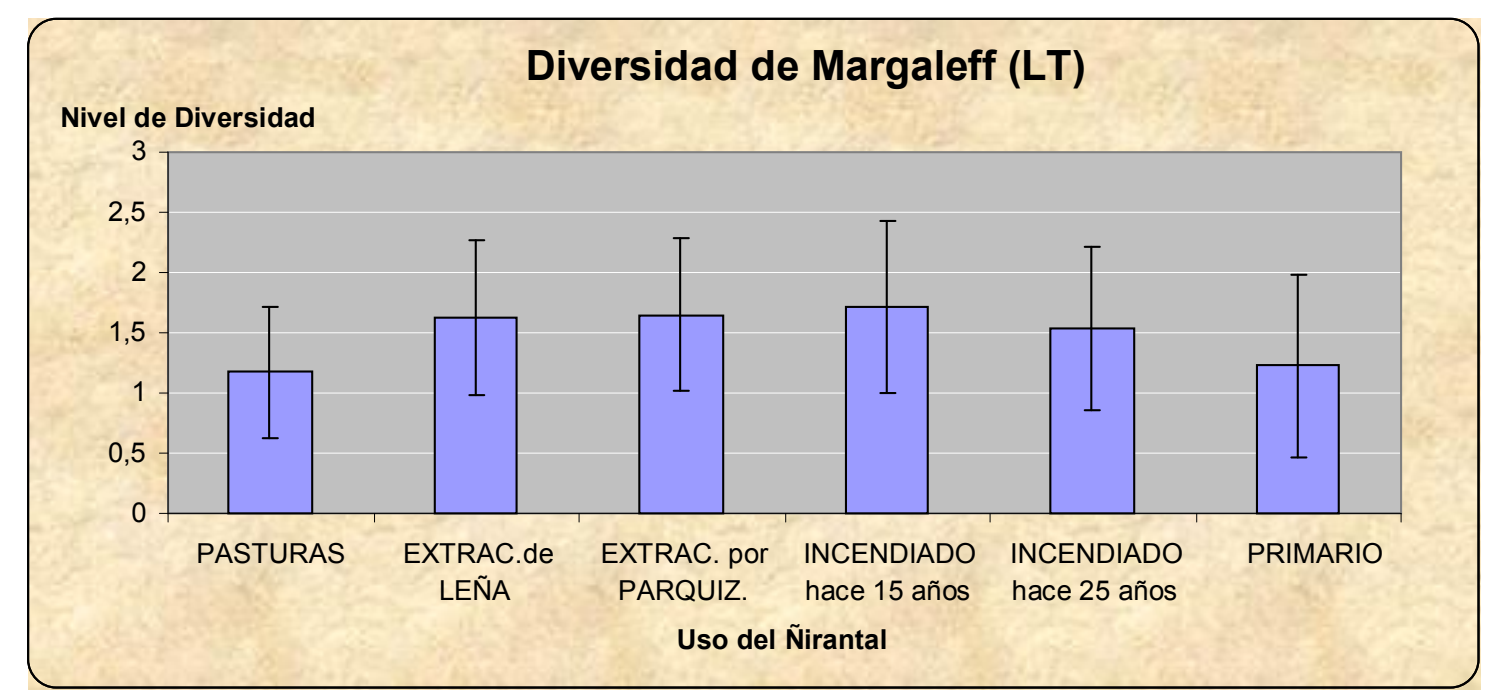

Fig. 4.61: Índice de Diversidad de Margaleff de las comunidades de aves asociadas a los ñirantales sometidos a diferentes usos. Los datos fueron relevados mediante línea transecta durante el período bianual 2008-2010.

\subsubsection{1 Índice de Equitatividad (modificado por Pielou)}

Tanto al analizar la información derivada de censos por PC (Prueba no paramétrica de Kruskal-Wallis: Chí $^{2}=2 ; g l=5 ; p<0,891$; Fig. 4.62) como por LT (Kruskal-Wallis: Chí $^{2}=7,5 ;$ gl=5; p<0,186; Fig. 4.63), el Índice de Equitatividad (modificado por Pielou) fue similar entre comunidades de aves asociadas a ñirantales sometidos a diferentes usos.

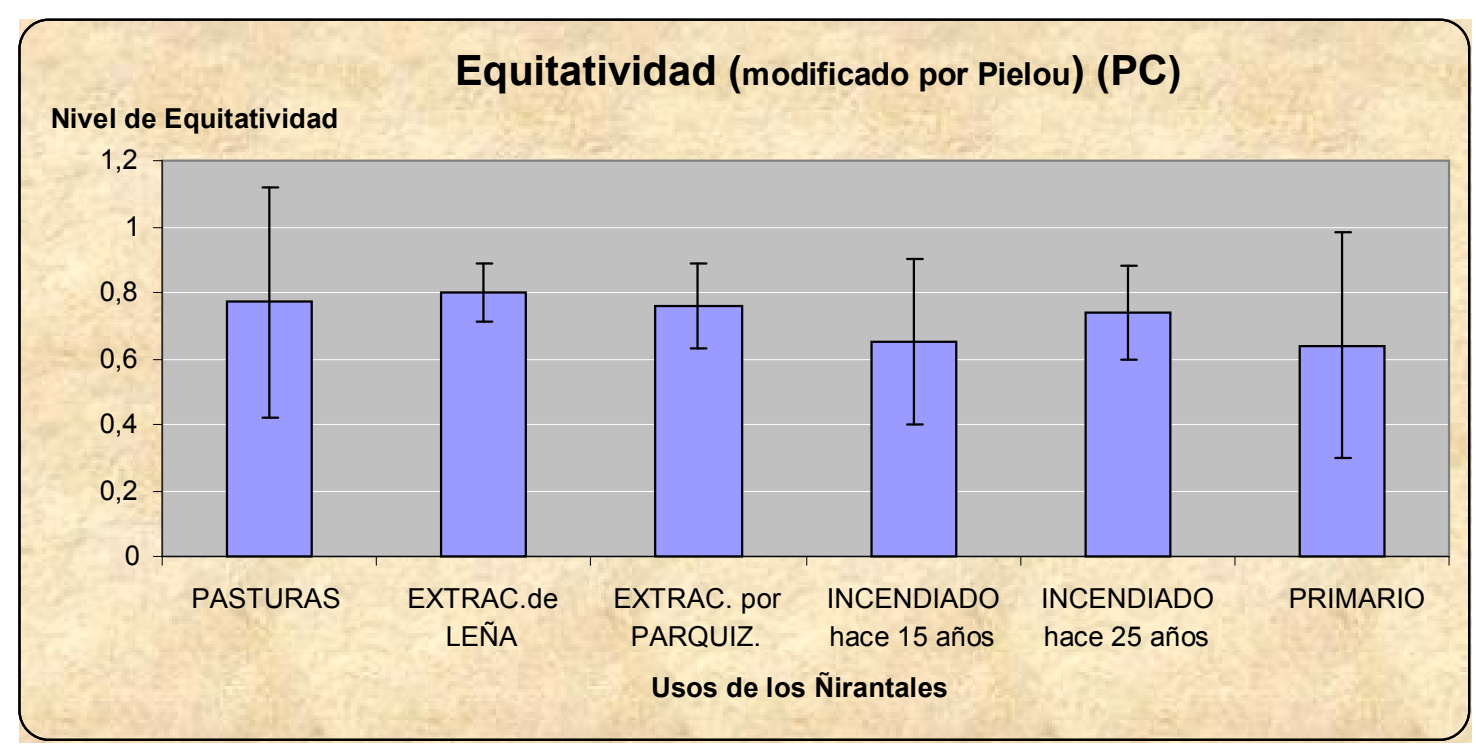

Fig. 4.62: Índice de Equitatividad (modificado por Pielou) de las comunidades de aves asociadas a ñirantales sometidos a diferentes usos. Los datos fueron relevados mediante punto de conteo durante el período bianual 2008-2010. 


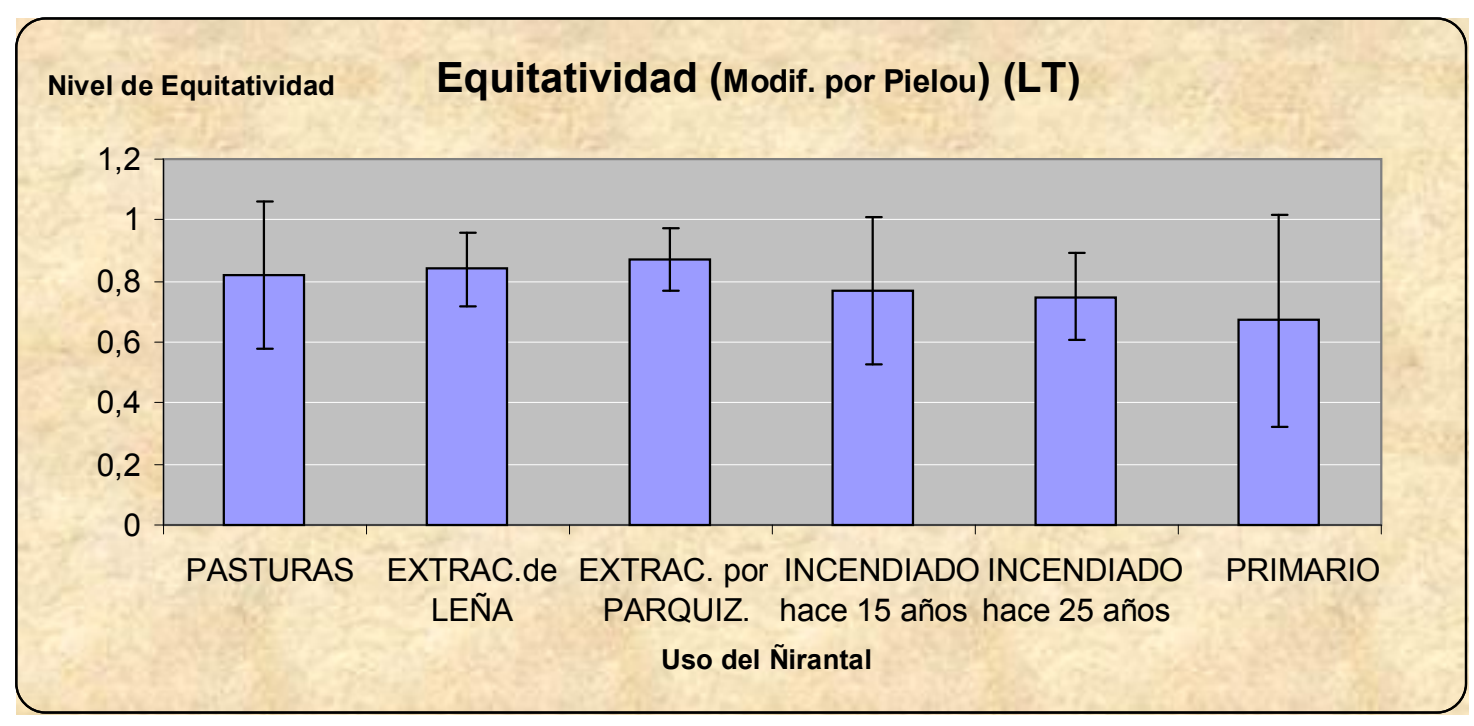

Fig. 4.63: Índice de Equitatividad (modificado por Pielou) de las comunidades de aves asociadas a ñirantales sometidos a diferentes usos. Los datos fueron relevados mediante el método línea transecta durante el período bianual 20082010.

\subsubsection{Trofismo}

Basado en información bibliográfica (ver metodología), se elaboró una tabla (Tabla 4.43) con el/los principal/es alimento/s de la dieta de cada una de las aves, a partir del cual se determinó el uso trófico de ese grupo de aves para cada una de las tipologías de los ñirantales. A continuación se desarrollan los valores resultantes correspondientes a cada especie:

Tabla 4.43: Composición de los gremios tróficos de las comunidades de aves asociadas a ñirantales sometidos a los diferentes usos. Los colores subyacentes corresponden a cada uno de los gremios.

\begin{tabular}{|l|l|l|l|l|l|l|l|}
\hline Insectívoro & Omnívoro & Frugívoro & Carnívoro & Granívoro & Herbívoro & Carroñero & Nectívoro \\
\hline
\end{tabular}

\begin{tabular}{|l|l|c|c|}
\hline \multicolumn{1}{|c|}{ Especie } & \multicolumn{1}{c|}{ Nombre científico } & $\begin{array}{c}\text { Gremio } \\
\mathbf{1}^{\circ}\end{array}$ & $\begin{array}{c}\text { Gremio } \\
\mathbf{2}^{\circ}\end{array}$ \\
\hline Águila mora & Geranoaetus melanoleucus & $\mathbf{1}$ & \\
\hline Aguilucho común & Buteo polyosoma & $\mathbf{1}$ & \\
\hline Avutarda & Chloephaga picta & 1 & \\
\hline Bandurria baya & Theristicus melanopis & $\mathbf{0 , 5}$ & $\mathbf{0 , 5}$ \\
\hline Bandurrita común & Upucerthia dumetaria & $\mathbf{0 , 5}$ & $\mathbf{0 , 5}$ \\
\hline Becasina común & Gallinago gallinago & $\mathbf{0 , 7 5}$ & $\mathbf{0 , 2 5}$ \\
\hline Cabecita negra austral & Carduelis barbatus & $\mathbf{0 , 7 5}$ & $\mathbf{0 , 2 5}$ \\
\hline Caburé grande & Glacidium nanum & $\mathbf{0 , 5}$ & $\mathbf{0 , 5}$ \\
\hline
\end{tabular}




\begin{tabular}{|c|c|c|c|}
\hline Cachaña & Enicognathus ferrugineus & 1 & \\
\hline Cachirla pálida & Anthus hellmayri & 1 & \\
\hline Cachudito pico negro & Anairetes parulus & 1 & \\
\hline Cachirla común & Anthus correndera & 1 & \\
\hline Canastero coludo & Asthenes pyrrholeuca & 1 & \\
\hline Canastero pálido & Asthenes modesta & 1 & \\
\hline Carancho & Polyborus plancus & 1 & \\
\hline Carpintero bataráz grande & Picoides lignarius & 1 & \\
\hline $\begin{array}{l}\text { Carpintero gigante } \\
\text { patagónico }\end{array}$ & Campephilus magellanicus & 1 & \\
\hline Carpintero pitío & Colaptes pitius & 1 & \\
\hline Chimango & Milvago chimango & 0,75 & 0,25 \\
\hline Chingolo & Zonotrichia capensis & 0,75 & 0,25 \\
\hline Chucao & Scelorchilus rubecula & 1 & \\
\hline Churrin andino & Scytalopus magellanicus & 1 & \\
\hline Codorníz califórnica & Callipepla californicus & 1 & \\
\hline Coludito cola negra & Leptasthenura aegithaloides & 1 & \\
\hline Comesebo andino & Phrygilus galli & 1 & \\
\hline Comesebo patagónico & Phrygilus patagonicus & 1 & \\
\hline Diuca común & Diuca diuca & 0,65 & 0,35 \\
\hline Diucón & Xolmis pyrope & 1 & \\
\hline Espartillero austral & Asthenes anthoides & 1 & \\
\hline Esparvero variado & Accipiter bicolor & 1 & \\
\hline Fiofío silbón & Elaenia albiceps & 0,6 & 0,4 \\
\hline Gaucho grande & Agriornis livida & 0,5 & 0,5 \\
\hline Gaucho serrano & Agriornis montana & 1 & \\
\hline Gavilán ceniciento & Circus cinereus & 1 & \\
\hline Gaviota cocinera & Larus dominicanus & 1 & \\
\hline Golondrina barranquera & Notiochelidon cyanoleuca & 1 & \\
\hline Golondrina patagónica & Tachicineta leucopiga & 1 & \\
\hline Halcón peregrino & Falco peregrinus & 1 & \\
\hline Halconcito colorado & Falco sparverius & 1 & \\
\hline Huet huet & Pteroptochos tarnii & 1 & \\
\hline Jote cabeza negra & Coragyps atratus & 1 & \\
\hline Loica común & Sturnella loyca & 0,5 & 0,5 \\
\hline Ñacurutú & Bubo virginianus & 1 & \\
\hline Pato barcino & Anas flavirostris & 1 & \\
\hline Peutrén & Colorhamphus parvirostris & 1 & \\
\hline Picaflor andino & Oreotrochilus leucopleurus & 0,75 & 0,25 \\
\hline Picolezna & Pygarrhichas albogularis & 1 & \\
\hline Rara & Phitotoma rara & 0,5 & 0,5 \\
\hline Ratona común & Troglodites aedon & 0,75 & 0,25 \\
\hline Rayadito & Aphrastura spinicauda & 1 & \\
\hline Tero & Vanellus chilensis & 1 & \\
\hline Torcaza & Zenaida auriculata & 1 & \\
\hline Tordo patagónico & Curaeus curaeus & 1 & \\
\hline Tordo renegrido & Molothrus bonariensis & 1 & \\
\hline Yal andino & Melanodera xanthogramma & 1 & \\
\hline Yal plomizo & Phrygilus unicolor & 1 & \\
\hline Zorzal patagónico & Turdus falklandii & 0,5 & 0,5 \\
\hline
\end{tabular}


En todos los tipos de ñirantales se observó una clara predominancia de aves insectívoras, seguidas por especies granívoras, salvo en bosques convertidos a pasturas donde dominaron las aves insectívoras, seguidas por las carnívoras (Fig. 4.64). 

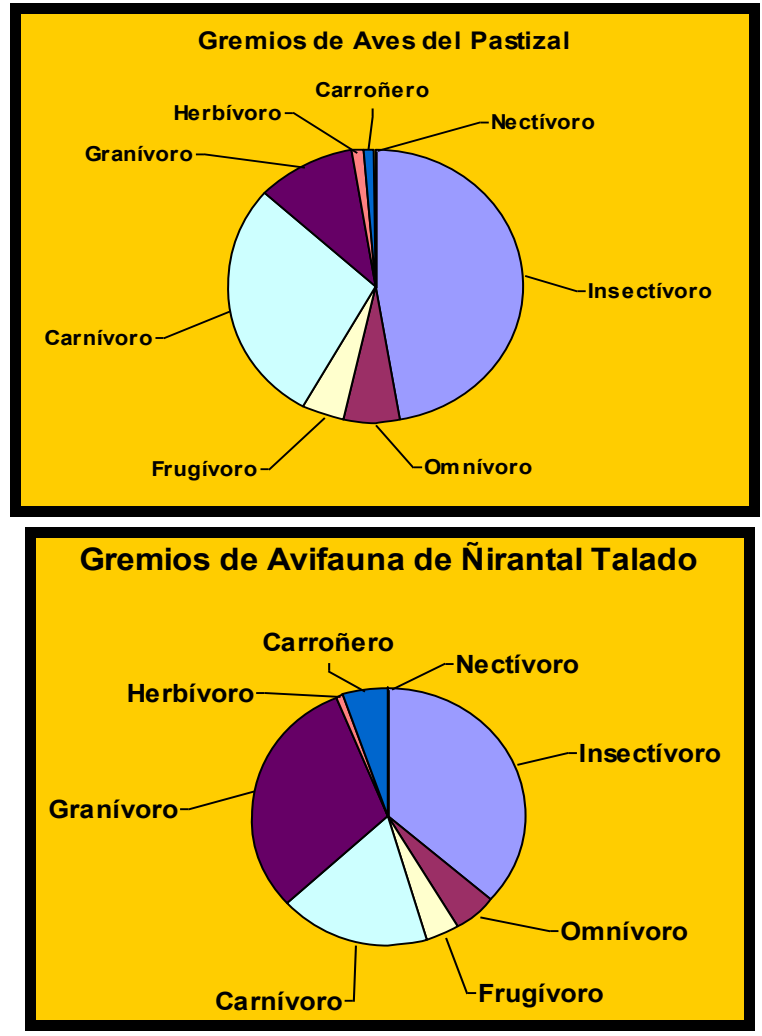

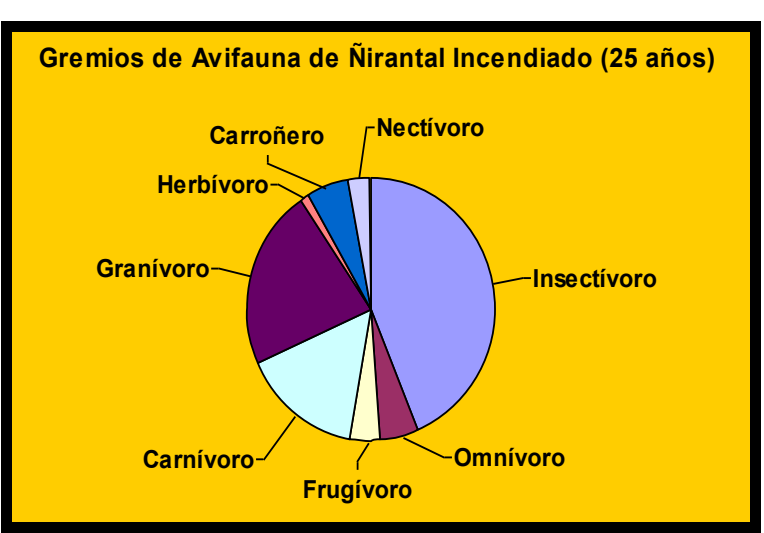

Gremios de Avifauna de Ñirantal en Parque

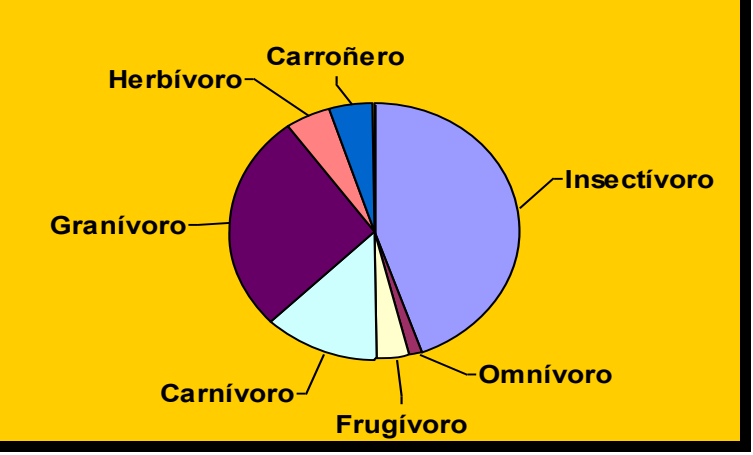

$\square$ Carnívoro

\begin{tabular}{|llll|}
\hline$\square$ Insectívoro & $\square$ Omnívoro & $\square$ Frugívoro & $\square$ Carnívoro \\
$\square$ Granívoro & $\square$ Herbívoro & $\square$ Carroñero & $\square$ Nectívoro \\
\hline
\end{tabular}

Fig. 4.64: Proporción de especies correspondientes a los gremios tróficos presentes en cada uno de los ñirantales sometidos a diferentes usos. 


\subsubsection{3 Índices Biológicos vs. Estacionalidad}

Salvo por la Equitatividad estimada a partir de la información derivada de censos por PC y LT, los índices biológicos variaron entre las diferentes estaciones (Tabla 4.44).

Tabla 4.44: Niveles de significancia resultantes de la aplicación del Test no paramétrico de Kruskall-Wallis al análisis de la relación entre los Índices biológicos de las comunidades de aves y la estacionalidad (invierno, verano, otoño y primavera de ambos ciclos) mediante la aplicación de las metodologías de punto de conteo y línea transecta durante el período bianual 2008-2010. Se indica en color amarillo los índices donde se registraron diferencias significativas.

\begin{tabular}{|c|l|c|c|c|}
\hline Metodología & \multicolumn{1}{|c|}{ Índice Biológico } & Chi $^{2}$ & $d f$ & $p$ \\
\hline \multirow{4}{*}{$\begin{array}{c}\text { PUNTO DE } \\
\text { CONTEO } \\
(\text { PC) }\end{array}$} & SUMIN & 9,333 & 3 & 0,0252 \\
\cline { 2 - 5 } & RIQ. ESPECIFICA & 29,49 & 3 & 0,0001 \\
\cline { 2 - 5 } & ABUND. ABSOLUTA & 36 & 3 & 0,0001 \\
\cline { 2 - 5 } & DIVERSIDAD SHANNON & 19,33 & 3 & 0,0002 \\
\cline { 2 - 5 } & DIVERSIDAD MARGALEFF & 16,33 & 3 & 0,001 \\
\cline { 2 - 5 } & EQUITATIVIDAD & 1,33 & 3 & 0,7212 \\
\hline \multirow{4}{*}{$\begin{array}{c}\text { LINEA } \\
\text { TRANSECTA } \\
(\text { LT) }\end{array}$} & SUMIN & 14,4 & 3 & 0,0024 \\
\cline { 2 - 5 } & RIQ. ESPECÍFICA & 34,57 & 3 & 0,0001 \\
\cline { 2 - 5 } & ABUND. ABSOLUTA & 43 & 3 & 0,0001 \\
\cline { 2 - 5 } & DIVERSIDAD SHANNON & 26,34 & 3 & 0,0001 \\
\cline { 2 - 5 } & DIVERSIDAD MARGALEFF & 19,33 & 3 & 0,0002 \\
\cline { 2 - 5 } & EQUITATIVIDAD & 3,66 & 3 & 0,2998 \\
\hline
\end{tabular}

\subsubsection{Análisis de los Agrupamientos (Cluster Analysis)}

De acuerdo a la información derivada de los censos mediante PC, la comunidad de aves de los ñirantales transformados en pasturas difirió marcadamente de las representadas en el resto de los ñirantales relevados (Fig. 4.65 y 4.66 ; Tablas 4.45 y 4.46 ).

En relación a estos ñirantales, se observaron dos agrupamientos: uno conformado por los ñirantales primarios y por los incendiados hace 25 años, y el constituido por los ñirantales sometidos a extracción de leña por manchones y por los incendiados hace 15 años. Los ñirantales sometidos a extracción de leña por parquizado presentaron características similares a estos dos grupos. 
Tabla 4.45: Especies representadas en los diferentes tipos de ñirantales de acuerdo a los censos desarrollados mediante puntos de conteo (Abreviaturas; PAST: ñirantales transformados en pasturas, PARQ: ñirantales con extracción de leña por parquizado, TALA: ñirantales con extracción de leña por manchones, INCEN 15: ñirantales incendiados hace 15 años, INCEN 25: ñirantales incendiados hace 25 años, PRIM: ñirantales primarios o testigos.

\begin{tabular}{|c|c|c|c|c|c|c|c|}
\hline Especie & Nombre científico & PAST. & PARQ. & TALA. & INCEN. 15 & INCEN.25 & PRIM. \\
\hline Águila mora & Geranoaetus melanoleucus & - & - & - & - & + & - \\
\hline Aguilucho común & Buteo polyosoma & + & - & - & + & + & - \\
\hline Bandurria baya & Theristicus melanopis & + & + & + & + & - & - \\
\hline Bandurrita común & Upucerthia dumetaria & - & - & - & + & - & - \\
\hline Becasina común & Gallinago gallinago (G. paraguaiae) & + & - & - & - & - & - \\
\hline Cabecita negra austral & Carduelis barbata & - & + & + & + & + & + \\
\hline Cachaña & Enicognathus ferrugineus & - & + & + & + & - & - \\
\hline Cachirla común & Anthus correndera & + & - & - & - & - & - \\
\hline Canastero coludo & Asthenes pyrrholeuca & - & - & - & + & - & - \\
\hline Carancho & Polyborus plancus & + & + & + & - & + & + \\
\hline Carpintero bataráz grande & Picoides lignarius & + & + & - & - & + & + \\
\hline Carpintero gigante patagónico & Campephilus magellanicus & - & - & - & - & - & + \\
\hline Carpintero pitío & Colaptes pitius & - & + & + & + & + & + \\
\hline Cauquén común & Chloephaga picta & - & + & - & - & - & - \\
\hline Chimango & Milvago chimango & + & + & + & + & + & + \\
\hline Chingolo & Zonotrichia capensis & + & + & + & + & + & + \\
\hline Chucao & Scelorchilus rubecula & - & - & - & + & + & + \\
\hline Churrin andino & Scytalopus magellanicus & - & - & - & - & + & + \\
\hline Codorníz califórnica & Callipepla californica & - & - & + & - & + & + \\
\hline Coludito cola negra & Leptasthenura aegithaloides & - & - & - & - & + & - \\
\hline Comesebo andino & Phrygilus galli & - & + & - & - & + & - \\
\hline Comesebo patagónico & Phrygilus patagonicus & - & + & + & - & - & - \\
\hline Diuca común & Diuca diuca & + & + & + & + & + & + \\
\hline Diucón & Xolmis pyrope & + & + & + & + & + & + \\
\hline
\end{tabular}




\begin{tabular}{|c|c|c|c|c|c|c|c|}
\hline Especie & Nombre científico & PAST. & PARQ. & TALA. & INCEN. 15 & INCEN.25 & PRIM. \\
\hline Esparvero variado & Accipiter bicolor & + & - & - & - & - & - \\
\hline Fiofío silbón & Elaenia albiceps & + & + & + & + & + & + \\
\hline Gaucho grande & Agriornis lividus & + & - & - & - & - & - \\
\hline Gaucho serrano & Agriornis montanus & + & - & - & - & - & - \\
\hline Gavilán ceniciento & Circus cinereus & - & - & - & - & - & + \\
\hline Gaviota cocinera & Larus dominicanus & - & - & + & - & - & - \\
\hline Golondrina barranquera & Pigochelidon cyanoleuca & - & - & - & + & - & - \\
\hline Golondrina patagónica & Tachicineta leucopiga (T. ellen) & + & + & + & + & + & + \\
\hline Halconcito colorado & Falco sparverius & + & + & + & - & - & - \\
\hline Huet huet & Pteroptochos tarnii (P. castaneus) & - & - & - & - & - & + \\
\hline Jote cabeza negra & Coragyps atratus & - & + & + & - & + & - \\
\hline Loica común & Sturnella loyca & + & + & - & - & - & + \\
\hline Peutrén & Colorhamphus parvirostris & - & - & - & - & - & + \\
\hline Picaflor andino & Oreotrochilus leucopleurus & - & - & - & + & + & - \\
\hline Picolezna & Pygarrhichas albogularis & - & + & - & - & - & - \\
\hline Rara & Phitotoma rara & - & - & - & + & - & - \\
\hline Ratona común & Troglodites aedon & + & + & + & + & + & + \\
\hline Rayadito & Aphrastura spinicauda & - & + & + & + & + & + \\
\hline Tero & Vanellus chilensis & - & + & + & - & - & - \\
\hline Torcaza & Zenaida auriculata & - & + & + & + & + & - \\
\hline Tordo patagónico & Curaeus curaeus & - & + & + & + & + & - \\
\hline Tordo renegrido & Molothrus bonariensis & - & - & - & + & - & - \\
\hline Yal andino & Melanodera xanthogramma & - & - & - & + & - & - \\
\hline Yal plomizo & Phrygilus unicolor & - & - & - & + & - & - \\
\hline Zorzal patagónico & Turdus falklandii & + & + & + & + & + & + \\
\hline \multicolumn{2}{|c|}{ Número Total de Especies Registradas } & 19 & 25 & 22 & 25 & 24 & 21 \\
\hline
\end{tabular}


Tabla 4.46: Especies representadas en los diferentes tipos de ñirantales de acuerdo a los censos desarrollados mediante línea transecta (Abreviaturas; PAST: ñirantales transformados en pasturas, PARQ: ñirantales con extracción de leña por parquizado, TALA: ñirantales con extracción de leña por manchones, INCEN 15: ñirantales incendiados hace 15 años, INCEN 25: ñirantales incendiados hace 25 años, PRIM: ñirantales primarios o testigos.

\begin{tabular}{|c|c|c|c|c|c|c|c|}
\hline Especie & Nombre científico & PAST. & PARQ. & TALA. & INCEN. 15 & INCEN.25 & PRIM. \\
\hline Águila mora & Geranoaetus melanoleucus & + & - & - & + & + & - \\
\hline Aguilucho común & Buteo polyosoma & + & - & - & - & + & - \\
\hline Bandurria baya & Theristicus melanopis & + & + & + & - & - & - \\
\hline Bandurrita común & Upucerthia dumetaria & - & + & - & + & - & - \\
\hline Cabecita negra austral & Carduelis barbata & - & + & - & + & + & + \\
\hline Caburé grande & Glacidium nanum & - & + & + & + & - & + \\
\hline Cachirla común & Anthus correndera & + & - & - & - & - & - \\
\hline Cachirla pálida & Anthus hellmayri & + & - & - & - & - & - \\
\hline Cachudito pico negro & Anairetes parulus & + & - & - & - & - & - \\
\hline Canastero pálido & Asthenes modesta & - & - & - & + & + & - \\
\hline Carancho & Polyborus plancus & - & + & + & - & - & + \\
\hline Carpintero bataráz grande & Picoides lignarius & - & + & + & + & + & + \\
\hline Carpintero pitío & Colaptes pitius & - & + & - & + & - & - \\
\hline Cauquén común & Chloephaga picta & - & - & - & + & - & - \\
\hline Chimango & Milvago chimango & + & - & - & + & + & + \\
\hline Chingolo & Zonotrichia capensis & + & + & + & + & + & + \\
\hline Chucao & Scelorchilus rubecula & - & - & - & + & + & + \\
\hline Churrin andino & Scytalopus magellanicus & - & - & - & - & + & - \\
\hline Codorníz califórnica & Callipepla californica & - & - & - & - & + & - \\
\hline Coludito cola negra & Leptasthenura aegithaloides & - & - & - & + & - & - \\
\hline Comesebo andino & Phrygilus galli & + & + & + & + & + & + \\
\hline Comesebo patagónico & Phrygilus patagonicus & - & + & - & - & - & - \\
\hline
\end{tabular}




\begin{tabular}{|c|c|c|c|c|c|c|c|}
\hline Especie & Nombre científico & PAST. & PARQ. & TALA. & INCEN. 15 & INCEN.25 & PRIM. \\
\hline Diuca común & Diuca diuca & + & + & + & + & + & - \\
\hline Diucón & Xolmis pyrope & + & + & + & + & + & - \\
\hline Fiofío silbón & Elaenia albiceps & - & + & + & + & + & + \\
\hline Gaucho grande & Agriornis lividus & - & - & - & - & - & - \\
\hline Gavilán ceniciento & Circus cinereus & - & - & - & + & + & - \\
\hline Golondrina patagónica & Tachicineta leucopiga (T. meyeni) & + & + & + & + & - & - \\
\hline Halcón peregrino & Falco peregrinus & + & - & + & - & - & - \\
\hline Halconcito colorado & Falco sparverius & + & - & - & - & - & - \\
\hline Huet huet & Pteroptochos tarnii (P. castaneus) & - & - & - & - & - & + \\
\hline Jote cabeza negra & Coragyps atratus & - & + & + & - & + & - \\
\hline Loica común & Sturnella loyca & - & - & - & - & + & - \\
\hline Ñacurutú & Bubo virginianus & - & + & - & - & - & - \\
\hline Pato barcino & Anas flavirostris & - & + & - & - & - & - \\
\hline Picaflor andino & Oreotrochilus leucopleurus & - & - & + & + & + & - \\
\hline Rara & Phitotoma rara & - & - & - & + & + & - \\
\hline Ratona común & Troglodites aedon & - & + & - & + & + & + \\
\hline Rayadito & Aphrastura spinicauda & - & + & + & + & + & + \\
\hline Tero & Vanellus chilensis & + & + & + & - & + & - \\
\hline Torcaza & Zenaida auriculata & - & + & + & - & + & - \\
\hline Tordo patagónico & Curaeus curaeus & - & + & + & + & + & - \\
\hline Yal plomizo & Phrygilus unicolor & - & - & - & + & - & - \\
\hline Zorzal patagónico & Turdus falklandii & + & + & + & + & - & + \\
\hline \multicolumn{2}{|c|}{ Número Total de Especies Registradas } & 16 & 23 & 18 & 25 & 24 & 13 \\
\hline
\end{tabular}


Los resultados del análisis del agrupamiento basado en la información derivada de censos LT (Fig.4.66) fueron practicamente similares a los obtenidos al considerar la información registrada mediante censos PC (Fig.4.65).

Los ñirantales convertidos en pasturas conformaron un grupo claramente disímil del resto de los sitios y entre estos se observaron dos agrupamientos, uno conformado por los ñirantales primarios y el otro por los ñirantales sometidos a extracción de leña por manchones y los incendiados hace 15 años. Los ñirantales incendiados hace 25 años y los sometidos a extracción de leña por parquizado presentaron características de esos últimos dos agrupamientos.

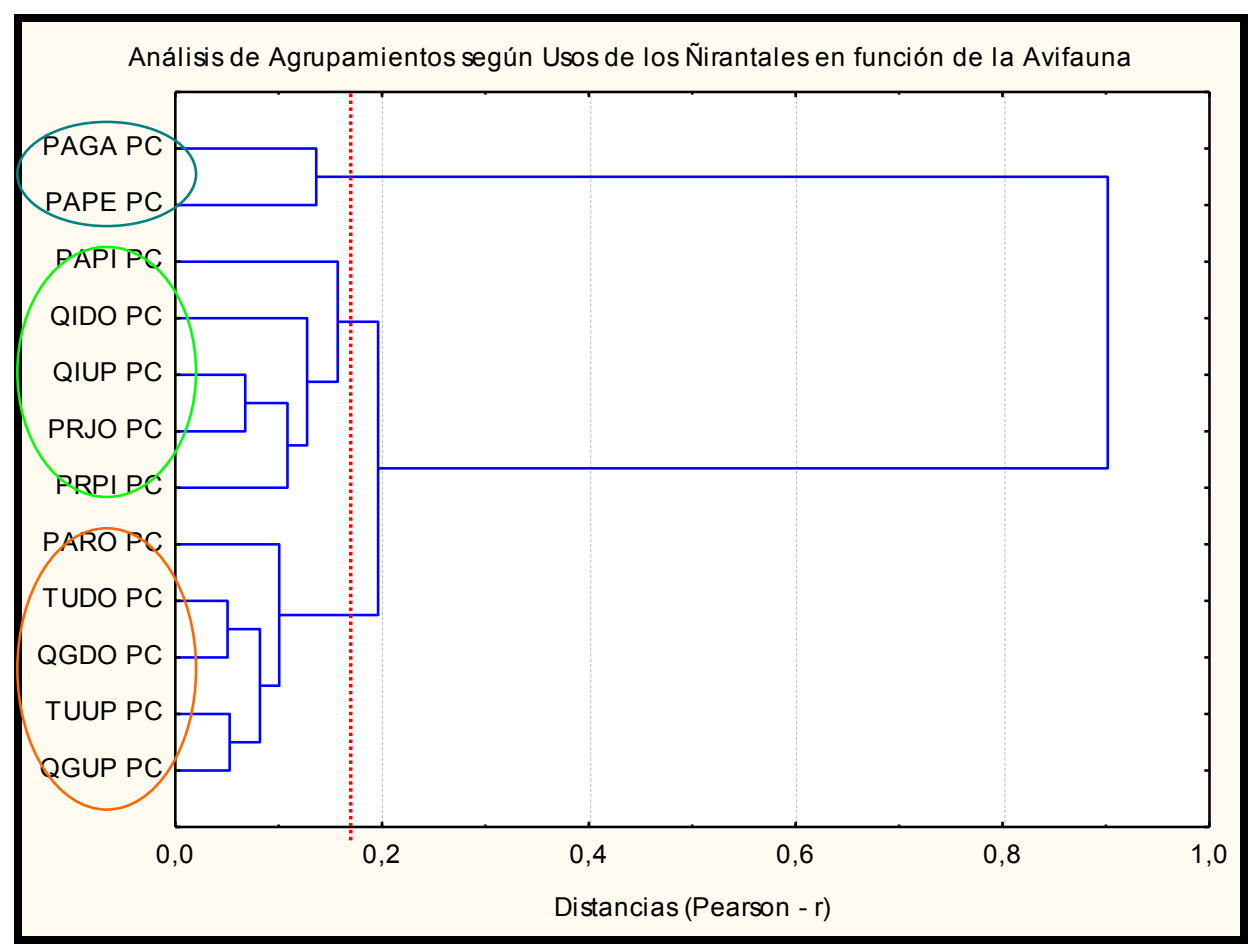

Fig. 4.65: Dendrograma de similitudes de estructuras de los ñirantales en base a la composición de las comunidades de aves de acuerdo a a la información derivada de censos por puntos de conteo. Código de sitios: PAGA y PAPE ñirantales transformados en pasturas, TUDO y TUUP ñirantales con extracción de leña por manchones, PRPI y PRJO ñirantales primarios, QGDO y QGUP ñirantales incendiados hace 15 años, QIDO y QIUP ñirantales incendiados hace 25 años y PAPI y PARO ñirantales con extracción de leña por parquizado. 


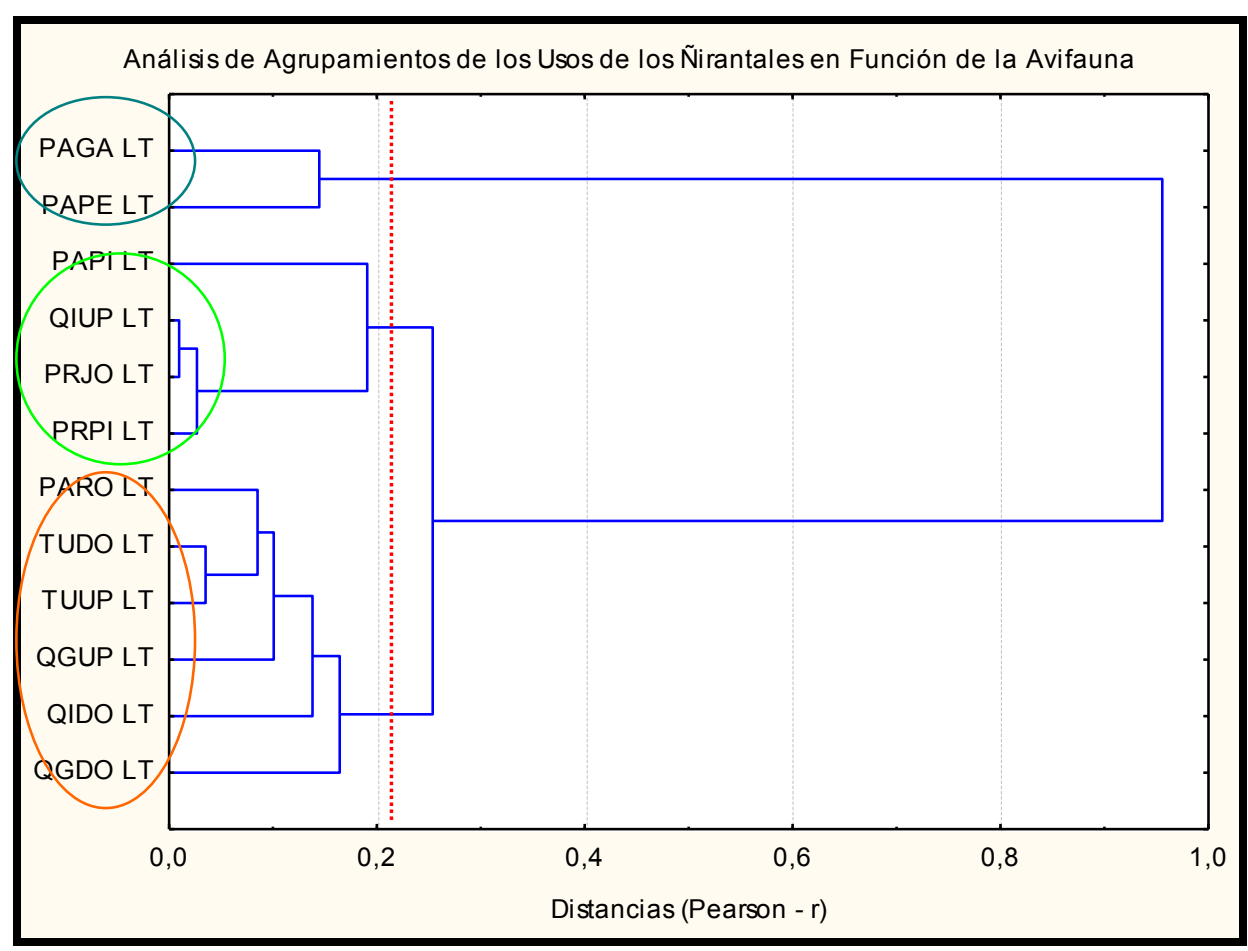

Fig. 4.66: Dendrograma de similitudes de estructuras de los ñirantales en base a la composición de las comunidades de aves de acuerdo a a la información derivada de censos por línea transecta. Código de sitios: PAGA y PAPE ñirantales transformados en pasturas, TUDO y TUUP ñirantales con extracción de leña por manchones, PRPI y PRJO ñirantales primarios, QGDO y QGUP ñirantales incendiados hace 15 años, QIDO y QIUP ñirantales incendiados hace 25 años y PAPI y PARO ñirantales con extracción de leña por parquizado.

\subsubsection{Análisis de Correspondencia Canónica (CCA)}

De acuerdo al análisis de Correspondencias Canónicas (CCA) basado en los datos de abundancia de aves (49 especies) según el método PC (Fig.4.67), los ejes CCA1 (autovalor: 0,338) y CCA2 (autovalor: 0,208 ) explicaron el $51,8 \%$ de la varianza de la relación entre las especies y las variables ambientales, observándose una alta correlación entre estas $(>0,86)$ (Tabla 4.47). Asimismo el modelo quedó validado por el Test de Montecarlo indicando que los ejes extraídos fueron significativos $(p=0,0002)$.

El eje 1 (CCA 1), permitió discriminar un gradiente ambiental en función de las características espaciales de los sitios, el que quedó definido por la mayor o menor transitabilidad del bosque, el viento y la contribución de frutos y semillas de distintas especies arbustivas y arbóreas (Laura, Rosa Mosqueta y Maytenus). De este modo los 
ñirantales convertidos a pasturas de Stipa sp., Azorella trifoliada, Poa ligularis y Madia sativa presentaron una mayor transitabilidad y mayores intensidades de viento, determinando que estos sitios se encuentren hacia el lado positivo del eje CCA1. Por el contrario, las parcelas con ñirantales primarios presentaron una menor transitabilidad y exposición al viento y mayor oferta de frutos, por lo que se ubicaron en el extremo negativo de dicho eje. El eje 2 (CCA $2)$, definió un gradiente ambiental relacionado con la estacionalidad, particularmente la temperatura del aire, y con atributos de la comunidad de invertebrados (abundancia, diversidad y equitatividad).

A lo largo del eje CCA 2 quedaron localizados los sitios de acuerdo al momento del año y por ende según la temperatura del aire, esto es, hacia el extremo negativo se situaron los ñirantales con extracción de leña mediante parquizado (PAPI, PARO), ñirantales con extracción de leña mediante extracción por manchones (TUUP y TUDO), ñirantales incendiados hace 15 años (QGDO y QGUP) y ñirantales incendiados hace 25 años (QIDO y QIUP) en primavera y verano y que además, presentaron correlación con variables descriptoras (diversidad y equitatividad) de las comunidades de los artrópodos. Hacia el extremo positivo del eje CCA2, se ubicaron los mismos ñirantales mencionados anteriormente en otoño y a los que se les agregaron los ñirantales primarios en invierno. A diferencia del eje negativo, los mencionados ñirantales no mostraron correlación con la diversidad y equitatividad de la comunidad de artrópodos (Fig. 4.67). Cabe aclarar que debido a que los artrópodos poseen características generalistas y a que los estudios multivariados son más potentes a nivel de análisis estadístico es por lo cual se evaluó directamente la comunidad de artrópodos mediante un Análisis Multivariado, evitándose de este modo, realizar el análisis de Cluster.

Las especies de aves con mayores densidades en sitios con mayor transitabilidad e intensidad de viento quedaron agrupadas 
sobre el lado positivo del CCA1 (Fig. 4.67), en tanto que aquellas aves asociadas a sitios de menor transitabilidad e intensidad de viento y con mayor contribución de frutos de Maytenus, Rosa Mosqueta y Laura, aparecen en el extremo del eje negativo CCA1. En relación al eje 2 (CCA2), las especies de aves asociadas a sitios con mayor oferta de invertebrados y con mayores abundancias en primavera y verano se agruparon en el semieje negativo.

Tabla 4.47: Autovalores de los ejes del Análisis de Correspondencias Canónicas y correlaciones intraset de la abundancia de las especies de aves según el método de puntos de conteo. Se presenta la significación de los ejes según el test Montecarlo.

\section{Autovalores}

Correlaciones especies-ambiente

\% de la varianza explicada de los datos de las especies

$\%$ de la varianza explicada de las relaciones especie ambiente

Correlación con los ejes:

Abundancia de Díptera

Abundancia total de artrópodos

Diversidad de artrópodos

Equitatividad de artrópodos

Diversidad de vegetación

Equitatividad de vegetación

Dominancia de vegetación

Transitabilidad

Laura (Schinus patagonicus)

Rosa mosqueta (Elanterea rosa)

\begin{tabular}{ccc} 
CCA 1 & CCA 2 & CCA 3 \\
\hline 0,338 & 0,208 & 0,102 \\
0,862 & 0,885 & 0,845 \\
12,0 & 19,4 & 23,1 \\
& & \\
32,0 & 51,8 & 61,5 \\
& & \\
& & \\
$-0,21$ & $-0,01$ & $-0,27$ \\
$-0,26$ & $-0,28$ & $-0,48$ \\
$-0,23$ & $-0,38$ & $-0,33$ \\
$-0,13$ & $-0,44$ & $-0,18$ \\
$-0,26$ & $-0,02$ & $-0,56$ \\
0,12 & 0,12 & $-0,10$ \\
0,01 & 0,03 & 0,46 \\
0,53 & 0,11 & 0,39 \\
$-0,46$ & $-0,09$ & $-0,45$ \\
$-0,31$ & $-0,08$ & 0,66 \\
$-0,36$ & 0,07 & $-0,71$ \\
0,15 & $-0,84$ & $-0,16$ \\
0,60 & $-0,25$ & 0,18
\end{tabular}

Maytenus (Maytenus disticha)

Temperatura del aire

Viento

0,60

$-0,25$

0,18

Test de significación del primer eje canónico; autovalor $=0,338$

$P$ - valor para el test de permutación de Monte Carlo

CCA1: $4,647, p<0,0006$

Todos los ejes canónicos: $F=1,573, p<0,0002$ 


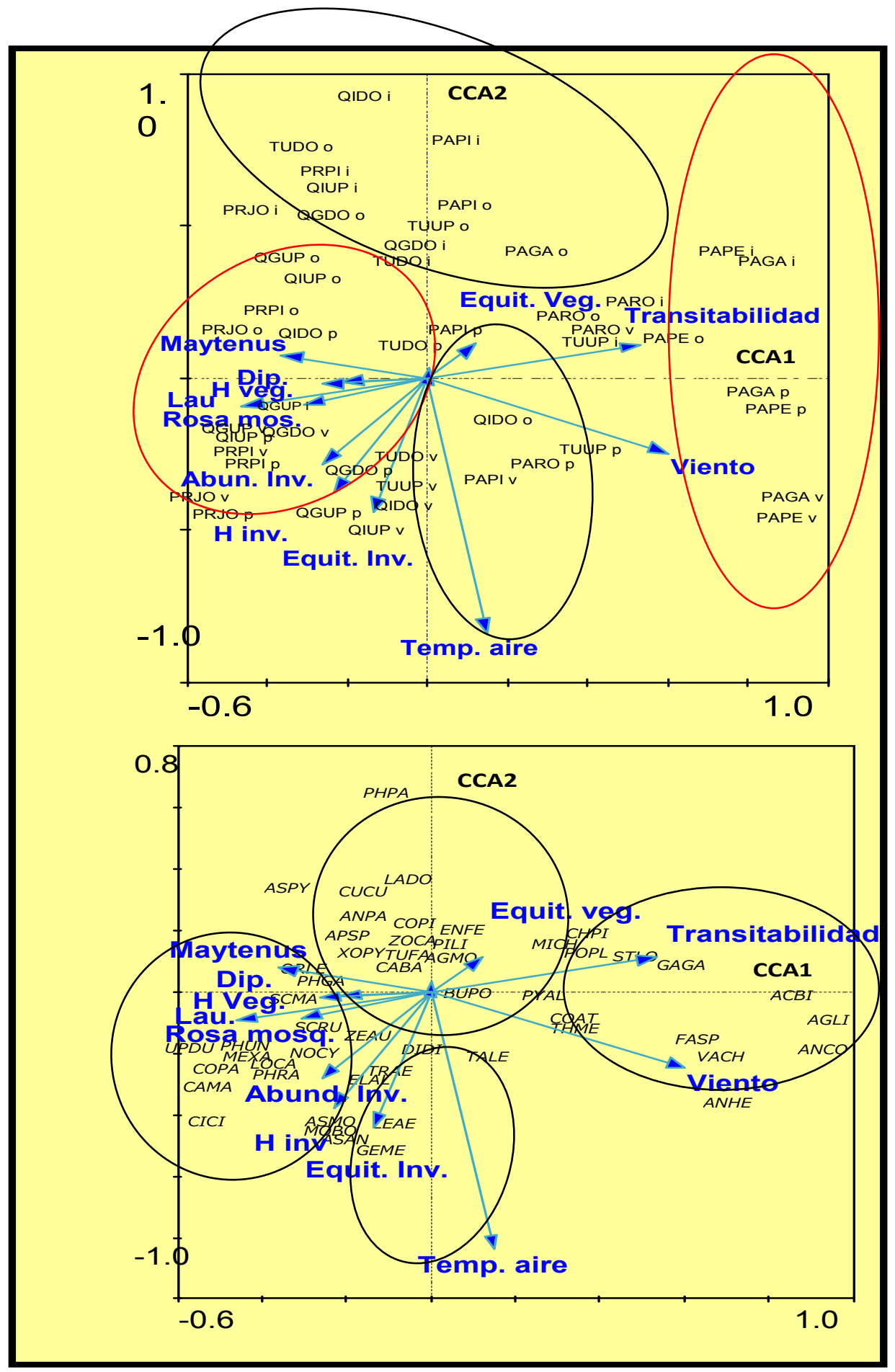

Fig. 4.67: Representación gráfica (biplot) de: a) sitios de estudio y variables ambientales y b) especies de aves y variables ambientales, según el Análisis de Correspondencias Canónicas basado en la abundancia de especies de aves (método por puntos de conteo) por estación del año en parcelas con distintos usos. PAGA y PAPE ñirantales transformados en pasturas, TUDO y TUUP ñirantales con extracción de leña por manchones, PRPI y PRJO ñirantales primarios, QGDO y QGUP ñirantales incendiados hace 15 años, QIDO y QIUP ñirantales incendiados hace 25 años y PAPI y PARO ñirantales con extracción de leña por parquizado, i: invierno, p: primavera, o: otoño, y v: verano. Las especies de aves se expresan con las dos primeras letras del género y de la especie, ver Tabla 4.63. 
El Análisis de Correspondencias Canónicas (CCA) basado en los datos de abundancia de aves (44 especies) según el método de línea transecta (LT)(Fig. 4.68), los ejes CCA1 (autovalor: 0.393) y el CCA2 (autovalor: 0.209) explicaron el $55 \%$ de la varianza de la relación entre las especies y las variables ambientales, observándose una alta correlación entre éstas $(>0,80)$ (Tabla 4.48). Asimismo el modelo quedó validado por el test de Montecarlo indicando que los ejes extraídos fueron todos significativos $(p=0.0002)$ (Tabla 4.48).

El eje 1 (CCA 1), permitió discriminar un gradiente ambiental en función de las características espaciales de los sitios, el cual quedó definido por la mayor o menor transitabilidad del bosque, el viento y la contribución de frutos de distintas especies arbustivas y arbóreas (Laura, Rosa Mosqueta y Maytenus). De este modo los ñirantales transformados en pasturas de Stipa sp., Azorella trifoliada, Poa ligularis y Madia sativa presentaron una mayor transitabilidad y mayores intensidades de vientos, lo que estableció que estos sitios se encuentren en el lado del eje CCA1. Por el contrario, los sitios correspondientes a los ñirantales primarios (PRPI y PRJO), poseían menor transitabilidad y exposición al viento, aunque mayor oferta de frutos (Laura, Rosa Mosqueta y Maytenus), de tal modo que se ubicaron, por el contrario en el extremo negativo de dicho eje.

El eje 2 (CCA 2), definió un gradiente ambiental relacionado con la estacionalidad, especialmente la temperatura del aire y con atributos de la comunidad de artrópodos (abundancia de artrópodos en general y abundancia de dípteros) y dominancia vegetal (Fig. 4.68).

A lo largo del eje CCA 2 quedaron localizados los sitios de acuerdo al momento del año y por ende según la temperatura del aire, de tal modo que hacia el extremo negativo se situaron principalmente los ñirantales con extracción de leña mediante parquizado (PAPI, PARO), ñirantales con extracción de leña mediante extracción por manchones (TUUP y TUDO), ñirantales incendiados 
hace 15 años (QGDO y QGUP) y ñirantales incendiados hace 25 años (QIDO y QIUP) con su estructura de primavera y/o verano, los cuales además, presentaron correlación con la variable descriptora de abundancia de las comunidades de los artrópodos y en menor medida abundancia de dípteros. Hacia el extremo positivo del eje CCA2, se ubicaron los mismos ñirantales mencionados anteriormente pero durante los meses fríos (otoño e invierno), los que también se correlacionaron con la dominancia vegetal. A diferencia del eje negativo, los mencionados ñirantales no mostraron correlación con la abundancia de la comunidad de artrópodos y de dípteros (Fig. 4.68 superior). Cabe aclarar que debido a que los artrópodos poseen características generalistas y a que los estudios multivariados son más potentes a nivel de análisis estadístico es por lo cual se evaluó directamente la comunidad de artrópodos mediante un Análisis Multivariado, evitándose de este modo, realizar también el análisis de Cluster.

Las especies de aves con mayores densidades en sitios con mayor transitabilidad e intensidad de viento quedaron agrupadas sobre el lado positivo del CCA1 (Fig. 4.68), en tanto que aquellas aves asociadas a sitios de menor transitabilidad e intensidad de viento y con mayor contribución de frutos de Maytenus, Rosa Mosqueta y Laura, aparecen en el extremo del eje negativo CCA1. En relación al eje 2 (CCA2), las especies de aves asociadas a sitios con mayor oferta de artrópodos y dípteros y, a su vez, con mayores abundancias en primavera y verano se agruparon en el semieje negativo. 
Tabla 4.48: Autovalores de los ejes del Análisis de Correspondencias Canónicas y correlaciones intraset de la abundancia de las especies de aves según el método de línea transecta. Se presenta la significación de los ejes según el test Montecarlo.

\section{Autovalores}

Correlaciones especies-ambiente

$\begin{array}{rrr}\text { CCA 1 } & \text { CCA 2 } & \text { CCA 3 } \\ 0,393 & 0,209 & 0,143 \\ 0,806 & 0,850 & 0,784\end{array}$

$\%$ de la varianza explicada de los datos de las especies

$\%$ de la varianza explicada de las relaciones especie ambiente

$11,4 \quad 17,4 \quad 21,6$

Correlación con los ejes:

Abundancia de Díptera

Abundancia total de artrópodos

Dominancia de vegetación

Transitabilidad

Laura (Schinus patagonicus)

Rosa mosqueta (Rosa moschata)

$35,9 \quad 55,0 \quad 68,0$

Maytenus (Maytenus disticha)

Temperatura del aire

$\begin{array}{lll}-0,2165 & -0,2104 & 0,2410\end{array}$

$-0,2967 \quad-0,6035 \quad-0,0055$

$0,0854 \quad 0,1578 \quad 0,2402$

$0,6750 \quad 0,0294 \quad-0,2366$

$-0,5462 \quad-0,1839 \quad 0,3115$

$-0,1920 \quad 0,1629 \quad-0,3434$

$-0,4434 \quad-0,0345 \quad 0,6017$

$0,1030 \quad-0,8257 \quad 0,0359$

Viento

0,6686

0,3914

Test de significación del primer eje canónico; autovalor $=0,393$

$\mathrm{P}$ - valor para el test de permutación de Monte Carlo

CCA1: $4,874, p<0,0007$

Todos los ejes canónicos: $F=1,960, p<0,0001$ 


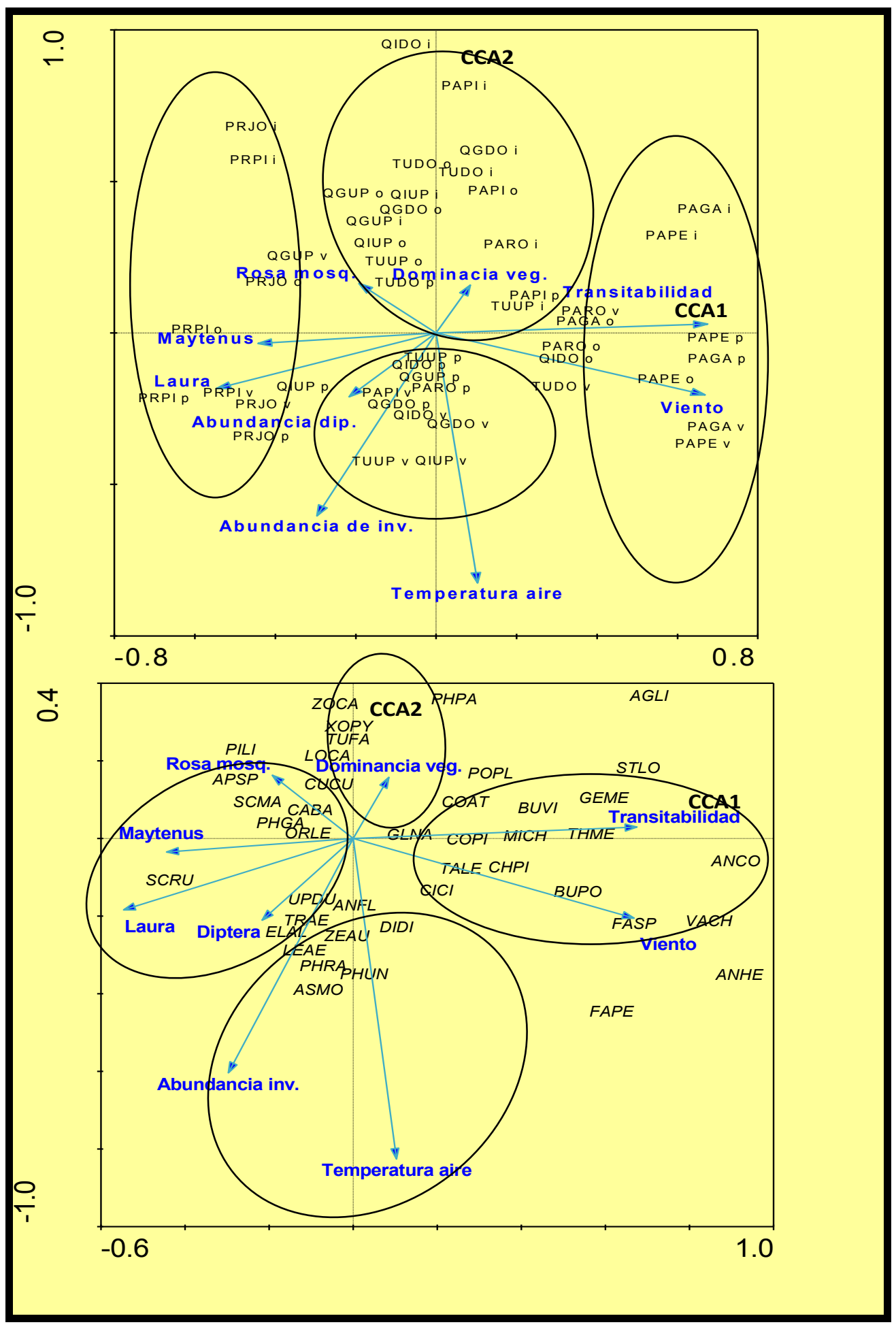

Fig. 4.68: Representación gráfica (biplot) de: a) sitios de estudio y variables ambientales y b) especies de aves y variables ambientales, según el Análisis de Correspondencias Canónicas basado en la abundancia de especies de aves (método por línea transecta) por estación del año en parcelas con distintos usos. PAGA y PAPE ñirantales transformados en pasturas, TUDO y TUUP ñirantales con extracción de leña por manchones, PRPI y PRJO ñirantales primarios, QGDO y QGUP ñirantales incendiados hace 15 años, QIDO y QIUP ñirantales incendiados hace 25 años y PAPI y PARO ñirantales con extracción de leña por parquizado, i: invierno, $p:$ primavera, o: otoño, y v: verano. Las especies de aves se expresan con las dos primeras letras del género y de la especie, ver Tabla 4.63. 


\section{CAPÍtULO $N^{\circ} 5$ \\ DISCUSIÓN}

Los estudios sobre la abundancia y diversidad específica de las aves andino-patagónicas y sobre sus patrones espacio-temporales de uso del hábitat son escasos (Jaksic y Feinsinger 1991, Lantschner 2005) por tal motivo, el presente estudio analizó la estructura y dinámica de la avifauna según: los datos registrados, las características observadas, los índices biológicos y de conservación obtenidos.

\subsection{Dinámica General de la Avifauna}

\subsubsection{Abundancia y riqueza específica}

El número de especies observadas mediante las metodologías de LT (44) y PC (49) está en consonancia con lo observado en otros estudios desarrollados en comunidades del bosque andino-patagónico (Jakcic y Feinsinger 1991, Rozzi et al. 1996a, Lantschner 2005, Lantschner y Rusch 2007).

En este sentido Jakcic y Feinsinger (1991) reportaron un total de 30 especies para el bosque andino-patagónico chileno. Estudios realizados por Rozzi et al. (1996a) reportaron 44 especies asociadas a los bosques templados del sur de Chile. En la Argentina, Lantschner (2005) y Lantschner y Rusch (2007) registraron 34 especies de aves asociadas a los ñirantales de la cuenca del río Foyel ubicados en el Noroeste patagónico.

Comparado con lo reportado para bosques de otras regiones las riquezas específicas observadas en los bosques templados de Patagonia son consideradas bajas (Vuilleumier 1985, Villagrán 1991) y se debería principalmente a procesos geológicos y paleoclimáticos (como la orogenia andina y las glaciaciones del cuaternario) que afectaron la región patagónica dejando a estos 
bosques con una fauna empobrecida (Vuilleumier 1985). Según Ralph (1985) la escasa diversidad de la avifauna patagónica se debería a la condición de insularidad de los bosques andino-patagónicos de Nothofagus y araucarias de Argentina y Chile, la que se debe a la separación de al menos 2000 Kilómetros de otros bosques por desiertos o estepas. Dicha distancia generó poblaciones pequeñas que estarían más expuestas a la extinción, a lo que contribuyó el clima extremo de la región con alta cobertura de nieve en los meses invernales.

Con respecto al origen de la avifauna, la mayoría de las especies registradas fueron nativas, lo que coincide con lo reportado para ambientes similares (Rozzi et al. 1996 ayb, Aizen et al. 1999, Christie et al. 2004, Lantschner y Rusch 2007). Solo se registró una especie introducida, la Codorníz Califórnica. Del total de las especies autóctonas 14 son endémicas, lo que refleja el alto endemismo de la avifauna en la región bajo estudio (Rozzi et al. 1996 ayb). El alto nivel de endemismo podría estar asociado también con la condición "insular" que los bosques andino-patagónicos presentan en relación a otros bosques sudamericanos (Vuilleumier 1972 y 1985, Ralph 1985).

Es así que, la estructura del hábitat (en general evaluada a través de la estructura de la vegetación) está fuertemente relacionada con las variaciones en la riqueza de aves (Pitelka 1941, Recher 1969, Rotenberry y Wiens 1980, Crowe y Crowe 1982, Emlen et al. 1986, Gentilli 1992, Tellería et al. 1992), aunque su relevancia parece ser mayor a escala local (Willson 1974, Roth 1976, Rice et al. 1983, Rotenberry 1985). En relación a lo antedicho, se observó que la abundancia de aves en los ñirantales disturbados por incendios y con extracción de leña por manchones o parquizado poseen una mayor abundancia, riqueza específica y diversidad de aves que los ñirantales primarios. Los mencionados impactos reemplazan la vegetación típica de los bosques primarios por una nueva y más diversa comunidad vegetal, compuesta por especies típicas de 
ambientes mas abiertos propios del ecotono bosque/estepa (Lantschner y Rusch 2007).

Tal cambio en la vegetación amplía la disponibilidad, variedad y cantidad de alimento y la transitabilidad del ambiente, lo que contribuiría a generar una comunidad de aves con mayor: abundancia, riqueza específica y número de gremios (Lantschner y Rusch 2007). Lo indicado es un patrón común en los sistemas patagónicos ya que varios autores (Vuilleumier 1972, Ralph 1985, Christie et al. 2004, Lantschner y Rusch 2007) también han reportado comunidades de aves mas abundantes y diversas en ambientes más abiertos y disturbados que los bosques primarios lo cual puede ser explicado por la hipótesis del disturbio intermedio (Connell 1978).

Aunque los impactos negativos mencionados (cambios en las estructuras y coberturas vegetales, modificación de los factores micro-climáticos, pérdida y degradación de ecosistemas boscosos entre otros) afectan principalmente a las especies de aves endémicas (Vuilleumier 1985, Donoso 1995). Se ha observado una mayor sensibilidad de las especies especialistas de hábitats a las transformaciones introducidas por el hombre en los ecosistemas, por ejemplo, en las poblaciones de los pájaros carpinteros (Short 1970, Ojeda et al. 2007), lo que repercute en una fuerte disminución en la riqueza y abundancia de las aves de este grupo con respecto a las que son más generalistas en cuanto a sus requerimiento de alimentación (Siriwardena et al. 1998, Robinson y Sutherland 2002, La Sorte 2006).

\subsubsection{Estado de Conservación}

Como se indicó previamente, la pérdida o modificación del hábitat afecta la avifauna ya sea reduciendo su hábitat, disminuyendo la disponibilidad de alimento y refugio o modificando su potencial de 
dispersión (Noss y Cooperrider 1994, Estades y Temple 1999, Santos et al. 2002). Sin embargo, la respuesta de las aves a la modificación del hábitat depende no solo del tipo y grado de perturbación sufrida por el ambiente sino también de los atributos de cada especie (Lantschner y Rusch 2007). En función de ello, algunas especies podrían no ser afectadas o hasta incluso ser beneficiadas por las perturbaciones del ambiente (Lantschner y Rusch 2007). Por ello, para evaluar los efectos de las perturbaciones en el ambiente sobre las comunidades de aves no solo es importante analizar los cambios en la abundancia, riqueza y diversidad de especies sino también, los cambios en la estructura de las comunidades, por lo que se debe poner especial énfasis en aquellas especies que están amenazadas o que son claves en el funcionamiento de un ecosistema (Rusch et al. 2005, Lantschner y Rusch 2007). En relación a esto, diversos estudios demostraron la relevancia que poseen algunas de las especies de aves que habitan el bosque andino-patagónico, las cuales son detalladas a continuación:

1) Aizen et al. (1999) y Lantschner y Rusch (2007) indicaron que las especies claves para el bosque andino-patagónico son el Carpintero Gigante Patagónico, el Chucao, el Rayadito, el Huet Huet, el Fío Fío Silbón y el Picaflor Cabeza Rubí (Sephanoides galeritus). Excepto por el Picaflor Cabeza Rubí que no fue observado en ninguno de los sitios de muestreo, el resto de las especies estuvieron presentes en los ñirantales primarios. Por el contrario, ninguna de estas especies fue observada en los ñirantales transformados en pastizales.

2) El Carpintero Gigante Patagónico, la Cachaña, el Picolezna y el Rayadito hacen un uso importante de los troncos y ramas para alimentarse de los invertebrados que allí se encuentran y para nidificar (Short 1970, Ojeda et al. 2007). Por ello, la disponibilidad de 
árboles de gran porte, añejos o muertos en pie es crucial para la supervivencia invernal de estas especies (Becerra Serial y Grigera 2005, Peri et al. 2011). Los ñirantales primarios corresponden a la tipología que cuenta con una mayor predominancia de árboles de gran porte, añejos o muertos en pie y por ello cuenta en su comunidad con todas las especies mencionadas.

3) Reid et al. (2002) indicó que en los bosques templados de Chile las especies endémicas Cachaña, Carpintero Gigante Patagónico, Huet Huet, Huet Huet Castaño (Pteroptochos castaneus), Chucao, Loro Choroy (Enicognathus leptorhinchus), Comesebo Patagónico y Churrín Grande (Eugralla paradoxa) son muy sensibles a los cambios ambientales. Cinco de estas especies sensibles a los cambios ambientales (Cachaña, Carpintero Gigante Patagónico, Comesebo Patagónico, Huet Huet y Chucao) estuvieron representadas en los ñirantales primarios considerados en este estudio, en tanto que estuvieron ausentes o fueron observadas ocasionalmente en el resto de las tipologías consideradas.

4) Willson et al. (1994) y Sieving et al. (1996, 2000) indicaron que las especies pertenecientes a la familia Rhinocryptidae (Huet Huet, Huet Huet Castaño, Chucao y Churrín Andino (Scytalopus magellanicus) se encuentran entre las especies más sensibles a la fragmentación de los bosques templados de Sudamérica.

En los ñirantales primarios se observaron todas las especies pertenecientes a la familia Rhinocryptidae que habitan el área de estudio (Narosky y Babarskas 2000, Narosky e Yzurieta 2004).

5) El nivel del Índice SUMIN (Suma de Índices) expresa el esfuerzo que se debe realizar para conservar una determinada especie (Reca et al. 1994, Grigera et al. 1996). 
Solamente tres de las especies observadas en este estudio (Carpintero Gigante Patagónico (19), Churrín Andino (17) y Picolezna (15)) poseen valores de SUMIN superiores a 15 (valor que corresponde a la mitad superior de la tabla y a partir del cual, aumenta el nivel de amenaza hacia la especie), fueron halladas en los ñirantales primarios, siendo éste el único ambiente donde dichas especies estuvieron representadas conjuntamente.

6) El Carpintero Gigante Patagónico fue catalogado como una especie con alto valor de conservación (Úbeda y Grigera 1995, Grigera et al. 1996, López Lanús et al. 2009) y como especie focal de la Ecorregión Valdiviana (Vila 2000, 2002) fundamentalmente debido a:

- Solo habitan los sectores no disturbados o con bajo impacto como por ejemplo los ñirantales primarios (Short 1970).

- Están fuertemente ligados a la disponibilidad de recursos y por ende fuertemente influenciados por el manejo forestal (Stenberg y Hogstad 1992, Angelstam y Mikusinski 1994, Dolby y Grubb 1999).

- Es un ave especializada en el uso de especímenes arbóreos añejos o muertos de solo ocho especies de árboles (incluidas las cinco especies de Nothofagus) (Short 1970, Saavedra 1996, 1998).

- Las cavidades para realizar sus nidos son realizados en árboles total o parcialmente muertos (Short 1970) y al ser estas abandonadas son utilizadas por otras especies, principalmente Caburé Grande (Glaucidium nanum), Halconcito Colorado (Falco sparverius) y Pitío (Colaptes pitius).

- Si bien también puede alimentarse de frutos como por ejemplo Calafate (Berberis buxifolia)(Mc Bride 2000), su 
principal alimento son larvas de Cerambycidae y Columbiformes (Rageot y Gedda 1978) solo existentes en árboles de elevada edad.

- Obtienen su alimento principalmente de grandes árboles cuya altura fluctúa entre 5 y 15 metros (Short 1970), con un DAP superior a $20 \mathrm{~cm}$. puesto que los árboles de menor talla suelen no estar infectados por artrópodos (Vergara y Schlatter 2004).

- Utiliza la totalidad del tronco e incluso las grandes ramas (Short 1970, Ojeda et al. 2007) debido a ello, el estado forestal puede ser considerado un indicador de la adecuación del ambiente para ser utilizado por la especie (Jones y Hunt 1996).

- Ocupa un gran nicho no existiendo prácticamente competidores (Short 1970).

- La distancia del vuelo está inversamente correlacionada con la cobertura forestal, a mayor cobertura es menor la distancia de vuelo y viceversa (Vergara y Schlatter 2004), lo que estaría indicando el nivel de disponibilidad de recursos.

7) Las especies Fío Fío Silbón (Elaenia albiceps) y Zorzal Patagónico (Turdus falklandii) son consideradas las principales aves responsables de la dispersión de un gran número de plantas leñosas productoras de frutos carnosos (Aizen et al. 2002).

En función de ello, los ñirantales primarios (PRPI y PRJO) conforman la estructura que alberga la mayor cantidad de especies de avifauna en estado vulnerable, sensibles, con mayores necesidades de conservación o de importancia para el ecosistema, lo cual está en concordancia con lo observado por diversos autores en áreas prístinas del bosque andino-patagónico (Correa et al. 1990, 
FVSA 1994, Grigera et al. 1996, Pavic 2000, Lantschner 2005, Grigera y Pavic 2007, Lantschner y Rusch 2007).

A diferencia de los ñirantales primarios, los ñirantales transformados en pasturas poseen solamente dos especies de importancia ecológica, por lo que esta información debería ser tenida en cuenta para la elaboración de políticas de conservación y prácticas acordes a un uso sustentable del bosque andino-patagónico (Becerra Serial y Grigera 2005, Lantschner 2007).

\subsubsection{Gremios tróficos}

El gremio es definido como un grupo de especies que explotan la misma clase de recursos ambientales de una manera similar (Root 1967, Mc Naughton 1978, Adams 1985, Krebs 1985 y 1994). Este término agrupa especies que se superponen significativamente en sus requerimientos de nicho, sin importar su posición taxonómica (Root 1973, Mc Naughton 1978, Krebs 1985 y 1994, Holmes 1990). Por tal motivo, los gremios pueden ser definidos sobre la base de cualquiera de los recursos ambientales utilizados y potencialmente repartidos por las especies. Es así que se han definido gremios en función del hábitat (Gorman 1988, Holmes 1990), según sitio de nidificación (Whittam y Siegel Causey 1981), entre otros recursos y/o estructuras ambientales por lo que la determinación de los gremios puede ser compleja (Ver Fig. 5.1): 


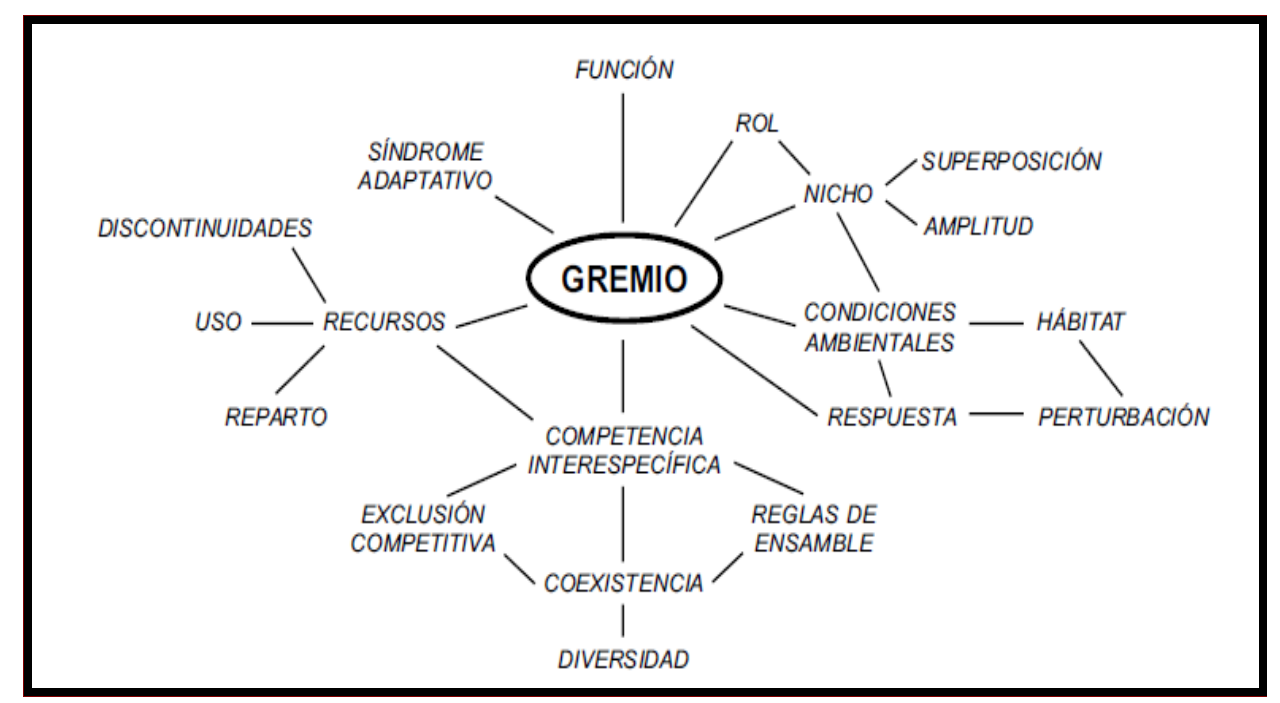

Fig. 5.1: Interacciones biológicas que generan la conformación de una estructura gremial, se observa la alta complejidad de las interacciones. (Diagrama tomado de López de Casenave 2001).

Por todo lo mencionado, por un lado, se debe distinguir entre grupos de especies con las mismas preferencias y/o modos de responder a las condiciones ambientales, debido a que es una herramienta útil para evaluaciones ambientales, ya sea utilizando a los gremios como indicadores de prácticas de manejo o de perturbaciones, o para la predicción de cambios ecológicos y/o climáticos (Short y Burnham 1982, Landres 1983, 1986, Block et al. 1986, Andersen 1997, Gitay y Noble 1997, Wilson 1999).

Por otro lado, al analizar los hábitos de alimentación se deben considerar en general, dos grupos de especies en cuanto a su grado de especialización en los usos de los hábitats de alimentación: las especies generalistas y las especialistas (Stotz et al. 1996). Las especies generalistas son buenas colonizadoras de varios tipos de hábitats tanto para alimentarse como para nidificar, lo que les permite mantener poblaciones viables en los agroecosistemas, de hecho varias de estas especies están consideradas como asociadas a hábitats antropizados (Parker et al. 1996). Por su parte, las especies especialistas se alimentan y nidifican exclusivamente en un único tipo de hábitat (Vickery et al. 1999), siendo más suceptibles a los cambios del hábitat. 
Al analizar la comunidad bajo estudio se constató que la mayoría de las especies observadas fueron insectívoras aunque varias de ellas también utilizan otros recursos, tal como fue observado en ambientes similares del bosque andino-patagónico (Lantschner 2005, Lencinas et al. 2005, Grigera y Pavic 2007, Lantschner y Rusch 2007). El gremio subdominante correspondió al conformado por las aves granívoras, con la única excepción de los ñirantales transformados en pasturas (ver abajo).

Las aves granívoras cumplen un papel de relevancia en un ecosistema puesto que representan el grupo más importante de dispersores de semillas (Snow 1981, Willson 1991) las que pueden aumentar o disminuir su tasa de germinación al pasar por el tracto digestivo de las aves dispersoras (Herrera 1984, Figueroa y Castro 2002, Traveset y Verdú 2002).

En los ñirantales convertidos en pasturas, existe menor disponibilidad de granos, lo que podría deberse a que primariamente el consumo ganadero no permitiría semillar a las gramíneas, lo que generaría un efecto directo sobre la abundancia de las especies granívoras (Milesi et al. 2002, Martín y Possingham 2005). Otros autores (Polop 1989, García et al. 2008) también observaron una disminución de aves granívoras en estos ambientes, aunque de un modo diferente, atribuyen dicho fenómeno a la competencia con los roedores.

Si bien las aves frugívoras ocupan el $4^{\circ} \circ 5^{\circ}$ lugar en nivel de importancia dentro de los gremios según los diferentes usos a los que fueron sometidos los ñirantales, son consideradas especies relevantes del bosque andino-patagónico debido a que:

a) Son importantes dispersores de semillas (Sabag 1993, Willson et al. 1996a, Amico y Aizen 2005). 
b) El $60 \%$ de las plantas leñosas del bosque andino-patagónico poseen frutos carnosos (Armesto y Rozzi 1989, Aizen y Ezcurra 1998)

c) El nivel de mutualismo frugívoros-plantas en el bosque andino-patagónico es mayor que en otros biomas de zonas templadas (Wilson et al. 1996b) y similar a la registrada en biomas de selvas tropicales (Gentry 1982).

d) En función de ello, las especies frugívoras son críticas para la integridad y funcionamiento del ecosistema del bosque andino-patagónico (Armesto et al. 1995a, Rozzi et al. 1996a, Willson et al. 1996b, Aizen et al. 1999). Los representantes mas relevantes de este gremio son el Fío Fío Silbón, el Zorzal Patagónico (Sabag 1993, Willson et al. 1996a, Amico y Aizen 2005), seguidos por el Diucón (Xolmis pirope), el Carpintero Pitío (Colaptes pitius) y el Tordo Patagónico (Curaeus curaeus) aunque en un significativo menor nivel (Sabag 1993).

Tal como sucedió en el presente estudio, se registraron escasas especies frugívoras por lo que algunos autores (Rozzi et al. 1996b, Lantschner y Rusch 2007), expresaron que las aves que consumen frutos son principalmente generalistas, característica ésta debido al carácter insular de los bosques templados de Sudamérica (Ralph 1985, Vuilleumier 1985), de tal modo que la mayoría de las especies halladas en los bosques de Nothofagus utiliza numerosos ambientes para subsistir (Lencinas et al. 2005) a lo largo de un ciclo anual. Debido a que no se cuenta en los bosques andino-patagónicos con frutos a lo largo de un ciclo anual algunas de las aves adoptan una estrategia de dieta generalista, la cual es posible debido a que, los bosques nativos andino-patagónicos proveen una gran heterogeneidad de hábitats con su consecuente gran provisión de diversos y 
abundantes recursos para alimentar las especies de aves nativas (Lantschner y Rusch 2007).

Cabe aclarar que existen especies que aún no fue determinada su importancia como frugívoras: Rara (Phitotoma rara), Carpintero Gigante Patagónico, Chucao y Huet Huet (Correa et al. 1990, Sabag 1993, Hernández 1995, Rozzi et al. 1996b).

Los cambios en los patrones de abundancia de las aves pueden tener profundas consecuencias en los procesos ecológicos de un ecosistema y en el bienestar humano ya que contribuyen en los principales servicios ecosistémicos (Sekercioğlu et al. 2004): las nectarívoras son agentes polinizadores (Arizmendi et al. 1996), las aves frugívoras cumplen un papel fundamental en la dispersión de semillas (Garcia et al. 2010), algunas insectívoras pueden controlar potenciales plagas (Mols y Visser 2002) y las aves rapaces y carroñeras colaboran con la sanidad ambiental regulando vectores de enfermedades y el ciclado de nutrientes (Sekercioğlu 2006). Además, las aves proveen de servicios culturales y beneficios económicos a través del ecoturismo (Whelan et al. 2008).

La pérdida de abundancia y diversidad de aves podría limitar algunos de los servicios (Whelan et al. 2008) tales como la reducción en el control de plagas en agroecosistemas (Gavier-Pizarro et al. 2012), el control de vectores de enfermedades (Kay et al. 1994) y la dispersión de semillas, lo que podría resultar en la desaparición del ambiente de especies vegetales (Cordeiro y Howe 2001).

\subsubsection{Variación de los índices biológicos según la estacionalidad climática}

Son escasos los estudios orientados a analizar la abundancia y diversidad específica de las aves andino-patagónicas con respecto a los patrones espacio-temporales de uso del hábitat, lo cual sería de gran importancia no solo para acrecentar el conocimiento de la 
dinámica de los ñirantales sino también para la formulación de prioridades de conservación (Jaksic y Feinsinger 1991).

Existen significativos cambios estacionales en las abundancias de las aves en los bosques templados de Sudamérica (Reid et al. 2002), lo que coincide con las marcadas variaciones observadas en los índices biológicos analizados en el presente estudio. Entre los numerosos factores ecológicos que determinan la variación espacial de la riqueza de especies de aves, el clima tiene gran importancia a escala macrogeográfica (Tramer 1974, MacArthur 1975, Herrera 1978, Rotenberry 1978, Schall y Pianka 1978, Short 1979, Heggberget 1987, Virkkala 1987, Root 1988, Tellería y Santos 1993, 1994). En éste trabajo se observó una clara estacionalidad en la conformación de las comunidades de aves, lo que se reflejó en la elevada fluctuación de la diversidad, equitatividad, abundancia y riqueza específica. La fuerte estacionalidad de las comunidades de aves con respecto a su abundancia y riqueza específica fue motivada por los altos cambios de temperatura del semestre otoño-invierno con respecto al semestre primavera-verano generando que alrededor del $50 \%$ de las especies migren total o parcialmente durante la temporada fría (ver también Rozzi et al. 1996b) en el presente trabajo se registró una migración total o parcial del $36 \%$ de las especies observadas.

Cabe aclarar que pocos estudios han evaluado la importancia relativa de la influencia del hábitat y el clima en conjunto, en función del tamaño de la superficie analizada (Wiens 1989a). Rabinovich y Rapoport 1975 indicaron que la variación de la riqueza de especies depende de la escala de la escala de análisis empleada, y que las diferencias en los factores determinantes de la riqueza de especies podrían estar relacionadas con la escala espacial. A gran escala (e.g., continental) el efecto de la estructura del hábitat podría ser despreciable y ser más importante el papel del clima, y la situación inversa podría ocurrir a escala local (Myers y Giller 1988). En el 
semestre otoño-invierno los bosques andino-patagónicos generan baja o nula oferta de semillas, frutos, brotes, etc., en tanto que en términos generales, se observó que los artrópodos asociados a los ñirantales se mantuvieron activos durante todo el año, aunque presentando picos de actividad durante los meses más cálidos (Gonc 2014). Resultados similares fueron observados por Debandi (1999) en comunidades de artrópodos asociados a Larrea divaricata y L. cuneifolia en la reserva de Ñacuñan, Mendoza, y por Lauterbach (1964), Brunsting (1981), Lowman (1982), Brandmayer y Brandmayer (1986) y, Niemelä et al. (1988) en bosques de Europa, lo cual determina que el gremio de aves predominante en estos bosques sea principalmente insectívoro (Lantschner 2005, Lencinas et al. 2005, Grigera y Pavic 2007, Lantschner y Rusch 2007). Por todo lo mencionado, el número de especies de aves varió estacionalmente de modo muy marcado en todos los sitios, lo que les permite a las especies utilizar mejor el alimento ofrecido a lo largo del año en todos los ambientes (Lencinas et al. 2005).

\subsubsection{Migración de las aves}

La migración de las aves andino-patagónicas tendría dos causas: a) abiótica, por disminución de la temperatura térmica anual y, b) biótica, debido a la disminución de la oferta de recursos alimenticios en el semestre otoño-invierno (Rozzi et al. 1996a).

Todo lo mencionado ocasiona una alta variación en el número de especies de aves a lo largo de un ciclo anual debido principalmente a la alta estacionalidad climática imperante en el bosque andino-patagónico, lo cual genera la migración de numerosas especies de aves, estos resultados son coincidentes con lo observado en el presente estudio y con lo reportado por Cody (1970), Wiens (1989a), Wenny et al. (1993) y Faaborg et al. (1998). 
Los cambios climáticos estacionales inciden sobre la estructura de los hábitats, afectando la abundancia, la diversidad y la distribución de las aves (Cody 1970, Wiens 1989a, Wenny et al. 1993, Faaborg et al. 1998) debido a que la disponibilidad de recursos es un factor determinante de la densidad de las poblaciones de aves (Raitt y Pimm 1976, Loiselle y Blake 1991, Marone 1992) ya que la disponibilidad y productividad de los sustratos son factores que influyen sobre la oferta de alimento en cada estación (Ralph 1985, Wiens 1989ayb, Becerra Serial y Grigera 2005).

Complementariamente, la variabilidad en la disponibilidad del alimento explica los cambios estacionales en la estructura de los ensambles (Brooks 1997, Soave et al. 1999, Cueto y López de Casenave 2000).

Cabe aclarar, por un lado, que algunos grupos como los Rinocryptidos, la conducta residente podría estar reforzada por su baja capacidad de vuelo (Rozzi et al. 1996b), por otro lado, algunos autores (Codesido y Bilenca 2000, Cueto 1996) expresaron que por el contrario, para las especies migrantes que se desplazan grandes distancias (desde los sitios de invernada hasta los sitios de reproducción o viceversa) hacen en general un uso oportunista de los hábitats y por lo tanto no existe una asociación estrecha con la heterogeneidad y los cambios del paisaje.

\subsubsection{Variación de los índices biológicos en relación a los usos de los ñirantales}

Los índices biológicos variaron según los diferentes usos a los que fueron sometidos los ñirantales.

Los valores extremos de cobertura y diversidad vegetal correspondieron a los ñirantales primarios (valores máximos en ambas variables) y a los ñirantales convertidos en pasturas (valores mínimos en ambas variables). No se observaron cambios en la equitatividad entre los sitios, lo que podría deberse, a que la menor 
diversidad de un determinado sitio podría estar compensado por una menor riqueza específica (ver también Ralph 1985).

Contrariamente a lo mencionado, numerosos autores observaron que el número de especies y la diversidad de aves está positivamente relacionado con la complejidad estructural de la vegetación (Mac Arthur 1961 y 1964, Recher 1969, Karr y Roth 1971, Pearson y Ralph 1978), lo que no fue observado en el presente estudio. Según estos autores (Mac Arthur 1961 y 1975, Recher 1969, Karr y Roth 1971, Pearson y Ralph 1978), la mayor complejidad de la composición de la estructura vegetal albergaría un mayor número de especies de aves (alta riqueza) y/o mayor número de especímenes, lo que se interpretaría como una alta dependencia de la comunidad de aves con respecto a la estructura del hábitat (obtención de refugio y alimento principalmente) y por ello, conociéndose la estructura vegetal se podría realizar algún grado de predectibilidad en cuanto al número de especímenes o riqueza específica que podría albergar.

En coincidencia con lo registrado en este estudio, Vuilleumier (1972) y Ralph (1985) observaron que los bosques de Nothofagus primarios y los ñirantales transformados en pasturas poseen una menor complejidad de aves en relación a los ñirantales con disturbios intermedios representados en este estudio por los ñirantales con extracción de leña por parquizado y por manchones y, los ñirantales quemados hace 15 y 25 años, donde se ha encontrado una mayor abundancia absoluta, riqueza específica y diversidad de avifauna (Vuilleumier 1972, Ralph 1985, Christie et al. 2004, Lantschner y Rusch 2007).

Los disturbios intermedios determinan un aumento en la heterogeneidad de la vegetación del ñirantal debido a que la vegetación de los ñirantales primarios es reemplazada por una nueva y más rica flora, compuesta por especies típicas de ambientes mas abiertos, por ejemplo, especies vegetales del ecotono bosque/estepa (Vuilleumier 1972, Ralph 1985, Christie et al. 2004, Lantschner y 
Rusch 2007), por ello, es esperable un incremento en la biodiversidad de avifauna al disponer éstos de mayores recursos alimenticios, de sectores para nidificación (Iglesias 1988, Gallo et al. 2004, Gordon et al. 2004, Lantschner 2005, Lantschner y Rusch 2007), mayor facilidad para localizar alimento sobre el suelo, la superficie y entre las hojas o, para detectar predadores (Devereux et al. 2004, Whittingham y Evans 2004, Devereux et al. 2005, Whittingham et al. 2006).

Por otro lado, las aves tendrían en los ñirantales transformados en pasturas una menor complejidad de la estructura de la comunidad por una menor oferta de granos generada por el consumo ganadero, el cual no permitiría semillar a las gramíneas (Milesi et al. 2002, Martín y Possingham 2005) aunque, algunos autores indican que la disminución de aves granívoras o generalistas estaría relacionada con la competencia con los roedores (Polop 1989, García et al. 2008).

Todo lo mencionado, es un patrón común en los sistemas patagónicos (Vuilleumier 1972, Ralph 1985, Christie et al. 2004, Lantschner y Rusch 2007).

\subsection{Dinámica de los ñirantales sometidos a diferentes usos}

Los bosques andino-patagónicos usualmente han sido manejados sobre la base de conocimientos parciales acerca del funcionamiento de los sistemas naturales o de conceptos de producción forestal, lo cual ha llevado a un manejo inadecuado de los bosques con consecuencias diversas, tales como desequilibrios en el ambiente (Laclau 1997, Gallo et al. 2004, Gonc 2014). Actualmente hay acuerdo en que las prácticas de uso de la tierra están cambiando rápidamente el paisaje de la región patagónica principalmente por la conversión de los bosques nativos en pasturas y por los distintos tipos de explotación forestal (Miserendino et al. 2010). Los cambios 
en las condiciones abióticas y bióticas de los bosques afectan profundamente no solo el crecimiento y el desarrollo de las plantas, sino también el crecimiento, la abundancia y la diversidad de los artrópodos asociados (Wolda 1978, Wolda 1988, Janzen 1983, Andersen 1997, Vasconcelos 1999, Vasconcelos et al. 2000, Sinclair et al. 2003, Chown et al. 2004, Lencinas et al. 2008) y aves asociadas (Vuilleumier 1972, Ralph 1985, Christie et al. 2004, Lantschner y Rusch 2007, Lencinas et al. 2008, Miserendino et al. 2010).

En función de ello y con el fin de configurar una aproximación a la dinámica generada por la acción de los distintos impactos a los que fueron sometidos los ñirantales sobre las comunidades de aves, a continuación se analizarán conjuntamente los resultados de la estructura vegetal y de las comunidades de invertebrados y de aves con los estadíos sucesionales del bosque de Ñire propuestos en el Modelo de Estados y Transiciones (ME\&T) (Rusch et al. 2015).

\subsection{1 Ñirantales Primarios}

Los estudios realizados en los bosques nativos sudamericanos determinaron que estos poseen una alta variación de hábitats y una elevada proporción de endemismos a nivel de géneros y especies de vegetación, artrópodos y aves, lo que deriva de la gran extensión latitudinal, de los extremos gradientes de temperatura y humedad, y de las barreras geográficas, entre otros factores (Dimitri 1972 y 1977, Armesto et al. 1995b, Donoso 1995, Simonetti et al. 1995).

Los ñirantales primarios considerados en este estudio, presentaron un estrato arbóreo dominado principalmente Ñire y en menor medida por Maitén, un estrato arbustivo donde también predominaron especies nativas tales como Schinus patagonicus, Ribes sp. y Berberis parodii y un estrato herbáceo donde las especies nativas fueron Stipa sp., Bromus sp., Viola maculata y Valeria 
carnosa, entre otras. Estos ñirantales presentaron un estado de conservación adecuado u óptimo, permitiendo la preservación de su variabilidad espacial y estacional natural, lo cual se reflejó en su estado sanitario diferencial. Estos sitios poseen una estructura arbórea heterogénea con componentes generados por el desmoronamiento de ñires añejos o muertos, sectores con regeneración de especímenes $y$, ñires en estadío de fustal u oquedal determinando un paisaje cerrado, con algunos algunos sectores semicerrados donde se observó una mayor presencia de gramíneas exóticas. Estos ambientes soportaron una presión de pastoreo baja o nula con eventos de fuegos esporádicos y ocurridos hace al menos 60-70 años (Informe PIARFON 2005).

Todo lo mencionado determina que, según el ME\&T (Rusch et al. 2015) el ñirantal primario considerado en este trabajo se corresponda con el estadío I denominado Bosque puro de Nire cerrado o semicerrado donde las principales especies y estructuras vegetales que lo definen son bosque de Ñire de gran porte con fustales cerrados o semicerrados, con un sotobosque donde dominan principalmente Maytenus chubutensis y las especies Berberis buxifolia y Osmorrhiza chilensis (Fig. 5.2).

En relación a los artrópodos, no se observaron diferencias en la estructura de las comunidades ni en la abundancia de los artrópodos entre los sitios sometidos a diferentes usos, solamente se observaron diferencias con respecto a los ñirantales transformados en pastizales.

Se observaron en los propios ñirantales primarios diferencias en la abundancia y en la riqueza específica de los diferentes órdenes de los artrópodos a lo largo de un ciclo anual y, según diversos autores (Wolda 1978, Mattson 1980, Strong et al. 1984, Lawton 1978, Marinoni y Ganho 2003, Gonc 2014) estas diferencias parecerían estar en estrecha relación con:

a) Las condiciones climáticas del ambiente. 
b) Las relaciones complejas entre los propios individuos y el ambiente.

c) Las condiciones abióticas a las que se encuentran sometidos, las que a su vez se manifiestan a nivel ambiental.

En referencia a los órdenes, dominaron los dípteros, homópteros, himenópteros y coleópteros. Estos órdenes fueron similares a los observados en bosques del resto de las especies de Nothofagus sp. y de Ciprés de la Cordillera de Patagonia, donde diversos autores (Coscarón y Wygodzinsky 1962, Lanfranco 1991, Spagarino et al. 2001, Sakcmann et al. 2006, Lencinas et al. 2008) sugieren que la abundancia de estos órdenes podría estar relacionada con el estado de descomposición de muchos árboles en pie y con la presencia de residuos leñosos sobre el suelo, características propias de los ñirantales primarios.

La abundancia de individuos de los órdenes representados en las capturas aumentó en paralelo con el incremento de la cobertura en especial del estrato arbóreo y arbustivo, resultados similares fueron observados por Mazía et al. (2006) en el Noroeste de Patagonia, en donde la cobertura de arbustos tales como Maytenus boaria, Mulinum spinosum, Schinus patagonicus, entre otros, se relacionó positivamente con el número de artrópodos capturados.

La preferencia de los artrópodos por ambientes con mayor cobertura vegetal se debería a la mayor disponibilidad de alimento, refugio y otras condiciones asociadas a la cobertura de la vegetación (Kotliar y Wiens 1990, Levin 1992). En base a lo mencionado, y tal como se observó en este trabajo, la abundancia de artrópodos se encuentra estrechamente relacionada a la fenología de la vegetación y a las condiciones climáticas (Gonc 2014).

El análisis multivariado de la estructura ecosistémica demostró que la mayor correlación se observó entre la abundancia y diversidad de los artrópodos y las estructuras conformada por los ñirantales 
primarios, siendo lo opuesto a lo observado en los ñirantales convertidos en pasturas lo cual, está de acuerdo con observaciones realizadas por diversos autores (Wallner 1978, Crawley 1983, Coley 1998).

Con respecto a la avifauna, la presencia de la vegetación autóctona es uno de los factores de mayor relevancia para mantener la comunidad de aves propias del bosque nativo (Estades 1994, Estades y Temple 1999, Vergara y Simonetti 2004, Lantschner y Rusch 2007), debido a que estos bosques poseen una gran heterogeneidad de hábitats con su consecuente gran provisión de diversos y abundantes recursos necesarios para alimentar las especies de aves nativas (Lantschner y Rusch 2007) pero a pesar de ello, los ñirantales primarios poseen valores menores de abundancia absoluta, riqueza específica y diversidad de avifauna con respecto a los ñirantales sometidos a extracción de leña por manchones o por parquizado $y$, los incendiados (Vuilleumier 1972, Ralph 1985), contrariamente a lo expresado por otros autores (Mac Arthur y Mac Arthur 1961, Mac Arthur 1964, Willson 1974) quienes sostienen que hay una alta correlación positiva entre la diversidad de avifauna y la diversidad de vegetación.

Los sitios cerrados de los ñirantales primarios, ofrece una variada biota apta para especies insectívoras, por ejemplo Ratona Común (Troglodytes aedon), Picolezna, o el emblemático Pájaro Carpintero Gigante Patagónico al obtener artrópodos en ramas y/o troncos de árboles añejos o moribundos de Ñire (Short 1970, Vergara y Schlatter 2004) pero, por otro lado, generan un sotobosque cerrado que no es propicio para aves granívoras o herbívoras como por ejemplo Chingolo, entre otras.

Los estudios multivariados arrojaron también como resultados una fuerte relación entre la comunidad de aves de los ñirantales primarios con la abundancia de frutos ofrecidos por las especies vegetales Laura, Rosa Mosqueta y Maytenus aunque esta sugiere que 
estaría mas en relación indirecta con la diversidad del ambiente que con la oferta de los propios frutos puesto que solo fueron registradas en el estudio tres especies frugívoras de importancia de las cuales solo dos habitaban los ñirantales primarios Fio Fío Silbón y Rara.

Se puede resumir en que las funciones de las aves en los ecosistemas primarios están relacionadas con la reproducción de especies vegetales por la dispersión de polen, frutos y semillas (Anderson 2003), la regulación de las poblaciones de insectos, su papel en la dieta de predadores y el ciclado de nutrientes y energía en las cadenas tróficas, contribuyendo al equilibrio y persistencia del ecosistema (Vammiere y Maurette 1995).

Una característica claramente distintiva de los ñirantales primarios con respecto al resto de los usos de los ñirantales es la gran estabilidad de la comunidad de aves, la cual está determinada por la relación entre las aves residentes (16) y las aves migradoras (5) arrojando un resultado de la relación muy superior $(5,33)$ comparado al resto de los ñirantales sometidos a diferentes usos.

Los ñirantales primarios son el único sitio evaluado donde habita el pájaro carpintero gigante patagónico (Campephilus magellanicus) debido a que encuentra especímenes arbóreos de Ñire de gran tamaño, con alturas que fluctúan entre los 5 y $15 \mathrm{~m}$. (Short 1970), con diámetros mayores a $40 \mathrm{~cm}$. y de sanidad deficiente aunque aptos para anidar (Rusch et al. 2005).

En estos ñirantales además fueron observadas ocho especies con necesidades de conservación sobre un total de once aves emblemáticas, vulnerables y/o con necesidades de conservación, actuando de este modo los ñirantales primarios como refugios para la conservación de las aves.

Lo anterior podría ser un indicativo de que la avifauna constituye una herramienta relevante para la investigación del impacto de actividades humanas sobre el ambiente, debido a lo cual, han sido estudiadas en diversos trabajos como indicadoras del estado 
de salud y de perturbaciones en los ecosistemas forestales y para analizar la dinámica de la comunidad de aves (Martin 1984, Canterbury et al. 2000, Deferrari et al. 2001, Sekercioğlu et al. 2002). Así, se arriba a la idea de que la conservación de estos ecosistemas boscosos naturales requiere del conocimiento de todas las especies que alberga (Elliot y Swank 1994) y de los cambios producidos por las modificaciones antrópicas y naturales.

\subsection{2 Ñirantales con extracción de leña por parquizado}

En el estrato arbóreo de los ñirantales con extracción de leña por parquizado predominó el Ñire con algunos ejemplares de Maitén y Laura. Los ejemplares de Ñire allí presentes poseían un estado sanitario muy bueno ( $100 \%$ sano) y, donde se observaron árboles de gran porte (entre 4 y $8 \mathrm{~m}$ de altura) y DAP $(32 \mathrm{~cm}$ d.s. $=5 \mathrm{~cm}$.).

Teniendo en cuenta que estos sitios se encuentran expuestos a intensos usos antrópicos, la presencia de ñires de gran tamaño y ausencia casi total de renovales es consecuencia de la introducción de ganado que no permiten el renuevo del bosque (Richter y Frangi 1992, Somlo et al. 1997, Martínez Pastur et al. 1999, Hansen et al. 2005, Carranza y Ledesma 2009), situación que compromete seriamente su rehabilitación natural (Laclau 1997).

Los ñirantales con extracción de leña por manchones y los ñirantales con extracción de leña por parquizado poseen cierta similitud en cuanto a la riqueza específica, diversidad, DAP y estado sanitario pero en los ñirantales con extracción de leña por parquizado se observó una estructura boscosa de mayor calidad forestal.

En el nivel herbáceo se observó la presencia principalmente de Stipa sp., Taraxacum officinale y en el nivel arbustivo se encontraría como especie dominante Laura y algunos ejemplares de Lomatia hirsuta. En estos sitios, la diversidad de especies del estrato herbáceo fue más elevada en relación a los bosques primarios sin manejo, lo 
cual se debería a la apertura del dosel y su consecuente nuevo microclima (Conticello et al. 1996, Bran et al. 1998, Mariottinni et al. 2002, Lencinas et al. 2003, Quinteros et al. 2010).

En el estrato arbustivo correspondientes al sotobosque se registraron especies tales como Bromus sp., Schinus patagonicus, Poa ligularis y Senecio sp., entre otras, las que son propias de ñirantales con extracción de leña por parquizado con sectores abiertos.

Debido a todo lo anterior, la estructura vegetal mencionada del bosque de Ñire con extracción de leña por parquizado se condice con el Estadío II denominado Bosque de Nire abierto con pastizal según el Modelo de Estados y Transiciones (ME\&T) (Rusch et al. 2015) (Fig. $5.2)$.

En relación a los artrópodos, la abundancia de especímenes de obtenidos en este estudio sugiere que las perturbaciones generadas por la extracción de leña por parquizado no afectan de manera significativa la abundancia de individuos de los órdenes capturados.

Excepto por el orden Heteróptera que solo fue capturado en PAPI y por el orden Ortoptera que solo fue capturado en PARO, el resto de los órdenes fueron capturados en ambas réplicas. Estos resultados sugieren que las técnicas de extracción de leña por parquizado no afectan la estructura de la comunidad de artrópodos.

Lo anterior, podría deberse a que las especies de artrópodos presentes son principalmente generalistas, por lo que responden fácilmente a los cambios generados en el ambiente como consecuencia de las perturbaciones, tales como cambios en la humedad, radiación, presión de predación, entre otros (Saunders et al. 1991, Andren 1995, Chen et al. 1995, Murcia 1995, Donovan et al. 1997, Laurance 2000, Vance y Nol 2003, Moore et al. 2004).

En relación a las aves y debido a que la diversidad de especies de vegetales del estrato herbáceo fue más elevada en relación a los ñirantales primarios, generado por la apertura del dosel y su 
consecuente nuevo microclima (Conticello et al. 1996, Bran et al. 1998, Mariottinni et al. 2002, Lencinas et al. 2003, Quinteros et al. 2010), produjo un ambiente de parches heterogéneos con áreas principalmente semicerradas con algunos sectores abiertos que promovió una oferta de alimento variado que permitió constituir una comunidad de aves de mayor diversidad, riqueza específica y abundancia en relación a los ñirantales primarios.

La mayor diversidad específica de aves del sitio puede ser explicada (como en los ñirantales con extracción de leña por manchones y los quemados hace 15 años y 25 años) por la hipótesis de la perturbación intermedia (Connell 1978). En estos sitios quedaron fragmentos con la fisonomía original conjuntamente con algunas áreas donde la vegetación herbácea se enriqueció con el ingreso de especies exóticas, generando un mosaico de especies vegetales de diferentes edades. Debido a lo mencionado se encontró una relación positiva entre la abundancia y riqueza de las especies de aves y las características asociadas a la heterogeneidad del paisaje, que incluyen un mayor número de nichos y de formas de explotación de los recursos a lo largo del ciclo anual (Tews et al. 2004).

Si bien la abundancia y riqueza de especies de aves es un indicador confiable de la calidad del hábitat (Bock y Jones 2004), algunas especies son más vulnerables al cambio disminuyendo su ocurrencia y abundancia mientras que otras se ven beneficiadas (Davies et al. 2000, Carignan y Villard 2002, Henle et al. 2004).

Dicha sensibilidad está relacionada con la historia de vida de las especies incluyendo el tipo de hábitat que ocupan, el tipo de alimentación, su estrategia reproductiva, entre otras (Cushman y McGarigal 2004, Henle et al. 2004)

Los cambios en composición específica y abundancia de los gremios tróficos del ensamble estuvo asociado a las variaciones en los niveles de recursos, principalmente artropodos, frutos, semillas y diversos organismos que tienen lugar en los ecosistemas durante un 
ciclo anual (Brickle et al. 2000, Robinson y Sutherland 2002, Boatman et al. 2004).

Se observaron siete especies de aves emblemáticas, vulnerables y/o con necesidades de conservación sobre un total de 11 , siendo superadas solamente por los ñirantales primarios.

En base a todo lo indicado el desarrollo de sistemas silvopastoriles en la Patagonia podría constituir una alternativa productiva sustentable, contemplando inclusive la posibilidad de recuperar ecosistemas degradados (Peri et al. 2011).

Aunque al igual que en otros ecosistemas (Westoby et al. 1989; Cingolani et al. 2005), el pastoreo en bosques nativos, no puede ser propuesto como un período estable. El modelo a seguir debería contemplar la necesidad de mantener el sistema productivo mediante medidas activas como la plantación de Ñire y la exclusión temporaria del pastoreo (Rusch et al. 2015).

\subsubsection{Nirantales sometidos a la acción del fuego}

Los bosques andino-patagónicos particularmente los de Ñire y Ciprés de la Cordillera (Urretavizcaya 2005) han estado sometidos a incendios desde hace aproximadamente 400 años y actualmente el 93\% de los incendios forestales son de origen humano ya sea por intencionalidad o negligencia (Dapoto 2003, SAyDS 2005), a pesar de ello y a excepción del trabajo de Grigera y Pavic (2007), aún no se ha analizado de modo integral (vegetación, artrópodos y aves) el impacto del fuego sobre los ecosistemas afectados.

Los incendios de bosques destruyen la vegetación y afectan las condiciones de fertilidad de los suelos, disminuyendo la disponibilidad de nutrientes, el contenido de materia orgánica y la humedad, condicionando la capacidad de regeneración de las especies vegetales (Veblen et al. 1983). 
La recuperación post-incendio de la vegetación depende, en gran medida, del régimen de perturbaciones al que ha estado expuesta la comunidad a lo largo de su historia evolutiva, del tamaño y composición del banco de semillas, de la capacidad de rebrote de las especies vegetales y de las condiciones ambientales que permitan la expresión de las mismas (Kozlowski 2002).

En los ñirantales incendiados la regeneración post-disturbio de algunas especies vegetales nativas es muy lenta y se caracteriza por un proceso sucesional dominado en sus primeros estadios por especies herbáceas exóticas oportunistas (Gobbi 1995, Kitzberger et al. 2005). Las secciones de bosque incendiado considerados en este estudio fueron afectados por los incendios su masa forestal está compuesta por árboles renuevo, latizales y algunos individuos exóticos. Tanto en los sitios quemados hace 15 como 25 años se observó una clara dominancia en los estratos arbóreos de Ñire, en tanto que en el arbustivos fue Berberis parodii y Chusquea culeou ambos de origen nativo, aunque en el herbáceo, el estrato con mayor predominancia, dominaron especies exóticas.

El hecho de haber encontrado especies exóticas naturalizadas, por ejemplo Rosa Mosqueta, particularmente en los sitios quemados hace 25 años, no es sorpresivo ya que esta especie está reportada como invasora de bosques de Nothofagus. Esto se debe a su capacidad para ingresar y establecerse fácilmente en las zonas quemadas (Varela et al. 2006) constituyéndose así en indicadores del grado de perturbación de estas comunidades (Quintanilla Pérez 2005). En estos sitios el estado de conservación del Ñire fue en general bueno, aunque el DAP de los individuos fue muy bajo, principalmente en los ñirantales incendiados hace 15 años, lo que se corresponde con el estado de regeneración de los mismos. Se sabe que el Ñire puede reproducirse vegetativamente y rebrota vigorosamente desde la base después de un incendio (Kitzberger et al. 2005), por lo cual podría suponerse que luego de los disturbios se ha 
producido un proceso de regeneración de esta especie, el que estaría controlado por una conjunción de factores, tales como cambios en la fertilidad del suelo, disponibilidad de semillas, cambios en los patrones de temperatura del suelo, modificaciones en la cobertura arbórea y arbustiva luego del incendio (La Manna y Barroetaveña 2010) factores que coinciden con los reportados por otros autores para bosques incendiados de otros Nothofagus (Kitzberger 2003, Kitzberger et al. 2000).

En este estudio no se cuenta con información sobre la severidad de los incendios ocurridos, sobre los cambios ocurridos en el suelo, ni sobre el banco de semillas o los brotes disponibles luego del disturbio, sin embargo, el Ñire logró restablecerse en la zona perturbada, como también lo hicieron especies autóctonas oportunistas como el Radal (Lomatia hirsuta), la Caña Colihue y exóticas como la Rosa Mosqueta, lo que coincidió con lo observado en otros estudios (Burns 1993, González et al. 2005, Quintanilla Pérez 2005, Varela et al. 2006). Toda esta información indicaria que la mayor parte de las especies presentes luego de un evento ígneo posee características autoecológicas, adaptaciones y estrategias para resistir y/o responder en forma relativamente exitosa a estos eventos (Veblen 1982, Burns 1993, Quintanilla Pérez et al. 2008).

En relación al ME\&T (Rusch et al. 2015) el bosque de Ñire incendiado hace al menos 15 años se correlacionó con el Estadío III denominado Bosque mixto de Nire con Laura y Retamo (Rusch et al. 2015) principalmente en su fase 2 (Fig. 5.2). Esta fase comprende una estructura de bosque de Ñire mono-específico, cuyo dosel no supera los 3 metros de altura y donde debido al incendio y a la presión de pastoreo se redujo la cobertura de Ñire promoviendo un bosque abierto o semicerrado.

Este bosque posee un sotobosque de pastizales principalmente de Stipa sp., Taraxacum officinale con algunos ejemplares de Caña Colihue y Berberis sp. 
En esta fase del ñirantal los bosques presentaron diversas estructuras como troncos en pie, raíces de especies rebrotantes y nutrientes del suelo que son de gran importancia para la recuperación del sistema por lo que resulta una fase crítica y posible de recuperación según el manejo que se realice de la misma (Cavallero et al. 2015).

El bosque de Ñire incendiado hace al menos 25 años se correspondió con el Estadío III denominado Bosque de Ñire abierto con pastizal (Rusch et al. 2015) fase 3. En estos sitios el ganado eliminó las especies mas palatables como por ejemplo la Caña Colihue y rebrotes de Ñire generando consecuentemente un ambiente con baja cobertura de Ñire. La mencionada baja cobertura de Ñire determinó una etapa sucesional de codominancia entre Ñire, Laura y Retamo y la especie arbórea introducida Pinus sp. (Fig. 5.2).

El sotobosque estuvo dominado por herbáceas, principalmente Stipa sp., Taraxacum officinale y Bromus sp. y en menor medida Holcus lanatus, Poa sp. y Trifolium repens. Las gramíneas fueron preponderantemente de origen nativo, siendo en todos los casos especies palatables para el pastoreo del ganado bovino.

En relación a los artrópodos los efectos ocasionados por el fuego en los diferentes sitios estudiados ha sido disímil. En este sentido Lyon et al. (1978), Martin y Mitchell (1980), Mitchell (1990), Okland et al. (1996), Yanowsky y Kiselev (1996) y York (2000) observaron que la riqueza de especies de artrópodos es afectada negativamente por los incendios debido a la alteración de las propiedades del suelo y de disminución de la cobertura vegetal, entre otros efectos, lo que confluye para reducir la disponibilidad de microhábitats. Sin embargo, otros estudios han demostrado que los incendios diversifican la disponibilidad de hábitats, lo que favorece a diferentes tipos de artrópodos (Buddle et al. 2000, Gandhi et al. 2001, Moretti et al. 2004). En este estudio no se pudieron comparar las estructuras de las comunidades de artrópodos antes y después de 
los incendios, por lo que no se puede tener certeza acerca de si tales eventos modificaron o no las estructuras de las comunidades preexistentes.

Al comparar los sitios incendiados con los ñirantales primarios se observó que la abundancia de órdenes y los índices de riqueza y diversidad no presentaron diferencias significativas por lo que se puede especular que, tal como observaron Richardson y Holliday (1982), Danks y Footitt (1989), Mitchell (1990) y Friend (1995), las estructuras de las comunidades de artrópodos no fueron afectadas por los incendios, lo que podría deberse a la resiliencia y/o capacidad de adaptación a nuevas condiciones de las especies allí representadas. En relación a la comparación de sitios incendiados con diferente antigüedad en los sitios afectados por el fuego hace 25 y 15 años se observó la misma riqueza de órdenes y número de individuos. Al parecer, la regeneración vegetal observada en los sitios afectados por incendios de distinta antigüedad fue relativamente similar, lo que resultó en estructuras de comunidades de artrópodos similares.

Con respecto a la avifauna los ñirantales que sufrieron el impacto de un incendio hace 15 años y 25 años, al igual que los ñirantales con extracción de leña por parquizado y por manchones, poseen una mayor riqueza específica, diversidad y abundancia que los ñirantales primarios. La mayor diversidad específica de los sitios quemados puede ser explicada por la hipótesis de la perturbación intermedia (Connell 1978). En este sitio quedaron fragmentos con la fisonomía original y algunas áreas donde la vegetación herbácea se enriqueció con el ingreso de especies exóticas, generándose un mosaico de especies vegetales de diferentes edades, promoviendo un aumento en la heterogeneidad del hábitat (Grigera y Pavic 2007) con su consecuente mayor oferta de recursos.

A diferencia de lo observado en este trabajo, en otros estudios se observó que las características del fuego generaron una simplificación estructural del hábitat, determinando la disminución del 
número de especies capaces de utilizarlo, favoreciendo la dominancia de especies de ambientes abiertos (Sousa 1984, Pickett y White 1985, Marone 1990).

Tanto en los ñirantales incendiados 15 y 25 años se observaron especies de gran valor de conservación, emblemáticas y/o de importancia para el ecosistema. Con respecto a la estructura de los gremios, se observaron diferencias de baja magnitud entre ambos sitios incendiados en relación a los porcentajes de aves correspondientes al gremio insectívoro (dominante). Como se indicó previamente los artrópodos, son generalistas y por lo tanto pueden habitar todos los ambientes proveyendo de este modo de alimento disponible para las aves en todos los diferentes sitios de muestreo.

El gremio granívoro fue el segundo en abundancia pudiendo haber sido negativamente afectado, debido a que la presión de pastoreo impidió el semillado de numerosos especímenes vegetales lo cual afecta principalmente a estas.

Las especies carnívoras presentaron una abundancia aún menor, comparativamente este gremio fue mas abundante en los ñirantales incendiados hace 25 que en los ñirantales incendiados hace 15 años lo que podría deberse deberse a la existencia en los primeros de áreas abiertas de mayor tamaño, lo que permite una mejor visualización de las presas por parte de estas aves.

En relación a las diversidades observadas, debe tenerse en cuenta que como consecuencia de los efectos sinérgicos del fuego y de la fragmentación, la presencia de una especie en un área no implica su persistencia (Barlow et al. 2006). En este sentido, la presencia en sitios incendiados de dos especies de Rinocriptidos (Chucao y Churrín Andino) podría deberse a que éstos utilizaron fragmentos que podrían funcionar como trampas ecológicas, haciéndolas desaparecer a largo plazo por el aumento de la predación de sus nidadas (Vergara y Simonetti 2003). 


\subsection{4 Ñirantales con extracción de leña por manchones}

En los ñirantales utilizados para extracción de leña por manchones, predominaron especies pertenecientes al estrato arbóreo de origen nativo tales como Ñire y Laura. Los ñires allí presentes presentaron un estado sanitario muy bueno (100\% sano) $y$, comparado con los sitios quemados, el tamaño de los árboles fue relativamente mayor. Este relativo mayor tamaño de los ejemplares en parte se debe a la ausencia de renovales, lo que se debería al manejo silvopastoril que allí se desarrolla (Richter y Frangi 1992, Somlo et al. 1997, Martínez Pastur et al. 1999, Hansen et al. 2005, Carranza y Ledesma 2009) lo que comprometió seriamente la rehabilitación natural (Laclau 1997). En los estratos herbáceos y arbustivo se registraron especies tales como Bromus sp., Schinus patagonicus, Poa ligularis y Senecio $s p$., entre otras, las que son propias de ñirantales con sectores abiertos.

Los sitios con extracción de leña por manchones poseen cierta similitud en cuanto a la riqueza específica y diversidad vegetal, al DAP y al estado sanitario de los ñires con aquellas afectadas por la extracción de leña por parquizado. Sin embargo, en el primer tratamiento se observó una estructura mas degradada. La diversidad de especies del estrato herbáceo fue más elevada que en los bosques primarios, lo cual se debería a la apertura del dosel y su consecuente nuevo microclima (Conticello et al. 1996, Bran et al. 1998, Mariottinni et al. 2002, Lencinas et al. 2003, Quinteros et al. 2010)

En lo que respecta a los artrópodos, los resultados obtenidos en este estudio sugieren que las perturbaciones generadas por la extracción de leña por manchones no afecta de manera significativa la abundancia de individuos de los órdenes capturados. Además la totalidad de los órdenes representados en el estudio estuvieron presentes en los sitios sometidos a extracción de leña por manchones. Esto podría deberse a que las especies de artrópodos 
capturadas, son principalmente generalistas, por lo que responden fácilmente a los cambios generados en el ambiente como consecuencia de las perturbaciones, tales como cambios en la humedad, radiación, presión de predación, entre otros (Saunders et al. 1991, Andren 1995, Chen et al. 1995, Murcia 1995, Donovan et al. 1997, Laurance 2000, Vance y Nol 2003, Moore et al. 2004). Debido a lo mencionado se encontró una relación positiva entre la abundancia y riqueza de las especies residentes y las características asociadas a la heterogeneidad del paisaje, que incluyen un mayor número de nichos y de formas de explotación de los recursos a lo largo del ciclo anual (Tews et al. 2004).

En relación a las aves, al igual que en el resto de los sitios estudiados el gremio dominante fue el de los insectívoros, seguido por el de los granívoros, lo que se debería a la mencionada heterogeneidad del ambiente y su concomitante diversidad de oferta de recursos vegetales.

Si bien la abundancia y riqueza de especies de aves es un indicador confiable de la calidad del hábitat (Bock y Jones 2004), algunas especies son más vulnerables al cambio disminuyendo su ocurrencia y abundancia mientras que otras se ven beneficiadas (Davies et al. 2000, Carignan y Villard 2002, Henle et al. 2004).

Dicha sensibilidad está relacionada con la historia de vida de las especies de aves, incluyendo el tipo de hábitat que ocupan, el tipo de alimentación, su estrategia reproductiva, entre otras (Cushman y McGarigal 2004, Henle et al. 2004)

Los cambios en composición específica y abundancia de los gremios tróficos del ensamble estuvo asociado a las variaciones en los niveles de recursos, principalmente artropodos, frutos, semillas y diversos organismos que tienen lugar en los ecosistemas durante un ciclo anual (Brickle et al. 2000, Robinson y Sutherland 2002, Boatman et al. 2004). 
Si bien los ñirantales con extracción de leña por manchones poseen una alta riqueza específica, diversidad y abundancia de aves al analizarse las características de conservación de la comunidad de aves solamente fueron observadas 4 especies de gran valor de conservación, emblemáticas o vulnerables en el mencionado ecosistema, con lo cual este exiguo resultado permitió superar únicamente a los ñirantales transformados en pasturas.

En relación al ME\&T (Rusch et al. 2015) las características del ñirantal con extracción de leña por manchones se corresponderían con el Estadío III denominado Bosque de Ñire con Laura y Retamo en su fase 4 lo que refleja una fase de degradación (negativa) (Fig. 5.2).

Esta estructura del bosque de Ñire con extracción de leña es un ambiente generado por una alta pérdida de masa arbórea debido al talado de árboles, lo que en conjunto con la presión de pastoreo, determinaron la eliminación de una de las especies más palatables para el ganado como son los rebrotes de Nire, concomitantemente al aumento de la cobertura de herbáceas en especial las de origen exótico (Arqueros 1999, Raffaele et al. 2011).

Lo anterior, produce un ambiente predominantemente abierto con sectores minoritarios semicerrados, modelando una estructura de ñirantal con un alto nivel de transitabilidad, solamente superado por los ñirantales con extracción de leña por parquizado y ñirantales transformados en pastizales.

A pesar de que los ñirantales con extracción de leña por manchones son sitios degradados, no significa que hayan perdido su potencial, por el contrario, son bosques que bajo prácticas silvícolas tendientes al manejo sustentable pueden ser recuperados (Montenegro et al. 2004), con el fin de mantener la biodiversidad puesto que los bosques de Ñire cumplen un servicio ambiental prioritario aunque, cabe aclarar, es un tema de difícil abordaje (Rusch et al. 2005). 


\subsubsection{Nirantales convertidos en pasturas}

Desde hace más de 100 años los bosques norpatagónicos han sido sometidos a intensos aprovechamientos madereros y a su transformación con destino a usos principalmente pastoriles (Laclau 1997, Veblen et al. 2003, Hansen et al. 2008, Quintanilla Pérez et al. 2008), por lo que son sometidos a intensas modificaciones tanto de sus componentes bióticos como abióticos (Soriano y Aguiar 1998).

La deforestación del bosque nativo y la conversión final de estas áreas en pasturas representa el cambio más importante en el uso del suelo en los últimos 50 años (Laclau 1997, Gallo et al. 2004, Hansen et al. 2005).

Los pastizales han sido generados principalmente por la eliminación total de la cobertura de Ñire mediante tala rasa (Fertig 2004, Peri 2005, Fertig et al. 2007, Hansen et al. 2008), tal como sucedió en las áreas estudiadas. Al eliminarse la cobertura arbórea, se pierden todas las funciones ecológicas de las formaciones boscosas, tales como la protección de cuencas, la fijación de carbono, la generación de oxígeno, y el mantenimiento de la diversidad biológica (Perry 1994, Ramírez et al. 1985, Rusch y Sarasola 1999, Peri et al. 2005). Al traspasarse los umbrales críticos, además de producirse cambios a nivel estructural (vegetación, suelo), se produce la pérdida de funciones o procesos claves del ecosistema como la productividad, la regeneración y la, estabilidad (López 2011), lo que se ve agravado por la introducción de ganado, el cual no permite la regeneración del bosque (Richter y Frangi 1992).

Los ñirantales convertidos en pasturas considerados en este trabajo presentaron una elevada cobertura de especies pertenecientes al estrato herbáceo de origen nativo, propios de las zonas de explotación ganadera (Hansen et al. 2008), tales como Stipa sp., Azorella trifoliolata, Poa ligularis, Madia sativa, entre otras. En el estrato arbustivo dominó Escallonia virgata acompañada por unos pocos ejemplares de Berberis buxifolia. En estos sitios no se 
registraron especies pertenecientes al estrato arbóreo, lo cual implica que la regeneración y, por ende, la rehabilitación del bosque se encuentra seriamente comprometida (Richter y Frangi 1992, Calderón 1993, Martínez Pastur et al. 1999).

En relación al ME\&T (Rusch et al. 2015), en base a las características de vegetación mencionadas, el bosque de Ñire transformados en pasturas se encontraría en el Estadío $V$ denominado Pastizal con Nires y arbustos y se correspondería con una fase de degradación (negativa) siendo además un estadío difícil de revertir ya que los rebrotes de Ñire se encontrarían impedidos de regenerarse naturalmente debido a la exclusión competitiva por parte de las gramíneas $y$, al efecto del ramoneo por parte del ganado (Rusch et al. 2015)(Fig. 5.2).

Los sitios convertidos a pasturas se caracterizan por una muy baja heterogeneidad espacial y temporal, determinada en gran medida por la periodicidad de las actividades agropecuarias, aunque es deficiente la información sobre como esto afecta a las comunidades de artrópodos (Macdonald y Smith 1990).

Sin embargo los sitios convertidos a pasturas considerados en este trabajo no son manejados, por lo que las variaciones estacionales allí observadas sólo dependen de los ciclos climáticos y de la fenología vegetal. Algunos autores consideran que la conversión de bosques a pasturas puede tener un efecto perjudicial en la dinámica comunitaria de los artrópodos, principalmente debido al cambio en el hábitat (Curry 1994, Gerstmeier y Lang 1996). Sin embargo, en este trabajo los sitios convertidos a pasturas no difirieron en la riqueza de los órdenes capturados con los sitios afectados por incendios, por extracción de leña por manchones y parquizado y tampoco con los ñirantales primarios sin manejo. Resultados similares fueron observados por Di Giulio et al. (2001), quienes concluyeron que éstos artrópodos pueden presentar un hábito generalista, adaptándose fácilmente a cambios en el ambiente 
y beneficiándose por las nuevas condiciones generadas en los sitios convertidos a pasturas.

A pesar de lo anterior, la abundancia de artrópodos en los pastizales fue menor que en el resto de los sitios considerados, lo cual podría estar generado por una mayor temperatura producto de la elevada incidencia solar que conjuntamente con la falta de los estratos arbustivos y arbóreos, tendría un efecto negativo directo sobre las poblaciones de estos invertebrados (Wallner 1978, Crawley 1983, Coley 1998).

La sumatoria de las características mencionadas determinó que los ñirantales transformados en pastizales fueran la estructura vegetal que más afectó la organización y abundancia de la avifauna (Lantschner 2005, Peri 2005, Lantschner y Rusch 2007).

En este ambiente el gremio dominante corresponde al de los insectívoros, lo que esta relacionado con la escasa oferta de frutos y semillas, éstos resultados son similares a los reportados en otros estudios realizados en el bosque andino-patagónico de Argentina y de Chile (Grigera et al. 1996, Rozzi et al. 1996ayb, Lantschner 2005, Informe PIARFON 2005).

A diferencia de lo observado en el resto de los ambientes considerados, el gremio subdominante fue el de las aves carnívoras y carroñeras que se vieron favorecidas por un ambiente mas abierto, lo que les permite una mayor visualización de las presas (Lantschner 2005).

También a diferencia del resto de los ñirantales las aves granívoras de los ñirantales convertidos en pasturas ocuparon el tercer lugar en abundacia, en acuerdo a algunos estudios donde se ha reportado que la disminución de especies granívoras es debida a competencia por la introducción de ganado (Robinson et al. 2001).

Con respecto al nivel de conservación de la avifauna, en los ñirantales transformados en pastizales se constataron solamente dos especies en estado vulnerable, sensibles y/o con mayores necesida- 
des de conservación (Correa et al. 1990, Grigera et al. 1996, Pavic 2000, Lantschner 2005, Grigera y Pavic 2007, Lantschner y Rusch 2007). Esto se debería a la baja heterogeneidad de los pastizales, lo que resulta en una menor disponibilidad de micro-hábitats promoviendo, por ejemplo, un efecto negativo sobre la variedad en la oferta de alimento (Saunders et al. 1991, Niemelä y Halme 1992, Halme y Niemelä 1993, Laurance 2000).

Lo señalado demuestra la notable sensibilidad con que los ensambles de aves responden a las transformaciones introducidas por el hombre en los agroecosistemas (Andren 1994, McLaughlin y Mineau 1995, Pärt y Söderstrom 1999, Tilman 1999, Herzon y O'Hara 2007).

La tala y el sobrepastoreo estarían modificando la trama trófica de éstos ambientes de tal modo, que las respuestas de las especies son en su mayoría negativas, ya sea disminuyendo su abundancia, retrayendo su distribución e incluso extinguiéndose localmente (Fuller et al. 1995, Siriwardena et al. 1998, Chamberlain y Fuller 2001, Robinson y Sutherland 2002, La Sorte 2006), lo cual se reflejó en los menores niveles de diversidad, abundancia y riqueza específica de la avifauna en relación al resto de los sitios estudiados.

Sin embargo, las respuestas de las aves a las transformaciones introducidas por el hombre en los agroecosistemas pueden variar de acuerdo a los diferentes aspectos particulares que han adoptado las especies (Robinson y Sutherland 2002, Fox 2004), y que comprenden características tales como: 1) su estatus de residencia, 2) sus diferentes requerimientos tróficos y 3) su grado de especialización en el uso de hábitats de nidificación. 


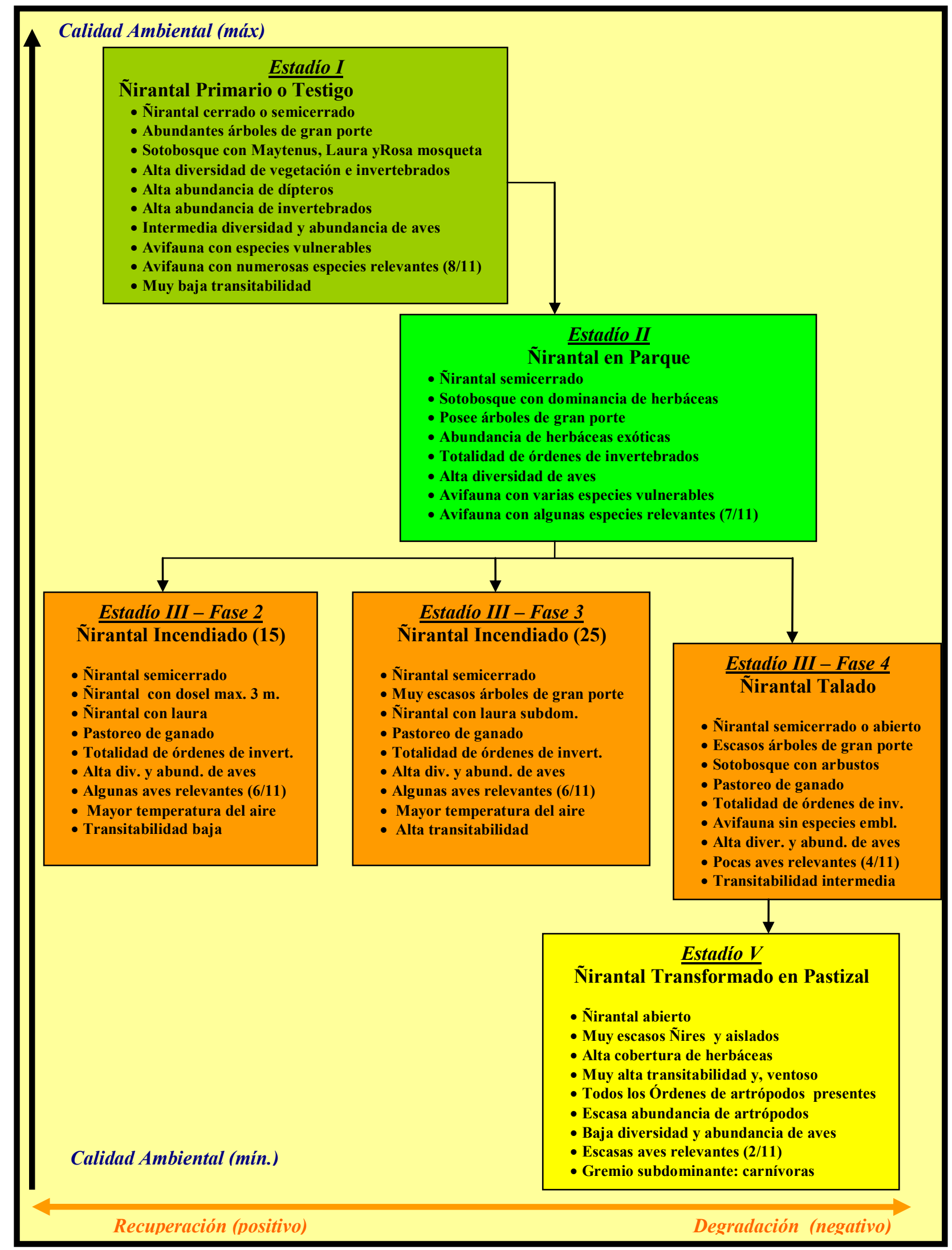

Fig. 5.2: Categorización de los Estadíos sucesionales del bosque de Ñire de acuerdo al Modelo de Estadíos y Transiciones (Rusch et al. 2015), según la estructura vegetal y las comunidades de invertebrados y aves observados en los ñirantales sometidos a diferentes usos. 


\subsection{Comparación de técnicas de muestreo}

\subsubsection{Muestreo de Artrópodos}

En relación a las técnicas de muestreo, en este estudio se observó que las muestras provenientes de las trampas "Sticky traps", "Fluid interception", y del dosel de la vegetación capturaron una mayor cantidad de individuos pertenecientes al orden Diptera, lo que se debería a que estas trampas son más eficientes en la captura de individuos voladores (Niemelä et al. 1990, Spence y Niemelä 1994, Melbourne 1999, Scudder 2000, Gotelli y Colwell 2001). Las muestras provenientes de las trampas "Fluid interception", del suelo y del dosel de la vegetación fueron más abundantes y diversas que las provenientes de las trampas "Sticky traps". Sin embargo, estos métodos resultaron ser complementarios ya que la composición de los órdenes y el número de individuos capturados fue diferente entre las trampas. Esto resalta la utilidad de implementar distintos métodos de muestreo, si lo que se busca es caracterizar una comunidad de manera completa (Sackmann 2006).

\subsubsection{Muestreo de Aves}

La técnica de puntos de conteo (PC) con respecto a línea transecta (LT) resultó ser más adecuada para el muestreo de aves en los diferentes ñirantales, sometidos a diferentes usos, debido a que en los PC:

1. Se observó un $22 \%$ más de especímenes.

2. Se detectó $10 \%$ más de especies.

3. Se registró por visión directa un mayor número de aves.

4. Se observó la totalidad de las aves en riesgo, con mayores necesidades de conservación y/o vulnerables representadas en los muestreos. 
5. Se reflejó la variación en el índice de diversidad en función de los diferentes tipos de impactos sobre los ñirantales.

Lo anteriormente mencionado está en consonancia con algunos autores (Ralph 1985, Bibby et al. 1992) quienes consideran que la metodología de PC sería la más adecuada para muestrear aves en ambientes selváticos, boscosos y/o con amplia cobertura boscosa. 


\section{CAPÍtULO $\mathbf{N}^{\circ} \mathrm{G}$}

\section{CONCLUSIONES}

- El método de muestreo mediante puntos de conteo resultó ser significativamente más eficiente que el de líneas transecta para llevar a cabo censos de aves en áreas boscosas o donde la vegetación es más densa, como en el presente estudio.

- Los diferentes métodos de muestreo de artrópodos demostraron ser complementarios entre sí.

- Los artrópodos hacen un uso generalista del hábitat, obteniéndose especímenes de todos los órdenes en las diferentes estructuras de los ñirantales sometidos a diferentes usos aunque en los ñirantales transformados en pasturas se observaron menores abundancias de especímenes.

- $\quad$ Principalmente la temperatura del aire y la intensidad del viento influenciaron sobre la diversidad de artrópodos y aves durante las temporadas y estaciones de muestreo. Siendo la temperatura, la principal variable climática que afecta y determina los patrones de distribución y abundancia de artrópodos y aves, independientemente del tipo de impacto al que fueron sometidos los ñirantales.

- Las diferentes condiciones ambientales generadas por las modificaciones en la estructura forestal debido a los diferentes usos a los que fueron sometidos los ñirantales 
producen un significativo impacto sobre las comunidades de los vegetales, los artrópodos y las aves.

- Los bosques nativos proveen una gran heterogeneidad de hábitats con su consecuente provisión de diversos y abundantes recursos para alimentar las especies de artrópodos y aves nativas.

- Las estructuras de los ñirantales que mayor número de especies de aves emblemáticas, vulnerables y/o con necesidades de conservación se observaron fueron en los ñirantales primarios siendo los ñirantales transformados en pasturas los sitios que mas impactaron sobre las comunidades de aves.

- Existe una mayor abundancia, riqueza específica, diversidad y equitatividad de aves en los sitios con disturbios intermedios (ñirantales con extracción de leña por parquizado, ñirantales incendiados hace 15 y 25 años y, ñirantales con extracción de leña por manchones) arrojando valores considerablemente menores en los ñirantales primarios y en los ñirantales transformados en pasturas.

- En los sitios afectados por incendios se observó una clara disminución de especies vegetales de origen nativo y la invasión de especies de origen exótico, tales como el arbusto Rosa Mosqueta.

- En los sitios convertidos a pasturas no se observaron renovales de Ñire, por lo que puede concluirse en que la recuperación y regeneración del bosque se encuentra seriamente 
comprometida debido a la cosecha de pasturas y a la carga ganadera.

- El gremio dominante estuvo conformado por las aves insectívoras secundado por el gremio de los granívoros en todos los sitios analizados con la única excepción de los ñirantales transformados en pasturas, donde el gremio de las aves insectívoras fue secundada por el gremio de las aves carnívoras.

- Teniendo en cuenta el rol de las aves, el concepto de gremio puede hacer más eficientes las tareas de evaluación ambiental y del monitoreo de los recursos ayudando a adoptar un mejor manejo de los ñirantales.

- La estructura arbórea de los ñirantales nativos son de gran relevancia para el natural desarrollo de las especies de aves emblemáticas, claves, vulnerables, de importancia ecológica o con necesidades de conservación, debido a lo cual tendría que conservarse una adecuada composición de especies, en cuanto a su riqueza y abundancia, como en la composición y distribución diamétrica y de altura de los árboles.

- Para el mantenimiento de aves insectívoras de tronco como el Carpintero Gigante Patagónico, Loro Cachaña o Lechuza Ñacurutú entre otras se debería mantener especímenes de sanidad deficiente para que puedan anidar $\mathrm{y} / \mathrm{o}$ encontrar microfauna la cual es base de su dieta.

- El Carpintero Gigante Patagónico es una de las principales especies a ser preservada en el bosque andino patagónico 
conjuntamente con los Rhinocryptidos (Churrín Andino, Chucao y Huet Huet) puesto que puede ser consideradas especies bioindicadoras del estado de los ñirantales.

- Sería necesario tener en cuenta, para el diseño de áreas protegidas, la selección de especies de aves focales como las mencionadas con el fin de conservar la diversidad boscosa en sistemas bajo manejo, puesto que estas aves amalgaman varias características del funcionamiento del ecosistema.

- Se debe adaptar el manejo silvo-pastoril e intervenir activamente, para poder mantener a los bosques nativos de Ñire en Patagonia Norte dentro de los límites estructurales y de productividad deseados, los cuales deben ser acordes a un uso conservacionista del ambiente.

- Para presevar el ecosistema nativo es necesario mantener sectores de bosques primarios, sin manejo, de modo de garantizar las características propias y específicas de estos ambientes, tales como refugios contra depredadores, condiciones micro-climáticas adecuadas para el crecimiento, y para el desarrollo de la vegetación, los artrópodos y aves nativas.

- Solamente teniendo una visión integral del ecosistema se podrá realizará un manejo apropiado de los bosques mediante una utilización sustentable con el objetivo de que se compatibilice su conservación con la necesidad de satisfacer los requerimientos de las comunidades implicadas. 


\section{COROLARIO FINAL}

Se puede concluir que: "para alcanzar el objetivo de hacer un uso ambiental, económico y ecológicamente sustentable de los ñirantales deberá, entre otros factores, estar implicada la conservación de las aves. Por ello, es necesario el trabajo conjunto de las instituciones científico-técnicas, agencias de gobierno nacionales e internacionales, fuerzas políticas, ONGs y ciudadanía en general, de tal modo, que se arriben a propuestas de manejo que luego se plasmen en acciones de usos conservacionistas de los recursos naturales". 


\section{BIBLIOGRAFÍA}

- Adams, J. (1985). The definition and interpretation of guild structure in ecological communities. Journal of Animal Ecology 54: 43-59.

- Aizen, M. y Ezcurra, C. (1998). High incidence of plant-animal mutualisms in the woody flora of the temperate forest of South America: biogeographical origin and present ecological significance. Ecología Austral 8: 217-236.

- Aizen, M., Bonino, N., Corley, J., Chehébar, C., Gonda, H., Kitzberger, T., Rusch, V., Sarasola, M. y Schlichter, T. (1999). Empleo de Criterios e Indicadores en el Manejo Sustentable. Biodiversidad. Parte II, La aplicación a los bosques Andino Patagónico - Actas $2^{\circ}$ Jornadas Iberoamericanas sobre Diversidad Biológica. Tomo II. San Luis, Argentina.

- Aizen, M. A., Vázquez, D. P. y Smith-Ramírez, C., (2002). Historia natural de los mutualismos planta-animal del Bosque Templado de Sudamérica Austral. Revista Chilena de Historia Natural No 75. Pp. 79-97.

- Albarracín Franco, S., D'Angelo, C. y Sosa, A. (2014). Reducción y fragmentación de un sector del bosque atlantico del Alto Parana (Misiones, Argentina) en el período 1989 - 2009. Avances en Energías Renovables y Medio Ambiente. Vol. 18: 55-63. Impreso en Argentina. ISSN 2314-1433.

- Alberdi, M. (1987). Ecofisiología de Especies Chilenas del Género Nothofagus. Bosque 8: 77-84.

- Alcántara, J.M., Rey, P.J., Valera, F. y Sánchez - Lafuente, A.M. (1997). Pérdidas de fruto y movilización de semillas en Olea europaea var. sylvestris Brot. (Oleaceae). Anales Jará. Bot. Madrid 55 (1): 101-110.

- Allison, A., Samuelson, A. y Miller, SE. (1997). Patterns of beetle species diversity in Castanopsis acuminatissima (Fagaceae) trees studied with canopy fogging in midmontane New Guinea rainforest, p. 224-236. In: N. E. 
Stork; J. Adis \& R. K. Didham (eds.). Canopy Arthropods. London, Chapman \& Hall, 567 pp.

- Amico, G. y Aizen, M. (2005). Dispersión de semillas por aves en un bosque templado de Sudamérica austral: ¿Quién dispersa a quién?. Ecología Austral 15: 89-100. Junio 2005.

- Andersen, A. (1997). Using ants as bioindicators: multiscale issues in ant community ecology. Conservation ecology (online). Http: //www.consecol.org/vol1/iss1/art8.

- Andersen, A., Hoffmann, B., Muller, W. y Griffiths, A. (2002). Using ants as bioindicators in land management: simplifying assessment of ant community responses. Journal of Applied Ecology 39: 8-17.

- Anderson, SH. (2003). The Relative Importance of Birds and insects as Pollinators of the New Zealand Flora. New ealand Journal of Ecology, vol 27, $n^{\circ} 2:$ 83-94.

- Andren, H. (1994). Effects of habitat fragmentation on birds and mammals in landscape with different proportions of suitable habitat: a review. Oikos 71: 355-366.

- Andren, H. (1995). Effects of landscape composition on predation rates at habitat edges. In: Hansson L., Fahrig, L. y Merriam, G. (eds.). Mosaic landscapes and ecological processes. London, Chapman y Hall, 225-255 pp.

- Angehr, G.R., J. Siegel, C. Acca, D.G. Christian y T. Pequeno. (2002). An assessment and monitoring program for birds in the Lower Urubamba Region, Peru. Environmental Monitoring Assessment 76: 69-87.

- Angelstam, P. y Mikusinski, G. (1994). Woodpecker assemblages in natural and managed boreal and hemiboreal forest: a review. Ann Zool Fenn 31: 157-172.

- Araya, MB. y Millie, GH. (1986). Guía de campo de aves de Chile. Editorial Universitaria. Santiago. Chile.

- Arizmendi, MC., Dominguez, CA., Dirzo, R. (1996). The Role of an Avian Nectar Robber and of Hummingbird Pollinators in the Reproduction of Two Plant Species. Funct. Ecol. 10: 119-127. doi: $10.2307 / 2390270$. 
- Armesto, JJ. y Rozzi, R. (1989). Seed dispersal syndromes in the rain forest of Chiloé: evidence of the importance of biotic dispersal in a temperate rain forest. J. Biogeographics 16: 219-226.

- Armesto, JJ., Smith-Ramírez, C. y Sabag, C. (1995 a). The importance of plant-bird mutualisms in the temperate rainforest of southern South America. Pp. 248-265.

- Armesto, JJ., Villagrán, C. y Arroyo, MK. (1995 b). Ecología de los Bosques Nativos de Chile. Editorial Universitaria, Santiago, Chile. Pp. 470.

- Armesto, JJ., Rozzi, R. y León-Lobos PM. (1996). Ecología de los bosques chilenos: Síntesis y proyecciones. En Armesto, JJ.; Villagrán, C. y Arroyo, MK. (eds.), Ecología de los bosques nativos de Chile. Editorial Universitaria. Universidad de Chile. Santiago, Chile, pp. 405-421.

- Arqueros, MX. (1999). Caracterización de los bosques de Ñire del paraje Trompul y del manejo que realizan los pobladores para proveerse de leña. PNL, Pcia. Neuquen, Argentina. T. Intens. FAUBA.

- Auer, V. (1960). The Quaternary history of Fuego in Patagonia. Proc. Roy. Soc. B, Vol. 152: 507-526.

- Baldi, A. y Kisbenedek, T. (1999). Species-specifics distribution of reed-nesting passerine bird across reed-bed edges: effects of spatial scale and edge type. Acta Zoo. Hun. 45: 97-114.

- Bangert, RK., Turek, RJ., Rehill, B., Wimp, GM., Schweitzer, JA., Allan, GJ., Bailey, KK., Martinsen, GD., Keim, P., Lindroth, RL. y Whitham, TG. (2006). A genetic similarity rule determines arthropod community structure. Molecular Ecology 15: 1379-1392.

- Barlow, J., Peres, C., Henriques, L., Stoufer, P. y Wunderle, J. (2006). The responses of understorey birds to forest fragmentation, logging and wildfires: an Amazonian synthesis. Biological Conservation 128: 182-192.

- Bava, J., Haag, GN., Aguado, H., Claverie, H. y López Bernal, P. (2008). Distribución, estado y potencialidad para la producción maderera de los bosques del Chubut. En: Libro de actas II Reunión sobre Nothofagus en la Patagonia. Esquel. Chubut. 
- Becerra Serial, RM. y Grigera, D. (2005). Dinámica estacional del ensamble de aves de un bosque norpatagónico de lenga (Nothofagus pumilio) y su relación con la disponibilidad de sustratos de alimentación. El Hornero 20 (2): 131-139.

- Berg, B. y Laskowski, R. (2006). Litter decomposition: A guide to carbon and nutrient turnover. Academic Press, New York.

- Berrios, P. (2002). Artrópodos asociados a suelo de renovales de Nothofagus obliqua (mirb.) oersted (fagacea) en la zona costera de la VIII Región. Gayana 66(1): 1-6.

- Bertonatti, C. y Corcuera, J. (2000). Situación Ambiental Argentina 2000. Fundación Vida Silvestre Argentina. Buenos Aires. 440 pp.

- Bibby, C.J., N.D. Burgess y D.A. Hill. (1992). Bird Census Techniques. Academic Press, Londres.

- Bibby, C., Jones, M. y Mardsen, S. (1998). Bird Surveys: Expeditions Field Techniques. Published by the Expedition Advisory Center. London, England. Pp. 135.

- Block, WM., Brennan, LA. y Gutiérrez, RJ. (1986). The use of guilds and guild indicator species for assessing habitat suitability. Pp. 109-113 en: Wildlife 2000. Modeling habitat relationships of terrestrial vertebrates. Verner, J., Morrison, ML. \& Ralph CJ. (eds). University of Wisconsin Press, Madison.

- Blondel J., Ferry C. y Frochot B. (1981). Point counts with unlimited distance. Stud. Avian Biol. 6: 414-420.

- Boatman, N.D., Brickle, NW., Hart, J.H., Milsom, A.J., Morris, T.P., Murray, AW., Murray, KA. y Robertson, PA. (2004). Evidence for the indirect effects of pesticides on farmland birds. Ibis 146 (Suppl. 2): 131-143.

- Bock, CE. y Webb, B. (1984). Birds as grazing indicators species in southeastern Arizona. J. Wildlife Manage 48:1045-1049.

- Bock, CE. y Bock, JH. (1999). Response of winter of birds to drought and short-duration grazing in southeastern Arizona. Conserv. Biol. 13:1117-1123. 
- Bock, CE. y Jones, ZF. (2004). Avian Habitat Evaluation: Should Counting Birds Count? Front Ecol Environ 2:403-410.

- Bran, D. (1991). Caracterización de la Estructura y Dinámica de los Ñirantales y Comunidades de Contacto en el Ecotono Bosque - Estepa en el Noroeste de la Patagonia. INTA, Informe Anual Plan I. San Carlos de Bariloche, Argentina. Pp. 16.

- Bran, D., Rusak, S., Ayesa, J. y Moraga, H. (1998). Los matorrales de Nothofagus antarctica (Ñire) en el contacto Bosque-Estepa. Estructura y regeneración después de una tala. Comunicación técnica No 47. INTA. EEA. Bariloche.

- Brandmayer, P. y Brandmayer TZ. (1986). Phenlogy of ground beteles and its ecological significance in some of the main hábitat types of Southern Europe. In: den Boer, PJ., Luff, M.L., Mossakowski, D. y Weber, F. (eds.). Carabid beetles, their adaptations and dynamics: 195-220. Gust. Fisher Stuttgart.

- Braun-Blanquet, J. (1932). Plan sociology, the study of plant communities, traducción del alemán, revision y edición de Fuller G.D. \& Conrad H.S., reimpresion of Hafner Pub. Co, Nueva York, 439 pag.

- Brickle, N., Harper, DGC., Aebischer, NJ. y Cockaine, SH. (2000). Effects of agricultural intensification on the breeding success of corn buntings Miliaria calandra. J. Appl. Ecology 37: 742-755.

- Brooks, DM. (1997). Avian seasonality at a locality in the central Paraguayan Chaco. Hornero 14: 193-203.

- Bruggen, J. (1948). La expansión del bosque en el sur de Chile en la época post-glacial. Revista Universitaria $\mathrm{N}^{\circ} 33$. Santiago de Chile.

- Brunsting, AMH. (1981). Distribution patterns, life cycle and phenology of Pterostichus oblongopunctatus F. (Col. Carabidae) and Phylonthus decorus Grav. (Col. Staphylinidae). Neth. Journal of Zoology 31: 418-452.

- Buddle, CM., Spence JR. y Langor, DW. (2000). Succession of boreal forest spider assemblages following wildfire and harvesting. Ecography 23: 424-436. 
- Burns, B. (1993). Fire-induced dynamics of Araucaria araucanaNothofagus antarctica forest in the southern Andes. Journal of Biogeography 20:669-685.

- Bustos, C. y Rocchi, V. (1993). Caracterización termopluviométrica de veinte estaciones meteorológicas de Río Negro y Neuquén. Comunicación Técnica $N^{\circ} 1$. INTA Bariloche.

- Cabrera, AL. (1976). Regiones Fitogeográficas Argentinas. Enciclopedia Argentina de Agricultura y Jardinería. (2 Ed). Tomo II Fase 1. ACME. Buenos Aires. 85 pp.

- Cabrera, AL. y Willinik, A. (1973). Biogeografía de América Latina. Monografías de la OEA. Washington D.C. 120 pp.

- Calderón, G. (1993). La explotación de Nothofagus al tapete. Chile forestal 11(1): 32-33.

- Cámara de Senadores y Diputados de la Nación Argentina (CSyDNA). (2007). Ley de Presupuestos Mínimos de Protección Ambiental de los Bosques Nativos. 24 pp.

- Canterbury, GE., Martin, TE., Petit, DR. y Bradford, YDF. (2000). Birds communities and habitat as ecological indicators of forest condition in regional monitoring. Conserv. Biol. Vol.14:544-558.

- Carabelli, E., y Peri, P. L. (2005). Criterios e indicadores de sustentabilidad [c e i] para los bosques nativos de Tierra del Fuego, Argentina: Una herramienta metodológica para la determinación de los c y i en patagonia. INTA. EEA Santa Cruz. Santa Cruz. Disponible en: http://catalogosuba.sisbi.uba.arvufind/Record/201603040 1153312066/Description\#tabnav.

- Carabelli, FA., Jaramillo, MM., Szulkin Dolhatz, D. y Gómez, M. (2003). Managament tools for using and preserving natural resources: Criteria and indicators for multiple use for forests in Andean Patagonia of Argentina. CIEFAP. 27 pp.

- Carignan, V., Villard, MA. (2002). Selecting indicator species to monitor ecological integrity: A review. Environ Monit Assess 78:45-61. doi: 10.1023/A:1016136723584.

- Carpenter, RA. (1983). Natural Systems for Development: What Planners Need to Know. Macmillan, New York. 
- Carranza, CA. y Ledesma M. (2009). Bases para el manejo de sistemas silvopastoriles. XIII Congreso Forestal Mundial. 9 pp.

- Carrascal, L y Tellería, J. (1985). Estudio multidimensional del uso del espacio en un grupo de aves insectívoras forestales durante el invierno. Ardeola 32: 95-113.

- Cavallero L., López D. Raffaele E. y Aizen M. (2015). Structuralfunctional approach to identify post-disturbance recovery indicators in forests from NW Patagonia: a tool to prevent state transitions. Ecol. Ind. 52: 85-95.

- Chamberlain, DE. y Fuller, RJ. (2001). Contrasting patterns of change in the distribution and abundance of farmland birds in relation to farming system in lowland Britain. Global Ecol. Biogeog. 10: 399-409.

- Chen, J., Franklin, JF. y Spies, TA. (1995). Growing-season microclimatic gradients from clearcut edges into oldgrowth Douglas - fir forests. Ecol. Appl. 5: 74-86.

- Chiozza, E. (1976). El país de los Argentinos: La Patagonia, la Antártida Argentina y el Noroeste. Centro Editor de América Latina, Buenos Aires.

- Chown, SL., Gaston, KJ. y Robinson, D. (2004). Macrophysiology: large-scale patterns in physiological traits and their ecological implications. Funct Ecol 18:159-167.

- Christie, M., Ramilo, E. y Bettinelli, M. (2004). Aves del Noroeste Patagónico: Atlas y Guía. Sociedad Naturalista Andino Patagónica San Carlos de Bariloche, Río Negro, Argentina. $328 \mathrm{pp}$.

- Cingolani, AM., Noy-Meir, I. y Díaz, S. (2005). Grazing effects on rangeland diversity: A synthesis of contemporary models. Ecological Applications 15: 757-773.

- Claps, L. E., Debandi, G. y Roig-Juñent, S. (eds). (2008). Biodiversidad de Artrópodos Argentinos (Volumen 2). Sociedad Entomológica Argentina.

- Codesido, M. y Bilenca, D. N. (2000). Comparación de los métodos de transectas de faja y de conteo de puntos de radio fijo en una comunidad de aves del bosque semiárido santiagueño. Hornero 015 (02): 085-091. 
- Cody, ML. (1970). Chilean bird distribution. Ecology 51: 455510.

- Coley, PD. (1998). Possible effects of climate change on plant/herbivore interactions in moist tropical forests. Climate Change 39: 455-472.

- Collantes M., Ontivero J. y Bianciotto O. (1989). Análisis de las comunidades de Nothofagus de Tierra del Fuego. Parodiana 6(1): 185-195.

- Collier KJ., Rutherford, JC., Quinn, JM. \& Davies-Colley, RJ. (2001). Forecasting rehabilitation outcomes for degraded New Zealand pastoral streams. Water Science and Technology, 43: 175-184.

- Connell, J. (1978). Diversity in tropical rain forests and coral reefs. Science 199: 1302-1310.

- Conticello, L., Gandullo, R., Bustamante, A. y Tartaglia, C. (1996). Fitosociología de los bosques caducifolios del norte del Departamento Lácar y sur de Huiliches de la provincia de Neuquén (Argentina). Bosque, 17: 27-43.

- Cooke, RE. (1979). Asexual reproduction: A further considerations. American Naturalist 113: 769-772.

- Cordeiro, NJ., Howe, HF. (2001) Low recruitment of trees dispersed by animals in African forest fragments. Conservations Biology 15: 1733-1741. doi: 10.1046/j.15231739.2001.99579.

- Coronato, F. y del Valle, H. (1988). Caracterización Hídrica de las Cuencas Hidrográficas de la Provincia del Chubut. Centro Nacional Patagónico, CENPAT - CONICET. 185 pp.

- Correa, A., Armesto, J., Schlatter, R., Rozzi, R. y Torres-Murua, J. (1990). La dieta del chucao (Scelorchilus rubecula), un Passeriforme terrícola endémico del bosque templado húmedo de Sudamérica austral. Rev. Chilena Historia Natural 63: 197-202.

- Coscarón, S. y Wygodzinsky, P. (1962). Simuliidae (DipteraInsecta) de Tierra del Fuego, Patagonia e Isla de Juan Fernández. Acta Zool. Lilloana 18: 281-333. 
- Crawley, MJ. (1983). Herbivory: The dynamics of animal-plant interactions. Blackwell Scientific Publications, Oxford. 437 pp.

- Crowe, TM. y Crowe, AA. (1982). Patterns of distribution, diversity and endemism in Afrotropical birds. Journal of Zoology 198: 417-442.

- Cueto, VR. (1996). Relación entre los ensambles de aves y la estructura de la vegetación. Un análisis a tres escalas espaciales. Tesis Doctoral. Universidad de Buenos Aires, Buenos Aires, Argentina.

- Cueto, VR. y López de Casenave, J. (2000). Bird assemblages of protected and exploited coastal woodlands in eastcentral Argentina. Wilson Bulletin 112: 395-402.

- Cueto VR. y López de Casenave J. (2001). Estructura gremial y organización de un ensamble de aves del desierto del Monte. Tesis doctoral, Universidad de Buenos Aires, Buenos Aires.

- Curry, JP. (1994). Grassland Invertebrates, $1^{\circ}$ edition. Chapman \& Hall. London, UK.

- Cushman, SA., McGarigal, K. (2004) Hierarchical analysis of forest bird speciesenvironment relationships in the Oregon Coast Range. Ecol. Appl. 14: 1090-1105. doi: 10.1890/03-5131.

- Damascos, M.A. y Llancaqueo, Y. (2008). Comparación del crecimiento de los ejes, ramificación, fenología y herbivoría foliar entre plantas jóvenes y adultas de Maytenus boaria. I Jornadas de Ciencias Naturales en la Patagonia. Biodiversidad y Conservación. UNPat. EsquelChubut.

- Danks, HV. (2001). Newsletter of the biological survey (Terrestrial Arthropods). Canadian Museum of Nature. Vol 20 (2): 1-33.

- Danks, HV. y Footitt, RG. (1989). Insects of the boreal zone of Canada. Can. Entomol. 121:625-90. de aves del Desierto del Monte. Tesis Doctoral. Biblioteca Electrónica: FCEN UBA. $110 \mathrm{pp}$.

- Dapoto, G. (2003). Cambios previsibles en la fauna entomológica en sectores de un bosque de Araucaria araucana y 
Nothofagus spp. afectados por incendios y sus consecuencias. Trabajo de Especialización, Universidad Nacional del Comahue y Universidad de Poitiers, Neuquén.

- Davies, KF., Marrgules, CR., Lawrence, JF. (2000) Which Traits of Species Predict Population Declines in Experimental Forest Fragments?. Ecology 81: 1450-1461.

- De la Peña, M. y Rumboll, M. (1998). Bird of southern south america and antarctica. Collins ilustrated check list. Harper Collins Publishers, Ltd. London. 304 pp.

- Debandi, G. (1999). Dinámica comunitaria de artrópodos asociados a Jarilla (Gén. Larrea: Zygophyllaceae). Tesis Doctoral, Tesis No 722, UNLP, Argentina.

- Deferrari, G. (2001). Changes in Nothofagus pumilio forest biodiversity during the forest management cycle: birds. Biodiversity and Conservation. 10(12): 165-174.

- Deferrari, G., Camilión, C., Martínez Pastur, G. y Peri, PL. (2001). Changes in Nothofagus pumilio forest biodiversity during forest management cycle. C 2. Birds. Biodiversity and Conservation 10: 2093-2108.

- Devereux, CL., McKeever, CU, Benton, TG. y Whittingham, MJ. (2004). The effect of sward height and drainage on Common Starlings Sturnus vulgaris and Northern Lapwing Vanellus vanellus foraging in grassland habitats. Ibis 146: 115-122.

- Devereux, CL., Whittingham, MJ., Férnandez-Juricic, E., Vickery, JA. y Krebs, JR. (2005). Predator detection and avoidance by starlings under different scenarios of predation risk. Behavioral Ecology 17: 303-309.

- Di Giacomo, A., De Francesco, M. y Coconier, E. (2007). Áreas importantes para la conservación de las aves en la Argentina. Sitios prioritarios para la conservación de la biodiversidad: $241-242$. Temas de naturaleza.

- Di Giulio, M., Edwards, PJ. y Meister, E. (2001). Enhancing insect diversity in agricultural grasslands: the roles of management and landscape structure. Journal of Applied Ecology 38: 310-319. 
- Didham, RK., J. Ghazoul, NE., Stork, AJ. y Davies, J. (1996). Insects in fragmented forests: a functional approach. Trends in Evolution and Ecology 11: 255-260.

- Dimitri, M. (1972). La región de los bosques andinopatagónicos. Sinopsis general. Colección Científica del Instituto Nacional de Tecnología Agropecuaria. Tomo X. República Argentina.

- Dimitri, M. (1977). Pequeña Flora Ilustrada de los Parques Nacionales Andino - Patagónicos. Separata de Anales de Parques Nacionales, Tomo XIII, p. 1-122, 1974.

- Dimitri, M. y Orfila, E. (1985). Tratado de Morfología y Sistemática Vegetal. Ed. ACME. S.A.C.I.

- Dirección General de Bosques y Parques del Chubut (DGByP). (2004). Reglamento Único de Aprovechamiento Forestal de los Bosques de la Provincia del Chubut. Reglamente $\mathrm{N}^{\circ}$ 764/04. Rawson - Chubut.

- Dirección General de Bosques y Parques del Chubut (DGByP). (2010). Ordenamiento Territorial de Bosques Nativos de la Provincia del Chubut - Ley XVII. Honorable Legislatura del Chubut. Rawson - Chubut. 51 pp.

- Dolby, AS. y Grubb, TC. (1999). Effects of winter weather on horizontal and vertical use of solated forest fragments by barkforaging birds. Cóndor 101: 408-412.

- Doll, U., San Martin, J., Ravanal, C., Cifuentes, S. y Muñoz, M. (2005). Evaluación de la producción potencial de frutos de Gevuina avellana, durante una temporada (1999-2000) en el secano costero de la VII región. Chile. Revista Bosque, vol. 26 (3): 87-96. Nota Técnica.

- Donoso, C. (1987). Variación Natural en especies de Nothofagus en Chile. Bosque 8 (2): 85-97.

- Donoso, C. (1995). Bosques Templados de Chile y Argentina: Variación, estructura y dinámica. Editorial Universitaria. $3^{\circ}$ edición. Santiago de Chile, Chile, 483 pp.

- Donoso, C. y Cabello, A. (1978). Antecedentes Fenológicos y de Germinación de Especies Leñosas Chilenas. Facultad de Ciencias Forestales: 31-41. 
- Donoso, C. y Lara, A. (1993). Silvicultura de los Bosques Nativos de Chile. Ed. Universitaria. Santiago de Chile.

- Donovan, TM., Jones, PW., Ammand, EM. y Thompson, FR. (1997). Variation in local-scale edge effects: mechanisms and land-scape context. Ecology 78: 2064-2075.

- Drapeau P., Leduc A. y McNeil R. (1999). Refining the use of point counts at the scale of individual points in studies of bird-habitat relationships. J. Avian Biol. 30: 367-382.

- Duncan, P., Hewison, AJM., Houte, S., Rosoux, R., Tournebize, T. y Dubs, F. (1999). Long term changes in agiculture practice and wildfowling in an internationally important wetland, and their effects on the guild of wintering ducks. Journal Appl. Ecology 36: 11-23.

- Easton, WE. y Martin, K. (1998). The effect of vegetation management on breeding bird communities in British Columbia. Ecol. Aplied. 8: 1092-1103.

- Elliot, K. y Swank, W. (1994). Changes in tree species diversity after successive clearcuts in the Southern Appalachians. Vegetation 115: 11-18.

- Ellum, DS. (2009). Floristic Diversity in Managed Forest: Demography and Physiology of Understory Plants Following Disturbance in Southern New England Forests. Journal Sust. For. 28: 132-151.

- Emlen, JT., DeJong, MJ. Jaeger, MJ. Moermond, TC., Rusterholz KA y White. RP. (1986). Density trends and range boundary constraints of forest birds along a latitudinal gradient. Auk 103: 791-803.

- Estades, CF. (1994). Impacto de la sustitución del bosque natural por plantaciones de Pinus radiata sobre una comunidad de aves en la Octava Región de Chile. Boletín Chileno de Ornitología 1: 8-14.

- Estades, CF. y Temple, S. (1999). Deciduous-Forest bird communities in a fragmented landscape dominated by exotic pine plantations. Ecology Applications, 9: 573-585.

- Estrada, J., Pedrocchi, V., Brotons, L. y Herrando, S. (Eds.) (2004). Atles dels ocells nidificants de Catalunya 19992002. Institut Català d'Ornitologia (ICO)/Lynx. Edicions. Barcelona. 
- Ewers, R. M. y Didham, RK. (2008). Pervasive impact of large scale Edge effects on a beetle community. PNAS 105: 5426-5429.

- Faaborg, J., Thompson, FR., Robinson, SK., Donovan, TM., Whitehead, DR. y Brawn, JD. (1998). Understanding fragmented midwestern landscape: the future. Avian Conservations Research and Managements. Island press, Washington, DC, pp. 193-207.

- Fertig, M. (2003). Producción forrajera en ñirantales del noroeste del Chubut. Carpeta Técnica - INTA. EEA Esquel. $4 \mathrm{pp}$.

- Fertig, M. (2004). Producción Forrajera en ñirantales del Noroeste del Chubut. Carpeta Técnica. INTA. 4 pp.

- Fertig, M., Hansen, N. y Tejera, L. (2007). Producción forrajera en bosques de Nothofagus antarctica (Ñire). IV Congreso Nacional sobre Manejo de Pastizales Naturales. San Luis, Argentina.

- Figueroa, J. y Castro, S. (2002). Effect of bird ingestion on seed germination of four woody species of temperate rainforest of the Chiloé island, Chile. Plant ecology 160: 17-23.

- Fischer, J. y Lindenmayer, BD. (2006). Beyond fragmentation: the continium model for fauna research and conservations in human - modified landscapes. Oikos (forum) 112: 473 -480 .

- Flores, GE., Lagos, SJ. y Roig-Juñent, S. (2004). Artrópodos epigeos que viven bajo la copa del algarrobo (Prosopis flexuosa) en la reserva Telteca (Mendoza, Argentina). Multequina 13: $71-90$.

- Foley JA., DeFries, R., Asner, GP., Barford, C., Bonan, G., Carpenter, SR., Chapin, FS., Coe, MT., Daily, GC., Gibbs, HK., Helkowski, JH., Holloway, T., Howard, EA., Kucharik, CJ., Monfreda, C., Patz, JA., Prentice, IC., Ramankutty, N. y Snyder, PK. (2005). Global consequences of land use. Science 309: 570-574.

- Fox, AD. (2004). Has Danish agriculture maintained farmland bird populations? J. Appl. Ecol. 41: 427-439. 
- Franklin, JF. y Armesto, JJ. (1996). La retención de elementos estructurales del bosque durante la cosecha: una alternativa para el manejo de bosques chilenos. Ambiente y Desarrollo 12: 69-79.

- Frederiksen P. (1988). Soils of Tierra del Fuego: a satellitebased land survey approach. Folia Geographica Danica. Tomo XVIII, p. 159.

- Friend, GR. (1995). Fire and invertebrates: a review of research methodology and the predictability of post-fire response patterns. In Landscape Fires 1993: Proc. Aust. Bushfire Conf., Perth, West. Aust., Sept. 1993. CALM Sci. Suppl. 4: $165-74$.

- Fuller, RJ. y Langslow, D. (1984). Estimating number of bird by point counts: How long should count last? Bird Study 31:195:202.

- Fuller, RJ. y Gough, SJ. (1999). Change in sheep numbers in Britain: implications for birds populations. Biological Conservation 91: 73-89.

- Fuller, RJ., Gregory, RD., Gibbons, DW., Marchant, JH. Wilson, JD., Baillie, SR. y Carter, N. (1995). Population declines and range contractions among lowland farmland birds in Britain. Conserv. Biol. 9: 1425-1441.

- Fundación Vida Silvestre Argentina (FVSA). (1994). Análisis de la Biodiversidad y Conservación de la Ecorregión Valdiviana, $2^{\circ}$ Etapa. Memoria del taller. San Carlos de Bariloche, Argentina. 10 pp.

- Furnes, RW. y Greenwood, JJD. (1993). Birds as Monitors of Environmental Change. Chapman y Hall. London. UK.

- Gallo, M., Lencinas, M. y Peri, P. (2004). Modificación de la biodiversidad por el manejo forestal: plantas, aves e insectos. Informe del Proyecto de Investigación Aplicada a los Recursos Forestales Nativos. Región Bosques AndinoPatagónicos. 25 pp.

- Gandhi, KJK., Spence, JR., Langor, DW. y Morgantini, LE. (2001). Fire residuals as habitat reserves for epigean beetles (Coleoptera: Carabidae and Staphylinidae). Biological Conservation 102: 131-141. 
- Garcia, D., Zamora, R., Amico, GC. (2008) Birds as suppliers of seed dispersal in temperate ecosystems: Conservation guidelines from real-world landscapes. Conserv Biol 24: 1070-1079. doi: 10.1111/j.1523-1739.2009.01440.x.

- Gavier-Pizarro, GI., Calamari, NC., Thompson, JJ. (2012). Expansion and intensification of row crop agriculture in the Pampas and Espinal of Argentina can reduce ecosystem service provision by changing avian density. Agricology Ecosystem Environmental 154: 44-55. doi: 10.1016/j.agee.2011.08.013.

- Gentilli, J. (1992). Numerical clines and escarpments in the geographical occurrence of avian species; and a search for relevant environmental factors. Emu 92: 129-140.

- Gentry, A. (1982). Patterns of neotropical plant diversity. Evol. Biol. 15: 1-84.

- Gerstmeier, R. y Lang C. (1996). Beitrag zu Auswirkungen der Mahd auf Arthropoden. Zeitschrift für Ökologie und Naturschutz, 5: 1-14.

- Gitay, H. y Noble, IR. (1997). What are functional types and how should we seek them? Pp. 3-19 en: Plant functional types. Their relevance to ecosystem properties and global change. Smith TM, Shugart HH y Woodward FI (eds). Cambridge University Press, Cambridge.

- Gobbi, ME. (1995). Regeneración post-incendio del sotobosque de cipresales. Medio Ambiente, 12: 9-15.

- Godagnone R. e Irisarri J. (1990). Mapa de suelos del Territorio Nacional de Tierra del Fuego. In: Moscatelli G. (ed), Atlas de suelos de la República Argentina. SAGyP-INTAProyecto PNUD. Vol. II, pp. 615-641.

- Gómez de Silva, G.H., F. González-García y M.P. Casillas-Trejo. (1999). Birds of the upper cloud forest of El Triunfo, Chiapas, Mexico. Ornitología Neotropical 10: 1-26.

- Gonc, R. (2014). Estudio de la Estructura de las Comunidades de Artrópodos asociados a ñirantales (Nothofagus Antarctica) del centro-oeste de la Provincia del Chubut, Patagonia Argentina, sometidos a diferentes tipos de impacto ambiental. Tesis Doctoral - UNLP. 200 pp. 
- González Bonorino, F. (1978). Geología de la Región de San Carlos de Bariloche. Asociación Geológica. Revista XXXIII (3): 175-210. Buenos Aires.

- González Bonorino, F. y González Bonorino, G. (1974). La Formación Millaqueo y la "Serie Porfírica" de la Cordillera Norpatagónica. Asociación Geológica. Revista XIX (2): 145-154. Buenos Aires.

- González García, F.G. (2013). Fauna Silvestre de México: Uso, Manejo y Legislación. Método para contar aves terrestres. Capítulo 4: 85-116. México.

- González, ME., Veblen, TT. y Sibold, J. (2005). Fire history of Araucaria- Nothofagus forests in Villarrica National Park, Chile. Journal of Biogeography 32: 1187-1202.

- Gordon, IJ., Hester, AJ. y Festa-Bianchet, M. (2004). The management of wild herbivores to meet economic, conservation and environmental objetives. Journal of Applied Ecology 41: 1021-1031.

- Gorgoglione, E. (1997). Aves de Neuquén - Guía de Campo. Neuquén. Argentina.

- Gorman, OT. (1988). The dynamics of habitat use in a guild of Ozark minnows. Ecological Monographs 58: 1-18.

- Gotelli, NJ. y Colwell, RK. (2001). Quantifying biodiversity: procedures and pitfalls in the measurement and comparison of species richness. Ecology Letters 4: 379391.

- Gregory, RD., van Strien, A. y Vorisek, P. (2005). Developing indicators for European birds. Philos Trans R Soc B Biol Sci 360:269-288. doi : 10.1098/rstb.2004.1602.

- Grigera, D. y Pavic, C. (2007). Ensambles de aves de un sitio quemado y en un sitio no alterado en un área forestal del noroeste de la Patagonia Argentina. Hornero 223 (1): 2937.

- Grigera, D., Úbeda, C. y Reca, A. (1996). Estado de conservación de las aves del Parque y Reserva Nacional Nahuel Huapi. Hornero 14:1-13.

- Guitart, E. (2004a). Diagnóstico productivo orientado a establecer la capacidad del sector ganadero del NO del 
Chubut para involucrarse y sostener un proyecto de diferenciación por calidad del producto carne vacuna. Informe Interno. INTA. 26 pp.

- Guitart, E. (2004b). Programa para el desarrollo local y competitividad de pequeñas empresas. BID-ATN/ME7295AR. Componente $\mathrm{N}^{\circ} 1$ : Fortalecimiento y diversificación productiva.

- Guo, Q., Thompson, DB., Valone, TJ. y Brown, JH. (1995). The effects of vertebrate granivores and folivores on plants community structure in the Chihuahuan Desert. Oikos 73: 251-259.

- Hagar J., McComb W. y Emmingham W. (1996). Bird communities in commercially thinned and unthinned Douglas-fir stands of western Oregon. Wildlife Soc. B. 24(2): 353-366.

- Halme, E. y Niemelä, J. (1993). Carabid beetles in fragments of coniferous forest. Ann. Zool. Fenn. 30: 17-30.

- Hansen, N. (1999). Seminario: Antecedentes sobra dinámica de los bosques de Nothofagus Antarctica (Ñire) de Chile y Argentina. Magister en Ciencias Mención Silvicultura. Universidad Austral de Chile.15 pp.

- Hansen, N. (2003). Uso Silvopastoril de ñirantales en el Chubut. INTA, Carpeta Técnica - Estación Experimental Agroforestal Esquel. Agosto 2003. 4 pp.

- Hansen, N., Coppa, R., Amico, I., Mondino, V., Tejera, J., Lugano, L., Schinelli Casares, T., Recalde, J., Buratovich, O. y Raso, M. (2002). Módulo I: Uso múltiple y manejo sustentable de un área boscosa. INTA AEE Esquel e INTA AEE Trevelin. 200 pp.

- Hansen, N., Tejera, L. y Fertig, M. (2004). Módulo II: Alternativas de manejo sustentable para el manejo forestal integral de los bosques de la Patagonia. Capítulo 3: Sistemas silvopastoriles en Chubut. Proyectos de Investigación Aplicada a los Bosques Nativos (PIARFON). Esquel - Argentina.

- Hansen, N., Fertig, M. y Tejera, L. (2005). Sistemas silvopastoriles en Chubut. Informe del Proyecto de Investigación Aplicada a los Recursos Forestales Nativos. Región bosques andino-patagónicos. 8 pp. 
- Hansen, N., Fertig, M., Escalona, M., Tejera, L., y Opazo, W. (2008). Ramoneo en regeneración de Ñire y disponibilidad forrajera. EcoNothofagus. Libro de actas II Reunión sobre Nothofagus en la Patagonia. INTA EEA Esquel. Pp. 137142.

- Hawkins, CP. y MacMahon, JA. (1989). Guilds: the multiple meanings of a concept. Annual Review of Entomology 34: 423-451.

- Heggberget, TM. (1987). Number and proportion of southern bird species in Norway in relation to latitude, spring temperature and respiration equivalent. Holartic Ecology 10: 81-89.

- Henderson, IG., Cooper, J., Fuller, RJ. y Vickery, J. (2000). The relative abundance of birds on set aside and neighbouring fields in summer. Journal Appl. Ecology 37:335-347.

- Henle, K., Davies, KF. y Kleyer, M. (2004). Predictors of species sensitivity to fragmentation. Biodivers Conserv 13:207251. doi:10.1023/B:BIOC.0000004319.91643.9e.

- Hernández, J. (1995). Efecto de los árboles percha sobre los patrones de lluvia de semillas en el establecimiento de plántulas: consecuencias para la sucesión secundaria del bosque de Chiloé. Tesis doctoral, Universidad de Chile. Santiago de Chile - Chile.

- Herrera, CM. (1978). Evolución estacional de las comunidades de paseriformes en dos encinares de Andalucía occidental. Ardeola 25: 143-180.

- Herrera, CM. (1984). A study of avians frugivores, birddispersed plants, and their interaction in Mediterranean shrublands. Ecological Monographs 54: 1-23.

- Herzon, I. y O'Hara, RB. (2007). Effects of lanscape complexity on farmlands birds in the Baltic States. Agric. Ecosyst. Environ. 118: 297-306.

- Hoffman, A. (1991). Flora Silvestre de Chile: Zona Araucana. Ediciones Fundación Claudio Gay. $2^{\circ}$ Edición. Santiago de Chile, Chile. 258 pp.

- Holmes, RT. (1990). Food resource availability and use in forest bird communities: a comparative view and critique. Pp. 
387-393, en: Biogeography and ecology of forest bird communities. Keast, A. (ed). PB Academic Publishing bv. The Hague.

- Iglesias, G. (1988). Diversidad de aves y su relación con los tipos de vegetación (natural y perturbada) en la cuenca del Río Manso Superior. Informe final beca de iniciación. CONICET.

- Iglesias, G. (1989). Explotación de recursos tróficos y espaciales por las aves de cuenca del Río Manso Superior. Informe final de proyectos anuales. Proyecto Anual E $1578 / 86$.

- Informe PIARFON. (2005). Módulo IV: Alternativas de manejo sustentable para el manejo forestal integral de los bosques de la Patagonia. Proyectos de Investigación Aplicada a los Recursos Forestales Nativos (PIARFON). Bariloche - Argentina.

- Jaksic, FM. y Feinsinger, P. (1991). Bird assamblages in temperate forests of North and South America: a comparison of diversity, dynamics, guild structure, and resource use. Revista Chilena de Historia Natural 64: 491510.

- Janzen, DH. (1983). Seasonal changes in abundance of large nocturnal dung-beetles (Scarabaeidae) in a Costa Rican deciduous forest and adjacent horse pasture. Oikos 41: 274-283.

- Jiménez J.E. (2000). Effect of sample size, plot size, and counting time on estimates of avian diversity and abundance in a chilean rainforest. J. Field Ornithol. 71(1): 66-87.

- Jones, CM. y Hunt, HE. (1996). Foraging habitat of the redcockaded woodpecker on the D'Arbonne National Wildlife Refuge, Louisiana. J. Field Ornithol 67: 511-518.

- Karr, JR. y Roth, RR. (1971). Vegetation structure and avian diversity in several New World areas. American Nature 105: 423-435.

- Kaspari, M. (1993). Body size and microclimate use in neotropical granivorous ants. Oecologia 96: 500-507. 
- Kay, B., Twigg, L., Korn, T. y Nicol, H. (1994). The use of artifical perches to increase predation on house mice (mus domesticus) by raptors. Wildl Res 21: 95-105. doi: 10.1071/WR9940095.

- Kay, JJ. (1997). Some notes on the ecosystem approach: ecosystems as complex systems. Pag. 69-98.

- Kim, K. (1993). Biodiversity, conservations and inventory: why insects matter. Biodiversity and conservations 2: 191214.

- Kitzberger, T. (2003). Regímenes de fuego en el gradiente bosque-estepa del noroeste de Patagonia: variación espacial y tendencias temporales, en: Kunst, CR., Bravo, S. y Panigatti, JL. (eds.), Fuego en los ecosistemas argentinos, Santiago del Estero, INTA. Pp. 79-92.

- Kitzberger, T., Iglesias, G., Pérez, A., Premoli, AC. y Veblen, T. (2000). Distribución y estado de conservación de alerce (Fitzroya cupressoides) en Argentina. Bosque $N^{\circ} 21$. Pp. 79-89.

- Kitzberger, T., Raffaele, E., Heinemann, K. y Mazzarino, MJ. (2005). Effects of fire severity in a north Patagonian subalpine forest. Journal of Vegetation Science 16: 5-12.

- Klinka, K., Chen, H., Wang, Q. y Montigny, L. (1996). Forest canopies and their Influence on undestory vegetation in early-seral stands on west Vancouverls land. North. Sci. 70: $193-200$.

- Kotliar, NB. y Wiens, JA. (1990). Multiple scales of patchiness and patch structure: A hierarchical framework for the study of heterogeneity. Oikos 59: 253-260.

- Kozlowski, TT. (2002). Physiological-ecological impacts of flooding of riparian forest ecosystems. Wetlands 22 (3): 550-561.

- Krebs, CJ. (1985). Ecología: Estudio de la Distribución y la Abundancia. $2^{\circ}$ Edición. Editorial Harla, México D.F. 753 pp.

- Krebs, CJ. (1994). Ecology: The experimental analysis of distribution and abundance. Fourth edition. Harper Collins College Publishers, New York. 
- La Manna, L. y Barroetaveña, C. (2010). Propiedades químicas del suelo en bosques de Nothofagus antartica y Astrocedrus chilensis afectados por el suelo. Rev. FCA UNCUYO. Tomo 43 (1): 41-55.

- La Sorte, FA. (2006). Geographical expansion and increased prevalence of common species in avian assemblages: implications for large-scale patterns of species richness. Journal Biogeografics 33: 1183-1191.

- Laclau, P. (1997). Los ecosistemas forestales y el hombre en el sur de Chile y Argentina. Fundacion Vida Silvestre Argentina (FVSA) y Fondo Mundial para la Naturaleza (WWF). Boletín Técnico Nº 34: 1-121.

- Laiolo, P., Dondero, F., Ciliento, E. y Rolando, A. (2004). Consequences of pastoral abandonment for the estructure and diversity of the alpine avifauna. Journal of Applied Ecology 41:294-304.

- Landres, PB. (1983). Use of the guild concept in environmental impact assessment. Environmental Management 7: 393398.

- Landres, PB. (1986). Guild applications to modern management problems. Pp. 48-49 en: Conference on applications of the guild concept to environmental management. Severinghaus WD y James TD (eds). US Army Corps of Engineers Technical Manuscript W-86/07, Champaign.

- Lanfranco, D. (1991). Sinopsis de los insectos que atacan bosques de lenga (Notfhogaus pumilio) (Poepp. Et Endl. Krass.) en Magallanes. Anales del Instituto de la Patagonia, Serie Ciencias Naturales 20: 89-93.

- Lantschner, M. (2005). Estructura de las Comunidades de Aves de los Fondos del Valle y Laderas de la Cuenca del Río Joyel (Prov. Río Negro) en Relación a los Disturbios Antrópicos. Tesis para opción del grado de Licenciatura en Cs. Biológicas. Universidad Nacional del Comahue. 116 pp.

- Lantschner, M. y Rusch, V. (2007). Impacto de diferentes disturbios antrópicos sobre las comunidades de aves de bosque y matorrales de Nothofagus antarctica en el NO Patagónico. Ecología Austral 17: 99-112. 
- Lara, A., Donoso, C. y Aravena, JC. (1996). La conservación del bosque nativo en Chile: problemas y desafíos. En Armesto, JJ., Villagrán, C. y Arroyo, MK. (eds.), Ecología de los bosques nativos de Chile. Editorial Universitaria. Universidad de Chile. Santiago, Chile, pp. 335-363.

- Laurance, WF. (2000). Do egde effect occur over large spatial scales? Trends Ecology Evolution 15: 134-135.

- Lauterbach, AW. (1964): Verbreitung und aktivitats bestimmend Factoren bei Carabiden in sauerländischen Wäldern. Abhandl. Landesmus. Naturkunde Münster 26: 1-103.

- Lavalle, A., Férnandez N., Lozanoff, J., Ferro, G. y Fiocchi, S. (2010). Política Forestal: Los bosques nativos y la preservación del medioambiente. Observatorio de Políticas Públicas. Secretaría de Gabinete de la Jefatura de Gabinetes de Ministros. 273 pp.

- Lavelle, P., T. Decaëns, M., Aubert, S., Barot, M., Blouin, F., Bureau, P., Margerie, P., Mora y J. P. Rossi. (2006). Soil invertebrates and ecosystems services, European Journal of Soil Biology, vol. 42: 3-15.

- Lawton, J. (1978). Host - plant influences on insects diversity: the effects of space and time. Symposium of the Royal Entomological Society of London 9: 105-125.

- Lencinas, MV., Martínez Pastur, G., Cellini, JM., Vukasovic, R., Peri, P. y Fernández, MC. (2002). Incorporación de la altura dominante y la calidad de sitio a ecuaciones estándar de volumen para Nothofagus antartica (Forster f.) Oersted. Bosque 23: 5-17.

- Lencinas, MV., Martínez Pastur, G., Cellini, JM., Busso, C. y Gallo, E. 2003. Manejo forestal sustentable en Patagonia: decisiones basadas en la biodiversidad. XII Congreso Forestal Mundial, Québec (Canadá).

- Lencinas, MV., Martínez Pastur, G., Medina, M. y Busso, C. (2005). Richness and density of birds in timber Nothofagus pumilio forests and their unproductive associated environments. Biodiversity Conservation 14: 2299-2320.

- Lencinas, M., Martínez Pastur, G, Gallo, E., Moretto, A., Busso, C. y Peri, E. (2007). Mitigation of diversity loss in 
Nothofagus pumilio managed forest of South Patagonia, en Pacha, M., Luque, S., Galetto, L. y Liverson, L. eds. Understanding biodiversity loss: on overview of forest fragmentation in South America. Part III: Landscape ecology and conservation, managements and restoration. IALE Landscape Research and Management papers. P. 112-120.

- Lencinas, MV., Martínez Pastur, G., Rivero, P. y Busso, C. (2008). Conservation value of timber quality versus associated non-timber quality stands for understory diversity in Nothofagus forests. Biodiverstiy Conservation 17: 2579-2597.

- Levin, SA. (1992). The problem of pattern and scale in ecology. Ecology 73: 1943-1967.

- Lewis, CN. y Whitfield, JB. (1999). Braconid wasp (Hymenoptera: Braconidae) diversity in forest plots under different silvicultural methods. Environmental Entomology 28 (6): 986-997.

- Loe, LE., Mysterud, A., Stien, A., Steen H., Evans, DM. y Austrheim, G. (2007). Postive short-term effects of sheep grazing on the alpine avifauna. Biology Letters 3:109111.

- Loiselle, BA. y Blake, JG. (1991). Temporal variation in birds and fruits along an elevational gradient in Costa Rica. Ecology 72: 180-193.

- López de Casenave, JN. (2001). Estructura gremial y organización de un ensamble.

- López Lanús, B., Grilli, P., Di Giacomo, A., Coconier, E. y Banchs, R. (2008). Categorización de las Aves de la Argentina según su estado de conservación. Informe de Aves Argentinas-AOP. Secretaría de Ambiente y Desarrollo Sustentable y Bird Life Internacional. Argentina. $64 \mathrm{pp}$

- López, DR. (2011). Una aproximación estructural-funcional del Modelo de Estados y Transiciones para el estudio de la dinámica de la vegetación en Estepas de Patagonia norte. Tesis, D Biol. UNCOMA, 97 pp. 
- López, DR., Bran, D. y Siffredi, G. (2009). Modelo de Estados y Transiciones: un enfoque para el manejo y recuperación de los pastizales naturales patagónicos. Área de Investigación en Recursos Naturales. INTA EEA Bariloche.

- López, DR., Rusch, V., Caballero, L., Letourneau, F., Carranza, C., Navall, M. y Varela, S. (2014). El Modelo de Estados y Transiciones como Herramienta para el estudio, evaluación y manejo sustentable de Bosques. INTA- EEA Bariloche.

- Lord, RD. (1961). Seasonal changes in roadside activity of cottontail. Journal of Wildife Management 25: 206-209.

- Lowman, MD. (1982). The effects of different rates and methods of leaf area removal on rainforest seedlings of coachwood (Ceratopetalum apetalum). Australian Journal of Botany 30: 477-483.

- Lugano, L., Tejera, L. y Mondino, V. (2001). Uso Múltiple y Sustentable de un Área Boscosa - Módulo III: Los bosques andino patagónicos y los bosques cultivados. INTA - EEA de Esquel. 35 pp.

- Luther, D., Hilty, J. y Weiss, J. (2008). Assessing the impact of local habitat variables and landscape context on riparian birds in agricultural, urbanized, and native landscapes. Biodivers Conserv 17: 1923-1935. doi: 10.1007/s10531008-9332-5.

- Lyon, JL., Crawford, HS., Czuhai, E., Fredricksen, RL., Harlow, RF., Metz, LJ. y Pearson, HA. (1978). Effects of fire on fauna: a state of knowledge review. USDA For. Serv., Gen. Tech. Rep. WO-6.

- Mac Arthur, JW. (1975). Patterns of species abundance and diversity. Pp: 74-80. En: Cody, M.L. y J.D. Diamond eds. Ecology and Evolution of Communities. Harvard University Press, Cambridge, USA.

- Mac Arthur, RH. (1964). Environmental factors affecting species diversity. Am. Nat. 98:387-397.

- Mac Arthur, RH. y Mac Arthur, JW. (1961). On Bird Species Diversity. Ecology 42 (3): 594-598. 
- Mac Gregor-Fors, I., Morales-Pérez, L. y Schondube, JE. (2010). Migrating to the city: responses of neotropical migrante bird communities to urbanization. The Condor 112: 711-717.

- Martin, TE. (1984). Impact of Livestock Grazing on Birds of a Colombian Cloud Forest. Tropical Ecology 25: 158-171.

- Martínez Pastur, G., Peri, P., Fernández, MC., Staffieri, G. y Lencinas, MV. (2001). Change in undestory species Diversity during Nothofagus pumilio forest Management cycle. Journal of forest research 7(3): 165-174.

- Morello, J. y Mateucci, S. (1999). Biodiversidad y uso de la tierra en la argentina. Conceptos y ejemplos de Latinoamérica: 463-498. Eudeba, Bs. As.

- Magurran, A. (1988). Ecological diversity and its measurement. Princenton University Press, New Jersey. 179 pp.

- Magurran, A. (2003). Diversidad ecológica y su medición. Ed. Vedra. España. 197 pp.

- Manacorda, M., Somlo, R., Pelliza Sbriller, A. y Williams, P. (1995). Dietas de Ovinos y Bovinos en la Región de los Bosques de Ñire (Nothofagus antarctica) de Río Negro y Neuquén. RIA 26 (1): 137-146.

- Marinoni, RC. y Ganho, NG. (2003). Fauna de Coleoptera no Parque Estadual de Vila Velha, Ponta Grossa, Parana, Brasil. Abundancia e riqueza das familias capturadas a traves de armadilha de solo. Revista Brasileira de Zoologia 20: 737-744.

- Markgraf, V. (1987). Paleoclimates of the southern Argentina Andes. Current Research Pleistocene 4: 150-157.

- Marone, L. (1990). Modification of local and regional diversity after a fire in the Monte Desert, Argentina. Revista Chilena de Historia Natural 63: 187-195.

- Marone, L. (1992). Seasonal and year-to-year fluctuations of bird populations and guilds in the monte desert, Argentina. Journal of Field Ornithology 63: 294-308.

- Martella, B., Trumper, E., Bellis, L., Renison, D., Giordano, P., Bazzano, G. y Gleiser, R. (2012). Manual de Ecología. Poblaciones: Introducción a las técnicas para el estudio de las poblaciones silvestres. Cátedra de Ecología. Fac. de 
Cs. Exactas, Físicas y Naturales. Universidad Nacional de Córdoba. Reduca (Biología). Serie Ecología. 5(1): 1-31.

- Martin, RE. y Mitchell, RG. (1980). Possible, probable, and proven fire-insect interactions. In: Proc. (1980) convention of the Society of American Foresters. 138144 pp. Bethesda MD.

- Martín, RG. y Possingham, HP. (2005). Predicting the impact of livestock grazing on birds using foraging height data, Journal of Applied Ecology 42:400-408.

- Martínez Pastur, G., Peri, P., Fernández, C. y Staffieri, G. (1999). Desarrollo de la regeneración a lo largo del ciclo del manejo forestal de un bosque de Nothofagus pumilio: Incidencia de la cobertura y el aprovechamiento 0 cosecha. Bosque 20(2): 39-46.

- Martínez Pastur, G., Peri, P., Fernández, MC., Staffieri, G. y Lencinas, MV. (2002). Changes in understory species diversity during the Nothofagus pumilio forest management cycle. Journal of Forest Research 7(3): 165174.

- Marvaldi, AE. y Lanteri, AA. (2005). Key to higher taxa of South American weevils based on adults characters (Coleoptera: Curculionidae). Revista Chilena de Historia Natural 78: 65-87.

- Mattson, WJ. (1980): Herbivory in relation to plant nitrogen content. Annu. Rev. Ecol. Sys. 11: 119-161.

- Mazía, CN., Chaneton, EJ. y Kitzberger, T. (2006). Small-scale habiat use and assemblage structure of ground-dwelling beetles in a Patagonian shrub steppe. Journal of Arid Environments 67: 177-194.

- Mc Bride, P. (2000). Magellanic woodpecker (Campephilus magellanicus) habitat selection in deciduous Nothofagus forests of Tierra del Fuego. MS Thesis, Western Washington University, Bellingham, Wash.

- Mc Ginley, K. y Finegan, B. (2002). Evaluación de la sostenibilidad para el manejo forestal. Determinación de un estándar integrado y adaptativo para la evaluación de la sostenibilidad ecológica del manejo forestal en Costa Rica. Turrialba, Costa Rica. CATIE. 74 pp. (Serie Técnica. 
Informe Técnico No 330. Colección Manejo Diversificado de Bosques Naturales. Publicación № 26.

- Mc Naughton, SJ. (1978). Stability and diversity of ecological communities. Nature 274:251-253.

- Mc Quenn, D. (1976). The Ecology of Nothofagus and Associated Vegetations in South America. Tuatara 22: 3668.

- Mc Cullough, D.R. (1982). Evaluation of night spotlighting as a deer study technique. Journal of Wildlife Management 46: 963-973.

- McLaughlin, A. y Mineau, P. (1995). The impact of agricultural practices on biodiversity. Agric. Ecosyst. Environ. 55: 202-212.

- Melbourne, BA. (1999). Bias in the effect of hábitat structure on pitfall traps: an experimental evaluation. Australian Journal of Ecology 24: 228-239.

- Michaels, K. y Mc Quillan, P. (1995). Impact of comercial forest management on geophilous carabid bettles (Coleoptera: Carabidae) in tall, wet Eucalyptus obliqua forest in southern Tasmania. Australian Journal of Ecology 29(VI): 3-16.

- Milesi, F., Marone, L., López de Casenave, J., Cueto, V. y Mezquida, E. (2002). Gremios de manejo como indicadores de las condiciones del ambiente: un estudio de caso con aves y perturbaciones del hábitat en el Monte Central, Argentina. Ecología Austral 12: 149-161.

- Ministerio de Agricultura Ganadería y Pesca (MAGyP). (2015). Principios y lineamientos nacionales para el Manejo de Bosques con Ganadería integrada en concordancia con la Ley Nacional $N^{\circ} 26331$. Buenos Aires - Argentina.

- Ministerio de la Producción del Chubut (MdIPCh). (2016). Apéndice de implementación: Plan de Manejo de Bosques con Ganadería Integrada - Provincia de Chubut. Gobierno de la Provincia del Chubut. 23 pp.

- Miserendino, ML., Casaux, RJ., Archangelsky, M., Di Prinzio, CY., Brand, C. y Kutschker, AM. (2010). Assessing landuse effects on water quality, in-stream habitat, riparian 
ecosystems and biodiversity in Patagonian northwest streams. Science of the Total Environment 409: 612-624.

- Mitchell, RG. (1990). Effects of prescribed fire on insect pests. In: Walstad, JD., Radosevich, SR. y Sandberg, DV., eds. Natural and prescribed fires in Pacific Northwest forests. Corvallis, OR: Oregon State University Press: 111-121.

- Moldenke, A., Pajutee, M. y Ingham, E. (2000). The functional roles of forest soil arthropods: the soil is a lively place. USDA Forest Service General Technical Report, 7-22.

- Mols, CMM. y Visser, ME. (2002). Great tits can reduce caterpillar damage in apple orchards. J. Appl. Ecol. 39: 888-899. doi: 10.1046/j.1365-2664.2002.00761.x.

- Montaña, C. (1982). Las comunidades de Ñire (Nothofagus antarctica) (Forst. Oerst.) de la cuenca del río Manso Superior (Río Negro, Argentina). Tesis Doctoral. Córdoba, Argentina. Univ. Nac. de Córdoba. 134 pp.

- Montenegro, C., Bono, J., Parmuchi, M.G. y Strada, M. (2003). La deforestación y degradación de los bosques nativos. Idia XXI. Pags. 262-265.

- Montenegro, C., Gasparri, I., Manghi, E., Strada, M., Bono, J. y Parmuchi, M. (2004). La deforestación y degradación de los bosques nativos. Unidad de Manejo del Sistema de Evaluación Forestal, Dirección de Bosques, SAyDS. IDIA XXI. 262-265 pp.

- Moore, JDR., Ouimet, D., Houle, C. y Camire, C. (2004). Effects of two silvicultural practices on ground beetles (Coleoptera: Carabidae) in a northern hardwood forests, Quebec, Canada. Can. J. For. Res. 34: 959-968.

- Morales, G., J. Pinowski, J.M. Pacheco, M. Madriz y F. Gómez. (1981). Densidades poblacionales, flujo de energía y hábitos alimentarios de las aves ictiófagas de los Módulos de Apure, Venezuela, Acta Biológica Venezuela 111: 145.

- Moran, VC. y Southwood, TR. (1982). The guide composition of Arthropod Communities in Trees. The Journal of Animal Ecology 52 (1): 289-306.

- Moreno, C. (2001). Métodos para medir la biodiversidad. Manuales \& Tesis SEA. Vol 1. Zaragoza. 84 pp. 
- Moretti M., Obrist, MK. y Duelli, P. (2004). Arthropod biodiversity after forest fires: winners and losers in the winter fire regime of the southern Alps. Ecography 27: 173-186.

- Morrone, JJ. (2006). Biogeographic areas and transition zones of Latin America and the Caribbean Islands based on Panbiogeographic and Cladistic analyses of the entomofauna. Annuario Review Entomologist 51: 467494.

- Morrone, JJ. y Coscarón, S. (1998). Biodiversidad de artrópodos Argentinos: una perspectiva biotaxonómica. Ediciones Sur, La Plata, Argentina. 599 pp.

- Morrow, PA. y La Marche, VC. (1978). Tree ring evidence for chronic insect suppression of productivity in subalpine Eucalyptus. Science 201: 1244-1246.

- Mostacedo, B. y Fredericksen, T. (2000). Manual de métodos básicos de muestreo y análisis en ecología vegetal. BOLFOR. Santa Cruz. 92 pp.

- MPC II․ (2015). Second Argentine Report for the Montreal Process. National Report Based and Criteria and Indicators of the Montreal Process (en línea). Cons. ago. 2016. Disponible en http://www.montrealprocess.org/documents/publications/general/2015/SecondArgentineR eportfortheMontrealProcess.pdf.

- Mueller - Dombois, D. y Ellenberg, H. (1974). Aims and methods of vegetation ecology. New York, NY: John Wiley and Sons, Inc. 547 pp.

- Murcia, C. (1995). Edge effects in fragmented forests: implications for conservation. Trends Ecol. Evol. 10: 5862.

- Myers, AA. y Giller, PS. (eds.). (1988). Analytical biogeography. Chapman \& Hall, London, England.

- Narosky, T. y Babarskas, M. (2000). Aves de la Patagonia: Guía para su reconocimiento. Vázquez Mazzini Editores. Buenos Aires, Argentina. 127 pp. 
- Narosky, T. e Izurieta, D. (2004). Aves de Argentina y Uruguay. $15^{\circ}$ Edición. Editorial Vázquez Manzini. Buenos Aires, Argentina. Pp. 348.

- Navarro Cerrillo, RM., Rosenfeld, M., Pérez Aranda, J., Padrón, E., Guzmán, JR., Hernández Clemente, R. y González, L. (2008). Evaluación de la mortalidad de bosques de ñirre (Nothofagus antarctica) en la Patagonia chilena mediante imágenes Landsat TM y ETM. Bosque 29 (1): 65-73.

- News, T. (1998). Invertebrate Surveys for Conservations. $1^{\circ}$ Editions. Oxford, University Press. Oxford, England. 240 pp.

- Niemelä, J. y Halme, E. (1992). Habitat associations of carabid beetles in fields and forests on the Aland Islands, SW Finland. Ecography 15: 3-11.

- Niemelä J., Haila, Y., Halme, E., Lahti, T., Pajunen, T. y Punttila, P. (1988). The distribution of carabid beetles in fragments of old coniferous taiga and adjacent managed forest. Ann Zool. Fenn. 25: 107-119.

- Niemelä, J., Halme, E. y Haila, Y. (1990). Balancing sampling effort in pitfall trapping of carabid beetles. Entomologica Fennica 1: 233-238.

- Niemelä, P., Chapin, FS., Danell, K. y Bryant, JP. (2001). Herbivory-mediated responses of selected boreal forests to climate change. Climate Change 48: 427-440.

- Nilsson, BO. (1978). Above ground food resources and herbivory in a beech forest ecosystem. Oikos 31: 273 279.

- Noriega, JA., Realpe, E. y Fagua, A. (2007). Diversidad de escarabajos coprófagos (Coleoptera: Scarabaeidae) en un bosque de galería con tres estadios de alteración. Universitas Scientiarum Edición especial I, 12:51-63.

- Noss, R. y Cooperrider, AY. (1994). Saving natures legacy: Projecting and restoring biodiversity. Defenders of Wildlife and Island Press, Washington.

- Okland, B., Bakke, A., Hågvar, S. y Kvamme T. (1996). What factors influence the diversity of saproxylic beetles? A multiscaled study from a spruce forest in southern Norway. Biodiversity Conservations 5: 75-100. 
- Ojeda, VS, Súarez, ML. y Kitzberger, T. 2007. Crown dieback events as key processes creating cavity habitat for Magellanic Woodpeckers. Ecological Sociecity of animalia. Austral Ecology 32: 436-445.

- Oliva, A. (1994). A revision of the genus Hemiosus Sharp, 1882 in South America (Coleoptera: Hydrophilidae). Bull. Annls. Soc. r. belge, Ent. 130(1994): 267-303.

- Olson, DM. y Dinerstein, E. (1997). The Global 200: Conserving the World's Distinctive Ecoregions. Conservation Science Program, WWF-US. Washington, DC, USA.

- Packard, J.M., D.B. Siniff y J.A. Cornell. (1986). Use of replicate counts to improve indices of trends in manatee abundance. Wildlife Society Bulletin 14: 265-275.

- Padoa-Schioppa, E., Baietto, M., Massa, R. y Bottoni, L. (2006). Bird communities as bioindicators: The focal species concept in agricultural landscapes. Ecol Indic 6:83-93. doi: $10.1016 /$ j.ecolind.2005.08.006.

- Parker, TA. (1991). On the use of tape recorders in avifaunal surveys. The Auk 108:443-444.

- Parker, TA., Stotz, D. y Fitzpatrick, J. (1996). Ecological and distributional databases. Pp. $115-140$ in: Neotropical birds: ecology and conservation (D. Stotz, J. Fitzpatrick, T. Parker III, D. Moskovits, Eds). The University of Chicago Press, Chicago, USA.

- Pärt, T. y Söderström, B. (1999). Conservation Value of SemiNatural Pastures in Sweden: Contrasting Botanical and Avian Measures. Conserv. Biol. 13: 755-765.

- Paruelo, JM., Jobbagy, EG. y Sala, OE. (1998). Biozones of Patagonia (Argentina). Ecología Austral 1998 8: 170-178.

- Pavic, C. (2000). Análisis de la abundancia y diversidad de aves en dos ambientes andino-patagónicos y su relación con disturbios antrópicos. Trabajo para optar al grado de Licenciatura en Ciencias Biológicas. Centro Regional Universitario Bariloche. Universidad Nacional del Comahue, Bariloche, Argentina.

- Pearson, OP. y Ralph, CP. (1978). The diversity and abundance of vertebrates along altitudinal gradients in Perú. 
Memoria del Museo de Historia Natural "Javier Prado", Nº18, Lima, Perú.

- Peri, PL. (2005). Sistemas silvopastoriles en ñirantales. IDIA XXI Revista de información sobre investigación y desarrollo agropecuario INTA: 255-261.

- Peri, PL., Sturzenbaum, MV., Monelos, L., Livraghi, E., Christiansen, R., Moreto, A. y Mayo, JP. (2005). Productividad de sistemas silvopastoriles en bosques nativos de Ñire (Nothofagus antarctica) de Patagonia Austral. En Actas III Congreso Forestal Argentino y Latinoamericano. Corrientes, Argentina Septiembre de 2005.

- Peri, P.L., Ferro, M., Salazar, L. y Rial, P. (2011). Pautas mínimas para la Presentación de Proyectos en el Manejo silvopastoril en bosques nativos de Nothofagus Antarctica (Ñire) en Santa Crúz.

- Perovic, P., Trucco, C., Tálamo, A., Quiroga, V., Ramallo, D., Lacci, A., Baungardner, A. y Mohr, F. (2008). Programa de monitoreo de biodiversidad del Parque Nacional Copo Parque y Reserva Provincial Copo y zona de amortiguamiento. Guía técnica para el monitoreo de la biodiversidad.

- Perry, DA. (1994). Ecosystem stability II: the role of ecosystems. In Perry, DA. (ed.). Forest Ecosystems. London, United Kingdom, The John Hopkins University Press: 509-532.

- Pickett, S. y White, P. (1985). The ecology of natural disturbance and patch dynamics. Academic Press, Nueva York.

- Pisano, E. (1977). Contribución de Enrique Ibar Sierra al conocimiento de la naturaleza de la Patagonia Oriental Austral. Anales del Instituto Patagónico. Punta Arenas Vol. No8.

- Pitelka, FA. (1941). Distribution of birds in relation to major biotic communities. American Naturalist 25: 113-137.

- Polop, JJ. (1989). Distribution and ecological observations of wild rodents in pampa de Achala, Córdoba, Argentina. Studies on Neotropical Fauna and Environment 24: 53-59. 
- Premoli, A. (1991). Morfología y Capacidad Germinativa en Poblaciones de Nothofagus Antarctica (Forster) Oerst. del Noroeste Andino Patagónico. Bosque 12 (2): 53-59.

- Quinn JM., Cooper, AB., Davies-Colley, RJ., Rutherford, JC. y Williamson, RB. (1997). Landuse effect on habitat, water quality, periphyton, and benthic invertebrates in Waikato, New Zeland, hill-country streams. New Zealand Journal of Marine and Freshwater Research 31: 579-598.

- Quintanilla Pérez, V. (2005). Perturbaciones ambientales por fuegos de 50 años atrás en bosques nordpatagónicos. Caso de estudio en Chile meridional. Anales de Geografía. $\mathrm{n}^{\circ}$ 28. Universidad Complutense de Madrid.

- Quintanilla Pérez, V., Meaza Rodríguez, G. y Cuesta Aguilar, MJ. (2008). Perturbaciones actuales del bosque norpatagónico chileno derivadas de los efectos de grandes fuegos de medio siglo atrás. Estudio preliminar en la cuenca andina del Río Figueroa. Boletín de la A.G.E. No 47: 109-124.

- Quinteros, P. (2007). Caracterización de la Vegetación del Sotobosque de Ñire (Nothofagus Antarctica) en un Área del Noroeste del Chubut. Tesis de Licenciatura. Facultad de Cs. Naturales - UNPat - Sede Esquel. 87 pp.

- Quinteros P., Hansen, N. y Kutschker, A. (2010). Composición y diversidad del sotobosque de Ñire (Nothofagus antarctica) en función de la estructura del bosque. Ecología Austral 20: 225-234.

- Rabassa, J., Rubulis, S. y Súarez, J. (1981). Moraine in transit as parent material for soil development and the growth of Valdivian rain forest on moving ice: casa Pangue Glacier, Mount Tronador (Lat $41^{\circ} 10^{\prime} \mathrm{S}$ ) Chile. Annals of Glaciology 2: 97-102.

- Rabinovich, JE. y Rapoport, EH. (1975). Geographical variation of diversity in Argentine passerine birds. Journal of Biogeography 2: 141-157.

- Raffaele, E., Veblen, T., Blackhall, M. y Tercero-Bucardo, N. (2011). Synergistic influences of introduced herbivores and fire on Vegetation change in northern Patagonia, Argentina. Jour. Veg. Sci. 22: 59-71. 
- Rageot, R. y Gedda, M. (1978). Observaciones sobre el Carpintero Negro. Interim report. Departamento Técnico de Conservación del Medio Ambiente, CONAF, Temuco.

- Ragonese, AM. (1977). Nothofagoxiylon menentezii, leño petrificado del Terciario de Gral. Roca, Río Negro, Argentina. Revista de la Asociación Paleontológica Argentina Tomo 14: 1-4.

- Raitt, RJ. y Pimm, SL. (1976). Dynamics of bird communities in the Chihuahuan desert, New México. Cóndor 78: 427-442.

- Ralph, CJ. (1985). Habitat association patterns of forest and steppe birds of Northern Patagonia, Argentina. The Condor 87: 471-483.

- Ralph, CJ., Geupel, GR., Pyle, P., Martin, TE., De Sante, DF. y Mila, B. (1995). Manual de Métodos de Campo para el Monitoreo de Aves Terrestres. Pacifics Southwest Research Stations, Albany, CA. Pp. 59.

- Ralph, CJ., Geupel, GR., Pyle, P., Martin, TE., De Sante, DF. y Milá, B. (1996). Manual de métodos de campo para el monitoreo de aves terrestres. Fauna silvestre de México: uso, manejo y legislación. General Technical Report, PSW-GTR-159, Pacific Southwest R Research Station, Forest Services, U.S. Department of Agriculture, Albany, California.

- Ramírez, C., Correa, M., Figueroa, H. y San Martín, J. (1985). Variación del Hábitat de Nothofagus antarctica en el Centro Sur de Chile. Bosque 6 (2). Pág. 55-73.

- Reca, A., Úbeda, C. y Grigera, D. (1994). Conservación de la Fauna de Tetrápodos I. Un Indice para su Evaluación. Mastozoología Neotropical 1 (1): 17:28.

- Recher, HF. (1969). Bird species diversity and habitat diversity in Australia and North America. American Naturalist 103: 75-80.

- Reid, R., Cornelius, C., Barbosa, O., Meynard, C., Silva García, C. y Marquet, P. (2002). Conservation of temperate forest birds in Chile: Implications from the study of an isolated forest relict. Biodiversity and Conservations 11: 19751990. 
- Relva, M. A. y Veblen, T.T. (1998). Impacts of introduced large herbivores on Austrocedrus chilensis forests in northern Patagonia, Argentina. Forest Ecology and Management $\mathrm{N}^{\circ}$ 108. Pp. 27-40.

- Reque, J., Sarasola, J., Gyenge, M.E. y Fernández, ME. (2007). Caracterización Silvícola de ñirantales del Norte de la Patagonia para la Gestión Forestal Sostenible. Bosque 28(1): 33-45 - Año 2007.

- Reynolds, T. (1980). A variable circular plot method for estimating bird densities. Journal Condor 82: 309-313.

- Reynolds T., Scott J. y Nussbaum R. (1980). A variable circularplot method for estimating bird densities. Condor 82: 309-313.

- Rice, J., Ohmart, RD. y Anderson, BW. (1983). Habitat selection attributes of an avian community: a discriminant analysis approach. Ecological Monographas 53: 263-290.

- Richards, OW. y Davies, RG. (1984). Tratado de entomologia Imms. Volumen 2: Clasificacion y Biologia. Ed. Omega, Barcelona, España. 998 pp.

- Richardson, RJ. y Holliday, NJ. (1982). Occurrence of carabid beetles (Coleoptera: Carabidae) in a boreal forest damaged by fire. Can. Entomology 114: 509-514.

- Richter, L. y Frangi, J. (1992). Bases ecológicas para el manejo del bosque de Nothofagus pumilio de Tierra del Fuego. Revista de la Facultad de Agronomía, La Plata 68: 35-52.

- Ringuelet, RA. (1961). Rasgos Fundamentales de la Zoogeografía de la Argentina. Physis 22: 151-170.

- Roberts, TH. (1987). Construction of guilds for habitats assessment. Journal Environmental Manage 11: 473-477.

- Robinson, RA. y Sutherland, W. (2002). Post-war changes in arable farming and biodiversity in Great Britain. J. Appl. Ecol. 39: 157-176.

- Robinson, RA., Wilson, JD., Crick, HQP. (2001). The importance of arable habitat for farmland birds in grassland landscapes. J. Appl. Ecol. 38: 1059-1069. 
- Romoser, WS. y Stoffolano, JG. (1998). The science of entomology. WCB/McGraw-Hill (EEUU). 605 pp.

- Root, RB. (1967). The niche exploitation pattern of the Blue Gray Gnatcatcher. Ecological Monographs 37: 317-350.

- Root, RB. (1973). Organization of a plant arthropod association in simple and diverse hábitats: the fauna of collards (Brassica oleracea). Ecological monographs 43(1): 95124.

- Root, T. (1988). Environmental factors associated with avian distributional boundaries. Journal of Biogeography 15: 489-505.

- Ross, H. (1973). Introducción a la entomología general y aplicada. Ed Omega, Barcelona - España. 536 pp.

- Rotenberry, JT. (1978). Components of avian diversity along a multifactorial climatic gradient. Ecology 59: 693-699.

- Rotenberry, JT. (1985). The role of habitat in avian community composition: physiognomy or floristic? Oecologia 67: 213217.

- Rotenberry, JT. y Wiens, JA. (1980). Habitat structure, patchiness, and avian communities in North American steppe vegetation: a multivariate analysis. Ecology 61: 1228-1250.

- Roth, RR. (1976). Spatial heterogeneity and bird species diversity. Ecology 57: 773-782.

- Rozzi, D., Martínez, D., Willson, MF. y Sabag, C. (1996a). Avifauna de los bosques templado de Sudamérica. Ecología de los Bosques Nativos de Chile. Capítulo N07. Pág. 135-152. Chile.

- Rozzi, R., Armesto, JJ., Correa, A., Torres Mura, JC., y Sallaberry, M. (1996b). Avifauna de bosques primarios templados en islas deshabitadas del Archipiélago de Chiloé, Chile. Revista Chilena de Historia Natural 69: 125139.

- Ruggiero, A., Sackmann, P., Farji-Brener, AG. y Kun, M. (2009). Beetle abundante-environment relationships at the Subantartic-Patagonian transition zone. Insect Conservation and Diversity 2: 81-92. 
- Rusch, VE. y Sarasola, M. (1999). Empleo de criterios e indicadores en el Manejo Forestal Sustentable. Biodiversidad. Parte I - Propuesta metodológica. 2, 15-24. Segundas Jornadas Iberoamericanas sobre Biodiversidad Biológica, San Luis.

- Rusch, VE., Roveta, R., Peralta, C., Márques, B., Vila, A., Sarasola, M., Todaro, C. y Barrios, B. (2004). Indicadores de sustentabilidad en sistemas silvopastoriles. Alternativas de Manejo Sustentable para el Manejo Forestal Integral de los bosques de Patagonia. Informe Final del Proyecto de Investigación Aplicada a los Recursos Forestales Nativos (PIARFON), Tomo II: 681797. Dirección de Bosques de la Secretaría de Ambiente y Desarrollo Sustentable de Nación (SAyDS). Proyecto BIRF 4085-AR.

- Rusch, VE., Sarasola, M. y Schlichter, T. (2005). Indicadores de biodiversidad en bosques de Nothofagus. IDIA XXI, 8: 8-14.

- Rusch, VE., López, DR., Cavallero, ML., Rusch, GM., Peri, PL., Cardozo, A., Hansen, N., von Muller, A., Garibaldi, LA. y Sarasola, MM. (2015). Un marco ecológico para establecer márgenes de manejo de sistemas silvopastoriles. 1- El caso de ñirantales del norte de la Patagonia, Argentina. $3^{\circ}$ Congreso Nacional de Sistemas Silvopastoriles - VII Congreso Internacional de Sistemas Agroforestales. Iguazú - Misiones. Argentina.

- Saavedra, M. (1996). Primer informe proyecto de conservación del carpintero grande (Campephilus magellanicus) (King 1828) en las áreas silvestres protegidas de la IX Región. CONAF, Temuco, Chile.

- Saavedra, M. (1998). Avances en el proyecto de conservación del carpintero grande (Campephilus magellanicus, King 1828) en las áreas silvestres protegidas de la IX región de la Araucanía. In: Valverde V (ed). La conservación de la fauna nativa de Chile, logros y perspectivas. CONAF, Santiago, 107-119 pp.

- Sabag, C. (1993). El rol de las aves en la dispersión de semillas en un bosque templado secundario de Chiloé $\left(42^{\circ} \mathrm{S}\right)$. Tesis de Maestría. Universidad de Chile. Santiago. Chile. 
- Sackmann, P. (2006). Efectos de la variación temporal y los métodos de captura en la eficiencia de un muestreo de coleópteros en la Reserva Natural Loma del Medio, El Bolsón, Río Negro. Revista de la Sociedad Entomológica Argentina 65 (3): 35-50.

- Sackmann, P., Ruggiero, A., Kun, M. y Farji-Brener, AG. (2006). Efficiency of rapid assessment of the diversity of ground beetles and ants, in natural and disturbed habitats of the Nahuel Huapi region (NW Patagonia, Argentina). Biodiversity and Conservation 15: 2061-2084.

- Sakai, A., Paton, DM. y Wardle, P. (1981). Freezing Resistance of Trees of the South Temperate zone, Specially Subalpine Species of Australasia. Ecology 62: 563-570.

- Sala, OE. (2000). Biodiversity - Global biodiversity scenarios for the years 2100. Science 287: 1770-1774.

- Samways, MJ. (1991). Insects in biodiversity conservation: some perspectives and directives. Biodiversity Conservation 2: 258-282.

- San Martín J., Troncoso A. y Ramírez C. (1987). Fitosociología de los bosques de Nothofagus antarctica (Forst) Oerst en la cordillera costera de Cauquenes (Chile). Bosque 7(2): 65-78.

- Santos, T. y Tellería, JL. (1997). Vertebrate predation on Holm Oak, Quercus ilex, acorns in a fragmented habitat: effects as seedling recruitment. Forest Ecology and Management 98: $181-187$.

- Santos, T., Tellería y Carbonell, R. (2002). Bird conservation in fragmented Mediterranean forest of Spain: effects geographical location, habitat and landscape degradation. Biological Conservation, 105: 113-125.

- Sarasola, M., López, D., Gaitán, J. y Siffredi, G. (2008). Productividad de sistemas silvopastoriles en bosques de Ñire en la cuenca del río Foyel. Libro de actas $\mathrm{II}^{\circ}$ Reunión sobre Nothofagus en la Patagonia. Esquel, Chubut.

- Saunders, DA., Hobbs, RJ. y Margules, CR. (1991). Biological consequences of ecosystem fragmentation: a review. Conserv. Biol. 5: 18-32. 
- Schall, JJ. y Pianka, ER. (1978). Geographical trends in numbers of species. Science 201: 679-686.

- Schlichter, T. y Laclau, P. (1998). Ecotono estepa-bosque y plantaciones en la Patagonia norte. Ecología Austral 8: 285-296.

- Schowalter, TD. y Zhang, YL. (2005). Canopy arthropod assemblages in four overstory and three understory plant species in mixed-conifer old-growth forest in California. Forest Science 51: 233-242.

- Scott, J. y Ramsey, F. (1981). Length of count period as a possible source of bias in estimating bird densities. Studies in Avian Biology. 6: 409-413.

- Scudder, GGE. (2000). Pitfall Trapping. Ecological Monitoring and Assesment Networ Coordinating Office. Ecosystem Science Directorate of Environment Canada. http: //eqbdqe.cciw.ca/eman.

- Seastedt, TR. y Crossley, DA. (1983). Nutrients in forest litter treated with naphtalene and simulated throughfall: a field microcosm study. Soil Biology and Biochemistry 15: 159 165.

- Secretaria de Ambiente y Desarrollo Sustentable (SAyDS). (2005). Primer inventario de bosques nativos. Proyecto Bosques Nativos y Aéreas Protegidas. Pp. 104.

- Secretaría de Agricultura y Desarrollo Sustentable (SAyDS). (2008). El avance de la frontera agropecuaria y sus consecuencias. Subsecretaría de Planificación y Política Ambiental. Dirección Nacional de Ordenamiento Ambiental y Conservación de la Biodiversidad. 12 pp.

- Secretaria de Ambiente y Desarrollo Sustentable (SAyDS). (2014). Guía para la confección de Planes de Manejo de Bosques con Ganadería. Ley Nacional N²6331 Resolución Nº 826/14. Buenos Aires - Argentina.

- Sekercioğlu, CH. (2006). Increasing awareness of avian ecological function. Trends Ecol Evol 21: 464-471. doi: 10.1016/j.tree.2006-.05.007

- Sekercioğlu, CH., Ehrlich, PR., Daily, GC., Aygen, D., Goehring, D. y Sandí, RF. (2002). Disappearance of insectivorous birds from tropical forest fragments. Proceedings of the 
National Academy of Science of the United States, Vol. 99, nº1: 263-267.

- Sekercioğlu, CH., Daily, GC. y Ehrlich, PR. (2004). Ecosystem consequences of bird declines. Proc Natl Acad Sci U S A 101:18042-18047. doi:10.1073/pnas.0408049101.

- Short, HL. \& Burnham, KP. (1982). Technique for structuring wildlife guilds to evaluate impacts on wildlife communities. Special Sci. Rep. Wildlife 244. USDI Fish and Wildlife Service. Washington DC, EE.UU.

- Short, JJ. (1979). Patterns of alpha-diversity and abundance in breeding bird communities across North America. Condor 81: 21-27.

- Short, L. (1970). The habits and relationships of the magellanic woodpecker. The Wilson Bulletin Vol. 82 N²: 115-129.

- Sieving, KE., Willson, MF. y De Santo, TL. (1996). Defining corridor functions for endemic birds in fragmented southtemperate rainforest. Conservation Biology 14: 11201132.

- Sieving, KE., Willson, MF. y De Santo, TL. (2000). Habitat barriers to movement of understory birds in fragmented south-temperate rainforest. The Auk 113: 944-949.

- Simanonok, MP., Anderson, CB., Martinez Pastur, G., Lencinas, JH. y Kennedy, MV. (2011). A comparison of impacts from silviculture practices and North American beaver invasion on stream benthic macroinvertebrate community structure and function in Nothofagus forests of Tierra del Fuego. Forest Ecology and Management 262(2): 263-269.

- Simonetti, JA., Arroyo, MTK., Spotorno, AE. y Lozada, E. (1995). Diversidad biológica en Chile. Comisión Nacional de Ciencia y Tecnología, Santiago, Chile. 364 pp.

- Sinclair, BJ., Addo-Bediako, A. y Chown, SL. (2003). Climatic variability and the evolution of insect freeze tolerance. Biol. Rev. 78, 181-195.

- Siriwardena, G., Baillie, S. Buckland, S., Fewster, R., Marchant, J. y Wilson, J. (1998). Trends in the abundance of farmland birds: a quantitative comparison of smoothed common bird census indices. J. Appl. Ecol. 35: 24-43. 
- Snow, DW. (1981). Tropical frugivorus birds and their food plants: a World Surrey. Biotropica 13: 1-14.

- Soave, GE., Marateo, G., Rey, P., Glaz, D. y Darrieu, C. (1999). Evolución estacional de los ensambles de aves de un talar del nordeste de la provincia de Buenos Aires, Argentina. Comisión de Investigaciones Científicas, La Plata.

- Sokal R. y Rohlf, F. (1995). Biometry. $3^{\circ}$ edition.W.H. Freeman and Company: New York. Pp 859.

- Somlo, R., Bonvisutto, G., Schlichter, T., Laclau, P., Peri, P. \& Allogia, M. (1997). Silvopastoral use of Argentine Patagonian Forests. In Gordon A, S Newman (eds.). Temperate agroforestry systems. CAB Internacional (UK). p. 237-250.

- Soriano, A., Aguiar, M.R. (1998). Estructura y Funcionamiento de los Agroecosistemas. Ciencia e Investigación 50: 6373.

- Southwood, T. (1989). Ecological Methods: Whit particular reference to the study of insect populations. $2^{\circ}$ Editions. Cambridge, University Press. Cambridge, England. Pp. 524.

- Sousa, W. (1984). The role of disturbance in natural communities. Annual Review of Ecology and Systematics 15: 353-391.

- Souza, MG. (2004). An extension to the known distribution of Berosus chalcocephalus (Coleoptera: Hydrophilidae) in southern Patagonia. Revista de la Sociedad Entomologica Argentina 63 (1-2): 68-69.

- Spagarino C., Martínez Pastur G. y Peri P. (2001). Changes in Nothofagus pumilio forest biodiversity during the forest management cycxle: insects. Biodiv. Conserv. 10: 20772092.

- Spence, JR. y Niemelä, J. (1994). Sampling carabid assemblages with pitfall traps: the method and the madness. The Canadian Entomologist 126: 881-894.

- Stenberg I, Hogstad O (1992) Habitat use and density of breeding woodpeckers in the 1990 in More og Romsdal County, Western Norway. Cinclus 15: 49-61. 
- Stotz, D., Fitzpatrick, J., Parker, T. y Moskovits, D. (1996). Neotropical birds: ecology and conservation. The University of Chicago Press, Chicago, USA.

- Strong, DR., Lawton, JH. y Southwood, T. (1984). Insects on plants. Community patterns and mechanisms. Cambridge, Massachusetts. Harvard University Press. 313 pp.

- Tecklin, D, Vila A. y Palminteri, S. (2002). A Biodiversity Vision for the Valdivian Temperate Rain Forest Ecoregion of Chile and Argentina. Estudio preliminary.

- Tellería, JL. y Santos, T. (1993). Distributional patterns of insectivorous passerines in the Iberian Forest: does abundance decrease near the border?. Journal of Biogeography 20: 235-240.

- Tellería, JL. y Santos, T. (1994). Factors involved in the distribution of forest birds in the Iberian Peninsula. Bird Study 41: 161-169.

- Tellería, JL., Santos, T., Sánchez, A. y Galarza, A. (1992). Habitat structure predicts bird diversity distribution in Iberian forest better than climate. Bird Study 39: 63-68.

- Temple, SA., Wiens, JA. (1989). Bird populations and environmental changes: can birds be bio-indicators? Am Birds 43: $260-270$.

- ter Braak, CJF. (1986). Canonical correspondence analysis: a new eigenvector technique for multivariate direct gradient analysis. Ecology 67: 1167-1179.

- ter Braak, CJF. (1995). Ordination. En: R.H.G. Jongman, ter Braak, C.J.F. \& van Tongeren, O.F.R. (eds.). Data analysis in community and landscape ecology. Cambridge University Press, Cambridge, UK.

- ter Braak, CJF. y Smilauer P. (1998). CANOCO reference manual and users guide to Canoco for Windows. Wageningen, the Netherlands: Centre of Biometry, Wageningen.

- ter Braak, CJF. y Smilauer P. (1999). CANOCO for Windows (vers, 4.02). A FORTRAN program for canonical community ordination. Wageningen, The Netherlands: Centre for Biometry, Wageningen. 
- Tews, J., Brose, U., Tielböroger, K., Wichmann, MC., Schwager, M. y Jeltsch, F. (2004). Animal species diversity driven by habitat heterogeneity/diversity: the importance of keystone structures. J. Biogeogr. 31: 7992.

- Thomas, SC., Halpern, CB., Falk, DA., Liguori, DA. y Austin, KA. (1999). Plant diversity in managed forest: Undestory responses to thinning and fertilization. Ecology Applied 9(3): 864-879.

- Thuiller, W. (2007). Climate change and the ecologist. Nature 448: $550-552$.

- Tilman, D. (1999). Global environmental impacts of agricultural expansion: The need for sustainable and efficient practices. Proc. Natl. Scad. Sci. 96: 5995-6000.

- Tilman, D. y Dowing, J. (1994). Biodiversity and stability in grassland. Nature 367:363-365.

- Tramer, EJ. (1974). On latitudinal gradients in avian diversity. Condor 76: 123-130.

- Traveset, A. y Verdú, M. (2002). A meta-analysis of the effect of gut treatment of seed germination. Pp. 339-350.

- Turner, MG. (2005). Landscape ecology: What is the state of the science?. Annual Review Ecology Evolutions $y$ Systematics. 36: 319-344.

- Úbeda, C. y Grigera, D. (1995). Recalificación del estado de conservación de la fauna silvestre argentina. Región Patagónica. Consejo Asesor Regional Patagónico de la Fauna Silvestre. Subsecretaría de Recursos Naturales, Buenos Aires.

- Unión Internacional para la Conservación de la Naturaleza (UICN). (2001). Categorías y Criterios de la Lista Roja de la UICN: Versión 3.1. Comisión de Supervivencia de Especies de la UICN. UICN, Gland, Suiza y Cambridge, Reino Unido. 33 pp. Disponible en el sitio oficial de la UICN.

- Unión Internacional para la Conservación de la Naturaleza (UICN). (2012). Categorías y criterios de elaboración de la Lista Roja. Versión 3.1. 2 Edición. Verna-Suiza. 
- Urretavizcaya, MF. (2005). Cambios ambientales y restauración ecológica postincendio en bosques de Austrocedrus chilensis Tesis de Doctorado. Bariloche, Argentina. Universidad Nacional del Comahue. 205 pp.

- Vammiere, B. y A. Maurette. (1995). Auditoría Ambiental a los Bosques Nativos de Lenga de la Patagonia. Office National des Forêts (ONF), Francia.

- Van Tyne y Verger. (1959). Fundament of ornithology. John Wiley y Sons INC. USA.

- Vance, CC. y Nol, E. (2003). Temporal effects of selection logging on ground betele communities in northern hardwood forest of Eastern Canada. EcoScience 10: 4956.

- Varela, S., Gobbi, ME. y Laos, F. (2006). Banco de semillas de un bosque quemado de Nothofagus pumilio: efecto de la aplicación de compost de biosólidos. Ecología Austral 16: 63-78.

- Vasconcelos, H. (1999). Effects of forest disturbance on the structure of ground foraging ant communities in central Amazonia. Biodiversity and Conservation 8: 409-420.

- Vasconcelos, H., Vilhena, J. y Caliri, G. (2000). Responses of ants to selective logging of a central Amazonian forest. Journal of Applied Ecology 37: 508-514.

- Veblen, TT. (1982). Regeneration patterns in Araucaria araucana forests in Chile. Journal of Biogeography 9: 1128.

- Veblen, T. y Lorenz, D. (1988). Recent vegetation changes along the forest/steppe ecotone of northern Patagonia. Annals of the Association of American Geographers 78:93-111.

- Veblen, TT., Ashton, D. , Schlegel, F. y Veblen, A. (1977). Plant Succession in a Timberline Depressed by Volcanism in South - Central Chile. Journal of Biogeografy 4: 275 294.

- Veblen, TT., Schlegel, F. y Oltremari, J. (1983). Temperate Broad - Leaved Evergreen Forest. Elsevier, Amsterdam 5 -31 . 
- Veblen, T. T., Mermoz, M., Martin, T. y Kitzberger, T.T. (1992). Ecological impacts of introduced animals in Nahuel Huapi National Park, Argentina. Conservation Biology N 6. Pp. 71-83.

- Veblen TT., Donoso, C., Kitzberger, T. y Rebertus, A. (1996). Ecology of Southern Chilean and Argentinean Nothofagus Forest. Veblen T. T., R. S. Hill \& J. Read (eds) En: The Ecology and Biogeography of Nothofagus Forest. Yale University press. London. 403 pp.

- Veblen, T. T., Kitzberger, T., Raffaele, E. y Lorenz, D.C. (2003). Fire history and vegetation changes in northern Patagonia, Argentina, en: Veblen, T. T., W. Baker, G. Montenegro \& T. W. Swetnam (eds.), Fire and Climatic Change in Temperate Ecosystems of the Western.

- Vergara, O. y Jerez, V. (2010). Insectos e infestaciones asociadas al follaje de Nothofagus antarctica (Forst) Oerst (Nothofagaceae) en la cuenca del rio Baker, Region de Aysen, Chile. Gayana vol.74 (2): 83-93.

- Vergara, PM. y Schlatter, RP. (2004). Magellanic woodpecker (Campephilus magellanicus) abundance and foraging in Tierra del Fuego, Chile. J. Ornithologen-Gesellschaft 145: 343-351.

- Vergara, PM. y Simonetti, J. (2003). Forest fragmentation and rhinocryptid nest predation in central Chile. Acta Oecologica 24: 285-288.

- Vergara, PM. y Simonetti, JA. (2004). Avian responses to fragmentation of the Maulino forest in central Chile. Oryx 38(4): 383-388.

- Verner, J. (1984). The guild concept applied to management of bird populations. Journal Environmental Manage 8: 1-14.

- Verner J. (1988). Optimizing duration of point counts for monitoring trends in bird populations. US Forest Service Research Note PSW, p. 395.

- Vickery, P., Tubaro, P., Silva, J., Peterjohn, B., Herkert, J., y Cavalcanti, R. (1999). Conservation of grassland birds in the Western Hemisphere. Stud. Avian Biol. 19: 2-26. 
- Vila, A. (2000). Análisis de la biodiversidad y conservación de la Ecorregión Valdiviana. Memoria del Taller, Segunda etapa. Boletín Técnico 52. Fundación Vida Silvestre Argentina, Buenos Aires.

- Vila, AR. (2002). Visión de la biodiversidad para la ecorregión de los bosques templados valdivianos. CD-Rom. Fundación Vida Silvestre Argentina, Buenos Aires.

- Villagrán, C. (1991). Historia de los bosques templados del sur de Chile durante el Tardiglacial y Postglacial. Revista Chilena de Historia Natural 64: 447-460.

- Villegas, M. y Garitano-Zavala, Á. (2008). Las comunidades de aves como indicadores ecológicos para programas de monitoreo ambiental en la ciudad de La Paz, Bolivia. Ecol en Boliv 43: 146-153.

- Virkkala, R. (1987). Geographical variation in bird communities of old, intact forest in northern Finland. Ornis Fennica 64: 107-118.

- von Müller, (2011). Factores ecológicos y de manejo en la selección de hábitat de herbívoros domésticos en las Sierras Grandes de Córdoba. Tesis Doctorado en Ciencias Biológicas Facultad de Ciencias Exactas, Físicas y Naturales. Universidad Nacional de Córdoba.

- Vuilleumier, B. (1971). Pleistocene changes in the fauna and flora of South America. Science 173: 771-780.

- Vuilleumier, F. (1972). Bird species diversity in Patagonia (Temperate South America). American Naturalist, 106: 266-271.

- Vuilleumier, F. (1985). Forest birds of Patagonia: ecological geography, speciation, endemism and faunal history. Ornithological Monographs 36: 255-304.

- Walker, BH. (1992). Biodiversity and Ecological Redundancy. Conservation Biology 6: 18-23.

- Wallner, WE. (1978). Scale insects: What the arboriculturist needs to know about them. J. Arboric. 4: 1-7.

- Walter, H. y Box, E. (1983). Climate of Patagonia. In Deserts and Semideserts of Patagonia West. N.E. Temperate 
Deserts and Semideserts, Pp. 432-435. Editions Elsevier. Amsterdam, Holanda.

- Warren, MW. y Zou, X. (2002). Soil macrofauna and litter nutrients in three tropical and tree plantations on a disturbed site in Puerto Rico. Forest Ecology and Management 170: 161-171.

- Weinberger, P. (1973). The Regenerations of the Araucano Patagonic Nothofagus species in relations to microclimatic conditions. Flora 162: 157-179.

- Wenny, DG., Clawson, RL., Sheriff, SL. y Faaborg, J. (1993). Population variation, habitat selection, and minimum area requirements of three forest interior warbles in central Missouri. The Condor 95: 968-979.

- Westoby M., Walker, B., y Noy-Meir, I. (1989). Opportunistic management for rangelands not at equilibrium. Journal Range Managegement: 42 (4): 266-274.

- Whelan, CJ., Wenny, DG. y Marquise, RJ. (2008). Ecosystem services provided by birds. Year Ecol Conserv Biol 2008 1134: 25-60. doi: 10.1196/annals.1439.003.

- Whittam, TS. y Siegel Causey, D. (1981). Species interactions and community structure in Alaskan seabird colonies. Ecology 62: 1515-1524.

- Whittingham, MJ. y Evans, KL. (2004). Effects of habitat structure on predation risk birds in agricultural landscapes. Ibis 146: 210-220.

- Whittingham, MJ., Devereux, CL, Evans, AD. y Bradbury, RB. (2006). Altering perceived predation risk and food availability; management prescriptions farmland birds on stubble fields. Journal Applied Ecology 43: 640-650.

- Wiens, JA. (1989a). The ecology of bird communities. Volume 1. Foundations and patterns. Cambridge University Press, Cambridge.

- Wiens, JA. (1989b). The ecology of bird communities. Volume 2. Processes and variations. Cambridge University Press, Cambridge.

- Wigley, TB. y Roberts, TH. (1997). Landscape level effects of forest management on faunal diversity in bottomland 
hardwoods. Forest Ecology and Management 90: 141154.

- Wilcox, B. y Murphy, D. (1985). Conservation strategy: the effects from fragmentation on extinction. American Nature 125: 879-887.

- Willson, MF. (1974). Avian community organization and habitat structure. Ecology 55: 1017-1029.

- Willson, MF. (1991). Dispersal of seeds by frugivorus animals in temperate forests. Rev. Chilena Historia Natural 64: 537554.

- Willson, MF., De Santo, TL., Sabag, J. y Armesto, JJ. (1994). Avian communities of fragmented south-temperate rainforest in Chile. Conservation Biology 8: 508-5202.

- Willson, MF., Sabag, J., Figueroa, J., Armesto, Jj. y Caviedes, M. (1996a). Seed dispersal by lizards in Chilean rainforest. Rev. Chilena Historia Natural 69: 339-342.

- Willson, MF., Smith-Ramírez, C., Sabag, J. y Hernández, JH. (1996b). Mutualismos entre plantas y animales en bosques templados de Chile. Pp. 251-264.

- Wilson R., Twedt J. y Elliot B. (2000). Comparison of line transects and point counts for monitoring spring migration in forested wetlands. J. Field Ornithol. 71(2): 345-355.

- Wilson, JB. (1999). Guilds, functional types and ecological groups. Oikos 86: 507-522.

- Wolda, H. (1978). Fluctuations in abundance of tropical insects. The American Naturalist 112 (988): 1017-1045.

- Wolda, H. (1988). Insect seasonality: why? Annual Review of Ecology and Systematics 19: 1-18.

- World Commision of Environment and Development (WCED). (1987). Our Common Future. Oxford University Press, Oxford.

- World Wildlife Foundations (WWF). (2001). A Biodiversity Vision for the Valdivian Temperate Rain Forest Ecoregion of Chile and Argentina, Working Draft. Tecklin, D.; A. Vila y S. Palminteri (eds.). Washington D C. 
- Wunderle, J.M., Jr. (1992). Sexual habitat segregation in wintering black-throated blue warblers in Puerto Rico. Pp. 299-307. En: Hagan, J. \& D.P. Johnston (Eds.). Ecology and conservation of Neotropical migrant landbirds. Smithsonian Institution, Washington, D.C.

- Wunderle, J.M., Jr. (1994). Métodos para contar aves terrestres del Caribe. General Technical Report SO-100. U.S. Department of Agriculture, Forest Service, Southern Forest Experiment Station, New Orleans, Louisiana.

- York, A. (2000). Long term effects of frequent low-intensity burning on ant communities in coastal blackbutt forests of southern Australia. Austral Ecology 25: 83-98.

- Zarrilli, A. (2008). Bosques y Agricultura: Una mirada a los límites históricos de sustentabilidad de los bosques argentinos en un contexto de la explotación capitalista en el siglo XX. Scielo: Luna Azul N²6 - ISSN 1909-2474.

- Zuloaga, F., Morrone, O. y Belgrano, MJ. (2008). Clusiaceae. Catálogo de las Plantas vasculares del Cono Sur (Argentina, sur de Brasil, Chile, Paraguay y Uruguay). Monogr. Syst. Bot. Missouri Bot. Gard. 107 (2): 19321933. 
Anexo 


\section{Censo Ornitológico}

Tipología del Ñirantal:

Sitio:

Fecha:

Hora:

Temperatura:

Velocidad del Viento:

Tipo de Muestreo: LT PC

Estación:

Nubosidad:

\section{Relevamiento}

\begin{tabular}{|c|c|c|}
\hline Especie & Sitio & Abundancia \\
\hline & & \\
\hline & & \\
\hline & & \\
\hline & & \\
\hline & & \\
\hline & & \\
\hline & & \\
\hline & & \\
\hline & & \\
\hline & & \\
\hline & & \\
\hline & & \\
\hline & & \\
\hline & & \\
\hline & & \\
\hline & & \\
\hline & & \\
\hline & & \\
\hline & & \\
\hline & & \\
\hline & & \\
\hline & & \\
\hline & & \\
\hline & & \\
\hline & & \\
\hline & & \\
\hline
\end{tabular}


Lista de especies ordenadas por familia para cada sitio de muestreo, incluyendo el origen ( $\mathrm{n}=$ nativas y e = exóticas) y estrato $(\mathrm{h}=\mathrm{herbáceo;} \mathrm{a}=$ arbustivo; $\mathrm{A}=$ arbóreo) al que pertenecen. $X$ indica presencia; - indica ausencia.

\begin{tabular}{|c|c|c|c|c|c|c|c|c|c|}
\hline Familia & Especie & Estrato & Origen & $\begin{array}{c}\text { Sitios } \\
\text { PRISTIN } \\
\text { OS } \\
\text { (PRJO y } \\
\text { PRPI) }\end{array}$ & $\begin{array}{c}\text { Sitios } \\
\text { Quemados } \\
\text { hace } 25 \text { años } \\
\text { (INUP e INDO) }\end{array}$ & $\begin{array}{c}\text { Sitios } \\
\text { Quemados } \\
\text { hace } 15 \\
\text { años (GAUP } \\
\text { y GADO) }\end{array}$ & $\begin{array}{c}\text { Sitios con } \\
\text { Extracción } \\
\text { leña por } \\
\text { parquizado } \\
\text { (PAPI y } \\
\text { PAJO) }\end{array}$ & $\begin{array}{c}\text { Sitios } \\
\text { con } \\
\text { extracció } \\
\text { n leña } \\
\text { por } \\
\text { manchon } \\
\text { es (TUUP } \\
\text { y TUDO) }\end{array}$ & $\begin{array}{c}\text { Sitios } \\
\text { convertidos } \\
\text { a pasturas } \\
\text { (PAGA y } \\
\text { PAPE) }\end{array}$ \\
\hline Alstromeriaceae & Alstroemeria aurea & $h$ & $n$ & $x$ & $x$ & - & $\mathrm{X}$ & - & - \\
\hline Anacardiaceae & Schinus patagonicus & $a$ & $n$ & $x$ & $x$ & $x$ & $x$ & $x$ & - \\
\hline Apiaceae & Azorella trifoliolata & $\mathrm{h}$ & $\mathrm{n}$ & - & $x$ & $x$ & $x$ & $x$ & $x$ \\
\hline Apiaceae & Mulinum echinus & $a$ & $n$ & $x$ & $x$ & - & $x$ & $x$ & - \\
\hline Apiaceae & Mulinum spinosum & $a$ & $\mathrm{n}$ & $x$ & $x$ & - & $x$ & $x$ & - \\
\hline Asteraceae & Madia sativa & $\mathrm{h}$ & e & - & $x$ & $x$ & $x$ & $x$ & $x$ \\
\hline Asteraceae & Mutisia decurrens & $a$ & $\mathrm{n}$ & $\mathrm{x}$ & - & - & $x$ & $x$ & - \\
\hline Asteraceae & Senecio filaginoides & a & $n$ & $\mathrm{X}$ & - & $x$ & $x$ & - & - \\
\hline Asteraceae & Senecio neaei & a & $\mathrm{n}$ & $X$ & - & $x$ & $X$ & $X$ & - \\
\hline Asteraceae & $\begin{array}{l}\text { Taraxacum } \\
\text { officinale }\end{array}$ & $\mathrm{h}$ & e & $X$ & $X$ & $X$ & $X$ & $X$ & $X$ \\
\hline
\end{tabular}




\begin{tabular}{|c|c|c|c|c|c|c|c|c|c|}
\hline Berberidaceae & Berberis parodii & $a$ & $\mathrm{n}$ & $x$ & $x$ & $x$ & $x$ & $x$ & - \\
\hline Bambusoideae & Chusquea culeou & $a$ & $\mathrm{n}$ & - & - & $x$ & - & - & - \\
\hline Celastraceae & Maytenus boaria & $A$ & $\mathrm{n}$ & $x$ & $x$ & - & $x$ & $x$ & - \\
\hline Celastraceae & $\begin{array}{l}\text { Maytenus } \\
\text { chubutensis }\end{array}$ & $a$ & $\mathrm{n}$ & - & $x$ & - & $x$ & - & - \\
\hline Cupressaceae & Astrocedrus chilensis & $A$ & $\mathrm{n}$ & - & $x$ & - & - & - & - \\
\hline Ericaceae & $\begin{array}{l}\text { Gautheria } \\
\text { mucronata }\end{array}$ & $a$ & $\mathrm{n}$ & - & $x$ & - & - & - & - \\
\hline Escalloniaceae & Chacaya trinervis & $a$ & $\mathrm{n}$ & - & - & $x$ & - & $x$ & - \\
\hline Escalloniaceae & Escallonia rubra & $a$ & $\mathrm{n}$ & - & - & - & $x$ & - & $\mathrm{x}$ \\
\hline Fabaceae & $\begin{array}{l}\text { Sphaerocarpa } \\
\text { rethama }\end{array}$ & $a$ & $\mathrm{n}$ & - & $x$ & $x$ & $x$ & - & - \\
\hline Geraniaceae & $\begin{array}{l}\text { Geranium sessili } \\
\text { orum }\end{array}$ & $\mathrm{h}$ & $\mathrm{n}$ & $x$ & - & - & - & - & - \\
\hline Nothofagaceae & $\begin{array}{l}\text { Nothofagus } \\
\text { antartica }\end{array}$ & $A$ & $\mathrm{n}$ & $x$ & $x$ & $x$ & $x$ & $x$ & - \\
\hline Orchidaceae & $\begin{array}{l}\text { Chloraea } \\
\text { magellanica }\end{array}$ & $\mathrm{h}$ & $\mathrm{n}$ & - & $x$ & - & - & - & $x$ \\
\hline Pinaceae & Pinus sp. & $A$ & $\mathrm{e}$ & - & $x$ & - & - & - & - \\
\hline Poaceae & Bromus setifolius & $\mathrm{h}$ & $\mathrm{n}$ & $x$ & $x$ & $x$ & $x$ & $x$ & $\mathrm{X}$ \\
\hline Poaceae & Bromus stamineus & $\mathrm{h}$ & $\mathrm{n}$ & $x$ & $x$ & $x$ & $x$ & $x$ & $\mathrm{x}$ \\
\hline Poaceae & Holcus lanatus & $\mathrm{h}$ & $\mathrm{e}$ & - & $x$ & - & - & - & - \\
\hline
\end{tabular}




\begin{tabular}{|c|c|c|c|c|c|c|c|c|c|}
\hline Poaceae & Poa ligularis & $\mathrm{h}$ & $\mathrm{e}$ & $x$ & $x$ & $x$ & $x$ & - & $x$ \\
\hline Poaceae & Poa pratensis & $\mathrm{h}$ & $\mathrm{e}$ & $x$ & $x$ & $x$ & $x$ & - & $x$ \\
\hline Poaceae & Trisetum sp. & $\mathrm{h}$ & $\mathrm{e}$ & $x$ & - & $x$ & $x$ & $x$ & $x$ \\
\hline Poaceae & Stipa sp. & $\mathrm{h}$ & $\mathrm{n}$ & $x$ & $x$ & $x$ & $x$ & $x$ & $x$ \\
\hline Proteaceae & Lomatia hirsuta & $A$ & $\mathrm{n}$ & - & $x$ & - & $x$ & - & - \\
\hline Rosaceae & Elanterea rosa & $a$ & $\mathrm{e}$ & - & $x$ & - & - & - & - \\
\hline Rosaceae & Fragaria chiloensis & $a$ & $\mathrm{n}$ & $x$ & - & $x$ & $x$ & - & - \\
\hline Saxifragaceae & Ribes magellanicum & $a$ & $\mathrm{n}$ & $x$ & - & $x$ & - & $x$ & - \\
\hline Saxifragaceae & Ribes cucullatum & $\mathrm{h}$ & $\mathrm{n}$ & $x$ & - & $x$ & - & $X$ & - \\
\hline Solanaceae & Fabiana imbricata & $\mathrm{a}$ & $\mathrm{n}$ & - & $x$ & - & $x$ & - & $x$ \\
\hline Thymelaeaceae & Ovidia andina & $a$ & $\mathrm{n}$ & $x$ & - & $x$ & - & - & - \\
\hline Valerianaceae & Valeriana carnosa & $\mathrm{h}$ & $\mathrm{n}$ & $x$ & - & - & - & - & - \\
\hline Violaceae & Viola maculata & $\mathrm{h}$ & $\mathrm{n}$ & $x$ & - & - & - & - & - \\
\hline
\end{tabular}

